UNIVERSIDAD POLITÉCNICA DE MADRID

ESCUELA TÉCNICA SUPERIOR DE INGENIEROS DE MONTES

\title{
LA REGENERACIÓN NATURAL DEL PINO SILVESTRE (Pinus sylvestris L.) EN EL VALLE DEL LOZOYA (MADRID): GERMINACIÓN Y SUPERVIVENCIA INICIAL
}

TESIS DOCTORAL

PEPA AROCA FERNÁNDEZ

Ingeniero de montes 



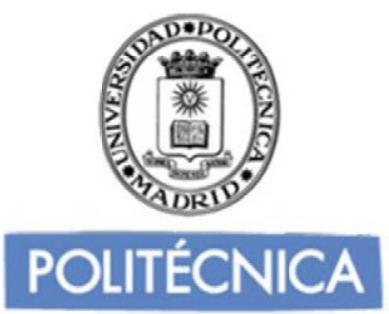

Tribunal nombrado por el Mgfco. y Excmo. Sr. Rector de la Universidad Politécnica de Madrid, el día 22 de diciembre de 2015.

Presidente D. José Anastasio Fernández Yuste

Vocal Dña. Asunción Cámara Obregón

Vocal D. Juan Picos Martín

Vocal Dña. Belén Turrión Nieves

Secretaria Dña. Yolanda Ambrosio Pérez

Realizado el acto de defensa y lectura de la Tesis el día 5 de Febrero de 2016 en Madrid Calificación: 

DEPARTAMENTO DE SILVOPASCICULTURA

ESCUELA TÉCNICA SUPERIOR DE INGENIEROS DE MONTES

LA REGENERACIÓN NATURAL DEL PINO SILVESTRE (Pinus sylvestris L.) EN EL VALLE DEL LOZOYA (MADRID): GERMINACIÓN Y SUPERVIVENCIA INICIAL

PEPA AROCA FERNÁNDEZ

Ingeniero de montes

DIRECTORES:

RAFAEL SERRADA HIERRO

Dr. Ingeniero de Montes
JOSÉ ALFREDO BRAVO FERNÁNDEZ

Dr. Ingeniero de Montes 

A mi familia pequeña

Carlos, María, Carmen y Pedro

y también a mis padres y a mis hermanos

y a todos los que en estos miles de años cuesta arriba os habéis empeñado en no dejarme caer

Para vosotros es esta tesis

y mi infinito agradecimiento 

A Dios pongo por testigo,

a Dios pongo por testigo de que no lograrán aplastarme.

Viviré por encima de todo esto y, cuando haya terminado, nunca volveré a saber lo que es hambre.

No, ni yo ni ninguno de los míos.

Aunque tenga que estafar, que ser ladrona o asesina

A Dios pongo por testigo

¡de que jamás volveré a pasar hambre!

Scarlett Ohara (comunicación personal) 



\section{ÍNDICE GENERAL}

1. ANTECEDENTES

1.1. EL PROCESO DE REGENERACIÓN NATURAL EN LOS SISTEMAS FORESTALES 1

1.1.1. Importancia, definición y fases $\quad 1$

1.1.2. Variables micrometeorológicas que regulan el proceso de regeneración 6

$\begin{array}{ll}\text { 1.1.3. Factores de influencia } & 7\end{array}$

1.2. PARTICUlaridades del PROCESO de REgeneración EN El PINO SILVEStRe (Pinus sylvestris L.) 14

1.2.1. Producción y dispersión de la semilla 14

1.2.2. Germinación y establecimiento 15

1.2.3. Primer desarrollo $\quad 15$

1.3. TRATAMIENTOS DE AYUDA A LA REGENERACIÓN 17

1.4. COMPACTACIÓN, REGENERACIÓN Y PRODUCTIVIDADEN LAS MASAS FORESTALES 19

2. OBJETIVOS__ 21

3. MATERIAL Y MÉTODOS__

3.1. DESCRIPCIÓN DE LA ZONA DE ESTUdIO: EL MONTE CABEZA DE HIERRO 27

3.1.1. Estado legal y Breve reseña histórica $\quad 27$

$\begin{array}{ll}\text { 3.1.2. Estado natural } & 28\end{array}$

$\begin{array}{ll}\text { 3.1.2.1. Suelos } & 29\end{array}$

3.1.2.2. Vegetación y fauna $\quad 30$

3.1.2.3. Ganado $\quad 31$

3.1.3. Estado forestal $\quad 31$

3.2. DISEÑO EXPERIMENTAL

3.2.1. Variables objeto de estudio $\quad 34$

3.2.2. Red de Muestreo I 36

3.2.2.1. Diseño experimental

3.2.2.2. Replanteo de la red de parcelas $\quad 39$

3.2.2.3. Siembras y Mediciones. Calendario de actuaciones 40

3.2.3. Red de Muestreo II 43

3.2.3.1. Diseño experimental 43

3.2.3.2. Replanteo del experimento $\quad 45$

3.2.3.3. Siembras y Mediciones. Calendario de actuaciones 46

3.2.4. Mediciones complementarias 48

3.2.4.1. Espesura de la masa arbórea $\quad 48$

3.2.4.2. Cobertura vegetal del suelo tras el tratamiento de escarificación 51

3.2.4.1. Parámetros micrometeorológicos de medición puntual: Humedad edáfica 52

3.2.4.4. Compactación edáfica $\quad 52$

3.2.5. Variables climáticas generales

3.4. ESQUEMA DE ANÁLISIS DE RESULTADOS

4. RESULTADOS Y DISCUSIÓN___

4.1.Caracterización Meteorológica del Período de experimentación (2004-2006) Con Respecto al año CLIMÁTICO MEDIO EN LA ZONA DE ESTUDIO___ 63

4.1.1. CARACTERÍSTICAS CLIMÁTICAS GENERALES DE LA ZONA DE ESTUDIO 65

4.1.2. CARACTERIZACIÓN TERMO-PLUVIOMÉTRICA DEL PERÍODO DE ESTUDIO 68

4.1.3. CONCLUSIONES PARCIALES $\quad 73$ 

4.2.1. CARACTERÍSTICAS GENERALES DE LA MASA EN LOS BLOQUES DE EXPERIMENTACIÓN

4.2.1.1. Masa Inventariable $\quad 77$

4.2.1.2. Regeneración $\quad 82$

4.2.1.3. Síntesis del estado de la masa en los bloques de experimentación 83

4.2.2. CARACTERIZACIÓN DE LA ESPESURA EN TORNO A LOS PUNTOS DE MEDICIÓN 85

4.2.2.1. Relación del área basimétrica en torno a un punto con la proporción de huecos en el dosel por encima de él. $\quad 86$

4.2.2.2. Relación del porcentaje de huecos del dosel con la radiación bajo cubierta 89

4.2.2.3. Radio óptimo de muestreo del área basimétrica. Selección de parámetros para la caracterización del efecto de la masa en torno a los puntos de muestreo 91

4.2.2.6. Conclusiones parciales del capítulo 93

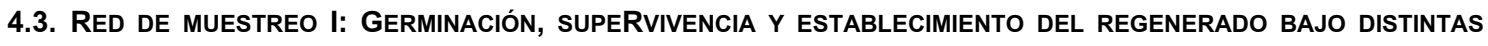
CONDICIONES DE CUBIERTA VEGETAL___

4.3.1. GERMINACIÓN Y SUPERVIVENCIA INICIAL EN EL ÁREA DE ESTUDIO (AÑO 1) 97

4.3.1.1. Cronograma del proceso de regeneración durante el primer período vegetativo 97

4.3.1.2. Cuantificación de los procesos de Germinación y supervivencia tras el período estival 100

$\begin{array}{ll}\text { 4.3.1.3. Influencia de la cobertura vegetal } & 101\end{array}$

4.2.2. ESTABLECIMIENTO DE LAS PLÁNTULAS DE PINO SILVESTRE (SUPERVIVENCIA AÑOS 2 Y 3) 110

$\begin{array}{ll}\text { 4.2.3. CONCLUSIONES PARCIALES } & 113\end{array}$

4.4. RED dE MUESTREO I: PERSISTENCIA DE LOS EFECTOS DEL TRATAMIENTO DE ESCARIFICACIÓN 115

4.4.1. ESTADO GENERAL DE LA CUBIERTA VEGETAL Y LA CAPA SUPERFICIAL DEL SUELO DOS AÑOS DESPUÉS DEL TRATAMIENTO DE ESCARIFICACIÓN 117

4.4.2. INFLUENCIA DE LA MASA EN LA EVOLUCIÓN POST-ESCARIFICADO 119

4.4.3. IMPLICACIONES PARA LA REGENERACIÓN 122

$\begin{array}{lr}\text { 4.4.4. CONCLUSIONES PARCIALES } & 130\end{array}$

4.5. RED DE MUESTREO I: LA COMPACTACIÓN EN LA MASA EN ESTUDIO___ 133

4.5.0. LA RESISTENCIA A PENETRACIÓN COMO ÍNDICE DE COMPACTACIÓN EDÁFICA 135

4.5.1. VALORES MEDIOS DE RESISTENCIA A PENETRACIÓN EN EL MONTE: ¿POTENCIALMENTE NOCIVOS? 137

4.5.2. INFLUENCIA DE LOS AGENTES COMPACTADORES: GANADO Y MAQUINARIA 139

4.5.2.1. Capa superficial del suelo 139

4.5.2.2. Nivel profundo 141

4.5.2.3. Comparación de los efectos generados por maquinaria y ganado 143

4.5.3 EFECTOS DE LA COMPACTACIÓN SOBRE LA PRODUCTIVIDAD DEL MONTE 147

$\begin{array}{ll}\text { 4.5.4. CONCLUSIONES PARCIALES } & 149\end{array}$

4.6. RED DE MUESTREO II: GERMINACIÓN Y SUPERVIVENCIA. DECAPADO VS. ESCARIFICADO__ 151

4.6.1. CUANTIFICACIÓN GENERAL DEL PROCESO

4.6.3. COMPARACIÓN ESCARIFICACIÓN VS DECAPADO+ACABALLONADO 158

$\begin{array}{ll}\text { 4.6.4. CONCLUSIONES PARCIALES } & 160\end{array}$

5. CONCLUSIONES _ 161

6. BIBLIOGRAFÍA _ 



\section{ÍNDICE DE FIGURAS}

Fig. 1. Ciclo de regeneración por semillas (sexual) ............................................................................... 2

Fig. 2. Croquis de situación del término municipal de Rascafría en la Comunidad de Madrid.........................28

Fig. 3. Croquis de situación del monte "Cabeza de Hierro" dentro del término municipal de Rascafría............28

Fig. 4. Representación gráfica de los factores relativos al vuelo considerados en el presente estudio............. 35

Fig. 5. Representación esquemática de la unidad experimental de muestreo de regeneración......................... 37

Fig. 6. Cuadro resumen del diseño experimental de la Red de Muestreo I................................................ 38

Fig. 7. Localización de las áreas de experimentación o bloques de la Red de Muestreo I (RM1) dentro del

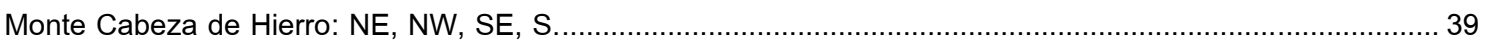

Fig. 8. Ejemplos del uso del bastidor sobre cuatro unidades experimentales........................................... 41

Fig. 9. Ejemplo de individuos germinados y señalizados con palillos junto a una de las líneas de siembra del bastidor.

Fig. 10. Representación esquemática de las unidades experimentales de muestreo de regeneración de la Red de Muestreo II: A) Sin tratamiento de ayuda a la regeneración. B) Decapado lineal con acaballonado. ...........43

Fig. 11. Cuadro resumen del diseño experimental de la Segunda Red de Parcelas (Diseño II)..................... 44

Fig. 12. Localización de las áreas de experimentación de la Segunda Red de Muestreo (RM2) dentro del

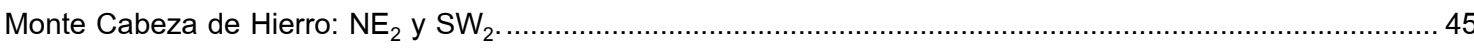

Fig. 13. Aspecto final de una subzona de experimentación de la Red de Muestreo II....................................4 47

Fig. 14. Detalle de una subzona de experimentación de la Red de muestreo II. ......................................... 47

Fig. 15. A) Esquema de proyección del hemisferio en las fotografías de ojo de pez (tomado de Rich (1990)) B) Ejemplo de fotografía hemisférica correspondiente a uno de los puntos de muestreo.................................. 49

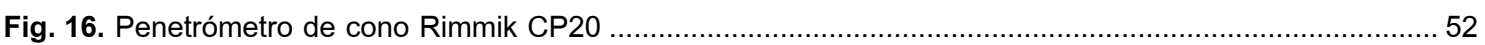

Fig. 17. Representación esquemática de cuatro de los 40 casquetes esféricos sobre los que se calcula el porcentaje acumulado de huecos del dosel arbóreo en cada unidad experimental.......................................5 56

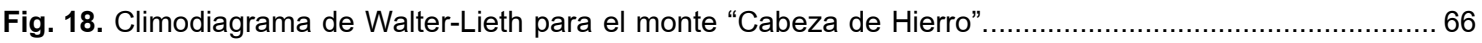

Fig. 19. Representación gráfica de la precipitación acumulada a lo largo del año para todos los años comprendidos entre 1995 y 2013 así como para el año promedio.

Fig. 20. Representación gráfica de la temperatura media mensual a lo largo del año para todos los años comprendidos entre 1995 y 2013 así como en el año promedio.

Fig. 21. Representación gráfica de la temperatura media mensual de las máximas diarias a lo largo del año para todos los años comprendidos entre 1995 y 2013 así como en el año promedio.

Fig. 22. Representación gráfica de la temperatura media mensual de las mínimas diarias para todos los años comprendidos entre 1995 y 2013 así como en el año promedio.

Fig. 23. Representación gráfica de la precipitación acumulada en el período comprendido entre el 15 de abril y el 15 de junio para todos los años comprendidos entre 1995 y 2013 así como en el año promedio..... .72

Fig. 24. Representación gráfica de la distribución diamétrica del pino silvestre para los distintos bloques de experimentación.

Fig. 25. Densidad total de pino silvestre y rebollo (pies/ha) en los distintos bloques de experimentación........ 79

Fig. 26. Porcentajes de pies menores y mayores en el total de pies/ha para cada bloque de experimentación para A) Pino silvestre y B) Rebollo...

Fig. 27. Densidad media del regenerado de pino silvestre (pies/ha) en los bloques de experimentación de las dos Redes de muestreo (Red M I y Red M II). 

Fig. 28. Influencia de los pies en el índice de huecos en el hemisferio sobre un punto bajo cubierta en función de su distancia horizontal al mismo.

Fig. 29. Coeficientes de correlación lineal entre el porcentaje de huecos del dosel (Sky fraction) en casquetes de ángulo cenital creciente durante la primavera y el $A B /$ ha de pino en torno al punto medida en parcelas de radio creciente $(5,10,15,20$ y $25 \mathrm{~m})$.

Fig. 30. Coeficientes de correlación lineal entre el porcentaje de huecos del dosel durante la PRIMAVERA en casquetes de ángulo cenital creciente y el AB/ha de PINO en torno al punto, medida en parcelas de radio creciente $(5,10,15,20$ y $25 \mathrm{~m})$.

Fig. 31. Coeficientes de correlación lineal entre la diferencia en porcentaje de huecos del dosel (\%HD) entre VERANO y PRIMAVERA en casquetes de ángulo cenital creciente y el AB/ha de REBOLLO en torno al punto, medida en parcelas de radio creciente $(5,10,15,20$ y $25 \mathrm{~m})$.

Fig. 32. Evolución del porcentaje acumulado de huecos del dosel en casquetes esféricos de ángulo cenital creciente

Fig. 33. Coeficientes de correlación entre la radiación incidente en cada punto y el porcentaje de huecos del dosel (\%HD) en casquetes esféricos de ángulo cenital creciente.

Fig. 34. Coeficientes de correlación entre la duración total de sunflecks para cada punto y el porcentaje de huecos del dosel (\%HD) en casquetes esféricos de ángulo cenital creciente.

Fig. 35. Cronograma medio del proceso de germinación en la zona de estudio durante el año 2004: porcentajes de germinación en los períodos indicados con respecto al total del período vegetativo

Fig. 36. Número medio de plántulas por parcela detectadas en las parcelas escarificadas de los distintos bloques durante el período de muestreo.

Fig. 37. Variación del porcentaje de mortalidad de las plántulas germinadas a lo largo del período de estudio.

Fig. 38. Cronograma del proceso de germinación en la zona de estudio durante el primer año de experimentación.

Fig. 39. Evolución del número total de brinzales vivos durante el período de estudio para los distintos tipos de cobertura considerados frente al total germinado en el año inicial (2004)

Fig. 40. Diagramas de caja para las variables relativas a la cobertura vegetal del suelo, para parcelas escarificadas y no escarificadas.

Fig. 41. Diagramas de caja para el espesor de restos no descompuestos y el del total de restos para las parcelas escarificadas y no escarificadas.

Fig. 42. Gráficos de intervalos de confianza para la resistencia a la penetración del suelo entre 0-10 cm de profundidad (izquierda) y 10-20 cm de profundidad (derecha), en función de la fracción de huecos y del tratamiento de escarificación aplicado.

Fig. 43. Representación de la evolución de los coeficientes estimados en la regresión penalizada para vía LASSO (\% de humedad edáfica estimada en función del resto de variables), en función del nivel de penalización aplicado $(\boldsymbol{\lambda})$

Fig. 44. Humedad del suelo en función de la resistencia a la penetración (kPa) en el momento del muestreo.

Fig. 45. Histogramas de frecuencia de la PR en función del tipo de perturbación y de la profundidad considerada.

Fig. 46. Resistencia a penetración en función del tipo de perturbacion: A) Bajo Tránsito, B) Alto tránsito de maquinaria, C) Álto tránsito de ganado.

Fig. 47. Evolución de la densidad y el volumen de la masa arbolada de pino silvestre entre 1957 y $2007 \ldots .147$ 

Fig. 48. Porcentaje medio de plántulas vivas con respecto al total sembrado en el BLOQUE NE en función de la espesura (baja, media o alta) y la existencia o no de tratamiento edáfico de ayuda a la regeneración....... 153

Fig. 49. Porcentaje medio de plántulas vivas con respecto al total sembrado en el BLOQUE SW en función de la espesura (baja, media o alta) y la existencia o no de tratamiento edáfico de ayuda a la regeneración...... 153

Fig. 50. Caracterización del dosel de copas en las distintas subzonas de experimentación contempladas en la Red de muestreo II. 



\section{ÍNDICE DE TABLAS}

Tabla 1. Situación geográfica del monte "Cabeza de Hierro".

Tabla 2. Posición orográfica y configuración del terreno del monte "Cabeza de Hierro".

Tabla 3. Características medias de pendiente altitud y orientación medias de los bloques de experimentación de la Red de Muestreo I.

Tabla 4. Resumen de operaciones anuales en la Red de Muestreo I.

Tabla 5. Características de partida de las semillas empleadas en la siembra de la Red de Muestreo I........... 42

Tabla 6. Características medias de pendiente, altitud y orientación de los bloques de experimentación de la

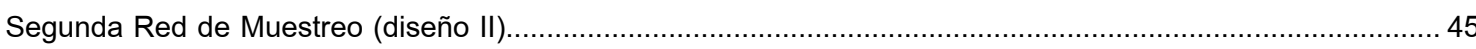

Tabla 7. Resumen de operaciones anuales en la Segunda Red de Muestreo (Diseño II).

Tabla 8. Características técnicas del instrumental utilizado en el inventario pie a pie de los bloques de experimentación.

Tabla 9. Resumen de los parámetros de calibración del software Gap Ligh analyzer (Frazer et al., 1999) para los puntos de muestreo.

Tabla 10. Coeficientes mensuales de nubosidad, radiación directa y fracción espectral considerados para el análisis de las fotografías hemisféricas.

Tabla 11. Características técnicas del instrumental utilizado en la medición de las variables micrometeorológicas.

Tabla 12. Correcciones altitudinales para la estimación de la precipitación y la temperatura a una altitud diferente a la de la toma de datos (Gandullo, 1994)

Tabla 13. Cuadro resumen del comportamiento medio mensual y anual de las principales variables climatológicas, durante el período 1995-2013, en la zona de estudio.

Tabla 14. Ficha hídrica del monte "Cabeza de Hierro".

Tabla 15. Comportamiento medio anual del régimen termo-pluviométrico en la zona de estudio durante el período de muestreo (2004-2006) en comparación con la media anual para el período 1995-2013.

Tabla 16. Régimen termo-pluviométrico mensual en la zona de estudio durante los años de muestreo de regeneración (2004-2006) en comparación con el año medio de la serie 1995-2013................................... 70

Tabla 17. Sequía fisiológica $(\mathrm{mm})$ durante el período de estudio (ficha hídrica de Thornthwaite)

Tabla 18. Balance hídrico para la zona de estudio entre el 8 de mayo y el 8 de junio de los años 2004, 2005 y 2006, así como en el año promedio

Tabla 19. Densidad media de pino silvestre (pies/ha) por clase diamétrica en los distintos bloques de experimentación (las clases diamétricas se indican por la marca de clase en $\mathrm{cm}$ ).

Tabla 20. Densidad media de rebollo (pies/ha) por clase diamétrica en los distintos bloques de experimentación (las clases diamétricas se indican por la marca de clase en $\mathrm{cm}$ ).

Tabla 21. Densidad media (pies/ha) de pies menores $(10 \mathrm{~cm}<\mathrm{dn}<20 \mathrm{~cm})$ y mayores $(\mathrm{dn}>20 \mathrm{~cm})$ de pino silvestre y rebollo en los bloques de experimentación.

Tabla 22. Área basimétrica por hectárea $\left(\mathrm{m}^{2} / \mathrm{ha}\right)$ de los pies menores $(10<\mathrm{dn}<20 \mathrm{~cm})$, mayores $(\mathrm{dn}>20 \mathrm{~cm})$ y totales de pino silvestre y rebollo en los distintos bloques de experimentación.

Tabla 23. Diámetro medio cuadrático $(\mathrm{cm})$ de los pies menores $(10<\mathrm{dn}<20 \mathrm{~cm})$, mayores $(\mathrm{dn}>20 \mathrm{~cm})$ y totales de silvestre y rebollo en los distintos bloques de experimentación 

Tabla 24. Alturas medias $(\mathrm{m})$, alturas de la primera rama viva $(\mathrm{m})$ y razón de copa de los pies menores $(10<$ $\mathrm{dn}<20 \mathrm{~cm}$ ), mayores $(\mathrm{dn}>20 \mathrm{~cm}$ ) y totales de pino silvestre en los distintos bloques de experimentación. Altura dominante $(\mathrm{m})$ por bloque.

Tabla 25. Alturas medias y alturas de la primera rama viva $(\mathrm{m})$ de los pies menores $(10<\mathrm{dn}<20 \mathrm{~cm})$, mayores $(\mathrm{dn}>20 \mathrm{~cm})$ y totales de rebollo en los distintos bloques de experimentación.

Tabla 26. Densidad media del regenerado (pies/ha) de pino silvestre en los distintos bloques de experimentación.

Tabla 27 Coeficientes de correlación máximos entre el porcentaje de huecos en el dosel (\%HD) y el AB para cada tipo de área basimétrica (rebollo, pino o ambas) y tipo de \%HD en función del período de muestreo (primavera, verano, verano-primavera)......

Tabla 28. Ángulos cenitales a los que se producen los máximos coeficientes de correlación de Pearson entre los parámetros de luz indicados y los porcentajes de huecos (\%HD) de los correspondientes casquetes esféricos

Tabla 29. Coeficientes de correlación máximos entre el $A B$ para cada tipo de área basimétrica (rebollo, pino o ambas) y cada tipo de parámetro lumínico (y período de medición).

Tabla 30. Valores medios de germinación y supervivencia estival durante el primer período vegetativo del regenerado en los distintos bloques de experimentación así como en el conjunto de todos ellos.

Tabla 31. Éxito en la regeneración durante el primer período vegetativo para las distintas combinaciones de Orientación y Tipo de Cobertura vegetal (E: Escarificado, H: Hierba, M: Matorral, R: Restos).

Tabla 32. Características medias de la capa de restos (recubrimiento superficial y espesor de restos frescos y totales) en las parcelas tipo "Restos" de los cuatro bloques experimentales.

Tabla 33. Coeficientes de correlación de Pearson entre las variables de masa y las tasas de germinación y supervivencia tras el período estival calculada para: a) conjunto de parcelas que presentaron germinación $(\mathrm{N}=188)$ y b) Parcelas que además presentaron supervivencia (eliminamos parcelas con sup $=0)(\mathrm{N}=67) \ldots 104$

Tabla 34. Tabla de contingencia Área Basimétrica Total x Viabilidad para la supervivencia ..... 105

Tabla 35. Coeficientes de los modelos de regresión logística calculados mediante LASSO para las variables Germinación, Supervivencia y Éxito en función de las variables regresoras que se indican (Términos del modelo)

Tabla 36. Porcentajes de germinación inicial (junio 2004), y Supervivencia y Éxito de establecimiento durante el mes de octubre de los tres años considerados para cada uno de los bloques experimentales......

Tabla 37. Porcentajes de Supervivencia y Éxito de establecimiento durante el mes de octubre de los tres años considerados para los distintos tipos de cobertura considerados. 111

Tabla 38. Efectos de la escarificación sobre el estado de la cubierta vegetal superficial y la capa superior del suelo dos años después del tratamiento

Tabla 39. Coeficientes de correlación de Pearson entre las variables de espesura de masa y las relativas a suelo y cobertura vegetal en superficie.

Tabla 40. Modelo de regresión para el espesor total de restos en función del espesor de restos no descompuestos y del tratamiento aplicado en el suelo (escarificación).

Tabla 41. Coeficientes estandarizados del modelo de regresión en el punto de corte determinado por el nivel de penalización $\lambda_{\mathrm{c}}$ seleccionado.

Tabla 42. Porcentaje de observaciones que exceden los valores umbral de resistencia a la penetración encontrados en bibliografía en los niveles superficial $(0-10 \mathrm{~cm})$ y sub-superficial $(10-20 \mathrm{~cm})$ del suelo.

Tabla 43. Valores medios de resistencia a penetración ( \pm desviación estándar) en función del nivel y tipo de tránsito en los 20 primeros $\mathrm{cm}$ de suelo. 

Tabla 44. Frecuencia de puntos de muestreo (\%) en los que la resistencia a penetración supera los límites que se indican $(2000,2500 \& 3000 \mathrm{kPa})$ en el horizonte subsuperficial $(10-20 \mathrm{~cm})$ en función del tipo de perturbación sufrida.

Tabla 45. Comparación de modelos de efectos fijos. Criterios de selección: Índice de Akaike (AIC), logaritmo de la verosimilitud (log Likelihood), p-valor asociado al cociente de verosimilitudes

Tabla 46. Coeficientes de los efectos fijos del modelo ajustado para la estimación de la Resistencia a Penetración $(\mathrm{kPa})$ en función de la profundidad (modelo polinómico) y el nivel de tránsito de maquinaria y ganado.

Tabla 47. Características del ganado pastante en el área de estudio.

Tabla 48. Especificaciones técnicas de la maquinaria empleada en el área de estudio. 145

Tabla 49. Evolución de la densidad y las existencias de la masa entre 1957 y 2005. 148

Tabla 50. Resultado del ensayo de regeneración de la Red de muestreo II. Tasas de germinación (\%Germ) y supervivencia (\%Sup) para las parcelaa tratadas con Decapado+Acaballonado (DEC+ACABALLONADO) y para las no tratadas (SIN TRATAMIENTO), en función de la orientación y la espesura.

Tabla 51. Espesura media de la masa en torno a las parcelas de muestreo de regeneración. Como las parcelas de cada tipo de espesura en cada bloque están lo bastante cerca como para suponerles espesura común, se les asigna un único valor de área basimétrica por grupo.

Tabla 52. Caracterización del dosel de copas en torno a las parcelas de experimentación 156

Tabla 53. Número de plántulas supervivientes en las fechas y bloques experimentales (Red de muestreo I) que se indican

Tabla 54. Número de plántulas supervivientes en las fechas y bloques experimentales (Red de muestreo I) en función de que hubiera existido o no de tratamiento de escarificación dos años antes de la siembra. 

RESUMEN 



\section{Resumen}

La fase de establecimiento del regenerado es un proceso crítico para el desarrollo posterior de la masa tanto por las elevadas tasas de mortalidad que habitualmente lleva asociadas, como por proporcionar el material de partida del que van a disponer las fases subsiguientes. Las restricciones a la germinación y establecimiento de la regeneración del pino silvestre varían enormemente entre las distintas regiones de su extensa área de distribución geográfica. La región Mediterránea constituye un hábitat marginal de la especie en el que las condiciones ecológicas son muy diferentes a las del grueso de su área de distribución. Frente a otras limitaciones (frío, luz, encharcamiento...), en el entorno mediterráneo la tasa de mortalidad parece estar asociada a las condiciones micrometeorológicas del período estival - particularmente, a la sequía -, así como a la presencia excesiva de ganado o ungulados silvestres. No obstante, la mayoría de la información disponible sobre el proceso de regeneración de la especie procede del centro y norte de Europa, por lo que no es de aplicación directa en nuestra región, en la que los estudios de este tipo son mucho más escasos.

El presente trabajo pretende contribuir a paliar esta relativa escasez a través del estudio del proceso de regeneración natural en el monte "Cabeza de Hierro", masa irregular por bosquetes de pino silvestre, paradigma de gestión sostenible y uso múltiple. En este entorno, se pretende caracterizar y cuantificar tanto el proceso de germinación y supervivencia de la especie como la influencia de la cobertura vegetal (estratos arbóreo, arbustivo y herbáceo, y capa de restos vegetales) en su desarrollo. Se persigue así mismo analizar el efecto de la compactación del suelo sobre la persistencia de la masa y contrastar y comparar la eficacia de dos tratamientos edáficos de ayuda a la regeneración: escarificado y decapado+acaballonado.

Con este fin se han planteado dos diseños experimentales consistentes en sendas redes de muestreo (Red de Muestreo I o RM I y Red de Muestreo II o RM II) integradas, respectivamente, por 192 y 24 parcelas de $1,5 \times 1,5 \mathrm{~m}$ ubicadas bajo distintas condiciones de cobertura vegetal. Sobre una parte de estas parcelas (1/4 en la Red de Muestreo I; $1 / 2$ en la Red de Muestreo II) se han aplicado tratamientos de ayuda a la regeneración (RM I: escarificado; RM II: decapado+acaballonado) y, tras llevar a cabo siembras controladas al inicio del período vegetativo, se han practicado controles periódicos de germinación y supervivencia durante uno (RM II) y tres años consecutivos (RM I). Se han realizado así mismo mediciones complementarias de variables micrometeorológicas, espesura, recubrimiento superficial del suelo y compactación.

Los resultados obtenidos a partir de las experiencias realizadas en el monte objeto de estudio permiten concluir que, en relación con el proceso de regeneración natural de la especie en este tipo masa y entorno: 1) la regeneración del pino silvestre durante el primer período vegetativo presenta una tasa de éxito muy baja ( $1,4 \%$ de los sembrados), provocada por una elevada mortalidad durante el primer período estival $(>92 \%)$ subsiguiente a una germinación de en torno al $17 \%$ de las semillas viables que llegan al suelo; 2) la mortalidad sigue siendo elevada hasta el tercer período vegetativo, en que comienza a reducirse significativamente hasta alcanzar el $45 \%$; 3 ) la cobertura vegetal influye significativamente tanto en el proceso de germinación como en el de supervivencia, aunque ambos procesos presentan una baja correlación linear que pone de manifiesto que los lugares idóneos para la germinación no siempre son los más adecuados para la supervivencia; 4) la escarificación del suelo mejora las tasas iniciales de germinación y supervivencia, pero empeora la tasa de supervivencia posterior (años 2 y 3), por lo que su efecto a medio plazo no resulta significativo; 5) el decapado+acaballonado presenta mejores resultados que el escarificado durante el primer verano, aunque sólo resulta efectivo en condiciones intermedias de espesura de masa; 6) la compactación edáfica no resulta limitante para la productividad ni la persistencia de la masa considerada. 



\begin{abstract}
Seedling establishment is critical for later stand progress because it involves high mortality rates and the surviving saplings constitute the starting material for all the subsequent stages. Restrictions for Scots pine germination and seedling survival may vary greatly across its geographical range, as it is widely distributed within north latitudes. Mediterranean region is a marginal sector within this species range and its ecological conditions differ greatly from those of the bulk of the area. Mortality rates in Mediterranean environments seem to be related to summer weather (mainly drought) and high livestock stocking rather than to cold, light or flooding. Most available information on scots pine regeneration process comes from north European experiences and is not transferable to Spanish forests, whereas studies on Mediterranean region are much scarcer.
\end{abstract}

The present work aims at broadening Scots pine regeneration knowledge within Mediterranean region by analyzing its establishment process in the "Cabeza de Hierro" forest: a Scots pine uneven-aged forest at blocklevel scale, exemplary managed for multi-services purpose. Germination and surviving processes are to be characterized and quantified as to vegetation cover both in trees, shrubs, grass and litter strata. Soil compaction effects on forest sustainability are also assessed and the efficacy of some site preparation techniques on regeneration success is tested and compared (scarification vs. scalping+mounding).

Two sampling networks comprising respectively 198 (SN I) and 24 plots (SN II) of 1.5x1.5m have been established over a wide range of vegetal cover conditions within the forest. Soil preparation techniques have been applied only to some of the sampling points; namely, 1 out of 4 plots have been scarified within Sampling Network I, while 1 out of 2 plots have been object of scalping \& mounding within Sampling Network II. After localized sowing prior to growing season, germination and surviving have been periodically sampled for either one (SN II) or three years (SN I). Supplementary measures for micrometeorological variables, stand density, ground vegetal cover and compaction have also been carried out.

Results obtained for the studied forest lead to the following insights regarding Scots pine natural regeneration process within this sort of forest and environment: 1) seedling establishment success rate is quite low $(0,15 \%$ of sowing seeds), due to high mortality during the first summer $(>92 \%)$, following a prior $17 \%$ rate of germination over viable seeds reaching the soil; 2) mortality rate remains high until the third year after emergence and then decreases to the $50 \%$ of surviving; 3) although vegetal cover significantly affects both seedling germination and survival, lineal correlation between those two processes is rather low, which may indicate that places fit for emergence are not necessarily suitable for summer surviving; 4) soil scarification improves both germination and survival during the first growing season, but it is associated to higher mortality rates during the next two years; hence it has no significant medium term effect; 5) scalping \& mounding treatment is more effective than scarification concerning establishment improving during the first summer; but its effects are only significant under intermediate stand density levels; 6) soil compaction does not restrict either forest productivity or persistence, despite the area's long history of high livestock stocking rates and mechanized logging. 

1. ANTECEDENTES 



\subsection{EL PROCESO DE REGENERACIÓN NATURAL EN LOS SISTEMAS FORESTALES}

\subsubsection{IMPORTANCIA, DEFINICIÓN Y FASES}

La consecución de regeneración en cantidad, calidad y distribución espacial adecuadas es, posiblemente, la tarea más importante y delicada en el marco de la gestión forestal sostenible. Así, no es de extrañar que la cuestión de la regeneración en masas forestales arboladas ocupe un papel protagonista en tratados de selvicutura general clásicos o contemporáenos (Artigas, 1890; Boppe, L. Jolyet, 1901; Boudru, 1992; Capelli, 1988; Daniel et al., 1982; Fron, 1910; González Vázquez, 1948; Hawley y Smith, 1982; Nyland, 2003; Olderman, s. f.; Oliver y Larson, 1996; Schülz, 1990; Ximénez de Embún, 1951), y sea objeto de estudio en múltiples artículos publicados en revistas científicas nacionales e internacionales de ámbito ecológico y forestal, algunos de los cuales serán citados en el presente texto. Resulta también obligado remitir al reciente compendio de selvicultura aplicada (Serrada et al., 2008) en el que, entre otras cosas, se revisan y proponen los tratamientos de regeneración para las principales especies forestales presentes en España; o a los cuadernos publicados por el grupo de trabajo de selvicultura de la Sociedad Española de Ciencias Forestales (http://www.secforestales.org/grupos/selvicultura).

Desde el punto de vista de la selvicultura, la regeneración se define como "el proceso mediante el cual se garantiza la creación o perpetuación de un tipo determinado de vegetación, bien mediante medios artificiales o a través de los mecanismos naturales con que cuentan las especies" (Pemán \& Navarro, 1998).

La regeneración es entonces "un proceso dinámico por el cual se generan nuevos individuos en la población adulta de manera que se compensan las pérdidas debidas a la mortalidad natural" (Harper, 1977). La persistencia de una masa forestal depende sobre todo de su capacidad de regeneración. Las masas que no son capaces de regenerarse están condenadas a la desaparición.

Este proceso depende de la forma de reproducción de la especie vegetal que se considere. La más general, común a todas las especies, es la reproducción sexual o por semillas, aunque existe en algunas especies una forma de reproducción vegetativa o agámica. En nuestro trabajo solo haremos referencia a la primera.

La mayoría de los principales manuales de selvicultura coinciden, aunque no es un criterio unánime (Lanier, 1986), en considerar la existencia o no de intervención humana en la dispersión de las semillas como el criterio clave de clasificación de la regeneración en dos categorías (Daniel, Helms, \& Baker, 1979; González, 2005; Hawley \& Smith, 1982; Matthews, 1994), sin tener en cuenta, a la hora de clasificar el proceso, los posibles tratamientos a realizar sobre el suelo o sobre el vuelo para facilitar la germinación y el establecimiento de las plántulas. Estas dos categorías son:

- Regeneración natural: aquélla obtenida a partir de la dispersión natural de las semillas de la masa adulta circundante.

- Regeneración artificial: se define, por oposición a la anterior, como la obtenida tras una acción humana de siembra o plantación de material procedente de rodales alejados.

Señalemos también que en el argot selvícola español el proceso de rebrote de especies tratadas en monte bajo también se denomina "regeneración natural" y que, dentro de nuestra terminología, mediante el apelativo de "regeneración" se suele hacer referencia tanto al proceso como al resultado del mismo, es decir, al conjunto de nuevas plántulas que se incorporan al sistema.

En nuestro trabajo reservaremos el término regeneración, siguiendo el criterio más frecuente en la literatura internacional, para la regeneración en monte alto. 
Tal como se puede leer en (Serrada, 2002) y exponemos con detalle en el capítulo VI de la memoria, cuando se considera la regeneración natural en sentido amplio conviene informar de si es consecuencia de una de las situaciones siguientes:

- Regeneración natural en espacios sin variación anterior de la espesura de la masa preexistente, proceso que podría ser denominado colonización.

- Regeneración natural en espacios que han sufrido fuertes perturbaciones (incendios, vendavales, plagas etc.). Este proceso podría conocerse por restauración.

- Regeneración natural en montes tratados mediante cortas destinadas principalmente a renovar el vuelo, que es lo que en Selvicultura se denomina regeneración natural (en sentido estricto).

La presente memoria se centra en el estudio de la regeneración natural en monte alto y en sentido estricto, motivo por el cuál, en los sucesivos apartados y siempre que no se detalle lo contrario, es únicamente a esta acepción a la que se hace referencia mediante la denominación de "regeneración natural".

Globalmente el proceso de regeneración natural sigue un ciclo (Figura 1) en el cuál cada una de las etapas es esencial. Los procesos de transición dependen de muchos factores de distinta naturaleza: así, la regeneración puede estar limitada por la cantidad de semilla producida, la efectividad de los dispersores, la disponibilidad de micrositios para la germinación y el establecimiento de plántulas o la actividad de predadores (Schupp y Fuentes, 1995), factores a los que habría que añadir la naturaleza y grado de compactación del suelo o la actividad del ganado, por ejemplo.

Como hemos señalado, la regeneración es un proceso dinámico y, como tal, capaz de actuar sobre sí mismo. Así, la presencia en exceso de individuos jóvenes inhibe el crecimiento de las plántulas y, en general, las variaciones en la distribución de individuos en distinto grado de crecimiento se traducen en la variación de sus probabilidades de subsistencia. El proceso tiende de modo natural a una situación de equilibrio y la acción humana debe estar encaminada a lograr que dicha situación se adapte lo más posible a lo que se considera ideal.

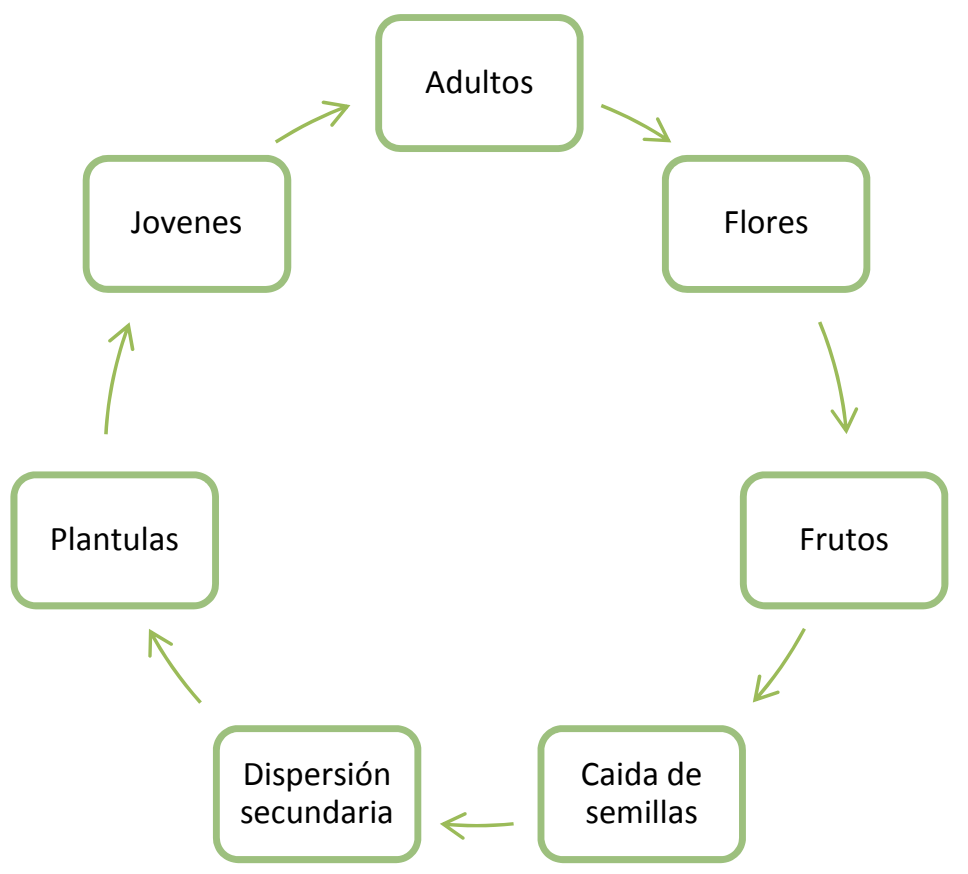

Fig. 1. Ciclo de regeneración por semillas (sexual). 
A continuación se resumen brevemente las principales etapas en que se puede considerar estructurado el proceso de regeneración natural. Aunque estas etapas básicas son comunes a todas las especies forestales, las particularidades dentro de cada una de ellas pueden variar enormemente. Por este motivo, para cada etapa se comentan las generalidades comunes al conjunto de las especies y, en caso de existir particularidades, sólo se comentan las referentes a las coníferas, grupo en el que se integra la especie objeto del presente estudio.

\section{Producción y dispersión de la semilla}

Según el "Manual para la identificación y reproducción de semillas de especies vegetales autóctonas de Andalucía" (Navarro y Gálvez, 2001), se entiende por material forestal de reproducción (MFR) al conjunto de estructuras, órganos y tejidos mediante los cuales una especie forestal garantiza la reproducción de nuevos individuos, definición ésta más adecuada que la más frecuente que entiende por material forestal de reproducción de una especie las semillas, las partes de plantas y las plantas producidas con el fin de ser utilizadas en las repoblaciones (Martín et al., 1997).

Limitándonos al MFR de las Gimnospermas, recordemos que esta clase agrupa a unas seiscientas especies que no presentan flores verdaderas y cuyos órganos sexuales se disponen en conos o estróbilos. Como todas las plantas, tienen una fase juvenil y otra adulta de características morfológicas y fisiológicas totalmente diferentes. Durante la etapa juvenil, cuya duración depende tanto de su genotipo como de las condiciones ambientales en que vegeta la planta, no alcanzan la madurez sexual. En el género Pinus la duración del periodo juvenil oscila entre los 10 y 20 años. Una vez alcanzada la madurez sexual las especies cadañegas producen flores anualmente pero, dado que la floración y la posterior producción de semillas va en detrimento del crecimiento vegetativo, son muchas las especies que presentan vecería y concentran su producción de semilla sólo en uno de cada tantos años.

Cuando los órganos masculino y femenino alcanzan la madurez, están en condiciones de que se produzca la fecundación. Ésta requiere que el polen alcance el macrosporangio, lo cual se produce bien por un proceso de autopolinización, bien por polinización cruzada. En las gimnospermas es más frecuente lo primero.

Usualmente y en función del vector de propagación del polen, las especies vegetales se clasifican en:

- Zoogamas: la transferencia del polen se efectúa por la acción de insectos (entomógamas), aves (ornitogamas) o murciélagos (quiropterógamas).

- $\quad$ Anemógamas: utilizan el aire como vector de propagación, en consecuencia, deben producir grandes cantidades de polen.

- $\quad$ Hidrógamas: la polinización se produce por la acción del agua.

En las gimnospermas el mecanismo de polinización habitual es el aire.

Una vez producida la polinización comienza el desarrollo del embrión, que en la mayoría de las especies se completa antes de la dispersión de las semillas. La duración del proceso de desarrollo es variable, pero en las especies del género Pinus se prolonga durante dos o tres estaciones.

La estructura de los frutos y conos de las especies forestales está muy relacionada con el modo de dispersión de las semillas. En Herrera y Jordano (1983) y Jordano (1993) se estudia la relación existente entre tipos de frutos y agentes de dispersión. La dispersión de semillas consta de tres etapas (Ribbens et al., 1994):

- El movimiento de la semilla desde la planta madre.

- $\quad$ El patrón de deposición de la semilla sobre el terreno.

- El patrón de distribución de brinzales tras los procesos de germinación de la semilla y nacimiento de la plántula. 
Tal como hemos señalado en la figura 1, la primera fase se puede dividir en dos etapas: una de dispersión primaria, que corresponde a la caída de la semilla sobre el terreno; y otra de dispersión secundaria, que agrupa los movimientos de las semillas sobre el terreno, debidos a diferentes causas, hasta su posición definitiva (Schupp y Fuentes, 1995).

Para el éxito del proceso de regeneración hay que tener en cuenta no solo la viabilidad de la semilla, sino su capacidad para superar factores meteorológicos adversos, plagas, enfermedades y la acción de los predadores.

Según el Compendio de Selvicultura aplicada en España (Montero et al., 2008) el pino silvestre florece de mayo a junio y la fecundación tiene lugar en la primavera siguiente. Los piñones maduran al año siguiente de la floración y diseminan en otoño hasta mediados de primavera, según la meteorología del año.

También el Compendio señala para Pinus sylvestris L. que:

- $\quad$ Produce gran cantidad de semillas a partir de los 40 años, si crece en espesura.

- En arboles aislados las produce a partir de los 25 años.

- Tiene un marcado carácter vecero, produce fructificaciones abundantes con una periodicidad de varios años, de cada siete años suelen ser buenos dos, medianos otros dos y malos los tres restantes.

- Disemina un $50 \%$ de la semilla bajo la copa, un $40 \%$ en la distancia de dos a cuatro veces la altura del árbol y el resto más lejos.

\section{2.- Germinación}

La germinación es un proceso esencial para las masas forestales. En su regulación intervienen mecanismos externos e internos. Por ejemplo, las especies leñosas pueden alterar la composición y la humedad del suelo, en cuyo caso se produce un fenómeno de feedback, común en los sistemas dinámicos, que puede llegar a limitar la composición de la comunidad y hasta la distribución de las especies (Catovsky y Bazzaz, 2002a). También son un factor importante las condiciones microclimáticas existentes en las proximidades de las semillas, que influyen en la germinación más que las condiciones climáticas de la zona.

Cuando las semillas caen pueden hacerlo sobre el suelo, sobre restos vegetales e incluso directamente sobre agua; el éxito o fracaso de la germinación dependerá de factores edáficos, naturaleza, composición química y estructura física del suelo y de la profundidad a la que queda la semilla.

La profundidad influye en la aireación y en la penetración de la luz. La composición química del suelo, o del agua, puede afectar la germinación de diversas formas; por ejemplo, sobre el suelo puede existir una capa de mayor o menos grosor de materia orgánica parcialmente descompuesta que puede contener sustancias que inhiban la germinación; también puede presentar un alto contenido en sales que la retarden o incluso la eviten.

Estas circunstancias externas pueden ser también beneficiosas. Por ejemplo, en regiones áridas o semiáridas la semilla puede caer en un sitio próximo a la copa de un árbol o arbusto frondoso o bajo un manto de hojarasca que permita reunir una serie de condiciones de humedad y temperatura óptimas para la germinación, además de evitar la alta radiación del entorno. Son los denominados safe sites que permiten el reclutamiento de nuevos individuos a la comunidad vegetal existente (Duncan et al., 2009; Graae et al., 2011). 
Según Daniel et al. (1979): la germinación comprende diversos procesos fisiológicos:

- Absorción de agua (que tiene lugar en gran medida por imbibición de la semilla).

- Comienzo del engrosamiento y la división celular.

- Activación de las enzimas.

- Hidrolización de los carbohidratos insolubles, el almidón, las grasas y las proteínas en sustancias simples hidrosolubles que se translocan desde el endospermo al embrión.

- Incremento de las tasas de respiración. La energía liberada se utiliza para crecer y aumentar la temperatura.

- Aumento del crecimiento y la división celular.

- Comienzo de la diferenciación celular en los distintos tejidos y órganos del regenerado.

La germinación se considera finalizada cuando el regenerado ha producido suficiente área fotosintética para cubrir por si misma sus necesidades de carbohidratos.

En González-Martínez y Bravo (1999) se indica que en condiciones naturales la perdida de viabilidad de la semilla es rápida, por lo que la germinación se produce en el primer año desde su caída. Es especialmente importante, en una primera etapa, favorecer el contacto de la semilla con el suelo mineral y eliminar la competencia con las herbáceas. La regeneración del pino silvestre puede verse favorecida en el primer desarrollo de la semilla por una ligera cubierta (Aguirre et al., 1991).

\section{Establecimiento y desarrollo inicial}

El desarrollo del regenerado desde la germinación hasta el establecimiento definitivo es el periodo más crítico y precario en la formación de la masa. La mayoría de la mortalidad tiene lugar durante este período. Todas las plantas pasan por esta etapa, pero su duración es pequeña para muchas especies herbáceas. Para coníferas este periodo es relativamente largo y la mortalidad potencial es mayor.

Se pueden reconocer dos períodos importantes en el desarrollo inicial:

- La etapa suculenta, que dura sólo unas pocas semanas. Comienza tan pronto como las plantas aparecen sobre la superficie del suelo y dura hasta que el hipocotilo se ha endurecido.

- La etapa juvenil, que sigue al endurecimiento del hipocotilo y dura varios años hasta que el regenerado está establecido y el riesgo de mortandad es bajo (Daniel et al., 1979).

La etapa juvenil finaliza (Daniel et al., 1979) en el momento en el que se puede considerar que el regenerado está establecido y tiene una tasa de mortalidad potencial baja. No es posible establecer unos valores umbral de densidad, altura o diámetro de las plántulas instaladas a partir de los que se pueden considerar "establecidas", puesto que esas cifras varían para cada caso concreto en función de la especie, la estación y las condiciones de masa.

En la literatura se definen, en orden a planificar intervenciones selvícolas, clases naturales de edad en términos de los estados de desarrollo del arbolado. Su duración varía en función de la especie, la estación y la densidad de pies. Estas clases son:

- Diseminado: plantas recién germinadas que alcanzan una altura de unos $25 \mathrm{~cm}$.

- Repoblado: caracteriza a los pies que han superado la edad de diseminado hasta que se inicia la tangencia de copas entre ellos. También se fija el límite superior del repoblado cuando se alcanza la altura normal $(1,30 \mathrm{~m})$.

- Monte bravo: abarca desde la tangencia de copas hasta el comienzo de la poda natural o muerte espontanea de las ramas de la parte inferior del fuste a causa de la reducción de la iluminación. 
- Latizal: comienza con la poda natural y termina cuando el diámetro normal (d) alcanza los $20 \mathrm{~cm}$. Se distinguen:

- Bajo latizal: $d<10 \mathrm{~cm}$.

- Alto latizal: $d=10-20 \mathrm{~cm}$.

- Fustal: a partir del diámetro normal de $20 \mathrm{~cm}$ comienza esta última clase de edad. También se subdivide en:

$$
\begin{array}{ll}
\text { - Fustal bajo } & d=20-35 \mathrm{~cm} \\
\text { - Fustal medio } & d=35-50 \mathrm{~cm} . \\
\text { - Fustal alto } & d>50 \mathrm{~cm} .
\end{array}
$$

\subsubsection{VARIABLES MICROMETEOROLÓgICAS QUE REGULAN EL PROCESO DE REGENERACIÓN}

Según Agúndez et al. (1992), el crecimiento del primer año está más influido por las condiciones ambientales y los efectos maternos de las semillas, mientras que en años posteriores se ha observado un mayor control genético. Analizaremos en primer lugar, como parte de esas condiciones ambientales, la influencia de las variables microclimáticas que, como hemos señalado anteriormente, son en esta fase de mucho más peso que el clima de la zona.

Las plántulas sobreviven a condiciones desfavorables muy diferentes en tanto en cuanto se lo permita la flexibilidad adaptativa de su genoma. Determinadas condiciones ambientales se tornan en desfavorables en cuanto se apartan de las condiciones óptimas de desarrollo (Gómez-Sánz y Elena, 1997).

\subsubsection{Humedad}

Para entender el establecimiento natural del regenerado del pino silvestre, un factor esencial es la humedad (Montero, 1994). También Montero (1987) señala la importancia para la regeneración de veranos muy secos con cosechas de semillas abundantes. Hay muchas referencias tanto sobre el terreno como en laboratorio que prueban que la intensidad de corta (influencia de la luz) y las precipitaciones de verano tienen una influencia significativa sobre la germinación y el desarrollo temprano del pino.

Un estudio de Fernández et al. (1999) sobre la respuesta de Pinus pinaster Ait. a la disponibilidad hídrica estableció que la supervivencia mayor del $97 \%$ aparece cuando el agua disponible es suficiente, pero este porcentaje es menor (entre el $67 \%$ y el $80 \%$ ) en condiciones de sequía.

En un completo trabajo de laboratorio Ruano et al. (2009) no se observa esa influencia tan clara de la disponibilidad hídrica sobre la supervivencia $y$, sin embargo, se presentan datos que muestran que la disponibilidad hídrica influye más sobre el crecimiento y la biomasa de las plántulas que la luz.

Un segundo factor de influencia de la humedad es de naturaleza puramente física: el golpeteo de la lluvia, el apelmazamiento del terreno, la erosión y la escorrentía son consecuencias de la acción del agua y tienen importancia en la regeneración.

\subsubsection{Temperatura}

Según García et al. (2013) la temperatura es un elemento del microclima aportado por la radiación solar que influye de manera trascendente en la regeneración, ya que participa en los procesos metabólicos de las plántulas. Altos niveles de radiación producen un aumento de la temperatura, tanto en los sistemas aéreos vegetales como en el suelo, y un aumento de la temperatura del aire próximo al suelo, inducido por el incremento de la temperatura superficial de éste. Este incremento puede ser perjudicial para las plántulas, al provocarles cambios fisiológicos y metabólicos. 
También la propia masa, en un proceso de feedback, actúa sobre la regeneración vía variaciones de temperatura. La presencia de materia orgánica sobre el suelo hace que se acumule el calor ambiente con el producido por descomposición y se comporte como acumulador de calor y humedad, provocando una elevada mortandad de los brinzales en verano, especialmente en climas mediterráneos con sequias estivales acusadas (Montero, 1987; Pardos et al., 2005).

\subsubsection{Luz}

Entendemos por luz la parte de la radiación solar que corresponde a la luz visible. La luz así entendida incide sobre el sistema incrementando su energía, pero además tiene unos efectos particulares al margen de dicho incremento. Señalemos también que los árboles utilizan muy poco la energía que les llega en forma de luz: son capaces de asimilar entre el 1 y el 2 por ciento de ella.

Como se puede leer en González-Martínez y Bravo (1999):

Otro factor de gran importancia es la luz. La radiación global afecta a la temperatura, fotosíntesis y tasa de crecimiento de las plantas y depende a su vez de la orientación, latitud y pendiente del terreno. Rojo-Sainz (1977) considera como óptimo de insolación para regeneración del pino silvestre en nuestras latitudes el $35 \%$ de la radiación a cielo abierto, eso indica que el pino silvestre puede verse favorecido por una ligera cubierta en los primeros pasos de su desarrollo.

El factor temperatura producido por la radiación solar es especialmente importante en nuestras latitudes, en las que se alcanzan fácilmente temperaturas, tanto edáficas como aéreas, superiores a los 50 grados (García et al., 2013).

\subsubsection{FACTORES DE INFLUENCIA}

Hemos analizado las variables microclimáticas que son de naturaleza puramente local. Serrada, (2011) agrupa en varios bloques los factores de naturaleza global que influyen en la regeneración natural, algunos de los cuales ya han sido tenidos en cuenta por su capacidad de alterar las condiciones microclimáticas. A continuación se comentarán brevemente.

\subsubsection{Factores relativos a la estación}

Tegelmark (1988) ha señalado la influencia del clima en varios estadios del proceso de regeneración del pino silvestre, mostrando que a nivel regional la precipitación es el factor más importante. Concretamente en la meseta castellana, las precipitaciones durante invierno y verano afectan favorablemente a la regeneración natural. Ruano et al. (2009) han demostrado, simulando la precipitación en laboratorio, que la lluvia veraniega tiene una influencia significativa en la germinación y el desarrollo temprano de Pinus pinaster. La temperatura es un segundo factor climático a considerar y tiene especial incidencia en la meseta castellana, en la que se producen variaciones extremas de temperatura. La posible confirmación de la hipótesis del cambio climático y de un incremento importante de las temperaturas estivales darán a este factor mucha más importancia en el futuro, dado que, como observa Serrada (2011), la regeneración natural es especialmente sensible a las condiciones meteorológicas extremas.

Tienen también gran importancia los factores relativos al suelo. Hemos de tener en cuenta que el suelo es, por una parte, soporte de la masa y, por otra, almacén de sustancias nutritivas. El suelo debe ser entendido como un sistema compuesto por partes sólida, liquida y gaseosa, con una posición espacial, una composición química, y una determinada distribución de partículas minerales y orgánicas. Estos factores posibilitan o dificultan determinados procesos de naturaleza tanto física como química trascendentales para el desarrollo 
de la masa forestal. En resumen: al considerar el suelo como soporte, importa la fisiografía del terreno (pendiente, elevación, orientación); y, en cuanto a fuente de alimentos, importan tanto los factores litológicos como los edáficos.

Por ejemplo, Gandullo y Nicolás (1967) señalan que la extraordinaria variación en calidades de estación deriva en gran medida de las propias diferencias climáticas y edáficas de los pinares. Respecto a la composición litológica del suelo, indican cinco tipos: pinares sobre suelos silíceos arenosos, francos y arcillosos y sobre suelos carbonatados arenosos y no arenosos. Son factores importantes para la definición de calidades la penetrabilidad del suelo y la precipitación anual, que puede compensar una reducida profundidad explorable por las raíces (Rodríguez Soalleiro et al., 2002).

Es obvio que la pedregosidad del perfil es un factor negativo, especialmente cuando su abundancia dificulta la penetración de las raíces.

Desde el punto de vista geológico, la roca madre es esencial. Por ejemplo: los basaltos, la diabasa y la diorita tienen un alto contenido de nutrientes (magnesio y calcio); las rocas ígneas (gneis granito etc.) son ricas, salvo en calcio; las silíceas son pobres en nutrientes, especialmente en fósforo y potasio; y las calcáreas contienen exceso de calcio y son deficientes en potasio y fósforo.

\subsubsection{Factores referentes a la masa}

Una característica relevante del dosel forestal es su capacidad para modular de forma directa o indirecta la disponibilidad y la variabilidad de recursos esenciales para los organismos que se asientan debajo de él, que condiciona su propia regeneración (García et al., 2007). Es obvio que las características del dosel condicionan esencialmente la llegada de luz y agua a las semillas y ejemplares jóvenes, además de incidir en la composición del suelo (especialmente en lo relativo al nitrógeno y fósforo) vía la acumulación de hojarasca. Por ejemplo, Campo y Peña (1922) encontraron que, debajo de ejemplares de pino silvestre de 80 a 100 años con copas grandes, la radiación solar era de un $70 \%$ de la radiación a cielo abierto y bajo masas cerradas o poco aclaradas de 120 años, se alcanzaba sólo el $32 \%$.

La apertura del dosel de copas permite la entrada de mayor radiación en el suelo y, por lo tanto, una mayor mineralización de la materia orgánica depositada sobre él, que se pone a disposición de los brinzales instalados. Por el contrario, esa mayor iluminación del suelo puede provocar la densificación del estrato herbáceo, lo que puede impedir la instalación de la semilla sobre el suelo (de mayor influencia en la germinación hipogea, (Cabrera, 2003). La mayor mineralización de la materia orgánica no sólo favorece la puesta a disposición de los nutrientes para el repoblado, sino que también evita un posible problema, ya que la materia orgánica acumulada, al ser mala conductora del calor y poseer un calor específico muy bajo, puede alcanzar en los primeros centímetros, durante los días de verano, una temperatura muy alta que mate las semillas, además de que, por su elevada porosidad, puede provocar la desecación más rápidamente.

Cañellas et al. (2005) presentan un trabajo de laboratorio sobre la influencia de la cobertura vegetal en la germinación natural de semillas del pino silvestre localizando diversas situaciones de cobertura, y encuentran que la germinación total estuvo fuertemente influenciada por los distintos substratos empleados y que el porcentaje de emergencia fue prácticamente nulo con capas densas de herbáceas y con acumulaciones de acículas. Concretamente, las acumulaciones de más de 10 centímetros son muy desfavorables. Encontraron también que el efecto de la sombra es esencial si las condiciones del suelo son desfavorables. 


\section{- Formaciones arbóreas}

Tal como expone el texto de Hawley y Smith (1982), el proceso de regeneración determina la forma de la masa resultante de ella. Unas veces se obtienen masa coetáneas homogéneas y otras, masas disetáneas con mayor o menor nivel de irregularidad. La distribución de clases de edad en la masa resultante del proceso depende esencialmente de la duración de éste:

- Si la regeneración se lleva a cabo durante un plazo continuo e indefinido, se llega a una masa completa con árboles de todas las clases de edad por unidad de superficie a pequeña escala (caso de masas irregulares).

- Si la regeneración se efectúa por medio de cortas a intervalos poco frecuentes, la masa puede tener tantas clases de edad como cortas se han hecho durante el turno. El plazo destinado a sustituir la masa adulta por nuevos individuos o plazo de regeneración definirá la amplitud de edad del regenerado. Es el caso de las masas regulares.

- Si el periodo de regeneración se reduce a un año, la masa es completamente uniforme en cuanto a edades (masa coetánea). En la práctica, se consideran también coetáneas las masas formadas por individuos cuyas diferencias de edad son muy pequeñas; digamos, por ejemplo, de un octavo del turno, como mucho.

Las masas uniformes en cuanto a edades tienden a ser homogéneas en altura, con troncos rectos, casi cilíndricos, y ramas pequeñas. Las masas irregulares son desiguales en altura y los ejemplares menores y más jóvenes crecen lentamente por la competencia con los mayores. Estos últimos tienden a adoptar una forma cónica con grandes ramas y copas anchas (Schülz, 1997).

En el libro La regeneración natural de los pinares en los arenales de la Meseta Castellana (cap. II, Pardos, 2012), se resalta que, para entender el efecto del arbolado dentro del proceso de regeneración, es preciso identificar los patrones espaciales del arbolado adulto y del regenerado. Para ello, el método más común consiste en utilizar la función K (d) de Ripley (Ripley, 1981), que es un estadístico eficiente para el análisis del patrón espacial y, por ejemplo, permite discriminar entre una distribución agregada, regular o al azar, independientemente del área de la parcela muestreada (Rozas, 2002). Por ejemplo: el patrón espacial del regenerado de Pinus sylvestris en la Sierra de Guadarrama es agregado (Pardos et al., 2005), repitiéndose el patrón descrito para esta especie en el norte de la Península Ibérica (González Martínez y Bravo, 2001) y para otros pinos mediterráneos como Pinus pinea y Pinus uncinata (Barbeito et al., 2008; Camarero et al., 2005).

Cuando se estudia la dinámica del regenerado en especies de copa amplia e irregular, como es el caso de Pinus pinea (Barbeito et al., 2008), en lugar de considerar cada árbol como un punto, a efectos del cómputo de la función de Ripley, tomamos la proyección ortogonal de su copa sobre el plano; así podemos identificar el grado en que la regeneración natural varía según el tamaño y la proximidad de la copa del árbol más cercano.

El tiempo de duración del proceso es, como ya hemos señalado, otro factor importante a tener en cuenta para inferir procesos a partir del patrón espacial. Cuando no existen datos cronosecuenciados, la edad o las clases de edad de las plantas se pueden emplear como sustitutos demográficos para incluir un componente del tiempo en el análisis (Barbeito et al., 2009). 
- Formaciones arbustivas subarbustivas y herbáceas

Las formaciones arbustivas, subarbustivas y herbáceas interfieren en el establecimiento y desarrollo de la regeneración del arbolado, cuyas plántulas pueden llegar a no desarrollarse por la falta de luz y la necesidad de hacer frente a la competencia excesiva. Además, con frecuencia el crecimiento de herbáceas y matorral es más rápido que el de los brinzales de las especies arbóreas en cuestión.

En cualquier masa que no está sometida a cortas de regeneración se puede observar o suponer que hay una diseminación más o menos abundante o continua, que nacen los brinzales pero que no hay viabilidad para ellos. Es la espesura, entendida en sentido genérico, la que impide su crecimiento o provoca su muerte. Es indispensable reducir la espesura, en la forma adecuada al temperamento de cada especie, para conseguir la regeneración natural (Serrada, 2011).

También el establecimiento del regenerado en las fases iniciales de crecimiento puede verse comprometido o facilitado por la competencia herbácea y arbustiva, siendo muy sensibles a dicha competencia en las primeras etapas del crecimiento. La interacción entre individuos de la misma o diferentes especies y el balance entre competencia y facilitación depende del estado de desarrollo de la planta, fisiología, condiciones ambientales, etc. Generalmente, el incremento del estrés abiótico conlleva una potenciación del efecto de la facilitación y, así, mejora el crecimiento y supervivencia de las plántulas que coexisten (Pardos, 2012).

La presencia de vegetación herbácea aumenta la competencia por la luz, el agua y los nutrientes. La importancia de este factor parece estar muy relacionada con la disponibilidad de agua en el suelo, sobre todo en los ambientes mediterráneos, donde los déficits hídricos durante el periodo vegetativo son notables; pero también con la disponibilidad lumínica (Laliberté et al., 2008). En este sentido, es conocido el efecto negativo que se produce cuando coinciden condiciones de sequía y sombra, dado que algunos mecanismos fisiológicos de aclimatación a la sombra no parecen adecuados en condiciones de sequía, por lo que el desarrollo de la planta puede verse comprometido.

En condiciones naturales, las «sombras vivas» que proporcionan el dosel arbóreo o el sotobosque al regenerado pueden agravar el estrés hídrico por competencia con el regenerado, creando una situación de sombra seca (Valladares y Pearcy, 2002); o, por el contrario, ofrecer microambientes más adecuados que los circundantes (aumento de la cantidad de materia orgánica, atenuación del calentamiento foliar) en situaciones de facilitación (Sack y Grubb, 2002). Rodríguez-García et al. (2011) encontraron que la respuesta de las plántulas de Pinus pinaster frente a la cobertura arbórea y del matorral dependía de su tamaño, por lo que el balance entre competencia y facilitación es dinámico. En todo caso, el efecto positivo o negativo del sotobosque variará en función de la especie del regenerado y la densidad del sotobosque. Además hay que considerar que el sotobosque no permanece estático y, a menos que se elimine, crece a la vez que lo hace el regenerado con el que compite (Harrington, 2006),.

- Restos vegetales acumulados sobre el suelo

Pinus sylvestris germina adecuadamente con un suelo preparado (con humus y suelo intacto) para mantener la humedad de la semilla lo suficientemente alta para permitir la germinación (Oleskog y Sahlén, 2000a). Por otra parte, la materia muerta ofrece varias ventajas potenciales al regenerado, para lo que es importante el estado de pudrición de la misma (Mori et al., 2004). Por ejemplo: para diferentes especies de Abies y Picea se establece una asociación estrecha entre la presencia de madera muerta y la germinación y supervivencia del regenerado; en algunos casos la presencia de troncos es necesaria para que la especie se regenere (Mori et al., 2004; Parish y Antos, 2005). Por el contrario, una capa de musgo puede inhibir en gran medida el establecimiento del regenerado (LePage et al., 2000). En general, la presencia de una capa densa de hierba dificulta el contacto de la semilla dispersada con el suelo mineral. Junto con el sustrato, la posición microtopográfica también condiciona la supervivencia. Así, la elevación y la pendiente en determinados micrositios proporciona protección frente a la acumulación de hojarasca (Parish y Antos, 2005). 


\subsubsection{Composición, textura y estructura de los primeros centímetros de suelo}

Las propiedades del suelo (profundidad, permeabilidad, capacidad de retención de agua, fertilidad, ausencia de disfunciones y estado de micorrización) sobre la que se asienta el rodal deben ser concordantes con la especie a regenerar y las condiciones superficiales del suelo deberán ser adecuadas para la germinación de las semillas y para el desarrollo inicial de las plántulas (Serrada, 2011).

Pueden presentarse dificultades en la regeneración debido a diversas causas entre las que podemos destacar:

- Presencia de compactación superficial, provocada frecuentemente por pastoreo o por paso de maquinaria, que dificulta el contacto de la semilla con la tierra mineral y, sobre todo, el adecuado enraizamiento.

- Presencia de abundantes restos orgánicos, hojarasca, ramillas, etc..., procedentes bien de los restos de corta, bien de una defectuosa descomposición anterior, que impide la germinación por evitar el contacto de la semilla con la tierra, o provoca enraizamientos con el cuello de la raíz sobre el nivel del suelo y/o con la radícula retorcida.

- Presencia de un tapiz herbáceo denso y continuo que, además de impedir el contacto de la semilla con la tierra, en caso de germinación dificulta el enraizamiento mecánicamente y provoca una elevada competencia por agua y nutrientes.

- Presencia de abundante matorral, con efectos similares a los descritos para el herbazal, aunque con menor importancia en esta fase del proceso.

\subsubsection{Fauna y actividad micológica}

La intervención de la fauna es de enorme importancia para la regeneración de las especies forestales. Esta intervención puede ser beneficiosa e incluso esencial en los procesos de polinización y dispersión de la semilla o perjudicial por la predación sobre las semillas y las plántulas, la compactación de los suelos o la transmisión de enfermedades. Señalemos además que algunos animales pueden comportarse como mutualistas o antagonistas dependiendo del momento y las condiciones del entorno. Por ejemplo: aves y roedores, responsables de la pérdida de muchas semillas, son vectores de dispersión de considerable importancia; el ganado ovino y cabrío puede, en, determinadas épocas y zonas, limpiar los pinares disminuyendo el riesgo de incendios; y, en otras, destruir los ejemplares jóvenes.

En nuestro caso particular, un factor reseñable de la actividad faunística de la zona estudiada es la acción de los ungulados. La literatura existente concluye que, para asegurar el éxito de la regeneración natural, la presión por ungulados debe mantenerse controlada. Tanto la caza mayor como las especies de ganado doméstico pueden cambiar la forma y arquitectura del regenerado, retardar su crecimiento (Kuiters y Slim, 2002), reducir la calidad de la madera (González Martínez y Bravo, 2001) e, incluso, matarlo si la presión herbívora es demasiado fuerte (Izhaki y Ne'eman, 1996), de tal forma que pueden evitar que el regenerado llegue al estado adulto (Zamora et al., 1999). Además, debido a su ramoneo selectivo, los herbívoros pueden promover cambios en la composición de las formaciones arbóreas (Putman, 1996); pero también, al comerse la hierba densa, pueden favorecer la germinación y establecimiento de determinadas especies leñosas o, por el contrario, contribuir con su pastoreo a la instalación de un denso tapiz herbáceo que dificulte la regeneración de aquéllas, de forma que los ungulados tienen un impacto sobre la sucesión cíclica de pastos en matorral y viceversa (Vera, 2000). Por otra parte, el acotamiento a la caza y ganado puede favorecer el desarrollo rápido de un estrato herbáceo con especies diferentes a las mantenidas por pastoreo, que impidan o dificulten también la regeneración de muchas especies leñosas. Por tanto, el pastoreo debe controlarse, más que eliminarse completamente (Mitchell y Kirby, 1990). 
El efecto de los herbívoros sobre el regenerado es especialmente nocivo en los ambientes mediterráneos, ya que la tasa de crecimiento lento de las especies agrava el impacto de los ungulados (Egli, 1998). En las últimas décadas, las poblaciones de caza y ganado doméstico han aumentado con frecuencia por encima de la capacidad de carga del monte, produciéndose fenómenos de sobrepastoreo (Rooney y Waller, 2003) que afectan negativamente a la regeneración de especies forestales leñosas, debido al ramoneo selectivo de rebrotes y regenerado (Zamora et al., 1996). Además, la presión por sobrepastoreo presenta una variación temporal aunque la población de ungulados se mantenga constante; de forma que la presión herbívora será mayor en años muy secos en los que hay poca producción de pasto herbáceo y se concentrará principalmente en verano, periodo que todavía puede ser activo para el crecimiento del regenerado (Zamora et al., 2001). Los efectos del ramoneo sobre el crecimiento del regenerado se observan el año en que se produce (con disminución de la biomasa) y al año siguiente (con disminución de la tasa de crecimiento de los entrenudos) (Honkanen et al., 1994). Otro aspecto a considerar es que la intensidad del ramoneo es función del tamaño del regenerado: las plantas de menos de $5-10 \mathrm{~cm}$ o superiores a $150 \mathrm{~cm}$ son menos pastoreadas; las primeras, porque pueden quedar ocultas entre el matorral; las segundas, porque sus brotes apicales se escapan del diente de los animales (Crawley, 1997).

La presencia de plagas - perforadores y defoliadores - sobre los regenerados es ocasionalmente importante y se resuelve con la aplicación de insecticidas. Entre las enfermedades, la que mayor incidencia puede tener es damping-off, respecto de la que no es posible en estas circunstancias aplicar medidas preventivas ni curativas.

Los hongos son muchas veces un factor de importancia en la regeneración o desaparición de muchas especies. Por no extendernos, nos limitaremos a citar que para el pino silvestre, en zonas con características ecológicas especiales o en rodales con un exceso de árboles envejecidos, es necesario prestar una atención especial a la eliminación de árboles afectados por hongos. En el pino silvestre son fundamentalmente Fomes pini y Cronartium flaccidum los que mayores daños producen. Estas dos enfermedades son abundantes en los pinares españoles de pino silvestre $y$, sobre todo, en la sierra de Guadarrama. Su único tratamiento es eliminar los arboles afectados.

\subsubsection{Factor antrópico}

Lo mismo que la acción de la fauna puede ser beneficiosa o perjudicial para el desarrollo de la masa, también puede serlo la acción humana Sin entrar en actuaciones evidentemente negativas para la dinámica forestal, como urbanización o creación de otras infraestructuras artificiales, incendios provocados, etc., nos centraremos en la actividad selvícola.

Según Serrada (2011) "Selvicultura es el modo de aplicar el conocimiento de la estructura, crecimiento, reproducción y formas de agrupación de los vegetales que pueblan los montes, de forma que se obtenga de ellos una producción continua de bienes y servicios necesarios para la sociedad".

Partiendo del hecho de que, si una masa existe en un determinado lugar autorregenerándose, independientemente de su origen natural o artificial, se debe a que las condiciones le son favorables o, al menos, no le impiden vivir o desarrollarse allí, es posible afirmar que la mayor limitación para la regeneración natural proviene de ciertas actividades humanas. Dentro de éstas, son dos las más susceptibles de afectar al proceso: la corta del arbolado y la ganadería extensiva.

Los métodos selvícolas de cortas de regeneración tratan de provocar las perturbaciones que las especies arbóreas precisan para autorregenerarse, imitando los episodios de crisis que se producen de manera natural adaptados al temperamento de la especie o especies en cuestión, a las condiciones concretas de la estación y a los condicionantes socioeconómicos y legales. De este modo, el selvicultor actúa abriendo huecos de 
tamaño adecuado para que se instale el diseminado. Dado el temperamento relativamente plástico del pino silvestre y la gran variabilidad de situaciones que presentan los montes españoles (Serrada, 2011), el pino silvestre admite una gran variedad de cortas de regeneración, si bien tradicionalmente las más aplicadas en España han sido los aclareos sucesivos y, en menor medida, las cortas a hecho.

Las cortas a hecho requieren una intensa preparación del terreno para conseguir una buena regeneración. El método tiene serios inconvenientes, descritos en la literatura europea (Mathews, 1989; Susmel, 1980; Troup, 1952). En España no hay suficiente información para confirmar una pérdida de fertilidad o un empobrecimiento del suelo, que no se han comprobado hasta el momento (Montero et al. 1993). Es claro que la necesidad de una cierta cobertura vegetal para la instalación y desarrollo de las plántulas hace que este método, siempre en su modalidad de corta a hecho en dos tiempos, no sea el más adecuado para la regeneración natural.

En cambio, con los aclareos sucesivos la masa adulta proporciona la protección que precisa en un principio el regenerado, permitiendo la puesta en luz de la planta joven cuando alcanza la fase de desarrollo y evitando la competencia de las masas madre e hija. Este entronque gradual no traumático entre las fases de destrucción y colonización ha dado lugar a que la mayoría de los textos nacionales sobre el pino silvestre se hayan inclinado por el método de aclareos sucesivos como el adecuado para conseguir la correcta regeneración natural de las masas de esta especie (González Vázquez, 1945; Laguna y de Ávila, 1883; Martínez de Pisón, 1948; Sainz Margareto, 1963, 1953).

La correcta aplicación del método de aclareos sucesivos requiere el cumplimiento de una serie de condiciones que no siempre se han seguido. Ésa es la razón del fracaso en el intento de regenerar los primero tramos, de muchas ordenaciones de monte de pino silvestre en nuestro país efectuadas a fines del siglo XIX y principios del XX (Martínez de Pisón, 1948). Según este autor, uno de los hechos que más contribuyó al descrédito de los aclareos sucesivos fue el miedo a cortar que se tuvo en los comienzos de las ordenaciones, miedo debido a que se desconocía la espesura en que sería necesario dejar un rodal para que se produjese la regeneración. Desconocimiento que se mantiene hasta hoy porque, aunque en los manuales se dan cifras orientativas, se desconocen los datos precisos que, además, son muy sensibles a las variaciones zonales y climatológicas. 


\subsection{PARTICULARIDADES DEL PROCESO DE REGENERACIÓN EN EL PINO SILVESTRE (PINUS SYLVESTRIS L.)}

El pino silvestre es una de las especies con mayor importancia forestal en España. La superficie forestal cubierta con masas de Pinus sylvestris L. es de casi 1.280 .000 hectáreas, de las que unas 600.000 son pinares naturales. Esta superficie supone unas existencias de madera con corteza de $91.338 .295 \mathrm{~m}^{3}$, con un crecimiento corriente anual de $3.691 .826 \mathrm{~m}^{3} \mathrm{año}^{-1}$. De este crecimiento se aprovecha anualmente en torno a $700.000 \mathrm{~m}^{3}$. Los objetivos preferentes adjudicados a las masas de pino silvestre varían en función de las particularidades de cada lugar, desde masas exclusivamente protectoras hasta puramente productivas, con numerosas situaciones de función múltiple: producción de madera y hongos, caza, recreo, protección de vida silvestre, etc. Debido a este interés ecológico, productor y protector, muchas masas de pino albar se encuentran ordenadas desde finales del siglo XIX, lo que ha aportado valiosa información sobre la selvicultura de esta especie. Sin embargo y pese a lo impactante de estos datos tomados literalmente de Montero et al. (2008), los estudios sobre esta especie son aún relativamente escasos en la literatura selvícola española. Uno de los estudios más completos es el de (González-Martínez y Bravo, 1999), cuyas principales observaciones y resultados resumimos a continuación.

\subsubsection{PRODUCCIÓN Y DISPERSIÓN DE LA SEMILLA}

- La regeneración comienza con la formación de los primordios florales casi un año antes de la floración (Kupila-Ahvenniemi, 1985).

- Con tiempo seco y templado se favorece el desarrollo de flores femeninas, mientras que en tiempo fresco y húmedo se favorece la floración masculina (Mátyás, 1991).

- La época de floración varía con el genotipo, la insolación recibida por el individuo y la latitud. En el huerto semillero de San Idelfonso, la floración tiene lugar en mayo-junio y las flores femeninas están receptivas de 1 a 4 días, con un máximo observado de 7 (Martín y Agúndez, 1992).

- La producción de polen es muy variable. Datos en el sur de Finlandia dan entre 9,0-34,5 kg/ha en rodales maduros, y puede llegarse a 30-130 kg/ha en años con buena floración (Sarvas, 1962).

- La fructificación abundante suele ser periódica, con intervalos entre 2 y 5 años, aunque en los restantes años la producción de piña es suficiente para la regeneración (Booth, 1984; Ceballos y Ruíz de la Torre, 1979; Mátyás, 1991). Una rama de pino silvestre puede presentar piñas viejas que ya han dispersado la semilla, piñas maduras que la dispersarán durante la siguiente temporada y piñas en maduración.

- La producción de semilla anual es muy variable: se han señalado datos medios de 35-100 semillas $/ \mathrm{m}^{2}$ y extremos de 0-400 semillas $/ \mathrm{m}^{2}$ (Sarvas, 1962).

- De los pies aislados se obtiene semilla a partir de los 25-30 años. El intervalo se alarga hasta los 40 años en masas de condiciones medias.

- La dispersión de la semilla puede alcanzar $500 \mathrm{~m}$, pero pocas se alejan más de $30 \mathrm{~m}$ y el $75 \%$ cae en los $18 \mathrm{~m}$ más próximos al árbol (Booth, 1984).

- Las principales pérdidas de semilla en el árbol se deben principalmente a las deficiencias de la polinización y al ataque de insectos; puede llegar a perderse más del 70 \% de la cosecha (Jeansson et al., 1989).

- Las pérdidas debidas a predación varían entre el $20 \%$ y el $95 \%$ de las semillas caídas en el suelo (Pukkala, 1987). En España el insecto más dañino es Pissodes validirostris Gyll, que ataca piñas en su último año de desarrollo. Menor importancia tiene el lepidóptero Dioryctria mendacella (Stgr.), cuya larva también perfora las piñas. 


\subsubsection{GERMINACIÓN Y ESTABLECIMIENTO}

- La mayor parte de la germinación se produce en el primer año desde la caída de la semilla (Granström y Fries, 1985).

- En esta primera etapa, las herbáceas actúan como barrera física, impidiendo el contacto de la semilla con el suelo (empradizado).

- Un efecto similar se produce cuando el grosor de la capa de materia orgánica fresca en bruto supera los $10 \mathrm{~cm}$ (Leroy, 1961).

- $\quad$ No siempre es aconsejable la preparación del terreno, que debe evitarse cuando la capa de pinocha sea pequeña (Jeansson et al., 1989; Oosterbaan, 1994; Rojo y Montero, 1996).

- Cuando la preparación del terreno es necesaria, hay que tener especial cuidado en la determinación de la profundidad más adecuada. Si ésta es escasa, sus efectos desaparecen rápidamente (Gong et al., 1991); y, si es profunda, en algunas estaciones (especialmente sobre podzoles) puede causar la muerte de la regeneración, al potenciar el efecto de las heladas (Jeansson et al., 1989).

- La luz es un factor importante. Rojo Sainz (1977) considera como óptimo de insolación para la germinación del pino silvestre en nuestras latitudes el $35 \%$ respecto a radiación sobre cielo abierto.

- El crecimiento del primer año está más influido por las condiciones ambientales y los efectos maternos de las semillas, mientras que en años posteriores se ha observado un mayor control genético (Agúndez et al., 1992).

- El efecto de la competencia es decisivo en los primeros años del rodal, de modo que las tasas de supervivencia son muy variables en función de ella (0-85\%).

- El crecimiento lento de la raíz del pino silvestre en el momento de la germinación potencia el efecto negativo de la competencia (Rojo Sainz, 1977).

\subsubsection{PRIMER DESARROLLO}

- En el primer desarrollo del pino silvestre tiene mucha importancia la competencia, tanto inter como intraespecífica.

- Las plántulas de pino compiten por su supervivencia con especies herbáceas y leñosas. Morillo (1987), Rubio (1987) y Santos (1987) encuentran relaciones significativas entre malas regeneraciones de $P$. sylvestris y la presencia de retamas (Sarothamnus scoparius), genistas (Genista florida), zarzas (Rubus sp.) o rebollos (Quercus pyrenaica) en el monte Cabeza de Hierro de Madrid.

- Aunque no hay estudios concretos para pino silvestre, está bien constatada la inhibición de la germinación de los compuestos fenólicos de las partes aéreas, raíces e incluso suelos donde se desarrollan especies como Erica vagans, Calluna vulgaris y Daboecia cantabrica (Ballester et al., 1982) o Erica australis (Carballeira, 1980).

- La importancia de la competencia del helecho común en los sistemas forestales ibéricos es notable, dadas sus agresivas características competitivas: poca palatabilidad, defensas químicas frente a los insectos, habilidad para rebrotar y producción de fitotóxicos.

- Los efectos fitotóxicos del humus y la hojarasca procedente de helechos pueden inhibir la germinación y establecimiento del pino silvestre procedente de semilla hasta su eliminación completa en tres años (Dolling, 1996).

- La competencia de herbáceas en las estaciones buenas puede impedir la regeneración de $P$. sylvestris (Ackzell, 1994; Montero, 1987) o reducir sus crecimientos.

- La competencia intraespecífica se produce tanto de forma directa (sombreo, competencia por agua y nutrientes, etc.) como indirecta (modificación de las condiciones edáficas, formación de una capa densa de pinocha, modificación del sotobosque, etcétera). 
- Pukkala, (1987) indica una mayor probabilidad de supervivencia de las plántulas de Pinus sylvestris situadas a 4-5 $\mathrm{m}$ de los árboles padre.

- La especie tiene capacidad de adaptarse a crecer bajo cubierta y establecer regeneración avanzada. Ésta mantiene su capacidad de responder a la liberación de la masa durante largo tiempo: en ocasiones, por encima de los 75 años (Andrzejczyk y Zybura, 1981).

- Un buen crecimiento inicial se considera necesario para el establecimiento de las plántulas y determinante de su futura posición social (De Schepper, 1988; Lust, 1988).

- Ackzell (1994) señalan que para obtener buenos crecimientos es mucho más importante el método de regeneración (siembra/plantación) y el ambiente de la misma (cortas a hecho/árboles padre) que la densidad inicial. 


\subsection{TRATAMIENTOS DE AYUDA A LA REGENERACIÓN}

Las condiciones climatológicas de la meseta central española marcan los límites de sequedad y calor extremos soportables por el pino silvestre. En esta región el pino silvestre, como ya hemos señalado, presenta vecería muy marcada. Aproximadamente, de cada siete años dos suelen ser buenos, otros dos regulares y los tres restantes malos (Ceballos y Ruíz de la Torre, 1979). Con estas condiciones, la germinación de las semillas y el proceso de establecimiento requieren procesos de regeneración ligeramente mayores, lo suficientemente largos para garantizar la inclusión en ellos de un año húmedo con producción abundante de semillas (Rojo y Montero, 1996).

El problema es aún mayor debido a otros factores habituales en los montes mediterráneos:

- $\quad$ Presencia de ganado con cargas elevadas (AGRESTA y INCA, 2012).

- Pasto herbáceo y matorral heliófilo, que colonizan con rapidez cuando las cortas de regeneración sobre la masa arbolada permiten la entrada de más luz (Montero et al., 2008).

- Presencia frecuente bajo masa arbolada de restos vegetales sin descomponer (Rojo y Montero, 1996).

Un modo de alargar indefinidamente los plazos de regeneración consiste en emplear tratamientos selvícolas que generen y mantengan masas irregulares. Aunque esta opción es compatible con el temperamento de la especie, no siempre es posible por diferentes razones: complejidad de gestión, costes más elevados por dificultad de mecanización y por dificultad de extracción de la madera sin dañar el regenerado, riesgo de incendios, variabilidad de tamaños de los productos maderables obtenidos por unidad de superficie etc. (Serrada, 2011).

En España, la gestión de las masas de pino silvestre se ha basado tradicionalmente en la aplicación de aclareos sucesivos (Montero et al., 2008) y lo más probable es que éste siga siendo el método más usado en el futuro. Pero estos tratamientos exigen emplear plazos de regeneración relativamente breves, de 20 años según la normativa vigente en España (Ministerio de Agricultura, 1971), aunque, en la práctica, llegan a extenderse hasta 25 o incluso 30 años. En cualquier caso, en medio mediterráneo el pino silvestre puede tener dificultades para regenerar en dichos plazos con cantidad y calidad suficiente, en unidades de gestión que habitualmente rondan o superan las 100 ha.

Una forma de acelerar la regeneración consiste en aplicar tratamientos sobre el suelo con los objetivos generales de alterar la cubierta vegetal y los restos en superficie y mejorar las condiciones edáficas para facilitar la germinación de las semillas y el arraigo y primer desarrollo de las plántulas, de modo que aumente su supervivencia. Los tratamientos aplicados sobre el suelo pueden ser muy diversos: actuar con diferente extensión superficial, con o sin inversión de horizontes; realizarse de manera manual o mecanizada y a diferente profundidad... Concretamente, según las condiciones de cada caso y el tipo de tratamiento aplicado se debe buscar (R., 2000):

- Presencia frecuente bajo masa arbolada de restos vegetales sin descomponer (Rojo y Montero, 1996).

- Controlar o eliminar herbáceas y matorral para facilitar la regeneración del pino silvestre, reduciendo las posibilidades de una posterior invasión de matorral.

- Incorporar restos orgánicos al suelo para favorecer su descomposición y humificación, y permitir la germinación y primer desarrollo de las plántulas.

- Aumentar la profundidad útil del perfil, disgregando capas profundas mediante acción mecánica, para conseguir una mayor profundización de los sistemas radicales. 
- Aumentar la capacidad de retención de agua del perfil a través del aumento de profundidad explicado en el punto anterior.

- Aumentar la velocidad de infiltración de agua en el perfil mediante un mullido que permita anular la escorrentía y, por tanto, la erosión hídrica.

- Facilitar la penetración mecánica de las raíces de las plantas mejorando transitoriamente la permeabilidad mediante las labores, de modo que un sistema radical más extenso pueda compensar la baja fertilidad y las posibles sequías. El mullido también facilita la aireación de las capas profundas del perfil mejorando el ambiente edáfico.

Hay abundantes antecedentes de tratamientos sobre el suelo que han facilitado la regeneración en masas arboladas de diferentes especies y ámbitos geográficos. Concretamente, en la zona en la que se localiza el presente trabajo (ver Material y Métodos) existe un ejemplo de masa de pino silvestre de origen natural en el que la regeneración en breve plazo se ha visto muy favorecida por la aplicación durante las últimas décadas de un decapado. Se trata del pinar de Navafría, situado en la vertiente norte del Sistema Central. El tratamiento se aplica mediante un pequeño bulldozer que va realizando un ligero decapado trazando un recorrido continuo, irregular y sinuoso, que intenta seguir todo lo posible las curvas de nivel.

Sin embargo, y pese a que los decapados parciales son muy adecuados para favorecer la regeneración en pináceas (Cabrera Bonet, 2003), es frecuente que limitaciones paisajísticas o de protección del suelo (Olarieta et al., 2007) impidan o limiten su aplicación. Esta limitación será más probable y evidente cuanto más enfocada esté la gestión a la obtención de múltiples productos y servicios, entre los que se incluyan la protección frente a la erosión, la biodiversidad, el uso público, etc.

Por eso, sería muy conveniente analizar alternativas menos agresivas que también sean efectivas en relación con la regeneración de pino silvestre, una de las cuáles podría ser la aplicación de escarificación. Se acepta ampliamente que la escarificación puede mejorar el contacto de la semilla con el suelo, disminuir la resistencia de este a la penetración y reducir la competición de otras especies facilitando el establecimiento de la planta (Jiménez Esquilín et al., 2008; Kubin y Kemppainen, 1994). Hablamos de una escarificación no continua, sino aplicada en pequeñas superficies distribuidas uniformemente por la unidad de corta. De este modo se reduce el impacto paisajístico a corto plazo; se evitan o reducen daños sobre especies vegetales cuya permanencia se considere adecuada; y se pueden evitar afloramientos rocosos, pendientes excesivas, puntos con matorral de tamaño considerable, etc., sin que tenga por qué reducirse el éxito en la regeneración conseguida si el número de zonas tratadas ( $\mathrm{y}$, por tanto, la superficie de suelo escarificada) es suficiente. 


\subsection{COMPACTACIÓN, REGENERACIÓN Y PRODUCTIVIDAD EN LAS MASAS FORESTALES}

La compactación edáfica y los problemas que de ella se derivan se citan de forma habitual en la bibliografía como una de las causas de pérdida de calidad en los suelos que puede llegar a repercutir en el desarrollo de la vegetación y, consecuentemente, en la productividad de los mismos (Kozlowski, 1999).

Básicamente, la compactación edáfica genera una disminución del volumen de poros (especialmente, la proporción de poros de gran tamaño) y una reordenación y mayor empaquetamiento de las partículas del suelo que tiende a aumentar las fuerzas de cohesión entre ellas y limitar la conectividad de la red de poros del sustrato (Lipiec y Hatano, 2003). Todo ello repercute en los cuatro parámetros edáficos que, en último término, determinan el desarrollo y la actividad radical de la vegetación (Letey, 1985): aireación, temperatura, disponibilidad hídrica y resistencia mecánica al desarrollo radical (Miller et al., 2004).

La alteración de estos parámetros por encima de unos ciertos rangos, que varían en función de las especies (Alameda y Villar, 2009; Materechera et al., 1991) y el clima (A. Gomez et al., 2002), hace que las raíces crezcan menos y tengan más dificultades para captar agua y nutrientes y llevar a cabo procesos básicos tales como la respiración. Si la afectación es lo bastante severa o prolongada en el tiempo, el crecimiento vegetal y la productividad pueden llegar a disminuir (Kozlowski, 1999).

En un principio, la mayoría de los efectos nocivos de la compactación edáfica sobre la vegetación fueron estudiados y caracterizados sobre cultivos agrícolas herbáceos de ciclo anual en los que el principal agente compactador era la maquinaria y la intensidad, frecuencia y superficie de afectación de las perturbaciones eran elevadas (Huberty, 1945; Moon, 1938; Veihmeyer y Hendrickson, 1945).

Desde los años cincuenta esta preocupación por la pérdida de calidad del medio como consecuencia de la compactación se ha extendido también al ámbito forestal (Cambi et al., 2015). Tras numerosos trabajos en relación con la compactación edáfica, parece haber quedado claro que tanto maquinaria como ganado pueden compactar los suelos forestales durante los aprovechamientos y que la intensidad, profundidad y superficie afectadas dependen tanto de las características de la estación (textura, estructura, [materia orgánica], [humedad], topografía, clima...) como de las del propio aprovechamiento (frecuencia, duración, dimensiones de la carga...) (Cambi et al., 2015; Greacen y Sands, 1980; Jones, 2000)

Ahora bien, la mayor parte de la literatura se ha centrado en comprobar y cuantificar la compactación sobre las zonas de tránsito, generalmente de maquinaria, y eso dentro de masas en las que la compactación era más susceptible de generar problemas (aprovechamientos intensivos en climas húmedos y fríos) (Blouin et al., 2005; Brais y Camiré, 1998; Claverie et al., 2000; Goutal et al., 2013; Jakobsen y Greacen, 1985; Miller et al., 1996). Así mismo, en lo referente a la vegetación tan sólo se ha comprobado de forma inequívoca el impacto de la compactación sobre la velocidad de crecimiento radical de plántulas jóvenes (Bengough et al., 2006; Chapman et al., 2012), mientras que los estudios sobre crecimiento de la parte aérea, particularmente en masas adultas, son mucho más escasos y poco concluyentes (Ampoorter et al., 2011), especialmente a largo plazo y a nivel de monte (Grigal, 2000; Kirby, 2007).

No obstante, tal y como sostienen Kirby (2007) o Worrell \& Hampson (1997), para dar recomendaciones de gestión a propietarios y administraciones es necesario un análisis finalista de los efectos de la compactación en los distintos escenarios posibles. No es suficiente comprobar que sobre la calle de desembosque se está produciendo una compactación tras el paso de maquinaria o ganado: lo que el gestor necesita saber es cuál es el efecto global que se está generando sobre la calidad de la estación y la productividad de la masa que gestiona. 
Pero el salto desde los efectos locales sobre suelo y sistemas radicales de regenerado al efecto global sobre la calidad de estación y el crecimiento de una masa no es trivial. En los aprovechamientos agrícolas todo el territorio se ve uniformemente afectado por el paso de la maquinaria, la vegetación se elimina y reinstala en cada ciclo y la frecuencia de intervención es máxima. Sin embargo, en el ámbito forestal los tiempos son muy diferentes y los patrones espaciales y las formaciones vegetales distan mucho de ser homogéneas.

Para definir el daño sobre el suelo asociado a un aprovechamiento, además de la intensidad y profundidad de la compactación local generada es necesario conocer en cada caso la superficie total afectada a nivel de monte y su patrón de distribución, así como la evolución esperada en función de la acumulación de efectos previsible (equilibrio entre recurrencia de impactos y capacidad de recuperación).

Si, además del daño sobre el suelo, se quiere evaluar el efecto sobre la vegetación, a todo ello habrá que añadir la resiliencia de la formación vegetal en función de la especie o especies implicadas, así como de las características de la masa (edad, estructura, densidad...etc). En este sentido hay que añadir que, en la mayoría de los casos en el ámbito forestal, el tránsito de maquinaria y ganado se produce bajo una masa preestablecida en la que hay presente una o varias clases de edad y en la que existen más estratos vegetales aparte del arbóreo (matorrales de distinta talla, herbáceas, restos acumulados sobre el suelo...etc.). Ello implica que los sistemas radicales afectados no son sólo los que están por desarrollarse, sino también los ya establecidos (tasa de renovación de raíces finas, tasa de expansión de raíces gruesas, viabilidad de las raíces preexistentes...) (Vasiliauskas, 2001). Hay que destacar así mismo que cabe esperar una mayor capacidad de adaptación y superación de posibles compactaciones parciales del suelo al existir sistemas radicales preexistentes que abarcan otras zonas no compactadas y que pueden mantener el suministro de agua y nutrientes hasta lograr recolonizar la zona compactada (Miller et al., 2004; Puhe, 2003). Cabe esperar también un aumento de la capacidad portante del suelo por efecto del entramado radical preexistente (susceptible de absorber y dispersar en parte las tensiones generadas) (Soane, 1990).

En definitiva, nos encontramos ante sistemas muy complejos en los que tanto dicha complejidad como los extensos horizontes temporales de manejo aumentan mucho el abanico de escenarios posibles y, por ende, el de los efectos esperables, la capacidad de recuperación del sistema y los riesgos de las alteraciones. No es posible, por tanto, establecer pautas generales para definir con precisión los riesgos de compactación. En cada caso se ha de trabajar teniendo en cuenta el contexto: tipo de suelo, tipo de clima, tipo/s de aprovechamiento/s; la formación vegetal y las especie/s implicadas; y, dentro de la caracterización de los aprovechamientos, turnos, tipos y periodicidad de tratamientos.

Llevar a cabo estudios detallados y bien especificados sobre los efectos finales de los aprovechamientos sobre la productividad de las masas forestales es muy complicado. Los plazos de funcionamiento de la gestión forestal, especialmente en las explotaciones en extensivo, y la enorme cantidad de factores que condicionan el crecimiento de una masa a lo largo de un turno completo hacen muy difícil llevar a cabo experimentos en los que se controlen mínimamente las relaciones causa efecto para los cambios en la productividad. Aun así, definir pautas claras de gestión y avanzar en el estudio de la compactación de suelos forestales exige que se realicen este tipo de trabajos asociados a una adecuada caracterización de estación, vegetación y aprovechamientos.

Más del $55 \%$ de la superficie en España es considerada forestal y aproximadamente el $37 \%$ es forestal arbolada (Montero y Serrada (2013); datos referidos a 2012). La mayor parte de estas masas arboladas están gestionadas de modo extensivo, con turnos superiores a 80 años y entradas de maquinaria con periodos de recurrencia superiores a 10-15 años. Así mismo, la presencia de ganado ha sido y es muy frecuente en los montes españoles, y explica en gran parte su paisaje (AGRESTA y INCA, 2012). Por tanto, en España es especialmente relevante caracterizar los impactos de compactación provocados por maquinaria y ganado en este tipo de montes. Se destaca que se trata de un medio mediterráneo en el que las condiciones climáticas pueden modificar (Powers et al., 2005) muchas de las consecuencias negativas que muchas veces se han asociado a la compactación como consecuencia de la investigación en climas húmedos y fríos (Kozlowski, 1999). 
2. OBJETIVOS 

El objetivo general de la presente Tesis Doctoral es profundizar en el conocimiento del proceso de regeneración del pino silvestre en la franja meridional de su área de distribución (Sistema Central español). En una masa irregular de pino silvestre ubicada en la Sierra de Guadarrama se han diseñado y desarrollado una serie de experiencias a partir de las cuáles se pretende caracterizar y cuantificar en dicho entorno tanto el proceso de germinación y supervivencia de la especie como la influencia que ejerce sobre dicho proceso la cobertura vegetal: estrato arbóreo, estratos arbustivo y herbáceo y capa de restos vegetales sobre el suelo.

Al tratarse de un monte gestionado con objetivo múltiple que incluye aprovechamientos mecanizados de madera y uso ganadero, se pretende así mismo comprobar la importancia de la compactación edáfica, mencionada habitualmente en otras latitudes y entornos como fuente de limitaciones para el regenerado, como variable limitante para la sostenibilidad de la masa analizada.

Por último, en relación con los problemas de regeneración detectados en algunas zonas, se desea contrastar y comparar la eficacia de dos tratamientos edáficos de ayuda a la regeneración, aplicados en superficies de pequeñas dimensiones: i) escarificación y ii) decapado por líneas con acaballonado..

A partir de los resultados y conclusiones obtenidos, se persigue extraer recomendaciones selvícolas sobre el proceso de regeneración natural en las masas de pino silvestre en entornos mediterráneos de montaña.

En definitiva, las preguntas que se pretende abordar con respecto a la fase de establecimiento del regenerado de pino silvestre en entornos de montaña mediterránea se pueden sintetizar como sigue:

$\checkmark$ SI PROPORCIONAMOS SEMILLA SUFICIENTE... ¿CUÁNTOS INDIVIDUOS NACEN Y CUÁNTOS SOBREVIVEN AL PRIMER, SEGUNDO Y TERCER VERANO?

$\checkmark$ ¿CÓMO LES AFECTAN LAS CONDICIONES DE CUBIERTA VEGETAL?:

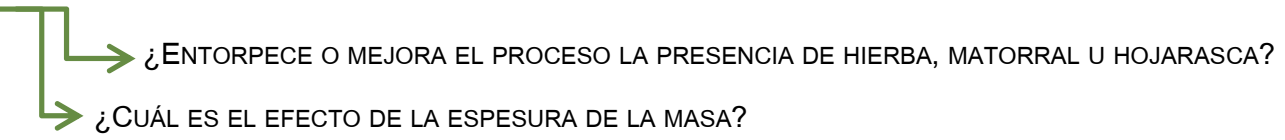

$\checkmark$ ¿ESTÁN COMPACTANDO EL SUELO DE FORMA IMPORTANTE LA MAQUINARIA Y EL GANADO QUE CIRCULAN POR EL MONTE? ¿AFECTAN SUS EFECTOS SOBRE LA COMPACTACIÓN A LA SOSTENIBILIDAD DE LA MASA?

$\checkmark$ ¿TIENE SENTIDO Y ES EFICAZ APLICAR EN PEQUEÑAS SUPERFICIES TRATAMIENTOS SOBRE EL SUELO DE AYUDA A LA REGENERACIÓN? ¿MEJOR ESCARIFICADO O DECAPADO POR LÍNEAS CON ACABALLONADO? 

3. MATERIAL Y MÉTODOS 



\subsection{DESCRIPCIÓN DE LA ZONA DE ESTUDIO: EL MONTE CABEZA DE HIERRO}

El presente estudio se ha llevado a cabo íntegramente dentro del monte denominado "Cabeza de Hierro", también conocido como "Pinar de los Belgas" En los siguientes apartados se describen sus principales características. La información aportada está basada en algunos de los documentos existentes sobre el monte (Bravo \& Serrada 2006; Oliveros 2006; Rojo \& Montero 1999) y sigue el esquema descriptivo de un proyecto de ordenación, aunque de modo muy resumido.

\subsubsection{Estado LEGAL Y BREVE RESEÑA HISTÓRICA}

"Cabeza de Hierro" es uno de los montes emblemáticos de la sierra de Guadarrama. Al igual que Valsaín y Navafría, constituye un ejemplo de masa de pino silvestre de origen natural, que no fue afectada por los procesos anticulturales derivados de la desamortización de Mendizábal y que ha sido gestionado ininterrumpidamente durante un largo periodo de tiempo.

El monte Cabeza de Hierro perteneció, desde la Reconquista hasta 1675, a la Comunidad de Villa y Tierras de Segovia. En 1675 la Corona lo entregó al Monasterio de El Paular, a quién perteneció hasta el año 1837. En este año se inició la desamortización de Mendizábal, en el curso de la cual se forzó a la propiedad a llevar a cabo la subasta pública del monte, que fue adquirido por un particular: D. Andrés Andreu. Tres años después de su compra, D. Andrés Andreu vendió el monte a la Sociedad Civil Belga del Monte del Paular.

Esta Sociedad es la antecesora de la actual titular, la Sociedad Anónima Belga de los Pinares de El Paular, que, con una u otra denominación, ha sido propietaria del monte durante los últimos 160 años.

La Sociedad Anónima Belga de los Pinares de El Paular aprovecha la madera de este monte, que se destina en su mayoría a un aserradero cercano perteneciente a la misma empresa. Este aprovechamiento se ha realizado desde 1957 bajo las directrices técnicas de un proyecto de ordenación y sus sucesivas revisiones.

El monte tiene una superficie de $2.016,5$ ha, que se clasifican del siguiente modo:

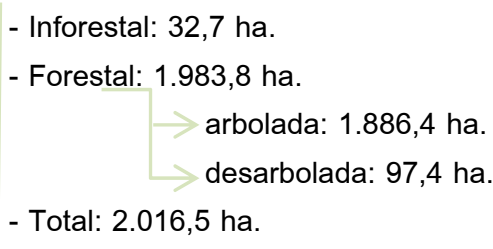

Desde su etapa original de pertenencia a la Comunidad y Tierra de Segovia, el monte está sujeto a una serie de servidumbres a favor de los vecinos de los pueblos del antiguo Sexmo de Lozoya, que han sido reconocidas en cada una de las sucesivas inscripciones en el Registro de la propiedad (Oliveros 2006):

- Pastos: sin limitación de especie, número de cabezas ni superficie a pastar.

- Leñas muertas y despojos de corta: con el deber por parte de los vecinos de prestar servicio en caso de incendios.

- Derecho a la madera necesaria para la construcción y reparación de edificios privados y públicos.

- Paso motorizado por los caminos previa adquisición de autorización de la entidad propietaria. 
Hasta la declaración del Parque Nacional de la Sierra de Guadarrama, una pequeña parte del monte estuvo incluida en el Parque Natural de la Cumbre, Circo y Lagunas de Peñalara, en cuya Zona Periférica de Protección se incardinaba el terreno restante.

Actualmente, el monte está incluido en de la ZEPA del Alto Lozoya y forma parte de la zona periférica del Parque Nacional de la Sierra de Guadarrama; concretamente, de la zona de conservación y mantenimiento de usos tradicionales.

\subsubsection{ESTADO NATURAL}

El monte "Cabeza de Hierro" se encuentra en la parte noroccidental de la Comunidad de Madrid, en la vertiente sur de la Sierra de Guadarrama, y ocupa la cabecera alta del Valle de Lozoya. En las figuras 2 y 3 se ubica, respectivamente, en la Comunidad de Madrid y en el término municipal dle Rascafría, al que pertenece. Las coordenadas U.T.M. se presentan en la tabla 1.

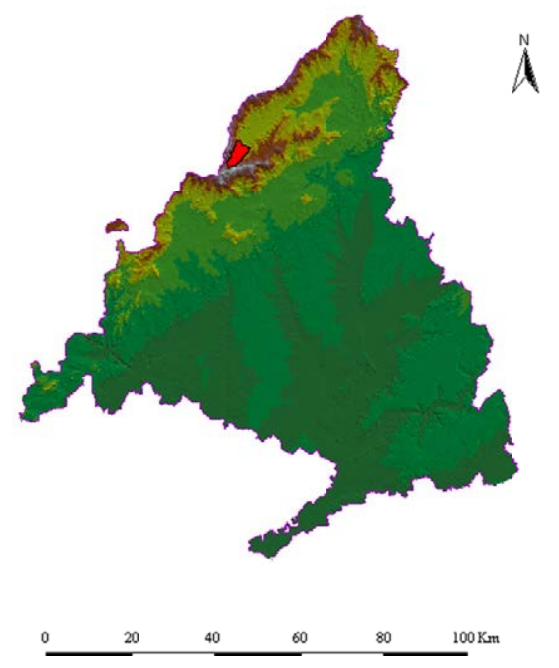

Fig. 2. Croquis de situación del término municipal de Rascafría en la Comunidad de Madrid.

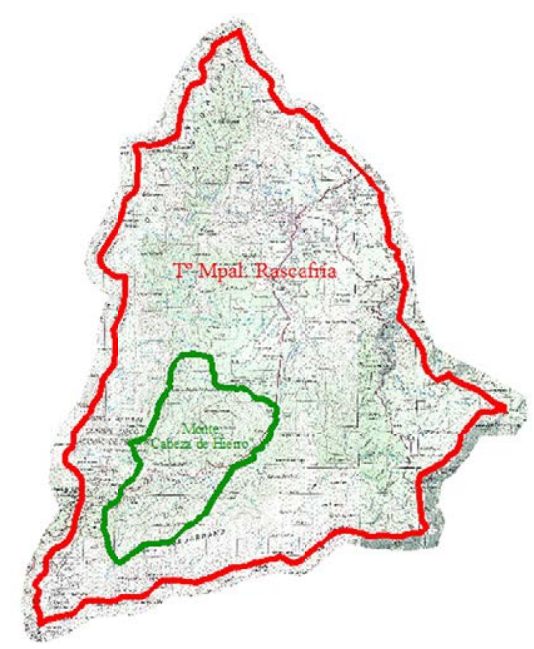

Fig. 3. Croquis de situación del monte "Cabeza de Hierro" dentro del término municipal de Rascafría. 
Tabla 1. Situación geográfica del monte "Cabeza de Hierro".

\begin{tabular}{lll}
\hline $\begin{array}{l}\text { Coordenadas } \\
\text { UTM }\end{array}$ & $\mathrm{X}$ & $\mathrm{Y}$ \\
\hline Norte & 422.756 & 4.524 .712 \\
Sur & 420.249 & 4.517 .689 \\
Este & 425.517 & 4.522 .909 \\
Oeste & 419.743 & 4.518 .904 \\
\hline Mapa & $\mathrm{N}^{\circ}$ de hoja & Nombre \\
\cline { 2 - 3 } Topográfico & 483 & Segovia \\
Nacional & 508 & Cercedilla \\
$1 / 50.000$ & 5
\end{tabular}

El Pinar de los Belgas se extiende por las laderas situadas al pie del pico de Peñalara y de la Cuerda larga, desde el puerto de Cotos hasta el Monasterio de El Paular, entre los 2.000 y los $1.260 \mathrm{~m}$ de altitud. Sus principales características orográficas se resumen en la tabla 2.

Tabla 2. Posición orográfica y configuración del terreno del monte "Cabeza de Hierro".

\begin{tabular}{|c|c|c|c|}
\hline Sistema montañoso & \multicolumn{3}{|c|}{ Sistema Central } \\
\hline Sierra & \multicolumn{3}{|c|}{ Sierra de Guadarrama } \\
\hline Altitud (m) & $\begin{array}{l}\text { Máxima } \\
2.000\end{array}$ & $\begin{array}{l}\text { Media } \\
1.670\end{array}$ & $\begin{array}{l}\text { Mínima } \\
1.260\end{array}$ \\
\hline Pendiente (\%) & 60 & 30 & 0 \\
\hline Forma general del terreno & ondulado & \multicolumn{2}{|c|}{ Exposición dominante SE y $\mathrm{NC}$} \\
\hline
\end{tabular}

Ocupa dos valles paralelos: el del arroyo de Garci-Sancho (o Valle de El Palero) y el del río Lozoya, que lo atraviesa de este a oeste y es el más destacado de los dos. Ambos pertenecen a la red hidrográfica del Tajo. Además, y debido a la configuración del terreno, discurren por el monte multitud de arroyos, tanto permanentes como temporales. También son frecuentes los tremedales.

\subsubsection{Suelos}

Los suelos en esta zona son franco-arenosos (Roig Gómez, 1999), profundos y fértiles en los fondos de valle y más superficiales y pedregosos a medida que se asciende por las laderas. Todos ellos están formados sobre roca madre de gneis glandulares (M.A.P.A., 1985) con un grado de alteración variable.

Según la descripción edafológica proporcionada por la Tercera Revisión del Proyecto de Ordenación del monte Cabeza de Hierro (Bravo Fernández y Serrada, 2007), los suelos de las cotas más altas - cuartel C y cumbres de Cabeza Mediana - son suelos zonales y maduros poco evolucionados, de perfil A; C, a clasificar como Ranker pseudoalpino o ranker-cambisol húmico.

Las dos zonas edáficamente homogéneas restantes, aparte de la zona de cumbres, son las laderas y los fondos de valle. Ambas presentan suelos de la Clase II (Gandullo, 1984), zonales, evolucionados y maduros. En las laderas, las migraciones oblicuas conforman perfiles del tipo A; Bw; C, a clasificar como suelos pardoácidos o cambisol dístrico. En las zonas de menor pendiente, el perfil aumenta su evolución como A; Bt; C, manteniendo zonalidad y madurez a clasificar como suelos argilúvicos o luvisol órtico (Gandullo, 1984) o alisol háplico (FAO, 1998).

Como conclusión a la reseña edafológica: Bravo Fernández y Serrada (2007) destacan que los suelos del monte no presentan ninguna propiedad física o química que resulte limitante para la instalación y desarrollo de masas de pino silvestre, aunque entre las propiedades del perfil estudiado aparece como más restrictiva la alta pedregosidad (tierra fina ponderada cercana al 30\%), con la correspondiente baja capacidad de retención de agua. 


\subsubsection{Vegetación y fauna}

En cuanto a la vegetación potencial, no es posible asignar un único piso bioclimático, dado el elevado rango altitudinal. Así, según la clasificación de Rivas Martínez (1987), las partes más bajas corresponden al piso supramediterráneo, mientras que las más elevadas pertenecen al piso oromediterráneo. Siguiendo al mismo autor, en función de la altitud le corresponderían dos series de vegetación potencial distintas:

Zonas bajas: serie 18a, serie supramediterránea carpetano-ibérico-alcarreña subhúmeda silicícola de Quercus pyrenaica o roble melojo (Luzulo forsteri-Querceto pyrenaicae sigmetum) VP, robledales de melojo.

Zonas altas: serie 13a, serie oromediterránea guadarrámica silicícola de Juniperus nana o enebro rastrero (Junipero nanae-Cytiseto purgantes sigmetum) VP, pinares, piornales y enebrales rastreros.

Esta potencialidad se refleja en la vegetación real existente en la zona. Así, en la zona en estudio encontramos una masa arbórea en la que la especie principal y única objeto de aprovechamiento es el pino silvestre, que conforma una masa mayoritariamente pura y de origen natural. No obstante, el rebollo (Quercus pyrenaica Willd) aparece también asociado al pino, especialmente en las zonas de menor cota. La vegetación acompañante es la típica del cortejo del pino silvestre: abedul (Betula celtiberica Rothm.\&Vasc.), serbal (Sorbus aucuparia L.), tejo (Taxus baccata L.), álamo temblón (Populus tremula L.), matorral de retamas (Genista florida L., G. cinerea (Vill.) DC., Cytisus scoparius (Lanier)), piornos (Cytisus oromediterraneus Rivas Mart.\&al.), cambroños (Adenocarpus hispanicus (Lam.) DC.), brezo (Erica arborea L.), acebo (Ilex aquifolium L.), helecho (Pteridium aquilinum (L.) Kunth) y enebro o jabino (Juniperus communis L.) (Bravo Fernández y Serrada, 2007). En ocasiones, la presencia de un denso estrato de algunas de las especies citadas dificulta o impide la instalación de regenerado de pino silvestre, circunstancia a tener en cuenta si se considera prioritaria la renovación del estrato arbóreo.

En cuanto a los pastos herbáceos, aparecen diferentes tipos en función de las condiciones estacionales cota, orientación, pendiente, suelo -, grado de insolación - espesura del estrato arbóreo -, y aprovechamiento realizado - presencia o no de ganado y características del pastoreo. Así, encontramos pastos alpinoideos en las cotas más altas; cervunales, en las zonas más altas donde se acumula la nieve durante gran parte del invierno; berciales en las laderas pedregosas con escaso suelo; vallicares, allí donde la topografía permite que se concentre una mayor humedad en el suelo; prados de diente, por evolución de los vallicares bajo intenso pastoreo; algunos majadales también formados por intenso pastoreo, aunque escasos por exceso de frío...

Al ser el productor uno de los usos del monte, se ha considerado interesante evaluar su productividad potencial, que se ha calculado a través de dos índices:

- Índice de Patterson (1956, en Gandullo y Serrada, 1977):

La productividad potencial obtenida es de $4,65 \mathrm{~m}^{3}$ de madera $/ \mathrm{ha}^{-1} \cdot$ año $^{-1}$.

- Índice de Productividad Forestal de Gandullo y Serrada (1977):

La productividad potencial obtenida es de $5,67 \mathrm{~m}^{3}$ de madera $/ \mathrm{ha}^{-1} \cdot$ año $^{-1}$.

Según Rojo y Montero (1996), la producción media de las masas con vocación productora en la Sierra de Guadarrama ronda los $2 \mathrm{~m}^{3}$ de madera por hectárea y año, por lo que, teniendo en cuenta que la productividad real del monte "Cabeza de Hierro" en los últimos años ha sido de $3 \mathrm{~m}^{3}$ de madera $\cdot$ ha $^{-1} \cdot$ año $^{-1}$, se puede concluir que los datos de productividad justifican la propuesta de fijar como una de las funciones del monte la producción maderable. 
La fauna está integrada por las especies típicas de pinares de media y alta montaña del Sistema Central, pero merecen mención especial, por su relevancia general o por su importancia específica para el presente estudio, las siguientes:

- Buitre negro (Aegypius monachus L.): el monte alberga más de 80 parejas de esta especie, que constituyen la colonia más importante de la Comunidad de Madrid y la octava del mundo. Este hecho ha sido el principal motivo para la declaración de la ZEPA mencionada en el apartado anterior y condiciona, en cierta medida, la gestión del monte (especialmente en lo referente a la ubicación y fechas de los tratamientos selvícolas a realizar).

- Corzo (Capreolus capreolus L.) y jabalí (Sus scrofa L.): son las principales especies cinegéticas del monte. Generan daños sobre el regenerado de las especies arbóreas por remoción, escodado o mordisqueo.

\subsubsection{Ganado}

A continuación comentaremos con más detalle algunos de los principales aspectos del uso ganadero en el monte "Cabeza de Hierro, dada la importancia que la actividad pastoral tiene en algunos apartados del presente trabajo".

- Tipo de ganado: en la actualidad, fundamentalmente vacuno; también algunas yeguas. En el pasado: vacuno, ovino, caprino y caballar.

- Razas: para vacuno, en el monte se encuentran fundamentalmente cruces entre negra avileña, charolés y limousine. En general se trata de animales con una considerable rusticidad, en los que se busca básicamente el aprovechamiento de las crías para carne.

- Tipo de pastoreo: continuo. Los animales pueden pastar libremente en toda la superficie del monte, incluyendo los cantones sometidos a cortas de regeneración. Obviamente, presentan querencias por ciertos cantones y ciertas zonas de algunos cantones por diversas razones: cercanía a puntos de agua, cercanía a pistas donde son suplementados por los ganaderos, venteaderos, rasos con pastos herbáceos de mayor calidad, zonas de paso, etc. En estos lugares de mayores cargas se observan a menudo daños especialmente graves sobre la vegetación leñosa e, incluso, sobre el suelo, donde en ocasiones aparece vegetación nitrófila.

- Fechas de entrada y salida: en el pasado, los animales podían permanecer durante todo el año en el monte, por lo que dañaban gravemente a la vegetación leñosa en los momentos en que la nieve impedía el acceso a las herbáceas. En la actualidad, la Administración sí controla que la permanencia se limite al periodo comprendido entre el 15 de abril y el 15 de noviembre.

- Alimentación del ganado: además de la vegetación consumida directamente en el monte por los animales, ha sido práctica frecuente que los ganaderos aportaran alimentos suplementarios en los momentos más críticos, cuando las herbáceas ya están agostadas o la nieve impide acceder a ellas.

\subsubsection{ESTADO FORESTAL}

El monte está dividido en seis cuarteles (nombrados con letras mayúsculas, de $A$ a $F$ ) y en 80 cantones. En cinco de los cuarteles (A, B, D, E y F) se compatibilizan las funciones protectora y productora, siguiendo el método de ordenación de entresaca regularizada y aplicando cortas de regeneración de aclareo sucesivo por 
bosquetes. En el cuartel $\mathrm{C}$, situado en las cotas más altas, la función preferente es la protectora y se aplica el método selvícola, con cortas a la esperilla y a la espesilla.

La forma fundamental de masa es monte alto para el pino silvestre (Pinus sylvestris L.) y monte bajo para el rebollo (Quercus pyrenaica Willd). Con frecuencia, ambas especies se entremezclan dando lugar a una masa mixta que se puede clasificar como monte medio irregular (estrato superior de monte alto, estrato inferior de monte bajo).

La forma principal de masa es irregular en la mayoría del monte, salvo en algunos cantones que presentan masas semirregulares como consecuencia de las cortas de regeneración por aclareo sucesivo aplicadas en el pasado.

\section{Historia dasocrática y estado actual de la ordenación}

La gestión técnica documentada mediante planificación sometida a normativa en el monte "Cabeza de Hierro" tiene su origen en un Proyecto de Ordenación redactado en 1957 por Joaquín Ximénez de Embún. En este documento, el monte quedaba dividido en seis cuarteles y en 80 cantones, a menudo separados por divisiones naturales o artificiales muy evidentes (división inventarial que se ha mantenido hasta la actualidad, con tan sólo algunos cambios de menor importancia); se establecían tres calidades de estación; se proponían el método de tramos permanentes para los cuarteles A, B, D, E y F - de carácter productor y protector -, con turno de 150 años, periodo de regeneración de 25 años y posibilidad de $3.750 \mathrm{~m}^{3} / a n ̃ o$, y la ausencia de cortas para el cuartel C - de carácter protector. Este Proyecto no llegó a aprobarse oficialmente por causas relacionadas con la servidumbre de pastos, pero se aplicó, en la práctica, en sus aspectos dasocráticos mediante los correspondientes planes anuales de aprovechamientos.

En 1967 se realizó un nuevo inventario, no ligado a documento de planificación alguno, para analizar la evolución del monte. Como consecuencia de los resultados obtenidos, se propuso reducir el turno a 120 años y el periodo de regeneración a 20 años. Además, la Administración Forestal competente autorizó el aumento de la posibilidad a $5.000 \mathrm{~m}^{3}$ /año.

En 1977 Alberto Madrigal redactó un nuevo Proyecto de Ordenación en el que proponía el cambio al método de tramo móvil en regeneración para los cuarteles A, B, D, E y F, y al de entresaca para el cuartel C. Es de destacar que ésta fue la primera ocasión en que se empleó oficialmente el método de tramo móvil en España.

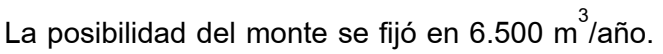

En 1987, Gregorio Montero propuso la Primera Revisión del Proyecto de Ordenación, que mantuvo los métodos de ordenación originales y redujo ligeramente la posibilidad, hasta los $5.750 \mathrm{~m}^{3}$ /año.

La Segunda Revisión, realizada por Alberto Rojo y Gregorio Montero, se presentó a la Administración competente en noviembre de 1999. Debería haberse aprobado en 1996 para el decenio 1997-2006, pero se retrasó a causa de los numerosos derribos ocasionados por el temporal de nieve y viento del invierno de 1995-96, que mantuvieron ocupado a todo el personal forestal de la Sierra de Guadarrama durante 1996 y parte de 1997 - ante el temor de que se produjese una plaga de insectos perforadores - e impidieron la conclusión en plazo del inventario para la Ordenación que se había iniciado el año anterior, además de forzar la espera hasta el fin de las tareas de extracción de todos los pies derribados para realizar su aprovechamiento y cubicación y considerarlos como posibilidad ordinaria de los dos primeros años de la vigencia del Plan Especial.

La principal novedad de esta Segunda Revisión fue la adopción del método selvícola - que se introducía por primera vez en España - en el cuartel C, de carácter eminentemente protector. En cuanto a la Posibilidad, los datos aportados por la Segunda Revisión indicaban, para el conjunto del monte, un volumen de $312.720 \mathrm{~m}^{3} \mathrm{y}$ 
un crecimiento de $7.090 \mathrm{~m}^{3} / a n ̃ o$, con lo que, aplicando las fórmulas de la masa cortable y de Mélard modificada, se obtienen posibilidades de 6.150 y $7.075 \mathrm{~m}^{3} / a n ̃ o$, respectivamente. Finalmente, se mantenía la posibilidad de la Primera Revisión: $5.750 \mathrm{~m}^{3}$ /año, lo que equivale a $3,03 \mathrm{~m}^{3} /$ ha poblada/año. Como se puede observar, dicha posibilidad era claramente inferior al crecimiento estimado.

La Tercera Revisión - presentada ante la Administración competente en 2007 y aprobada en 2008 - ha sido elaborada por José Alfredo Bravo Fernández y Rafael Serrada Hierro.. Destacan en ella se destacan los siguientes cambios: se lleva a cabo, por primera vez, un muestreo estadístico en toda la superficie; se consolida formalmente la realización de cortas de entresaca para mantenimiento de masas irregulares (cortas que, de hecho, se han venido practicando en el monte durante los últimos años, con alguna excepción no muy extensa); se cambia al método de entresaca regularizada en los cuarteles $A, B, D, E$ y $F$; y, en coherencia con lo anterior, se alarga el plazo de vigencia del Plan Especial propuesto a 15 años (2007-2021).

La Tercera Revisión mantiene la propuesta de uso múltiple, que se concreta en los siguientes objetivos: producción de madera de pino silvestre; consecución de regeneración en cantidad, calidad, momento y localización adecuados; protección del suelo y regulación del régimen hídrico; conservación y fomento de la biodiversidad y de los procesos ecológicos; protección específica del buitre negro; protección del paisaje; mantenimiento y/o fomento del uso recreativo; mantenimiento y/o fomento de las especies de uso cinegético; mantenimiento y/o fomento de la producción de setas; sostenibilidad del uso ganadero; diversificación en la obtención de rentas; y contribución al avance en el conocimiento de la gestión del medio y los procesos ecológicos. Todos estos objetivos se consideran como preferentes en los cuarteles A, B, D, E y F. En el cuartel $\mathrm{C}$ se mantienen todos ellos, aunque la producción de madera se plantea como secundaria. 


\subsection{DISEÑO EXPERIMENTAL}

Todas las experiencias objeto de la presente Tesis se llevaron a cabo dentro de la zona de estudio anteriormente descrita. De acuerdo con los objetivos perseguidos, estuvieron centradas en la evaluación de dos fases críticas del proceso de regeneración del pino silvestre (definidas en el apartado 1.1.1 de la Introducción):

1- La germinación.

2- El establecimiento inicial.

Básicamente, se diseñaron y replantearon en el monte dos redes de parcelas de pequeña dimensión $(1,5 \times 1,5$ $\mathrm{m}$ ), ubicadas bajo diferentes condiciones micro-estacionales, en las que, tras realizar una siembra inicial, se evaluó la germinación y la supervivencia del regenerado.

El objetivo de ambas redes de parcelas era el mismo: la caracterización de las fases iniciales del proceso de regeneración del pino silvestre bajo distintas condiciones de cobertura vegetal. No obstante, la amplitud, intensidad y duración de los muestreos fueron diferentes en cada caso.

La red inicial (Red de Muestreo I), integrada por un elevado número de parcelas repartidas por la masa, se mantuvo durante 3 períodos vegetativos con el objetivo de abarcar el estudio de las fases de germinación y establecimiento del pino silvestre en una amplia variedad de escenarios.

La segunda red de parcelas (Red de muestreo II) se planteó con el objetivo de complementar lo observado en la red inicial, por lo que se centró en analizar con más precisión la germinación y supervivencia del silvestre en un menor número de situaciones y tan sólo durante un período vegetativo.

En ambas redes se llevaron a cabo muestreos y mediciones adicionales sobre las parcelas y áreas de experimentación con el fin de mejorar la caracterización de los puntos de muestreo, así como de evaluar aspectos complementarios respecto al objetivo principal de los diseños experimentales.

A continuación se describen brevemente las variables y factores objeto de este estudio, así como las características de los diseños y muestreos que conformaron el esqueleto de la experimentación en que se basa la presente tesis.

\subsubsection{VARIABLES OBJETO DE ESTUDIO}

A continuación se describen brevemente las variables objeto del presente estudio, entre las que se incluyen tanto las variables objetivo cuyo comportamiento se pretende analizar y cuantificar como los factores en función de los cuales se analiza dicho comportamiento. Tal y como se ha puesto ya de manifiesto en los párrafos anteriores, los dos diseños experimentales planteados compartieron metodología (siembra localizada sobre parcelas de tamaño reducido y control posterior de emergencia y supervivencia) y objetivo general, por lo que la descripción de variables objeto de estudio es, a grandes rasgos, válida para ambos. 


\section{A. VARIABLES OBJETIVO}

Las variables objetivo son precisamente las que cuantifican el éxito del proceso de regeneración:

1- Tasa de germinación: proporción de individuos que emergen con éxito de la semilla, emitiendo radícula, hipocotilo y cotiledones, y se hacen visibles por encima de la superficie del suelo.

2- Tasa de supervivencia: proporción de individuos que sobreviven a lo largo del tiempo con respecto al total de individuos germinados

3- Tasa de éxito en la regeneración: proporción de individuos que sobreviven a lo llargo del tiempo con respecto al total de individuos sembrados.

\section{B. FACTORES DE INFLUENCIA}

De entre todos los factores que condicionan y controlan el proceso de regeneración (véase Serrada, 2002), en el presente trabajo se analiza únicamente la cobertura vegetal en sentido amplio (desdle el estrato arbóreo hasta los restos vegetales acumulados sobre el suelo). Por este motivo, sólo se tuvieron en cuenta en el diseño experimental los factores ligados al vuelo. Básicamente se consideró un factor para caracterizar la influencia del dosel arbóreo y otro factor para la caracterización de las condiciones de cobertura vegetal por debajo de éste (matorral, hierba y restos vegetales acumulados sobre el suelo).

$\mathrm{Ni}$ los factores relativos a la estación - entre los que se incluyen clima, fisiografía, geología y edafología - ni los antrópicos son objeto directo del presente estudio, por lo que en el trabajo de campo se intentó minimizar su efecto mediante la introducción de bloques en los diseños experimentales.

La figura 4, a continuación, representa sintéticamente los factores relativos al vuelo y su consideración en el presente estudio.

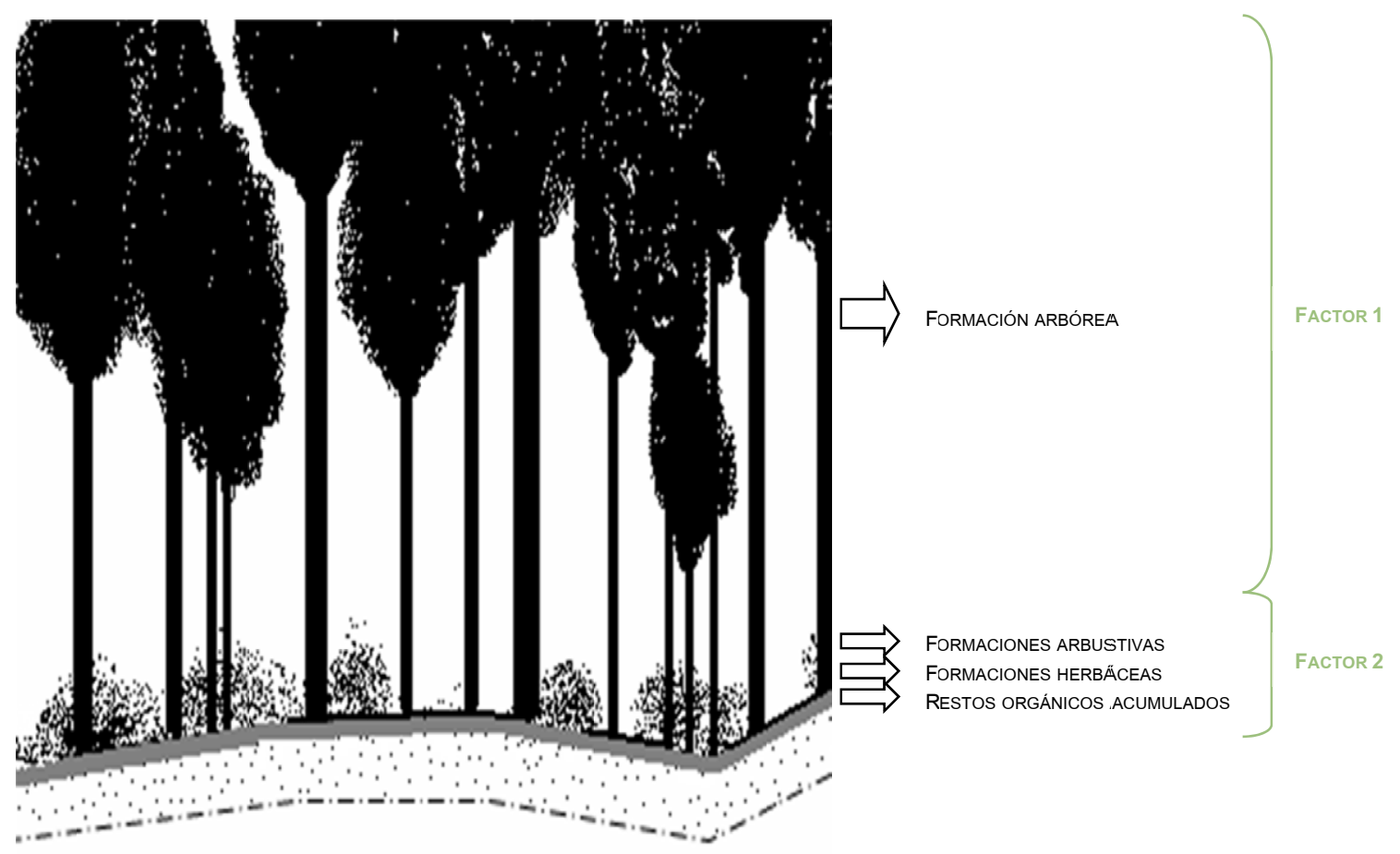

Fig. 4. Representación gráfica de los factores relativos al vuelo considerados en el presemte estudio. 
Los factores cuyos efectos se pretende valorar son, por tanto, los que se indican:

\section{b.1. Espesura de la masa arbórea}

El efecto de la masa en pie sobre la regeneración se valoró a través de la espesura, entendiendo como tal el grado de solidaridad que entre sí presentan los individuos que la forman (Serrada, 2002). De entre los índices existentes para la caracterización de la espesura de las masas forestales, se optó por utilizar en los diseños experimentales el área basimétrica por hectárea en torno a los puntos de muestreo. Como parte de los muestreos complementarios se midieron así mismo otras variables que se detallan a continuación en el apartado correspondiente.

\section{b.2. Cobertura superficial del suelo}

Al tener en cuenta este factor, se pretende valorar el efecto sobre el regenerado de la cobertura vegetal existente por debajo del dosel arbóreo. Así, se va a tratar de definir y cuantificar el efecto sobre el regenerado del tipo de cobertura vegetal predominante a ras de suelo, distinguiendo entre: 1) herbáceas; 2) formaciones arbustivas - en la zona de estudio, esencialmente, helechos (Pteridium aquilinum (L.) Kuhn), retamas (Genista florida L., G. cinerea L., Cytisus scoparius L.), enebros (Juniperus communis L.) y/o rebrote de rebollo (Quercus pyrenaica Willd) de baja talla; y 3) restos vegetales acumulados mayoritariamente, hojarasca procedente de la masa circundante, dispuesta en capas de espesor y niveles de humificación y mineralización variables.

Además del tipo de vegetación, se estudió el efecto de la aplicación de tratamientos sobre el suelo de ayuda a la regeneración; concretamente, escarificación y decapado por líneas con acaballonado, ambos realizados de forma manual.

En todos los casos este factor se valoró de forma cualitativa, asignando a cada parcela el tipo de vegetación predominante o el tratamiento sobre el suelo correspondiente en cada caso.

Partiendo de esta descripción general, a se detallan continuación las características concretas de los dos diseños experimentales planteados (redes de muestreo l y II), así como las de las mediciones que conformaron el esqueleto de la experimentación objeto de la presente tesis.

\subsubsection{RED DE MUESTREO I}

Inicialmente, como primera aproximación al tema de estudio, se trató de caracterizar el efecto de un amplio abanico de combinaciones de espesura de masa y condiciones superficiales del suelo sobre la germinación y la supervivencia del regenerado de pino silvestre.

Se planteó para ello una extensa red de experimentación integrada por una serie de parcelas ubicadas en lugares sometidos a distintas condiciones de cobertura vegetal. Sobre estas parcelas se realizaron siembras controladas para posteriormente valorar, con una cierta periodicidad, la germinación y la supervivencia del regenerado. A continuación se detallan las características de las parcelas de muestreo, su número y su distribución. 


\subsubsection{Diseño experimental}

\section{A. CARACTERÍSTICAS DE LA UNIDAD EXPERIMENTAL}

Como unidad experimental para la valoración de la germinación y la supervivencia en cada punto de muestreo se consideró una parcela cuadrada de 1,5 x 1,5 m con cinco líneas equidistantes de siembra y 25 puntos de siembra en cada una de ellas.

A continuación, en la figura 5 , se representa un croquis de la unidad experimental de muestreo de regeneración en la Red de Muestreo I.

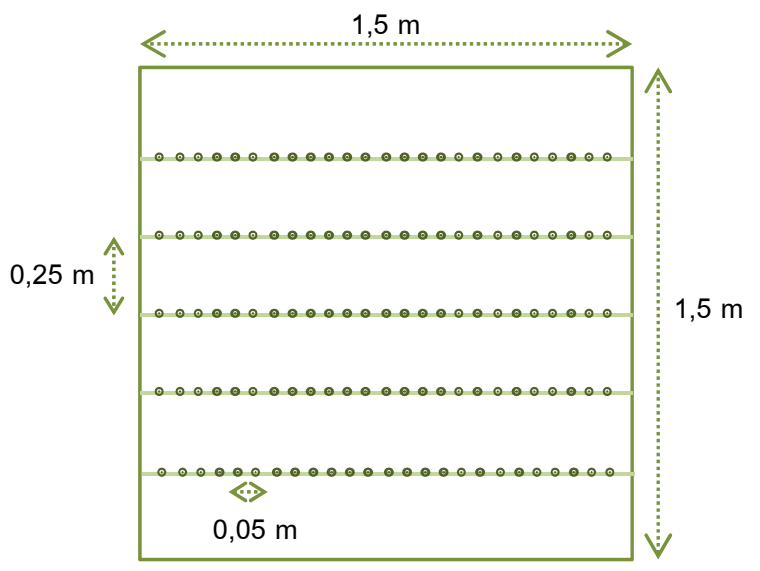

Fig. 5. Representación esquemática de la unidad experimental de muestreo de regeneración? Punto de siembra (25 puntos/línea)

\section{B. ESTRUCTURA DEL DISEÑO}

Dado que se pretendía estudiar el efecto sobre la regeneración de la espesura de la masa y el recubrimiento vegetal del suelo, descontando el efecto de otros factores ligados a la estación, se planteó un diseño factorial con dos factores fijos - 'espesura de masa' y 'cobertura superficial del suelo' - y un bloque. Como todo el muestreo se planteaba dentro de un mismo monte (sin cambios significativos en latitud o longitud) y tratando de no variar en exceso el rango altitudinal ni la fisiografía, se consideró que la principal variación en las condiciones de estación iba a ser debida al cambio en la orientación de las zonas de muestreo. Por este motivo, los bloques se establecieron en el diseño en función de la orientación dominante de las zonas de muestreo.

Los niveles considerados para cada uno de los factores y para el bloque se indican a continuación:

- Espesura de masa: 6 niveles en función del área basimétrica media en el entorno del punto de medición.

\begin{tabular}{|c|c|c|c|c|c|c|}
\hline Nivel & I & II & III & IV & V & VI \\
\hline $\mathrm{AB}\left(\mathrm{m}^{2} / \mathrm{ha}\right)$ & 0 & 5 & 10 & 15 & 25 & $>35$ \\
\hline
\end{tabular}

- Cobertura superficial del suelo: 4 niveles.

\begin{tabular}{|c|c|c|c|c|}
\hline Nivel & I & II & III & IV \\
Cond.Sup & Hierba & Matorral & Restos & Escarificado \\
\hline
\end{tabular}


En la asignación de los niveles del factor Cobertura superficial del suelo no intervino la composición específica, sino tan sólo el tipo de estrato predominante en el recubrimiento del suelo:

- Hierba: la superficie del suelo está recubierta por una formación herbácea densa y continua.

- Matorral: sobre la superficie del suelo aparece una formación arbustiva con un recubrimiento mínimo suficiente como para alterar las condiciones bajo cubierta.

- Restos: la superficie del suelo está recubierta de una capa de restos vegetales de $5 \mathrm{~cm}$ de espesor mínimo. No existen matorrales ni una formación continua de herbáceas.

- Escarificado: sobre la superficie de terreno original se llevó a cabo un escarificado a hecho manual mediante azada de $15 \mathrm{~cm}$ de profundidad.

- Exposición: 4 niveles.

\begin{tabular}{|c|c|c|c|c|}
\hline Nivel & I & II & III & IV \\
Exposición & NE & NW & SE & S \\
\hline
\end{tabular}

Las condiciones reinantes en cada unidad experimental quedaban, por tanto, definidas por la combinación de los niveles de los dos factores y el bloque: Espesura $x$ CondSup x Exposición. Dado que se pretendía comprobar el comportamiento de todas las combinaciones posibles de niveles, el total de situaciones a muestrear fue de $96(6 \times 4 \times 4)$. Para cada 'tratamiento' se optó por realizar dos réplicas, por lo que el total de unidades experimentales contemplado fue de $192(96 \times 2)$

En el cuadro siguiente (figura 6) se resume brevemente la estructura del diseño planteado.

Diseño bifactorial fijo por bloques

Variables respuesta: germinación y supervivencia

2 Factores fijos:

$\Rightarrow$ Espesura: 6 niveles $\quad-0$ (claro)

$$
-6\left(>35 \mathrm{~m}^{2} / \mathrm{ha}\right)
$$

$\Rightarrow$ Cobertura superficial del suelo: 4 niveles

- Hierba

- Matorral

- Restos

- Escarificado

1 Bloque:

$\begin{aligned} \Rightarrow \text { Exposición: } 4 \text { niveles: } & -\mathrm{NE} \\ & -\mathrm{NW} \\ & -\mathrm{SE} \\ & -\mathrm{S}\end{aligned}$

Repeticiones: 2

Número total de unidades experimentales:

$$
6 \times 4 \times 4 \times 2=192
$$

Fig. 6. Cuadro resumen del diseño experimental de la Red de Muestreo I. 


\subsubsection{Replanteo de la red de parcelas}

Una vez definido el diseño teórico, se procedió a localizar sobre la zona de estudio los tratamientos requeridos. Tal y como se ha comentado, con el fin de homogeneizar al máximo la variabilidad introducida por los factores ajenos al estudio se agruparon las unidades experimentales en cuatro grandes bloques, en función de la orientación dominante. Los bloques de experimentación se situaron en las laderas del cerro denominado Cabeza Mediana, incluido en su totalidad dentro del monte Cabeza de Hierro y que presenta las cuatro orientaciones requeridas.

Dentro de las laderas de Cabeza Mediana, se seleccionaron zonas de pendiente suave (10-15\%) en las que la masa presentase variaciones de área basimétrica tales que permitieran encontrar relativamente próximos bosquetes con los niveles requeridos por el factor 'espesura'. Esto fue posible como consecuencia de la particular estructura de la masa por agregación de bosquetes internamente homogéneos pero variables entre sí (clases de edad y distribución espacial), que permite encontrar un notable rango de espesuras en un radio relativamente pequeño.

La ubicación de los cuatro bloques experimentales de la Red de muestreo I se representa a continuación en la figura 7.

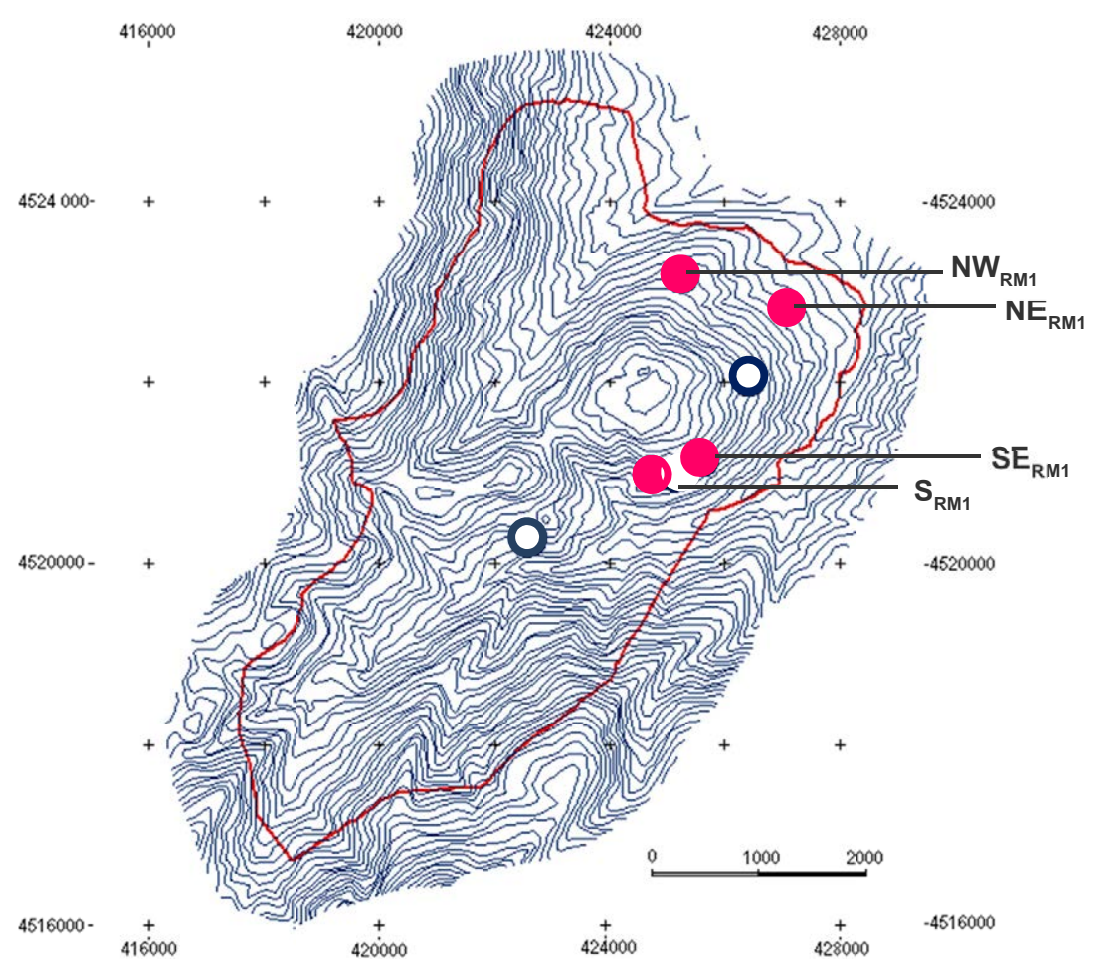

Fig. 7. Localización de las áreas de experimentación o bloques de la Red de Muestreo I (RM11) dentro del Monte Cabeza de Hierro: NE, NW, SE, S. Con una línea roja se señala el perímetro del monte ( $O$ Bloques de experimentación de la Red de muestreo II).

Las características medias de pendiente, altitud y orientación de los bloques de experimentación de la Red de muestreo I se resumen a continuación en la tabla 3. Se hace referencia a cada uno de los bloques mediante las iniciales de su orientación media teórica. Se hace constar así mismo la superficie aproximada sobre la que se extienden. 
Tabla 3. Características medias de pendiente altitud y orientación medias de los bloques de experimentación de la Red de Muestreo I.

\begin{tabular}{lcccc}
\hline \multirow{2}{*}{ Parámetro } & \multicolumn{4}{c}{ Bloque Experimental } \\
& $\mathrm{S}$ & $\mathrm{SE}$ & $\mathrm{NW}$ & $\mathrm{NE}$ \\
\hline Superficie aprox.(ha) & 1,34 & 1,17 & 1,48 & 1,36 \\
Pendiente media (\%) & 15,6 & 18,6 & 8,8 & 9,9 \\
Altitud media (m) & 1526,7 & 1517,4 & 1441,4 & 1338,6 \\
Orientación media $\left({ }^{\circ}\right)$ & 174,8 & 142,2 & 334,4 & 76,4 \\
\hline
\end{tabular}

Una vez localizados los bloques de experimentación debían seleccionarse en su interior 6 subzonas con nivel de espesura creciente desde 0 a $35 \mathrm{~m}^{2} / \mathrm{ha}$. No obstante, el replanteo de categorías específicas de $A B$ en campo resultaba poco viable, tanto por la dificultad para identificar niveles medios de espesura demasiado concretos como por el poco realismo de asignar un área basimétrica constante a todos los puntos dentro de una superficie.

Por este motivo, se optó por llevar a cabo la asignación y la valoración de la espesura en torno a los puntos de muestreo en dos etapas: 1) se seleccionaron las subzonas en campo, tratando de representar seis niveles cualitativos entre claro y alta espesura de forma aproximada a partir de valoraciones de visu y con mediciones relascópicas; 2) se llevó a cabo un muestreo pie a pie georreferenciado en todos los bloques (descripción en el apartado 3.2.4. Mediciones complementarias) y, a partir de esas mediciones, se asignó posteriormente a cada punto la espesura real de su entorno.

La espesura en torno a cada punto quedó transformada, por tanto, en una covariable cuantitativa, aunque asegurando la presencia de un amplio rango de espesuras dentro de cada bloque experimental.

Tras seleccionar las subzonas de cada bloque de experimentación, en cada una de ellas se ubicaron aleatoriamente las parcelas de muestreo (unidades experimentales), dentro de las superficies que presentaban las condiciones de suelo requeridas por el factor 'Cobertura superficial del suelo'. Las parcelas se ubicaron siempre con un lado paralelo a las líneas de nivel y se señalizaron sobre el terreno mediante dos estacas ubicadas en dos esquinas opuestas (esquinas superior izquierda e inferior derecha).

\subsubsection{Siembras y Mediciones. Calendario de actuaciones}

La Red de muestreo I se mantuvo durante tres años consecutivos, entre 2004 y 2006 . En la tabla 4 se resumen las operaciones realizadas en la red de experimentación durante los tres años de análisis. Se indica, por un lado, si se ha realizado siembra o no y, por otro, el número de conteos sucesivos que se han llevado a cabo dentro de cada fase correspondiendo a germinación y a supervivencia.

Tabla 4. Resumen de operaciones anuales en la Red de Muestreo I.

\begin{tabular}{cccc}
\hline Año & Siembra & Germinación & Supervivencia \\
\hline 2004 & $\checkmark$ & 6 & $5(+\mathrm{G})+4(\mathrm{~S})$ \\
2005 & & & 3 \\
2006 & $\checkmark$ & 1 & 2 \\
\hline
\end{tabular}

\section{A. Siembra 1 y control posterior}

Durante el primer año se llevaron a cabo siembras localizadas en todas las unidades experimentales a razón de 125 piñones por parcela (5 líneas de siembra y 25 semillas por línea), lo que supuso un total de 24.000 semillas distribuidas en el conjunto de la red de muestreo (la densidad de siembra en cada parcela fue aproximadamente de 55 semillas $/ \mathrm{m}^{2}$ o lo que es lo mismo 555.000 semillas/ha). 
La siembra se desarrolló durante los diez últimos días del mes de febrero (tras la retirada de la nieve); y, posteriormente, durante los meses de abril a diciembre, se llevaron a cabo controles tanto de germinación como de supervivencia.

Los primeros controles de germinación se realizaron a finales del mes de abril. En este mes la germinación era todavía incipiente, por lo que el conteo tuvo como objetivo tantear de forma rápida el estado del proceso y no pretendió proporcionar los valores definitivos del total de germinados. Por este motivo, inicialmente se contabilizaron sólo las parcelas correspondientes a escarificado, que fueron las primeras en empezar a germinar. A mediados del mes de mayo se llevó a cabo un segundo muestreo prospectivo en el que se contabilizaron las parcelas correspondientes a hierba y escarificado. El tercer y definitivo control del total de germinados se inició a primeros de junio. El elevadísimo número de plántulas presentes en algunas de las parcelas (>250 individuos), alargó enormemente el proceso de conteo, que se prolongó durante las tres primeras semanas del mes. Las posteriores evaluaciones de supervivencia se realizaron mensualmente durante los meses de julio, agosto, septiembre, noviembre y diciembre.

Los controles de supervivencia de los germinados durante la primavera de 2004 se prolongaron durante los dos años siguientes: 2005 (marzo, junio y octubre) y 2006 (junio y octubre).

\section{B. Siembra 2 y control posterior}

Al inicio de 2006 se llevó a cabo una nueva siembra en las parcelas de la Red de muestreo I aunque, en esta ocasión se actuó sólo sobre las parcelas de los bloques ubicados en las orientaciones más extremas (NE y S) y únicamente en tres de las cinco líneas de siembra de cada parcela. Se sembraron, por tanto, 75 piñones por parcela (333.000 semillas/ha) y un total de 7.200 semillas en el conjunto del experimento.

La siembra se realizó durante la última semana de marzo (diez días después de la retirarda de la nieve) y tan sólo se controló la germinación (junio) y la supervivencia de los germinados (fin septiembre) durante ese año.

\section{Procedimiento}

Con el fin de facilitar las operaciones de siembra y posterior control de germinación y supervivencia, se diseñó un bastidor articulado de $1,5 \times 1,5 \mathrm{~m}$ en el que se delimitaron con cuerda cinco líneas paralelas en las que, a su vez, se señalaron los puntos de siembra, a razón de 25 puntos por línea, con separaciones de $5 \mathrm{~cm}$. Dicho bastidor se empleó tanto para la siembra como para la posterior identificación de germinados y supervivientes. En la figura 8, a continuación, se muestran imágenes del bastidor sobre cuatro tipos dlistintos de cobertura superficial del suelo: escarificado, restos, hierba y matorral.

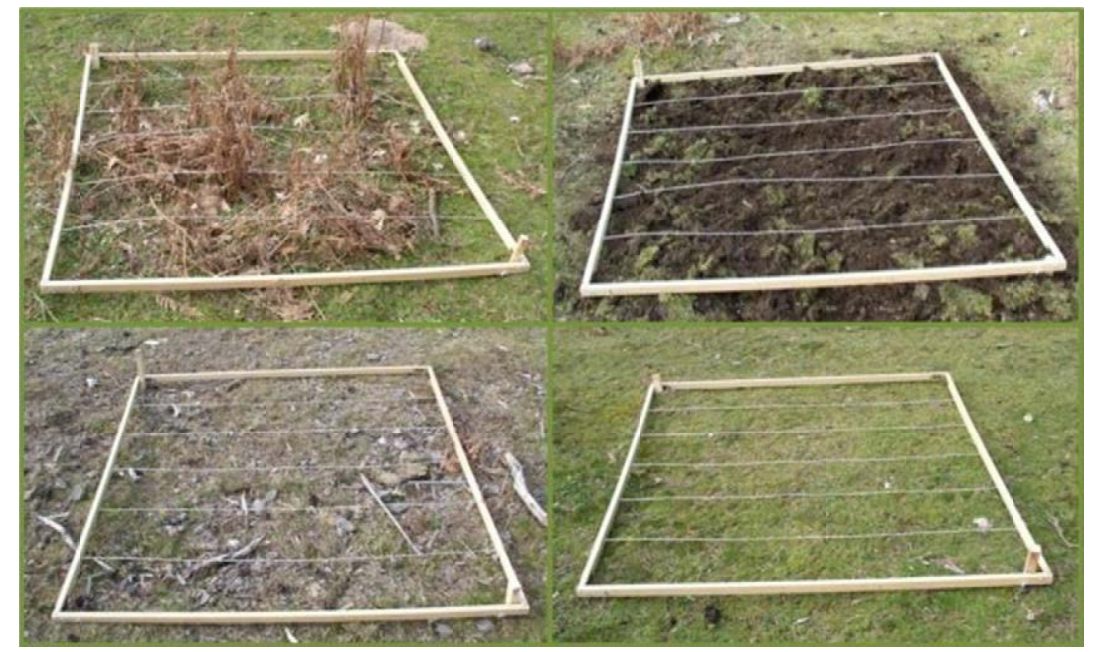

Fig. 8. Ejemplos del uso del bastidor sobre cuatro unidades experimentales. 
En todo caso, se contabilizaron:

\$ Germinados en la línea: individuos que germinan a lo largo de las líneas de siembra. Se consideran procedentes de la semilla introducida en la siembra.

\$ Germinados fuera de la línea: individuos que germinan fuera de las líneas de siembra. Se consideran procedentes de semilla de la masa circundante.

\$ Supervivientes en la línea.

ф Supervivientes fuera de la línea.

Durante el proceso de germinación, los individuos nuevos en los sucesivos conteos se señalizaron mediante palillos que permanecían clavados en el suelo entre inventarios y permitían el seguimiento de su evolución posterior. La figura 9, a continuación, muestra un ejemplo de esta metodología.

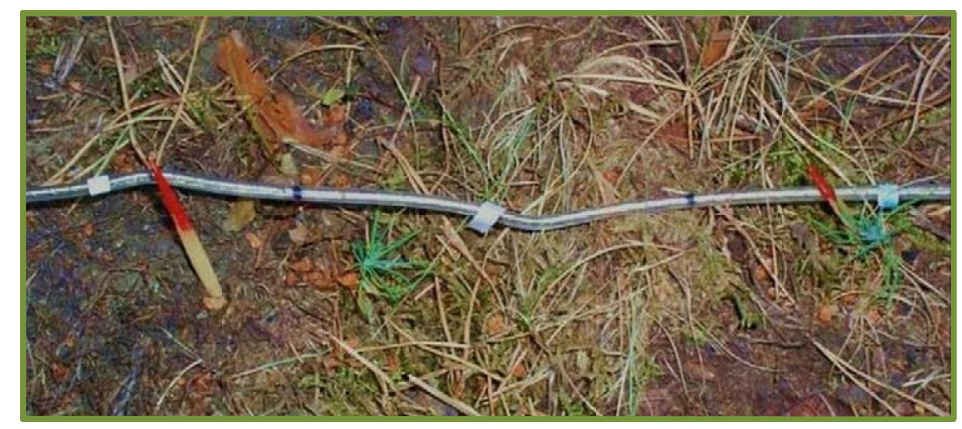

Fig. 9. Ejemplo de individuos germinados y señalizados con palillos junto a una de las líneas de siembra del bastidor.

En todos los casos, las siembras se llevaron a cabo con semilla con región de procedencia "Sierra de Guadarrama". Las características de partida de las semillas se indican en la tabla 5. Antes de cada siembra, se realizaron ensayos de germinación en laboratorio para comprobar la capacidad germinativa de las semillas antes de su introducción en campo (I.S.T.A., 1999)

Tabla 5. Características de partida de las semillas empleadas en la siembra de la Red dle Muestreo I.

\begin{tabular}{|ll|}
\hline Especie & Pinus sylvestris L. \\
Región de procedencia & Sierra de Guadarrama \\
Tipo de material base & Rodal Selecto \\
Año de maduración & $1999 / 2000$ \\
Material & Autóctono \\
Fecha análisis & $15 / 12 / 2003$ \\
Pureza & $99,6 \%$ \\
Germinación & $94,0 \%$ \\
\hline
\end{tabular}




\subsubsection{Red de Muestreo II}

Mediante la segunda red de parcelas se trató de contrastar el efecto que ejerce sobre la germinación y la supervivencia del regenerado de pino silvestre una preparación del terreno por decapado con formación de caballones, con respecto a la ausencia de tratamiento. El contraste se llevó a cabo bajo distintas condiciones de espesura de masa y de exposición.

El número de puntos analizados en esta red fue mucho menor que en la primera. Se redujo el número de niveles considerados en cada factor eliminando niveles intermedios, en previsión de que un menor número de parcelas permitiera aumentar la precisión en los procesos periódicos de conteo y reducir la duración de cada uno de ellos. Las características de las parcelas de muestreo, así como el número y distribución de las mismas, se detallan a continuación.

\subsubsection{Diseño experimental}

\section{A. CARACTERÍSTICAS DE LA UNIDAD EXPERIMENTAL}

Al igual que en el caso anterior, como unidad experimental para la valoración de la germinación y la supervivencia en cada punto de muestreo se consideró una parcela cuadrada de 1,5 x 1,5 m. No obstante, dado que lo que se deseaba contrastar es la eficacia del tratamiento de decapado lineal con acaballonado, el número de líneas de siembra en este caso se redujo a tres coincidiendo con las $1^{\mathrm{a}}, 3^{\mathrm{a}}$ y $5^{\mathrm{a}}$ líneas de la unidad de muestreo estándar (en las parcelas con tratamiento de ayuda a la regeneración, las otras dos líneas quedan cubiertas por los correspondientes caballones). Las unidades experimentales fueron, por tanto, de dos tipos: A) las no tratadas: iguales que las de la Red de muestreo I pero con menos líneas de siembra (figura 10-A) y B) las tratadas: las líneas de siembra impares decapadas y caballones sobre las líneas pares (figura 10-B). El número de puntos de siembra por línea una vez más ascendió a 25 con separaciones de $5 \mathrm{~cm}$ entre ellos.

A)

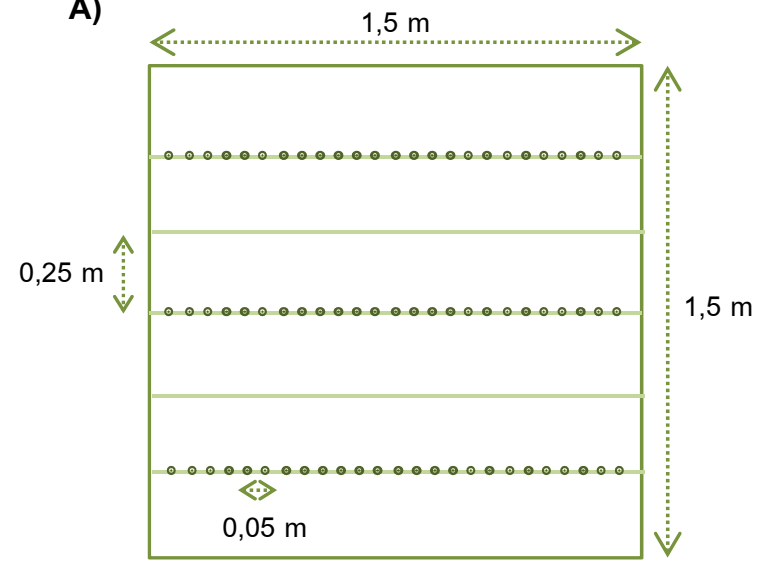

B)

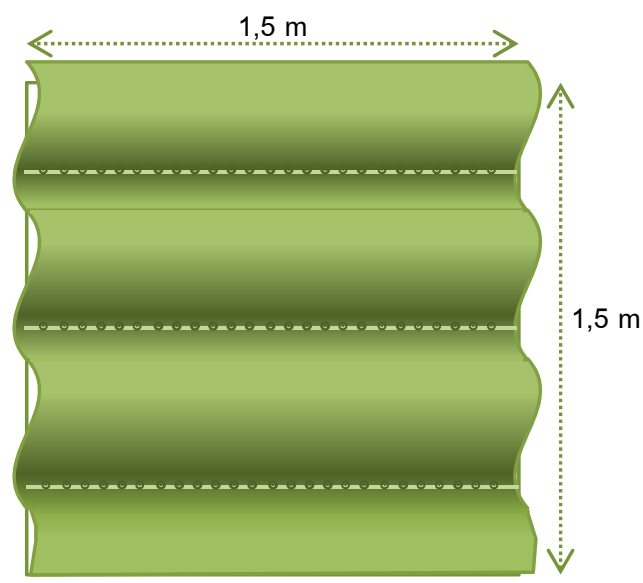

Fig. 10. Representación esquemática de las unidades experimentales de muestreo de regeneración de la Red de Muestreo II: A) Sin tratamiento de ayuda a la regeneración. B) Decapado lineal con acaballonado.

\section{B. ESTRUCTURA DEL DISEÑO}

De nuevo se planteó un diseño factorial con dos factores fijos - 'espesura de masa' y 'condiciones superficiales del suelo' - y un bloque - 'exposición'. Los niveles considerados para cada uno de ellos se indican a continuación: 
- Espesura de masa: 3 niveles cualitativos valorados de visu en torno al centro de cada subzona.

\begin{tabular}{|c|c|c|c|}
\hline Nivel & I & II & III \\
Espesura & Baja & Media & Alta \\
\hline
\end{tabular}

- Condiciones superficiales de suelo: 2 niveles.

\begin{tabular}{|c|c|c|}
\hline Nivel & I & II \\
Suelo & Inalterado & Decapado+Acaballonado \\
\hline
\end{tabular}

- Inalterado: la superficie del suelo presenta la vegetación y el recubrimiento originales. Corresponde en todos los casos a una mezcla de herbáceas y restos acumulados en una capa de espesor variable.

- Decapado + Acaballonado: sobre la superficie del terreno original, se lleva a cabo un decapado por líneas manual mediante azada. En cada parcela se realizan tres líneas de decapado. Con el material removido se forman caballones de baja altura entre líneas.

- Exposición: 2 niveles.

\begin{tabular}{|c|c|c|}
\hline Nivel & I & II \\
Exposición & NE & S \\
\hline
\end{tabular}

Las condiciones de cada unidad experimental resultaban definidas, por tanto, por una combinación de los niveles de los dos factores y el bloque: Espesura $x$ CondSup $x$ Exposición. El total de combinaciones fue de $12(3 \times 2 \times 2)$. Dado que se optó por plantear dos réplicas de cada tratamiento, el total de unidades experimentales consideradas fue de $24(12 \times 2)$. En el cuadro siguiente se resume brevemente la estructura del diseño planteado (figura 11).

Variables objetivo: germinación y supervivencia

2 factores fijos:

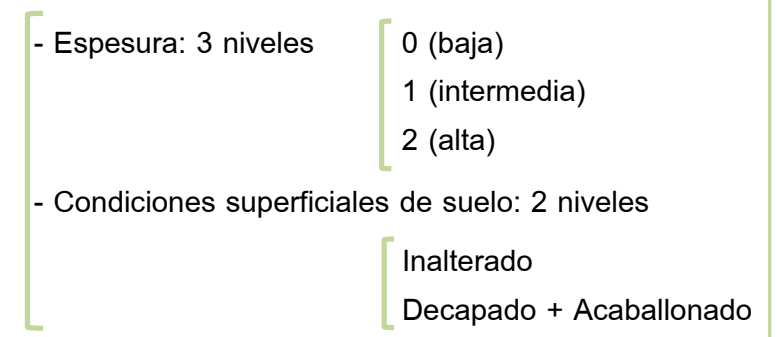

1 Bloque

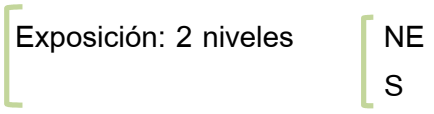

Repeticiones: 2

Número total de unidades experimentales

$$
3 \times 2 \times 2 \times 2=24
$$

Fig. 11. Cuadro resumen del diseño experimental de la Segunda Red de Parcelas (Diseño II). 


\subsubsection{Replanteo del experimento}

Partiendo del diseño teórico, se localizaron sobre el terreno los tratamientos requeridos. Al igual que en la red inicial, las unidades se agruparon por orientaciones, con el fin de disminuir la variabilidad introducida por los factores ajenos al estudio. Así, se localizaron en el monte dos zonas, ubicadas respectivamente en las exposiciones NE y S, en las que la masa presentaba bosquetes con espesura baja, media y alta relativamente próximos. En su interior se situaron las parcelas de la segunda red de experimentación.

Se mantuvo la localización en las laderas del monte Cabeza Mediana, aunque los lugares de ensayo fueron diferentes a los de la primera red. La localización de las áreas de muestreo y de las parcelas es la que se indica a continuación en el mapa adjunto (figura 12)

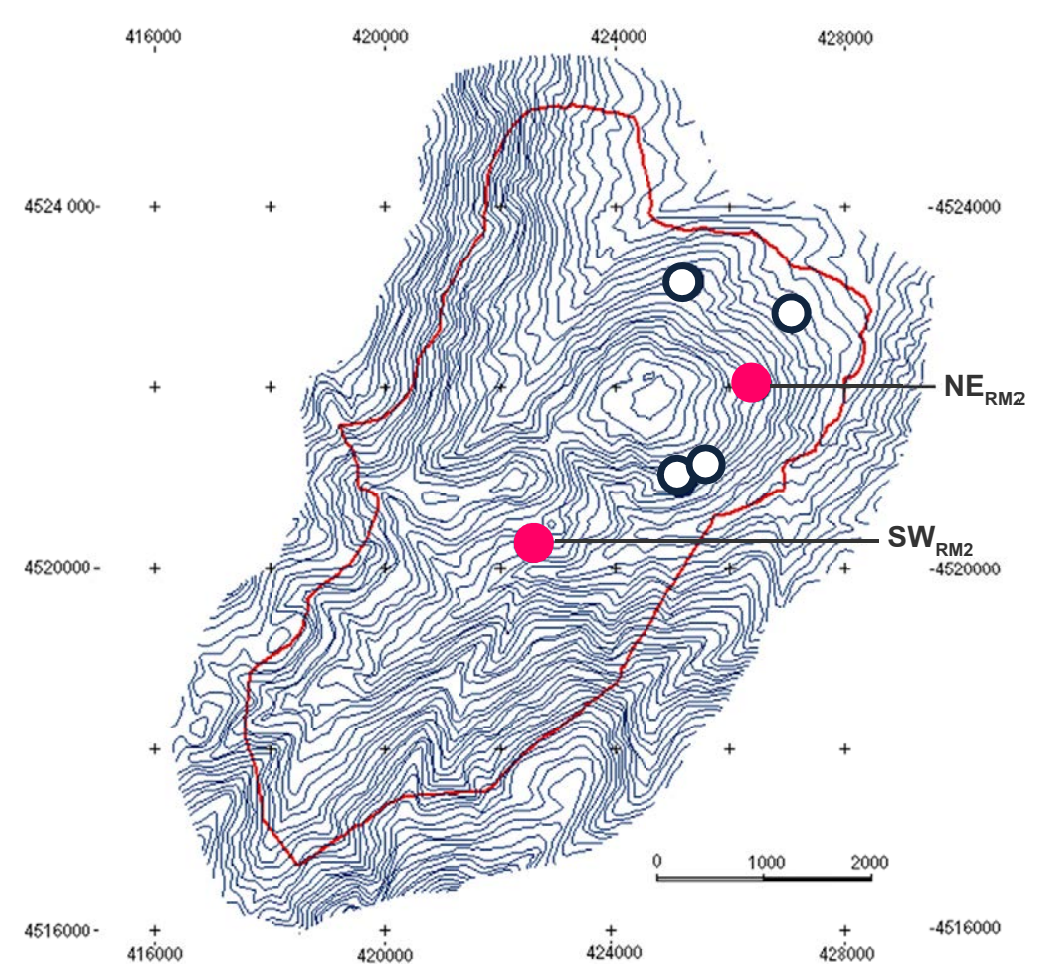

Fig. 12. Localización de las áreas de experimentación de la Segunda Red de Muestreo (RM2') dentro del Monte Cabeza de Hierro. $\mathrm{NE}_{2}$ y $\mathrm{SW}_{2}$. Con una línea roja se señala el perímetro del monte ( Oloques de experimentación de la Red de muestreol).

Las características medias de pendiente, altitud y orientación de los bloques de experimentación se resumen a continuación en la tabla 6 . Se hace referencia a cada uno de los bloques mediante las iniciales de su orientación media teórica seguidas de un subíndice n para indicar que son de la Red de muestreo II.

Tabla 6. Características medias de pendiente, altitud y orientación de los bloques de experimentaición de la Segunda Red de Muestreo (diseño II)

\begin{tabular}{lcc}
\hline \multirow{2}{*}{ Parámetro } & \multicolumn{2}{c}{ Bloque Experimental } \\
& $\mathrm{SW}_{\mathrm{n}}$ & $\mathrm{NE}_{\mathrm{n}}$ \\
\hline Superficie aprox. (ha) & 0,40 & 0,60 \\
Pendiente media (\%) & 17,7 & 13,2 \\
Altitud media (m) & 1503,8 & 1497,1 \\
Orientación media $\left(^{\circ}\right)$ & 252,6 & 79,2 \\
\hline
\end{tabular}

Una vez localizados los bloques de experimentación, en cada uno de ellos se seleccionaron de visu, al igual que en la Red de muestreo I, las subzonas con nivel creciente de espesura. Como en la Red de Muestreo I, 
inicialmente se llevó a cabo una selección aproximada y posteriormente se realizó un inventario georreferenciado pie a pie (descripción en el apartado 3.2.4. Mediciones complementarias) de todos los árboles del entorno y se asignó el área basimétrica real a cada punto.

Dentro de cada subzona, homogénea en cuanto a espesura y orientación, se localizaron las parcelas correspondientes a los niveles de estado superficial del suelo. Dado que los tratamientos requeridos eran únicamente dos y uno de ellos se generaba artificialmente, el replanteo experimental fue mucho más sencillo en este caso que en el anterior.

Tal y como se ha indicado anteriormente, en las parcelas tratadas (una de cada dos) se llevó a cabo un decapado por líneas, eliminando todo el material vegetal acumulado en superficie y poniendo al descubierto el suelo mineral. Con el material extraído se formaron caballones de unos $10-15 \mathrm{~cm}$ de altura por encima de las líneas de decapado.

Una vez más, las parcelas de experimentación se ubicaron siempre con un lado paralelo a las líneas de nivel y se replantearon sobre el terreno mediante estacas en dos esquinas opuestas (esquinas superior izquierda e inferior derecha).

\subsubsection{Siembras y Mediciones. Calendario de actuaciones}

La segunda red de experimentación se muestreó de forma efectiva únicamente durante el año 2006. En la tabla 7 se resumen las operaciones realizadas en la red de experimentación durante el período de análisis. Se indica, por un lado, si se realizó siembra o no y, por otro, el número de conteos sucesivos llevados a cabo para el control de la germinación y la supervivencia.

Tabla 7. Resumen de operaciones anuales en la Segunda Red de Muestreo (Diseño II).

\begin{tabular}{cccc}
\hline Año & Siembra & Germinación & Supervivencia \\
\hline 2006 & $\checkmark$ & 3 & 4 \\
\hline
\end{tabular}

Básicamente, durante este período se llevó a cabo una siembra y posteriormente se controló la germinación de nuevos individuos y su supervivencia posterior. La siembra se practicó de forma localizada en todas las unidades experimentales de la Red II a razón de 75 piñones por parcela (3 líneas y 25 piñones por línea), lo que supuso un total de 1800 semillas sembradas en toda la red (la densidad de siembra de cada parcela fue aproximadamente de 33 semillas $/ \mathrm{m}^{2}$ ).

La siembra se llevó a cabo durante la segunda semana del mes de marzo y los controles posteriores, aproximadamente mensuales, entre mayo y finales de septiembre. Inicialmente se realizaron dos controles de germinación en mayo y posteriormente se controló la supervivencia a finales de junio, agosto y septiembre.

\section{Procedimiento}

Con el fin de facilitar las operaciones de replanteo, siembra y posterior control de germinación y supervivencia se empleó el bastidor articulado ya descrito para la red inicial (aptdo 3.2.2.3): cuadrado de 1,5x1,5m, con cinco líneas paralelas separadas $20 \mathrm{~cm}$ en las que se señalan los puntos de siembra, a razón de 25 puntos por línea, con separaciones de $5 \mathrm{~cm}$. El tipo de decapado por líneas limita a tres el número de líneas de siembra que caben en cada parcela, por lo que en esta red sólo se usaron la primera, la tercera y la quinta líneas de siembra del bastidor. La siembra se realizó siempre en las líneas de decapado. Y las características de la semilla introducida fueron las mismas que en la red anterior. 
Como novedad, en esta red se instalaron, tras la siembra, mallas anti-pájaros y dispositivos para evitar la presencia del ganado (vacas y corzos, esencialmente). Cuestiones ajenas a esta tesis hacían inviable el vallado de las zonas de estudio, por lo que se plantearon medidas disuasorias a fin de reducir en lo posible las interferencias del ganado. Así, rodeando cada subzona de parcelas (misma espesura y exposición), se instalaron estacas de $1,2 \mathrm{~m}$ alineadas a distancias más o menos regulares $\mathrm{y}$, apoyándose en ellas, se colocaron dos bandas de cinta de obra en zigzag. En las figuras 13 y 14, a continuación, se muestra el aspecto final de una subzona de experimentación.

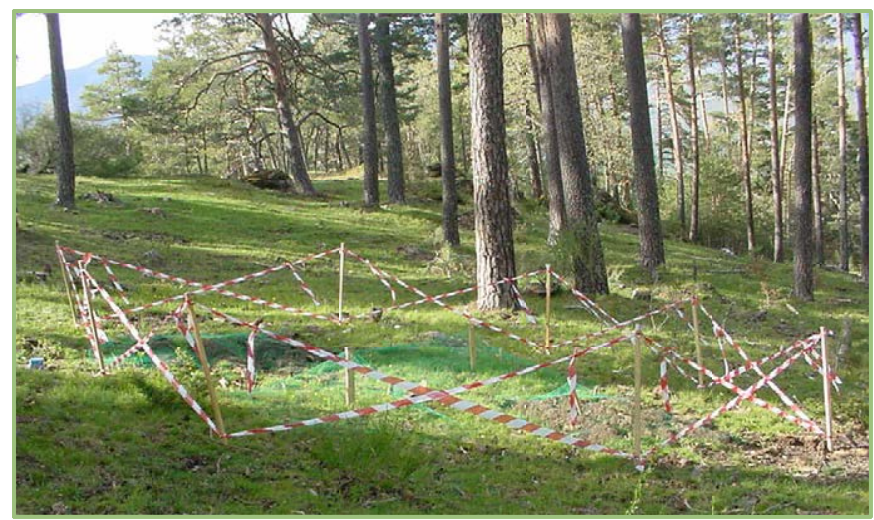

Fig. 13. Aspecto final de una subzona de experimentación de la Red de Muestreo II.

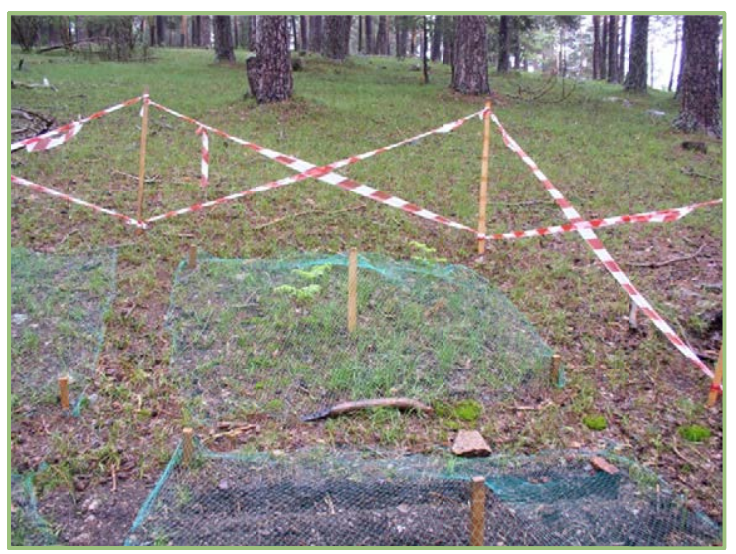

Fig. 14. Detalle de una subzona de experimentación de la Red de muestreo II.

Como en el caso anterior, las variables analizadlas fueron:

- Germinados en la línea (internos): individuos que germinan a lo largo de las líneas de siembra. Se consideran procedentes de la semilla introducida en la siembra.

\$ Germinados fuera de la línea (externos): individuos que germinan fuera de las líneas de siembra. Se consideran procedentes de semilla de la masa circundante.

\$ Supervivientes en la línea

\$ Supervivientes fuera de la línea

Para los conteos se empleó el mismo método que en la red inicial: se señalizaron los individuos que iban apareciendo mediante palillos, que permitían el posterior seguimiento de su evolución. 


\subsubsection{MEDICIONES COMPLEMENTARIAS}

Las mediciones que se describen en los siguientes apartados se llevaron a cabo con el objetivo de caracterizar los atributos reales de las unidades experimentales que fueron asignadas a los tratamientos del diseño experimental teórico durante el replanteo del presente estudio y proporcionar información sobre aspectos complementarios a los abordados con las redes de muestreo de interés para el regenerado.

Las mediciones realizadas se centraron en cinco aspectos fundamentales:

- Espesura de la masa en pie.

- Evolución de la composición y espesura de la cobertura vegetal de menor talla de las unidades experimentales tras el tratamiento de escarificado.

- Niveles de humedad en el suelo de las unidades experimentales tras el tratamiento de escarificado

- Nivel de compactación de los primeros centímetros de suelo.

\subsubsection{Espesura de la masa arbórea}

Con el fin de caracterizar la espesura de la masa, tanto en los bloques de experimentación como en cada uno de los puntos de muestreo de regeneración, se realizó un inventario referenciado de los árboles en pie y se hicieron fotografías hemisféricas en todas las parcelas de regeneración.

\section{A. INVENTARIO GEORREFERENCIADO}

En torno a cada uno de los bloques de experimentación (Red de Muestreo I: NE, NW, SE, S; Red de Muestreo II: NEn y SWn) se llevó a cabo el inventario georreferenciado de todos los árboles. La superficie inventariada en cada caso incluyó todas las parcelas de regeneración más un margen de $25 \mathrm{~m}$ alrededor de todas ellas. En total se inventariaron pie a pie 6,3 hectáreas.

Para los pies con altura mayor de $1,30 \mathrm{~m}$ se evaluaron las siguientes variables:

- Posición: coordenadas $\mathrm{x}$, y (o sus equivalentes rumbo y distancia al centro de medición).

- Especie.

- Diámetro normal (cm),

- Altura total (m).

- Altura de inicio de copa $(\mathrm{m})$ : entendiendo como tal el punto de inserción de la primera rama que puede considerarse integrada en la copa.

Para los pies menores de 1,30 se midió y/o tomó nota de:

- Posición: en los pies aislados se anotaron las coordenadas $x, y$ del pie; en el caso de golpes de regeneración o golpes de rebrote de rebollo se anotaron las coordenadas centrales del golpe y el radio aproximado de extensión.

- Especie.

- Altura total (m).

En una serie de puntos repartidos a lo largo de cada bloque se midieron, además, las cotas relativas y las coordenadas $x-y$, con el fin de elaborar posteriormente un modelo de pendientes del terreno que permitiera añadir con relativa precisión este dato para el entorno de cada unidad experimental. 
El procesamiento espacial de los datos se llevó a cabo mediante ArcView 3.1., mientras que para el tratamiento numérico del gran volumen de datos generado se elaboraron macros en Visual Basic 6.0. Las características técnicas del instrumental utilizado en el inventario pie a pie se hace constar a continuación en la tabla 8.

Tabla 8. Características técnicas del instrumental utilizado en el inventario pie a pie de losi bloques de experimentación.

\begin{tabular}{lcccccc}
\hline Variable & Aparato & Ud. & Marca & Modelo & Precisión & Resolución \\
\hline Coordenadas $(x, y)$ & Estación Total & M & Nikon & & & \\
\hline Altura arbolado & Vertex & M & $\begin{array}{c}\text { Haglöf } \\
\text { Sweden }\end{array}$ & Vertex III & $1 \%$ & $0,1 \mathrm{~m}$ \\
\hline
\end{tabular}

\section{B. FOTOGRAFÍA HEMISFÉRICA}

La fotografía hemisférica es una de las técnicas indirectas más corrientemente utilizadas para caracterizar la geometría del dosel de copas en torno a un punto y estimar sus condiciones de luz. Mediante un objetivo hemisférico (también denominado ojo de pez) acoplado a una cámara digital estándar y situado sobre el suelo y bajo el dosel, se hacen fotografías que, por proyección (de tipo variable, según la lente), proporcionan una imagen circular plana de todo el hemisferio situado por encima del punto (Rich, 1990).

En dicha imagen, el zenit queda situado en el centro, mientras que el horizonte corresponde con el perímetro. Cada dirección (definida por un ángulo cenital medido desde el zenit $\theta$ y uno acimutal medido desde el norte en el sentido de las agujas del reloj, $\alpha$ ) queda proyectada en un punto de la foto de ojo de pez de tal forma que las coordenadas, forma y dimensión de los huecos del dosel quedan perfectamente identificadas (figura 15).
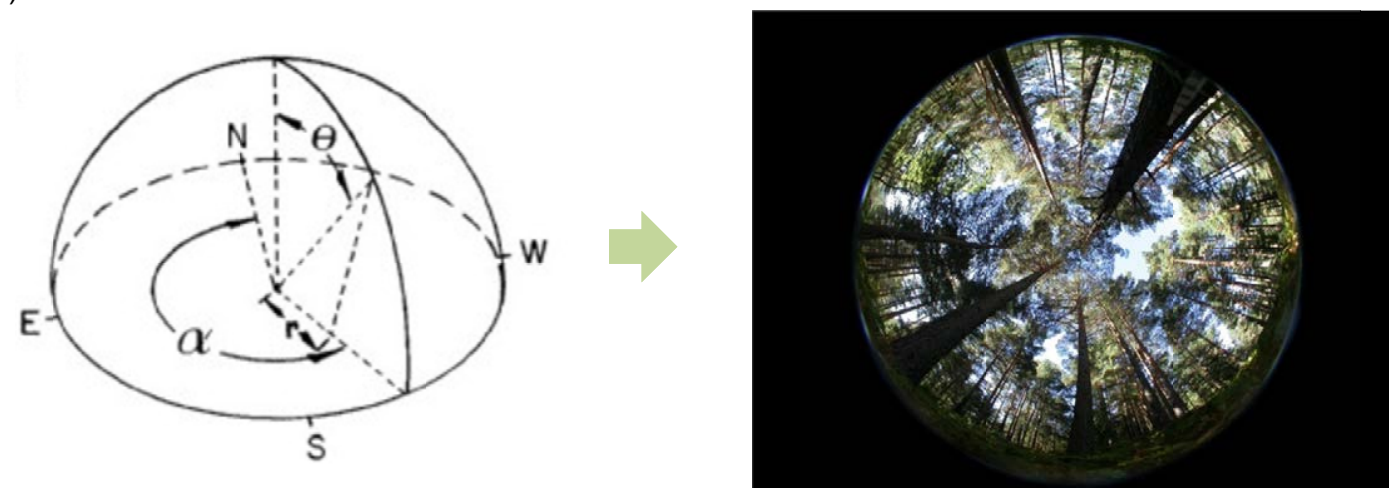

Fig. 15. A) Esquema de proyección del hemisferio en las fotografías de ojo de pez (tomado de Rich (1990)). $\theta$ ángulo cenital, $\alpha$ : ángulo acimutal medido desde el norte en el sentido de las agujas del rejoj. $r$ : radio correspondiente a la proyección del punto sobre la imagen de ojo de pez. N, S, W, E: iniciales de los puntos cardinales. B) Ejemplo de fotografía hemisférica correspondiente a uno de los puntos de muestreo.

A partir de esta información es posible estudiar la geometría del dosel de copas por encima de un punto, cuantificar la proporción de huecos existentes o calcular índices tipo LAI (Leaf Area Index) derivados de dicha proporción.

Así mismo, una vez obtenidas las imágenes hemisféricas, existen programas específicos para su procesamiento - SOLARCALC (Chazdon y Field, 1987), GLA (Frazer et al., 1999), Hemiview (Rich et al., 1999), GLI/C (Canham, 1995), CANOPY (Rich, 1989), etc. - que, tras proporcionarles una serie de parámetros sobre la ubicación del punto de muestreo (pendiente, orientación, longitud, latitud y altitud, índices de nubosidad y radiación generales de la zona...), realizan estimaciones de radiación incidente sobre el punto. 
Para realizar las estimaciones se asumen simplificaciones tales como que los huecos del dosel dejan pasar la luz sin alterarla en absoluto mientras que las hojas son $100 \%$ opacas y la interceptan por completo, así como otras relacionadas con el modo de dispersión de la luz difusa bajo cubierta, etc. Aún así, las estimaciones realizadas son, en general, aceptables (Rich, 1990). Entre otros parámetros, los programas suelen proporcionar porcentajes de luz directa y difusa (porcentaje recibido bajo el dosel con respecto al total que le llega de la atmósfera) y datos sobre como duración y frecuencia de sunflecks (períodos de duración variable en los que la luz directa incide sobre el punto de muestreo).

En el presente trabajo se hicieron dos fotografías hemisféricas en el centro de cada una de las parcelas de muestreo de regeneración como parte de las mediciones destinadas a caracterizar sus condiciones microestacionales. La primera imagen se tomó a principios de la primavera, antes de la brotación de los rebollos; la segunda, al final del verano, antes de la marcescencia de los mismos.

Todas las fotografías se realizaron con una cámara NIKON Coolpix 990 equipada con un conversor Ojo de Pez Nikon TC-E8 (reducción x 0,21 de la distancia focal del objetivo de la cámara y ángulo de visión de $183^{\circ}$ aproximadamente).

Una vez obtenidas las fotografías, se analizaron mediante el software de libre disposición Gap Light Analizar (Frazer et al., 1999). La extracción de índices mediante este programa requiere fijar una serie de parámetros relativos a la lente utilizada y a la ubicación espacio-temporal de la fotografía analizada que se describen a continuación en la tabla 9

Tabla 9. Resumen de los parámetros de calibración del software Gap Ligh analyzer (Frazer et al., 1999) para los puntos de muestreo.

\begin{tabular}{|c|c|}
\hline \multicolumn{2}{|l|}{ 1. Imagen } \\
\hline Posición inicial del cursor & Norte magnético \\
\hline Declinación Magnética & $2^{\circ} 12^{\prime}$ Oeste \\
\hline Ecuación distorsión proyección (Rich et al. 1999) & $r=\left(a_{1} \cdot z\right)+\left(a_{2} \cdot z^{2}\right) *^{1}$ \\
\hline \multicolumn{2}{|l|}{ 2. Localización } \\
\hline Latitud, Longitud, Altitud & Las del punto de muestreo \\
\hline Orientación & Pendiente: punto muestreo \\
\hline Máscara topográfica & No \\
\hline \multicolumn{2}{|l|}{ 3. Resolución } \\
\hline Intervalo Solar Analizado & 2 minutos \\
\hline Fecha inicio período vegetativo & 1 marzo / 1 junio \\
\hline Fecha fin período vegetativo & 31 mayo/ 30 septiembre \\
\hline$N^{0}$ regiones azimutales & 36 \\
\hline $\mathrm{N}^{\circ}$ regiones cenitales & 9 \\
\hline \multicolumn{2}{|l|}{ 4. Radiación } \\
\hline Tipo de datos & Modelizados \\
\hline Constante solar & $1367 \mathrm{Wm}-2$ \\
\hline Parámetros mensuales & $\star^{2}$ \\
\hline Modelo brillo regiones del cielo & SOC \\
\hline Coef. Transmisión cielo despejado & 0,6 \\
\hline
\end{tabular}

${ }^{*} \mathbf{r}$ indica la posición del punto sobre la proyección de la bóveda celeste expresada como porcentaje del radio del circulo obtenido; $\mathbf{z}$ es el ángulo cenital en radianes que indica la posición original del punto en la bóveda; $\mathbf{a}^{1}$ y $\mathbf{a}^{2}$ son parámetros específicos de cada lente que en el caso que nos ocupa toman los valores que se indican a continuación: $a 1=0,681 ; a 2=-0,028253$.

$*^{2}$ A continuación se resumen los coeficientes mensuales de nubosidad, radiación directa y fracción espectral considerados para el análisis de las fotografías hemisféricas de la zona de estudio mediante el software Gap Light Analyzer. Estos coeficientes han sido obtenidos a partir de la información aportada por el Atlas climático de irradiación solar a partir de imágenes del satélite NOAA (Vera Mella, 2005). 
Tabla 10. Coeficientes mensuales de nubosidad, radiación directa y fracción espectral considerados para el análisis de las fotografías hemisféricas (obtenidos a partir de la información aportada por el Atlas climático de irradiación solar de Vera Mella (2005))

\begin{tabular}{lccc}
\hline Mes & $\mathrm{K}_{\mathrm{t}}$ & $\mathrm{L}_{\mathrm{d}}$ & Fracción espectral \\
\hline Enero & 0,51 & 0,45 & 0,44 \\
Febrero & 0,54 & 0,49 & 0,44 \\
Marzo & 0,52 & 0,46 & 0,44 \\
Abril & 0,5 & 0,43 & 0,44 \\
Mayo & 0,49 & 0,42 & 0,44 \\
Junio & 0,55 & 0,51 & 0,44 \\
Julio & 0,56 & 0,52 & 0,43 \\
Agosto & 0,54 & 0,49 & 0,43 \\
Septiembre & 0,51 & 0,45 & 0,44 \\
Octubre & 0,49 & 0,42 & 0,44 \\
Noviembre & 0,48 & 0,4 & 0,44 \\
Diciembre & 0,52 & 0,46 & 0,44 \\
\hline
\end{tabular}

Kt: Índice de nubosidad, estimación regional de la nubosidad en una determinada zona. Se puede calcular para cualquier período de tiempo (diario, mensual, anual). En este caso, el parámetro calculado es la media mensual.

Ld: Coeficiente de radiación directa, esto es, tanto por uno de la radiación total que llega a un punto que lo hace en forma de radiación directa (entendiendo como tal la parte de la energía solar que atraviesa la atmósfera y llega a la superficie terrestre sin ser absorbida o reflejada).

Fracción espectral: fracción de la energía solar correspondiente a la radiación fotosintéticamente activa (PAE) con respecto al total recibido.

Las variables que se obtuvieron a partir del análisis de las fotografías hemisféricas fueron las siguientes:

1. Porcentaje Luz transmitida:

a. Directa: porcentaje de luz directa que es transmitida por el dosel arbóreo.

b. Difusa: porcentaje de luz difusa que es transmitida por el dosel arbóreo.

c. Global: porcentaje de luz total que es transmitida por el dosel arbóreo.

2. Fracción de Apertura del dosel ("SKY fraction"):

Variable que evalúa el porcentaje de huecos que presenta la bóveda del dosel arbóreo sobre cada punto muestreado. Se contabiliza el porcentaje de píxeles de cielo abierto con respecto al total en cada región de la bóveda (delimitada por un rango acimutal y cenital).

3. Sunflecks (períodos de exposición directa a la radiación solar): duración total y duración media.

\subsubsection{Cobertura vegetal del suelo tras el tratamiento de escarificación}

A lo largo de 2006, dos años después de realizar el tratamiento de escarificación sobre una de cada cuatro de las parcelas de la Red de Muestreo I, se llevó a cabo una valoración del estado del recubrimiento superficial en todas ellas. Los parámetros evaluados en cada unidad experimental fueron los que siguen:

- Estimación visual (Muukkonen et al., 2006) de los porcentajes de recubrimiento superficial de los distintos estratos considerados para el sotobosque: i) matorral; ii) hierba; iii) restos vegetales.

- Espesor de la capa de restos acumulada distinguiendo entre Espesor total y Espesor de la capa de restos no descompuestos.

Estos parámetros se midieron únicamente en las unidades experimentales de la Red Inicial. Se evaluaron tanto para las parcelas escarificadas como para las no alteradas, a fin de tener una referencia de normalidad para todos los parámetros estudiados. 


\subsubsection{Parámetros micrometeorológicos de medición puntual: Humedad edáfica}

Durante el último período de experimentación (año 2006) se realizaron mediciones de humedad edáfica en cada una de las parcelas correspondientes a la Red de muestreo I con el objeto de caracterizar la disponibilidad hídrica tanto en las parcelas que habían sido escarificadas dos años antes, como en las no escarificadas. El parámetro registrado fue por tanto la humedad edáfica a $10 \mathrm{~cm}$ de profundidad.

Las mediciones se llevaron a cabo en cada una de las parcelas de experimentación (RM I) a principios del mes de mayo de 2006 coincidiendo con los muestreos de resistencia a penetración que se describen el en apartado siguiente. En cada ocasión y para cada unidad experimental se realizaron tres mediciones de humedad siguiendo una de las diagonales principales de la parcela (esquina superior izquierda, centro y esquina inferior derecha). Las características técnicas de la sonda utilizada para las mediciones se muestran a continuación en la tabla 11.

Tabla 11. Características técnicas del instrumental utilizado en la medición de las variables micrometeorológicas.

\begin{tabular}{llllcrrr}
\hline Variable & Aparato & Ud. & Marca & Modelo & Precisión & Resolución & Rango \\
\hline Humedad edafica & $\begin{array}{l}\text { Sonda } \\
\text { TDR }\end{array}$ & $\%$ & $\begin{array}{c}\text { DeltaT } \\
\text { Devices }\end{array}$ & $\begin{array}{c}\text { WET } \\
\text { sensor } 1.2\end{array}$ & $\pm 4 \%$ & $0,1 \%$ & $20-80 \%$ \\
\hline
\end{tabular}

\subsubsection{Compactación edáfica}

En todas las unidades experimentales de la Red de Muestreo I se llevaron a cabo también mediciones del nivel de compactación edáfica. De entre los numerosos parámetros de uso habitual para la estimación de esta propiedad edáfica, se seleccionó la Resistencia a Penetración cuantificada a través de un penetrómetro de cono por su facilidad, rapidez y economía de medición (que lo hacen idóneo para muestreos a media y gran escala) y por su relación específica con la oposición del suelo al crecimiento radical (Bengough et al., 1997).

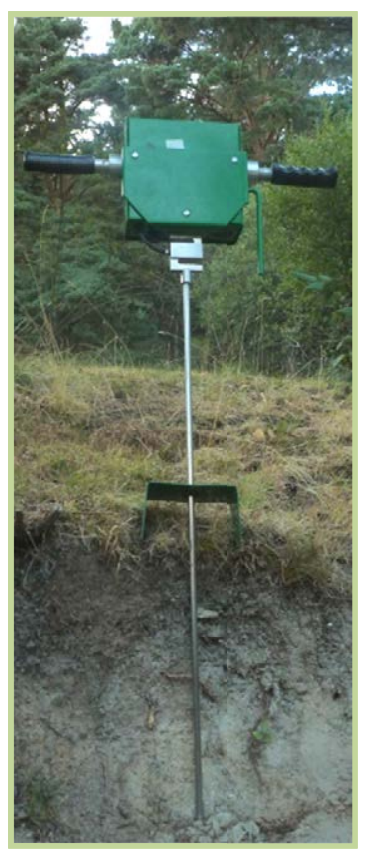

El penetrómeto de cono (figura 16) consta de una barra de acero de diámetro y ángulo en punta variable y un cabezal que permite ejercer fuerza vertical sobre la barra para introducirla en el suelo y registrar tanto la profundidad de inserción como la fuerza realizada en cada momento.

La barra metálica debe ser introducida en el suelo a velocidad uniforme y entonces el aparato, a partir de esas medidas de fuerza y profundidad de avance, proporciona una estimación de la resistencia a penetración del suelo, entendiendo como tal la presión que ha sido necesario ejercer para vencer dicha resistencia. Las unidades de medida son, por tanto, kPa y se proporcionan estimaciones para las distintas profundidades de inserción.

Se realizaron mediciones de Resistencia a Penetración en todas las parcelas de la Red de Muestreo I a principios de mayo de 2006. En cada caso se registraron medidas en profundidad cada $1,5 \mathrm{~cm}$ hasta $1055 \mathrm{~cm}$.

Fig. 16. Penetrómetro de cono Rimmik CP20

Para las mediciones de penetrabilidad se empleó un penetrómetro de cono marca Rimmik, modelo CP20 (diámetro y ángulo de cono de $1,27 \mathrm{~cm}$ y $30^{\circ}$ respectivamente). Paralelamente, se controló la humedad edáfica mediante una sonda TDR Trase System (características técnicas ya indicadas en el apartado 3.2.4.1). 


\subsubsection{VARIABLES CLIMÁtICAS GENERALES}

Con el fin de llevar a cabo la caracterización climática general de la zona de estudio y la caracterización meteorológica del período de estudio (2004 a 2006), se solicitaron a la Agencia Española de Meteorología (AEMET) los registros de las principales variables meteorológicas realizados por la estación de "Rascafría (el Paular)" (n० 3104; coordenadas: 3053'12”'W, 4053'16”'N; cota: 1.159 m.s.n.m.), ubicada en el término municipal del mismo nombre dentro de la Comunidad de Madrid, en el período 1995 a 2014 (máximo disponible). Dichas variables fueron:

- Temperaturas mensuales: media, media de las máximas, media de las mínimas, máxima absoluta y mínima absoluta.

- Precipitaciones mensuales.

- Precipitaciones diarias.

El análisis climático se llevó a cabo utilizando Excel y el paquete Climatol de R. 


\subsection{ESQUEMA DE ANÁLISIS DE RESULTADOS}

A continuación se describe brevemente el esquema que se sigue en el análisis y discusión de los resultados obtenidos mediante los diseños experimentales especificados en los apartados previos. Básicamente la información se estructura en cinco grandes bloques:

\section{Caracterización de las condiciones generales de experimentación:}

I.A. Condiciones meteorológicas del período de estudio

(Aptdo. 4.1. Caracterización meteorológica del período de experimentación (2004-2006) con respecto al año climático medio en la zona de estudio)

I.B. Condiciones de masa en las unidades experimentales

(Aptdo. 4.2. Caracterización de la masa en las unidades experimentales)

II. Cuantificación del proceso de regeneración natural en función de las características de la cubierta vegetal: eficacia del tratamiento de escarificación.

(Aptdo. 4.3. Red de muestreo I: Germinación, supervivencia y establecimiento del regenerado bajo distintas condiciones de cubierta vegetal)

III. Análisis de la persistencia de los efectos del tratamiento de escarificación sobre suelo y cubierta vegetal.

(Aptdo.4.4 Red de Muestreo I: persistencia de los efectos del tratamiento de escarificación)

\section{Posibles tratamientos alternativos, ¿hay compactación en el monte?}

(Aptdo. 4.5. Red de muestreo l: la compactación en la masa en estudio)

\section{Eficacia del tratamiento de 'Decapado + Acaballonado' sobre la germinación y la supervivencia del} regenerado. ¿Mejor escarificar o decapar?

(Aptdo. 4.6. red de muestreo II: Germinación y supervivencia. Decapado vs. Escarificado)

Dentro de cada uno de esos grandes bloques el análisis y tratamiento de la información se aborda como sigue:

\section{CARACTERIZACIÓN DE LAS CONDICIONES GENERALES DE EXPERIMENTACIÓN}

\section{I.A. Condiciones meteorológicas del período de experimentación (años 2004-2006)}

Las condiciones microestacionales dependen en gran medida de las características concretas (fisiografía, suelo, cubierta vegetal) de cada punto, pero sólo en la medida en que éstas cambian o modulan el régimen termo-pluviométrico general de la zona en que se encuentran. Dicho régimen varía a su vez en función de la posición geográfica, pero también presenta una fuerte variación interanual.

Dado que los procesos de regeneración natural de las especies forestales y el éxito de los mismos están estrechamente ligados a las condiciones ambientales de temperatura y humedad, antes de abordar el estudio de la regeneración propiamente dicho, se lleva a cabo un análisis pormenorizado del régimen termopluviométrico de la zona de estudio durante el período de experimentación (2004 a 2006). Como referencia de "normalidad" para definir qué es un año seco, húmedo, cálido o frío, se calcula la serie climática media a partir de los datos del período 1995 a 2014.

La caracterización climática de la serie media del período 1995 a 2014 se realiza a partir de los resúmenes mensuales de precipitación y temperatura: $T^{\mathrm{a}}$ media mensual, $\mathrm{T}^{\mathrm{a}}$ media de las mínimas, $\mathrm{T}^{\mathrm{a}}$ media de las máximas, $T^{\mathrm{a}}$ mínima absoluta, $\mathrm{T}^{\mathrm{a}}$ máxima absoluta y Precipitación mensual acumulada. Dichos resúmenes se calculan también por separado para cada uno de los años del período de estudio. 
Se calcula así mismo el climodiagrama de Walter y Lieth (1967) (serie media) y las fichas hídricas de Thornthwaite (1948) y los correspondientes balances hídricos anuales a fin de conocer en último término los períodos de sequía fisiológica que teóricamente correspondieron a cada uno de los años del período de estudio.

Se llevan a cabo también representaciones gráficas de la variación de las variables climáticas mensuales para todos los años del período 1995 a 2014, a fin de ubicar gráficamente el comportamiento de los años de estudio con respecto al resto de años de la serie.

\section{I.B. CONDICIONES DE MASA}

Al margen de la descripción general de las características del monte Cabeza de Hierro llevada a cabo en este capítulo, a partir de las mediciones obtenidas en el inventario pie a pie de las zonas de experimentación, se realiza la caracterización de las condiciones específicas de masa tanto a nivel del bloque experimental (cuatro para la Red de muestreo I y dos para la Red de muestreo II), como en torno a cada punto de muestreo de regeneración (192 en la Red de muestreo I y 12 en la Red de muestreo II).

La caracterización de la masa en los bloques se lleva a cabo por separado para las dos especies principales (pino silvestre y rebollo) distinguiendo dos fracciones (Bravo Fernández y Serrada, 2007): 1) masa inventariable $(\mathrm{dn}>10 \mathrm{~cm})$ y 2$)$ regenerado $(\mathrm{dn}<10 \mathrm{~cm})$. Dentro de la masa inventariable, para cada una de las especies se distingue entre pies mayores (diámetro normal $>20 \mathrm{~cm}$ ) y pies menores $(10 \mathrm{~cm}<$ diámetro normal<20cm). Teniendo en cuenta estas categorías se calculan algunos índices habituales de caracterización de la masa: distribución diamétrica, densidad, área basimétrica, diámetro medio cuadrático, alturas (dominante y media) y fracción de copa viva.

La regeneración se valora únicamente para el pino silvestre y para su cuantificación se consideran las siguientes categorías tomadas de Bravo Fernández y Serrada (2007):

$$
\begin{aligned}
& \cdot h<0,30 \mathrm{~m} \\
& \cdot 0,30<\mathrm{h}<1,30 \mathrm{~m} \\
& \cdot \mathrm{h}>1,30 \mathrm{~m} \text { y dn }<5 \mathrm{~cm} \\
& \cdot \mathrm{h}>1,30 \mathrm{~m} \text { y } 10>\mathrm{dn}>5 \mathrm{~cm}
\end{aligned}
$$

Una vez definidas las características generales de la masa en las zonas de experimentación se procede a definir el modo idóneo de caracterizar el efecto de la masa sobre cada parcela concreta de muestreo de regeneración. El área basimétrica por hectárea a nivel de rodal resulta adecuada para caracterizar la masa de cara a procesos de regeneración, pero a nivel de rodal. $\mathrm{Si}$, como en el presente trabajo, lo que se desea es valorar el modo en que la espesura afecta a las condiciones ambientales de un punto en concreto, cabe plantearse si el área basimétrica resulta o no un parámetro adecuado $\mathrm{y}$, caso de serlo, cuál es el tamaño de parcela en torno al punto en el que sería idóneo valorarla.

Partiendo del inventario georrefereciado de los bloques de experimentación y teniendo en cuenta las coordenadas de cada pie y de cada unidad experimental, se calculan en torno a cada una de ellas los valores promedio de área basimétrica $\left(\mathrm{m}^{2} / \mathrm{ha}\right)$ en parcelas concéntricas de $5,10,15,20$ y $25 \mathrm{~m}$.

Así mismo, mediante el software GLA (Frazer et al., 1999), para cada fotografía hemisférica se realizan estimaciones de algunas de las principales variables lumínicas convencionales (\% Luz directa, difusa y total transmitida por el dosel y duración de sunflecks) y el porcentaje de huecos del dosel en torno a cada punto de medición. Dicho porcentaje se calcula para el conjunto de la bóveda sobre el punto así como para 40 casquetes esféricos de ángulo cenital creciente desde $2,1^{\circ}$ hasta $90^{\circ}$ (figura 17 ). 

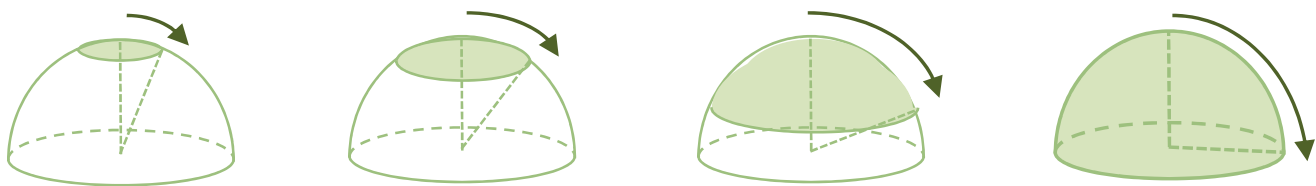

Fig. 17. Representación esquemática de cuatro de los 40 casquetes esféricos sobre los que se calcula el porcentaje acumulado de huecos del dosel arbóreo en cada unidad experimental.

Se calculan los niveles de correlación entre las mediciones de $A B$ en parcelas concéntricas y del índice de huecos del dosel $(\% \mathrm{HD})$ en casquetes esféricos de ángulo cenital creciente. De este modo se pretende establecer el ángulo de influencia sobre los huecos del dosel de los pies en torno al punto de muestreo en función de su distancia a éste. A cada radio de muestreo de área basimétrica se le asigna un ángulo cenital de influencia máxima de tal forma que en función del ángulo de ocurrencia sobre el dosel del proceso que se quiera estudiar, es posible elegir un radio óptimo de muestreo del área basimétrica.

Así mismo se correlacionan las distintas variables lumínicas con los índices de huecos del dosel y con el área basimétrica en parcelas concéntricas y se determina el radio óptimo de estimación de la misma en cada caso. Por último, a partir de toda la información analizada se seleccionan los parámetros que se considera que van a caracterizar mejor el efecto de la masa sobre el regenerado en cada punto de muestreo.

\section{CUANTIFICACIÓN DEL PROCESO DE REGENERACIÓN NATURAL EN FUNCIÓN DE LAS CONDICIONES DE LA CUBIERTA VEGETAL: EFICACIA DEL TRATAMIENTO DE ESCARIFICACIÓN.}

Tal y como se ha descrito anteriormente la masa en estudio presenta una enorme irregularidad estructural tanto vertical como horizontal que proporciona un amplio abanico de escenarios para el estudio de la regeneración con circunstancias de masa y sotobosque variables. La Red de Muestreo I, objeto del presente apartado, se diseñó para representar en la medida de lo posible esta variabilidad y permitir así caracterizar y cuantificar el proceso de germinación y establecimiento del pino silvestre en un rango de situaciones tan amplio como fuese posible y lógico considerar.

Una vez caracterizadas tanto las condiciones meteorológicas en el período de experimentación como las características de la masa en torno a los puntos de muestreo, en el presente apartado se procede a analizar el comportamiento del proceso de regeneración en la Red de muestreo I. El análisis de los resultados obtenidos se estructura en dos grandes bloques: por un lado se analiza la germinación y la supervivencia durante el primer año (mayor disponibilidad de escenarios con pies vivos, y mayor frecuencia de medición) y por otro el establecimiento al cabo de tres años.

Para el año I se proporcionan los valores medios generales de germinación y supervivencia, se describe el cronograma aproximado del proceso en el área de estudio y se analiza tanto el efecto de la cobertura (dosel y sotobosque), como el del bloque de experimentación. Para ello la probabilidad de supervivencia del regenerado se modeliza en función de las variables que caracterizan los microhábitats de germinación y supervivencia (Orientación, Cobertura vegetal superficial y espesura) mediante el método LASSO (Least Absolute Shrinkage and Selection Operator) de regresión logística penalizada (TIBSHIRANI 1996). La bondad de ajuste se evalúa con la proporción de devianza explicada estimada usando validación cruzada (función cv.glmnet del paquete glmnet de R (FRIEDMAN et al, 2010)). Se analiza de forma particular la influencia del escarificado con respecto al resto de coberturas sobre el suelo (hierba, matorral o restos)

En segundo lugar se cuantifica y se analiza el proceso de establecimiento del regenerado en el área de estudio a partir de la evolución de la supervivencia durante los años I, II y III en los distintos escenarios considerados. 


\section{ANÁLISIS DE LA PERSISTENCIA DE LOS EFECTOS DEL TRATAMIENTO DE ESCARIFICACIÓN SOBRE SUELO Y CUBIERTA VEGETAL}

Dado que una de las claves de la eficacia de los tratamientos de ayuda a la regeneración es la persistencia de sus efectos un tiempo mínimo suficiente para asegurar la instalación, transcurridos dos años desde la aplicación del tratamiento se procedió a determinar el nivel de recuperación de las parcelas escarificadas a través de la evaluación tanto del estado del recubrimiento vegetal como el de los primeros centímetros de suelo valorando: I) porcentajes de recubrimiento de herbáceas, matorral y restos (estimación visual, Muukkonen et al., 2006); II) espesor de la capa de restos acumulados sobre el suelo (diferenciando entre espesor de restos frescos no descompuestos y espesor total); III) humedad edáfica (a 10-12cm de profundidad); IV) resistencia a penetración del suelo $(0-20 \mathrm{~cm})$.

En el presente apartado se compara el comportamiento de las variables relativas al suelo y a la cobertura superficial entre el grupo de parcelas escarificadas y no escarificadas dos años después del tratamiento. Se calculan los valores medios por tratamiento y la significación estadística de las diferencias encontradas tanto para las variables de cobertura superficial como del suelo se analizan mediante tests de t-Student. También se emplean diagramas de caja para comparar gráficamente las distribuciones de las variables estimadas en las parcelas escarificadas y no escarificadas.

Con el objetivo de describir la velocidad de recuperación de los estratos vegetales analizados se calcula la tasa de recuperación de las variables relacionadas con cobertura del suelo. Las condiciones medias de los grupos de parcelas no escarificadas se consideran valores control ("cobertura esperada"), y dichas tasas se calculan como el porcentaje de recuperación con respecto a ellos:

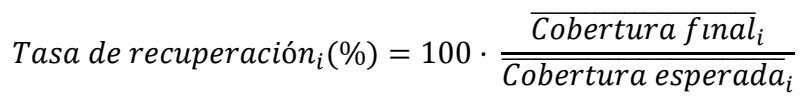

$\overline{\text { Cobertura }}$ final $_{i}=$ cobertura media en las parcelas escarificadas dos años después del tratamiento en el estrato "i"; $\overline{\text { Cobertura esperada }}_{i}=$ Cobertura media en parcelas no escarificadas en el estrato "i".

Las tasas de recuperación tan sólo se calculan para para aquellas variables en los que los valores medios encontrados en las parcelas escarificadas resultan ser significativamente diferentes de los valores de las parcelas no alteradas según los resultados del test de la t-student.

Una vez descrito el efecto remanente de la escarificación sobre los parámetros estudiados, se procede a evaluar el papel de la espesura del dosel arbóreo en el proceso de recuperación. Con este objetivo, se calculan los coeficientes de correlación de Pearson entre las variables de espesura de la masa arbolada y las variables consideradas en relación con el suelo y su cobertura superficial.

Por último, se valora la repercusión de los niveles de recuperación observados (y su variación en función de los distintos escenarios de espesura de masa) sobre los aspectos clave para los procesos de germinación y supervivencia del regenerado: 1) Contacto suelo-semilla. 2). Velocidad de elongación radical. 3) Disponibilidad hídrica.

En este sentido, tanto el efecto de la escarificación sobre el equilibrio entre espesor total de material orgánico sobre el suelo vs. porción correspondiente a restos frescos (capa de restos sin descomponer) como la relación de la disponibilidad hídrica encontrada con el resto de parámetros estudiados (estrato superior, sotobosque y suelo) se analizan a través del ajuste de sendos modelos lineales. En el caso de la disponibilidad hídrica, debido a los elevados niveles de correlación existentes entre las variables regresoras, el ajuste se lleva a 
cabo mediante regresión penalizada tipo LASSO (Least Absolute Shrinkage, and Selection Operator) (Tibshirani, 1996) a fin de seleccionar un modelo sencillo que sólo incluyera las variables más trascendentes de entre las posibles. La bondad de dicho ajuste se evalúa mediante la proporción de devianza explicada estimada y optimizada mediante validación cruzada. EI modelo lineal LASSO se lleva a cabo mediante las funciones glmnet y cv.glmnet del paquete R (Friedman et al., 2010).

\section{Posibles tratamientos ALteRnativos, ¿HAY COMPACtACIÓN EN EL MONTE?}

Los problemas de compactación edáfica han sido citados de forma habitual en bibliografía asociados tanto a los aprovechamientos mecanizados en los montes (Cambi et al., 2015; Curran et al., 2005) como a los ganaderos (Crush y Thom, 2011; Jones, 2000). El tránsito reiterado de ganado y maquinaria en las masas forestales es considerado susceptible de aumentar los niveles de compactación edáfica y llegar a generar restricciones al desarrollo vegetal si la intensidad (nivel alcanzado + superficie y volumen de suelo afectado) y la duración de los efectos, son lo suficientemente elevadas. La compactación supone en esos casos una disminución de la calidad de estación real de las zonas afectadas que se manifiesta tanto en la productividad de las masas como en la tasa de éxito del proceso de regeneración de las mismas (Froehlich, 1979; Kozlowski, 1999).

Tal y como se ha descrito en apartados anteriores, el monte "Cabeza de Hierro" se gestiona con objetivo múltiple de producción de madera, pastos, uso recreativo y conservación. En el momento de desarrollo de este estudio, tanto el aprovechamiento mecanizado de madera como el aprovechamiento ganadero habían tenido lugar en la masa durante períodos (>100 años de explotación ganadera y > 50 años de aprovechamientos mecanizados de madera) tanto o más largos que los mencionados en bibliografía asociados a pérdidas de calidad de estación (Adams, 1975; Greacen y Sands, 1980).

Cabía esperar por tanto que los niveles de compactación edáfica pudieran ser un limitante a la regeneración en el monte en estudio y, caso de serlo, los tratamientos de ayuda a la regeneración a plantear debían contemplar también este aspecto.

En el presente apartado se lleva a cabo el análisis de los niveles de compactación encontrados en la masa en estudio (valorados a través de la resistencia a penetración edáfica) a fin de determinar la trascendencia de este potencial factor limitante a nivel de monte. Para ello se hace uso de las parcelas de la red de muestreo I y las mediciones de resistencia a penetración en ellas realizada.

En primer lugar se valora la severidad de los niveles de resistencia a penetración encontrados en los bloques de experimentación de acuerdo a los rangos de referencia establecidos en bibliografía.

Posteriormente se identifican dentro de cada uno de los bloques los puntos de mayor intensidad de tránsito de ganado y maquinaria (zonas de querencia alimenticia, cargaderos y vías de saca) y a partir de ellos se caracteriza cuál es el efecto de ambos agentes compactadores sobre la Resistencia a penetración del suelo cuando la intensidad de tránsito es máxima. Dichos valores se comparan (tanto en intensidad como en profundidad afectada) con los valores observados en el resto de superficie.

El efecto de ganado y maquinaria va a depender de las características del medio sobre el que actúan así como de la frecuencia, duración e intensidad de las cargas. Dado que la gestión de maquinaria y ganado es común a todo el monte y que las características de la estación se pueden considerar suficientemente representadas con los bloques muestreados, cabe esperar que la cuantificación de los efectos observados sea 
suficientemente representativa de los efectos medios generados por los agentes compactadores en las zonas más transitadas. Por ese motivo, una vez que se cuantifica el efecto de maquinaria y ganado en las zonas de mayor tráfico, se procede a evaluar si ambos usos, con los niveles de alteración observados, han producido o no a nivel de monte una alteración de la productividad de la masa durante las décadas en las que han venido produciéndose. Para ello, en último lugar, se lleva a cabo un análisis de la evolución de la productividad de la masa durante los últimos 50 años (tiempo aproximado desde el inicio de los aprovechamientos mecanizados).

El estado general de la resistencia del suelo en los primeros $20 \mathrm{~cm}$ se describe los bloques experimentales mediante valores medios, intervalos de confianza y distribuciones de frecuencia. Los efectos de la maquinaria y del ganado en los horizontes superficial $(0-10 \mathrm{~cm})$ y sub-superficial $(10-20 \mathrm{~cm})$ del suelo sobre la resistencia a la penetración se analizan a partir de la comparación del comportamiento medio de los puntos de alto y bajo impacto de ambos agentes compactadores (t-student tests).

Las tendencias de la resistencia a la penetración en profundidades superiores a $20 \mathrm{~cm}$ se analizan mediante un modelo lineal de efectos mixtos ajustado a la totalidad del rango de profundidades muestreadas (de 0 a $49,5 \mathrm{~cm}$ ). Para profundidades mayores el análisis de datos se realiza mediante un modelo lineal de efectos mixtos con el objetivo de contrarrestar la progresiva reducción del tamaño de la muestra a partir de los $20 \mathrm{~cm}$ de profundidad. Las perturbaciones (maquinaria y ganado) se incluyen como efectos fijos, y los puntos de muestreo dentro del área de estudio como puntos aleatorios anidados. Los valores anormales de resistencia a la penetración incrementan su influencia sobre las medias al aumentar la profundidad debido a la reducción en el tamaño muestral. Al trabajar a la vez con todo el rango de profundidades e incluir un efecto aleatorio en el modelo para tener en cuenta el efecto del punto de muestreo, se minimiza esta influencia y por tanto se permite una descripción robusta de la realidad subyacente. Se seleccionan las estructuras óptimas de efectos fijos y aleatorios mediante el procedimiento descrito en Zuur et al. (2009). La evaluación de la bondad del ajuste del modelo se basa en los índices AIC (Akaike Information Criterion) y en el logaritmo de la verosimilitud (-2.Log Likelihood). Los análisis estadísticos se han realizado con los programas SPSS 15.0 y $R$ (versión 3.1.2). Los modelos lineales mixtos han sido desarrollados mediante la función Ime del paquete nlme R (Lindstrom y Bates, 1990, 1988).

\section{EFICACIA DEL TRATAMIENTO dE 'DECAPADO + ACABALLONADO’ SOBRE LA GERMINACIÓN Y LA SUPERVIVENCIA DEL REGENERADO. ¿MEJOR ESCARIFICAR O DECAPAR?}

Tras analizar el comportamiento de la regeneración natural del pino silvestre en un elevado número de escenarios de cobertura vegetal (diferentes combinaciones de espesura de masa y recubrimiento vegetal del suelo), se diseñó una segunda red de muestreo (Red de Muestreo II) centrada en comprobar con más precisión el efecto de un segundo tratamiento sobre el suelo que mejorase algunas de las deficiencias observadas en el tratamiento de escarificado. Dicho tratamiento fue un decapado por líneas con acaballonado.

Además de las siembras y mediciones que se desarrollaron sobre la Red de Muestreo II, simultáneamente se llevaron a cabo siembras y mediciones en una parte de las parcelas de la Red de Muestreo I, a fin de comprobar el tratamiento de 'decapado+acaballonado' y el de escarificado bajo unas condiciones meteorológicas comunes (las del año 2006).

En el quinto bloque de análisis de resultados se describen a grandes rasgos las peculiaridades del proceso de regeneración durante el año 2006 en relación con las características meteorológicas del período vegetativo de ese año. 
Para las parcelas de la Red de Muestreo II se cuantifican los procesos de germinación y supervivencia postestival en las parcelas no tratadas $y$ se comparan con los observados en las tratadas con 'decapado+acaballonado'.

Así mismo, se analiza el efecto de la espesura de la masa y la orientación tanto sobre las tasas de germinación y supervivencia observadas como sobre la eficacia del tratamiento de decapado. Dentro de las variables empleadas para caracterizar el efecto de la masa sobre las condiciones bajo cubierta (área basimétrica, porcentaje de huecos del dosel sobre el punto, \%Luz directa y difusa transmitidas, sunflecks) se comprueba qué variables afectan en mayor medida a la germinación y a la supervivencia dentro del abanico de parcelas analizadas.

Por último, se cuantifican las tasas de germinación y supervivencia observadas en las parcelas sembradas de la Red de Muestreo I y se comparan los resultados con los de la Red de Muestreo II durante ese mismo período para comparar a su vez la eficacia y los efectos de los dos tratamientos edáficos de ayuda a la regeneración: Decapado+acaballonado vs. Escarificado. 
4. RESULTADOS Y DISCUSIÓN 

4.1.

CARACTERIZACIÓN METEOROLÓGICA DEL PERÍODO DE EXPERIMENTACIÓN (2004-2006) CON RESPECTO AL AÑO CLIMÁTICO MEDIO EN LA ZONA DE ESTUDIO 



\subsubsection{CARACTERÍSTICAS CLIMÁTICAS GENERALES DE LA ZONA DE ESTUDIO}

La caracterización climática general de la zona de estudio se realiza a partir de los datos de la estación meteorológica de "Rascafría (el Paular)" (n³104; coordenadas: 353'12”W, 4053'16”'N; cota: 1.159 m.s.n.m.) ubicada en el término municipal del mismo nombre dentro de la Comunidad de Madrid.

La serie de datos disponible corresponde al período comprendido entre 1995 y 2013. Como la diferencia de altitudes entre los bloques de experimentación (altitud media $1.470 \mathrm{~m}$ ) y el observatorio $(1.159 \mathrm{~m}$ ) es superior a $100 \mathrm{~m}$ se aplica una corrección altitudinal a los datos. Concretamente, las correcciones altitudinales aplicadas a las temperaturas y a las precipitaciones son las recomendadas por Gandullo (1994) que se muestran a continuación en la tabla 12. Hay que reseñar que al ser la diferencia de altitudes mayor de $250 \mathrm{~m}$ es posible que los datos obtenidos de la corrección sean inexactos.

Tabla 12. Correcciones altitudinales para la estimación de la precipitación y la temperatura a una altitud diferente a la de la toma de datos (Gandullo, 1994)

$$
\begin{array}{ll}
\text { Precipitación: } & \mathbf{P}=\mathrm{P}_{\mathrm{obs}} \cdot\left(1+0,08 \cdot\left(\mathrm{Alt}-\mathrm{Alt}_{\mathrm{obs}}\right) / 100 *\right. \\
\text { Temperatura: } & \mathrm{T}^{\mathrm{a}}=\mathrm{T}_{\mathrm{obs}}^{\mathrm{a}}+0,65 \cdot\left(\mathrm{Alt}-\mathrm{Alt}_{\mathrm{obs}}\right) / 100
\end{array}
$$

Para el período correspondiente en cada caso: $\mathrm{P}_{\text {obs }}=$ precipitación registrada en el observatorio; $\mathrm{P}=$ precipitación estimada para la zona de estudio; $\mathrm{T}^{\mathrm{a}}{ }_{\mathrm{obs}}=$ temperatura registrada en el observatorio; $\mathrm{T}^{\mathrm{a}}=$ temperatura estimada para la zona de estudio. $\mathrm{Alt}_{\mathrm{obs}}=$ altitud del observatorio; Alt = altitud media de la zona de estudio considerada. ${ }^{*}$ La precipitación no se corrige para los meses de julio y agosto.

A continuación se presenta un cuadro resumen (tabla 13) del comportamiento medio de las variables climatológicas ya corregidas para la zona de estudio durante el período 1995-2013, así como su representación gráfica por medio del climodiagrama de Walter-Lieth (Walter y Lieth, 1967) realizado mediante la función diagwl del paquete Climatol de R (fig. 18).

Tabla 13. Cuadro resumen del comportamiento medio mensual y anual de las principales variables climatológicas, durante el período 1995-2013, en la zona de estudio.

\begin{tabular}{lcccccc}
\hline Mes & $\mathrm{P}$ & $\mathrm{T}^{\mathrm{a}}$ & $\mathrm{M}$ & $\mathrm{M}$ & $\underline{\mathrm{M}}$ & $\underline{\mathrm{m}}$ \\
\hline Enero & 155,5 & 0,6 & 13,3 & $-18,0$ & 6,1 & $-5,0$ \\
Febrero & 112,8 & 1,8 & 15,0 & $-17,0$ & 7,9 & $-4,4$ \\
Marzo & 109,5 & 4,0 & 17,7 & $-21,0$ & 10,7 & $-2,6$ \\
Abril & 119,1 & 6,0 & 20,6 & $-10,5$ & 12,7 & $-0,8$ \\
Mayo & 106,1 & 9,3 & 24,3 & $-7,0$ & 16,6 & 2,0 \\
Junio & 51,5 & 13,9 & 28,6 & $-5,0$ & 22,5 & 5,2 \\
Julio & 13,2 & 16,0 & 31,0 & $-2,0$ & 25,6 & 6,3 \\
Agosto & 23,8 & 15,9 & 30,9 & $-5,5$ & 25,6 & 6,2 \\
Septiembre & 51,7 & 12,4 & 27,0 & $-6,5$ & 21,0 & 3,8 \\
Octubre & 93,0 & 8,2 & 22,0 & $-11,0$ & 15,4 & 1,1 \\
Noviembre & 137,9 & 3,5 & 16,6 & $-13,0$ & 9,2 & $-2,3$ \\
Diciembre & 174,3 & 1,1 & 13,5 & $-17,0$ & 7,0 & $-4,9$ \\
\hline Anual & $1.148,5$ & 7,7 & 31,0 & $-21,0$ & 25,6 & $-5,0$ \\
\hline
\end{tabular}

$\mathrm{P}=$ precipitación $(\mathrm{mm}) ; \mathrm{T}^{\mathrm{a}}=$ temperatura media $\left({ }^{\circ} \mathrm{C}\right) ; \mathrm{M}=$ temperatura máxima absoluta $\left({ }^{\circ} \mathrm{C}\right) ; \underline{\mathrm{M}}=$ temperatura media de las máximas $\left({ }^{\circ} \mathrm{C}\right) ; \underline{m}=$ temperatura media de las mínimas $\left({ }^{\circ} \mathrm{C}\right) ; m=$ temperatura mínima absoluta $\left({ }^{\circ} \mathrm{C}\right) ;$

Tal y como se refleja en el resumen climático, la precipitación anual media en la zona de estudio asciende a los $1.148,5 \mathrm{~mm}$ de los cuáles sólo $37,0 \mathrm{~mm}$ se producen durante los meses de julio y agosto. La temperatura media anual es de $7,7^{\circ} \mathrm{C}$; la media de las máximas del mes más cálido, de $25,6{ }^{\circ} \mathrm{C}$; y la media de las mínimas del mes más frío, de $-5{ }^{\circ} \mathrm{C}$. 
Del climodiagrama representado a continuación (fig. 18) se deduce que el período vegetativo en la zona de estudio (curva de precipitaciones por encima de la de temperaturas y temperatura media por encima de los 6 ${ }^{\circ} \mathrm{C}$ ) se prolonga durante 4,5 meses: desde mediados de abril hasta finales de junio y, posteriormente, durante los meses de septiembre y octubre. Por su parte, el período seco (temperatura por encima de precipitaciones) se limita a los meses de julio y agosto.

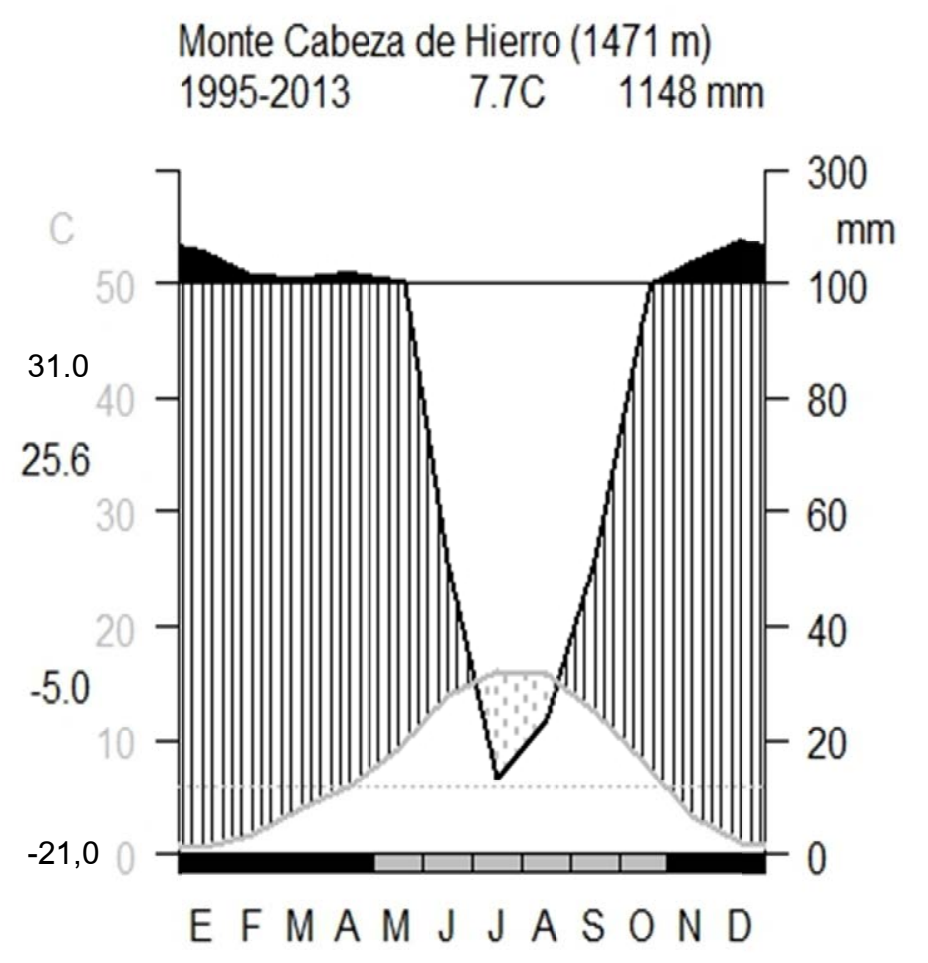

Fig. 18. Climodiagrama de Walter-Lieth para el monte "Cabeza de Hierro".

Del climodiagrama se deduce, además, la siguiente información:

\begin{tabular}{ccccccccccccc}
$\mathrm{H}$ & $\mathrm{n}$ & $\mathrm{T}^{\mathrm{a}}$ & $\mathrm{P}$ & $\mathrm{M}$ & $\underline{\mathrm{M}}$ & $\underline{\mathrm{M}}$ & $\mathrm{M}$ & $\mathrm{K}$ & $\mathrm{A}$ & $\mathrm{G}$ & $\mathrm{HS}$ & $\mathrm{HP}$ \\
\hline 1.471 & 19 & 7,7 & 1.148 & 31,0 & 25,6 & $-5,0$ & $-21,0$ & 0,022 & 1,56 & 4,5 & 6 & 4
\end{tabular}

$\mathrm{h}=$ altitud sobre el nivel del mar $(\mathrm{m}) ; \mathrm{n}=\mathrm{n}^{\circ}$ de años observados y registrados; $\mathrm{T}^{\mathrm{a}=}$ temperatura miedia anual $\left({ }^{\circ} \mathrm{C}\right) ; \mathrm{P}=$ precipitación anual $(\mathrm{mm}) ; \mathrm{M}=$ máxima absoluta del periodo $\left({ }^{\circ} \mathrm{C}\right) ; \underline{M}=$ media de las máximas del mes más cálido $\left({ }^{\circ} \mathrm{C}\right)$; $\underline{m}=$ media de las mínimas del mes más frío $\left({ }^{\circ} \mathrm{C}\right) ; \mathrm{m}=$ mínima absoluta del periodo $\left({ }^{\circ} \mathrm{C}\right) ; \mathrm{k}=$ valor de la intensidad de la sequía; a= duración de la sequía (meses); G= duración del periodo vegetativo (meses); HS= helada segura (meses) (banda en negro en climodiagrama); HP= helada probable (meses) (banda gris en climodliagrama)

$\mathrm{Si}$, además del régimen termo-pluviométrico, se tiene en cuenta el comportamiento del suelo mediante el balance hídrico anual proporcionado por la ficha hídrica (Thornthwaite, 1948), se pone de manifiesto que en la zona, por término medio, se produce sequía fisiológica entre los meses de junio y septiembre, aunque con mayor intensidad en los meses de julio y agosto (tabla 14) 
Tabla 14. Ficha hídrica del monte "Cabeza de Hierro".

\begin{tabular}{llllllllll}
\hline MES & $\mathrm{T}^{\mathrm{a}}$ & $\mathrm{P}$ & $\mathrm{ETP}$ & $\mathrm{S}$ & $\mathrm{D}$ & $\mathrm{R}$ & $\mathrm{ETRMP}$ & $\mathrm{SF}$ & $\mathrm{DRJ}$ \\
\hline Enero & 0,6 & 155,5 & 3,0 & 152,6 & 0 & 150 & 3,0 & 0,0 & 152,6 \\
Febrero & 1,8 & 112,8 & 8,8 & 104,0 & 0 & 150 & 8,8 & 0,0 & 104,0 \\
Marzo & 4,0 & 109,5 & 23,4 & 86,1 & 0 & 150 & 23,4 & 0,0 & 86,1 \\
Abril & 6,0 & 119,1 & 36,7 & 82,4 & 0 & 150 & 36,7 & 0,0 & 82,4 \\
Mayo & 9,3 & 106,1 & 62,3 & 43,8 & 0 & 150 & 62,3 & 0,0 & 43,8 \\
Junio & 13,9 & 51,5 & 91,6 & 0 & 40,1 & 114,8 & 86,7 & 4,9 & 0,0 \\
Julio & 16,0 & 13,2 & 106,2 & 0 & 93,1 & 61,7 & 66,2 & 40,0 & 0,0 \\
Agosto & 15,9 & 23,8 & 98,7 & 0 & 74,9 & 37,5 & 48,1 & 50,6 & 0,0 \\
Septiembre & 12,4 & 51,7 & 68,5 & 0 & 16,9 & 33,5 & 55,6 & 12,9 & 0,0 \\
Octubre & 8,2 & 93,0 & 42,7 & 50,3 & 0 & 83,8 & 42,7 & 0,0 & 0,0 \\
Noviembre & 3,5 & 137,9 & 16,2 & 121,7 & 0 & 150,0 & 16,2 & 0,0 & 55,5 \\
Diciembre & 1,1 & 174,3 & 5,3 & 169,0 & 0 & 150,0 & 5,3 & 0,0 & 169,0 \\
\hline ANUAL & 7,7 & 1148,5 & 563,4 & 810,0 & 224,9 & & 455,0 & 108,4 & 693,4 \\
\hline
\end{tabular}

$\mathrm{T}^{\mathrm{a}}=$ temperatura media mensual y media anual $\left({ }^{\circ} \mathrm{C}\right) ; \mathrm{P}=$ precipitación media mensual y total anual $(\mathrm{mm})$; $\mathrm{ETP}=$ evapotranspiración potencial mensual y anual $(\mathrm{mm}) ; \mathrm{S}=$ superávits mensual y total anual $(\mathrm{mm}) ; \mathrm{D}=$ déficits mensual y total anual $(\mathrm{mm}) ; \mathrm{R}=$ reserva mensual de agua en el suelo $(\mathrm{mm})$; ETRMP: evapotranspiraciones reales máximas posibles mensual y total anual $(\mathrm{mm})$; $\mathrm{SF}=$ sequías fisiológicas mensual y total anual $(\mathrm{mm})$; DRJ= drenajes mensual y total anual del suelo $(\mathrm{mm})$. Período de sequía fisiológica.

Para el cálculo de la ficha hídrica (tabla 14) se ha empleado el método de Thornthwaite en función del cuál el clima de la zona de estudio se define como microtérmico y perhúmedo (evapotranspiración total $=563,4 \mathrm{~mm}$; Índice hídrico= $119,8 \mathrm{~mm}$ ).

Como resumen final de los aspectos que definen el clima en el área de estudio de cara al proceso de regeneración, podemos decir:

- La zona de estudio presenta precipitaciones anuales abundantes en torno a $1150 \mathrm{~mm}$, de las que tan sólo un $7 \%$ se produce en el período estival.

- Los meses más fríos y más lluviosos suelen ser los meses de diciembre y enero (media de las mínimas de $-5^{\circ} \mathrm{C}$ y precipitación mensual de 150-170 mm), mientras que julio es habitualmente el mes más caluroso y más seco (media de las máximas de $25,5^{\circ} \mathrm{C}$ y precipitación de $13,2 \mathrm{~mm}$ ).

- En lo referente a la vegetación, según el climodiagrama el período vegetativo comienza a mediados del mes de abril y se prolonga hasta finales de octubre con, una pausa estival por sequía en los meses de julio y agosto.

- Las restricciones a la vegetación por sequía, teniendo en cuenta el balance hídrico de Thornthwaite, son, sin embargo, más extensas: dan comienzo en el mes de junio y se prolongan hasta finales del mes de septiembre. A pesar de ser junio el mes más seco y caluroso, la mayor tasa de sequía se produce en el mes de agosto debido a la duración de las reservas hídricas del suelo. La recuperación total de las reservas de agua tras la sequía estival se produce durante el mes de noviembre. 


\subsubsection{CARACTERIZACIÓN TERMO-PLUVIOMÉTRICA DEL PERÍODO DE ESTUDIO}

Una vez caracterizado el comportamiento climático medio de los últimos 20 años en la zona de estudio, a continuación se detallan las características meteorológicas de precipitación y temperattura de los años de ensayo (2004-2006) y se comparan con el año medio del período 1995-2013, a fin de ubicar el comportamiento térmico y pluviométrico del período de estudio con respecto a la "normalidad".

Tabla 15. Comportamiento medio anual del régimen termo-pluviométrico en la zona de estudio durante el período de muestreo (2004-2006) en comparación con la media anual para el período 1995-2013.

\begin{tabular}{lcccccc}
\hline Período & $\mathrm{P}$ & $\mathrm{T}^{\mathrm{a}}$ & $\underline{\mathrm{M}}$ & $\mathrm{M}$ & $\underline{\mathrm{m}}$ & $\mathrm{m}$ \\
\hline 2004 & 1095,8 & 7,8 & 14,7 & 31,0 & 0,8 & $-18,0$ \\
2005 & 866,3 & 7,3 & 14,9 & 33,0 & $-0,3$ & $-21,0$ \\
2006 & 887,1 & 8,0 & 15,5 & 31,5 & 0,5 & $-14,5$ \\
\hline Promedio & 1153,7 & 7,7 & 15,0 & 35,5 & 0,4 & $-21,0$ \\
\hline
\end{tabular}

$\mathrm{P}=$ precipitación anual $(\mathrm{mm}) ; \mathrm{T}^{\mathrm{a}}=$ temperatura media anual $\left({ }^{\circ} \mathrm{C}\right) ; \mathrm{M}=$ temperatura máxima absoluta $\left({ }^{\circ} \mathrm{C}\right) ; \underline{\mathrm{M}}=$ temperatura media de las máximas $\left({ }^{\circ} \mathrm{C}\right) ; \underline{m}=$ temperatura media de las mínimas $\left({ }^{\circ} \mathrm{C}\right) ; \mathrm{m}=$ temperatura mínima absoluta $\left({ }^{\circ} \mathrm{C}\right)$.

Los valores medios anuales resumidos en la tabla 15 ponen de manifiesto que los tres años de estudio fueron más secos que la media. No obstante, mientras que el año 2004 prácticamente igualó esta media, el 2005 y el 2006 presentaron precipitaciones anuales del orden de $300 \mathrm{~mm}$ menores que ésta (-25\%). En cuanto a las temperaturas, el año 2005 fue ligeramente más frío que la media y el 2006 ligeramente más caluroso, pero se trata en ambos casos de diferencias poco notables que, en el caso de las temperaturasi medias anuales, no superan el medio grado (la máxima variación térmica observada respecto a la media para la temperatura media fue de $1,4^{\circ} \mathrm{C}$ en 1995).

Además del resumen anual, dado que el objetivo final es caracterizar el comportamiento termo-pluviométrico de la zona de estudio de cara al proceso de regeneración, resulta adecuado considerar la distribución de valores a lo largo del año. A continuación, en las figuras 19, 20 y 21, se representan las distribuciones de precipitación, temperatura media, temperatura media de las máximas y temperatura media de las mínimas a lo largo del año, tanto para el período de estudio como para el resto de años de la serie climática disponible. Se representa así mismo el año medio. En el caso de la precipitación se representan los valores acumulados para facilitar la posterior interpretación.

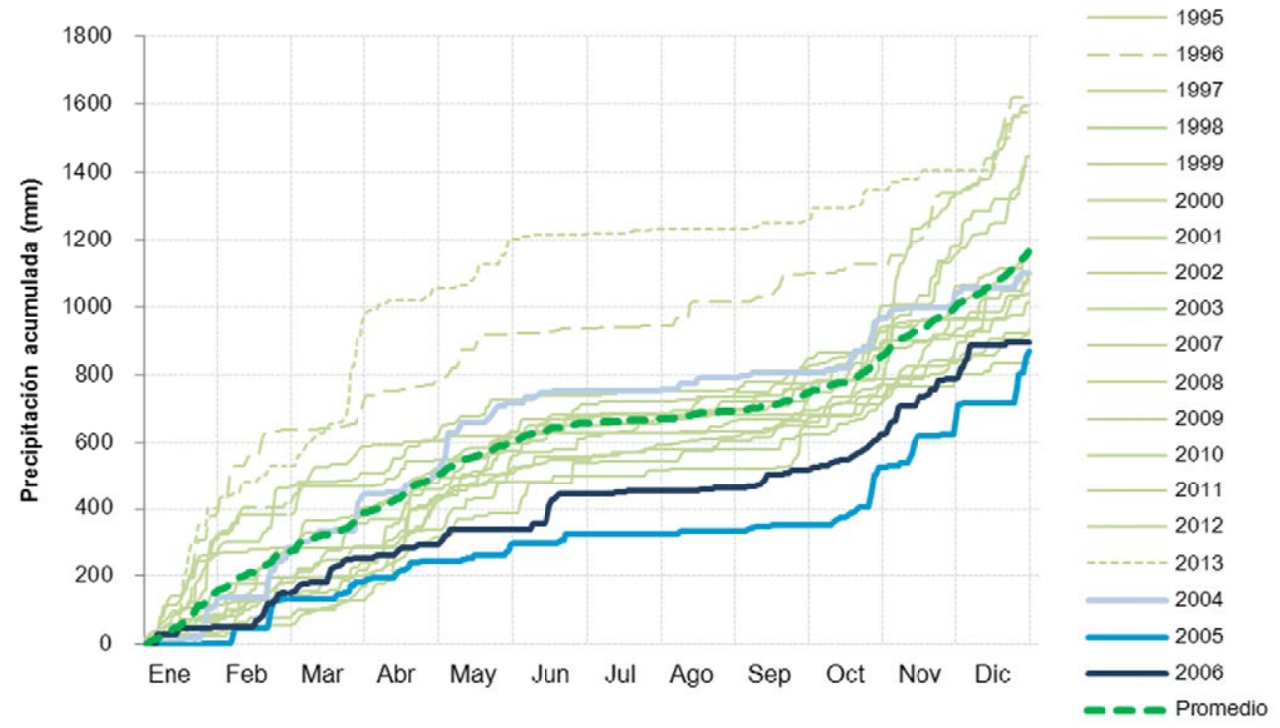

Fig. 19. Representación gráfica de la precipitación acumulada a lo largo del año para todos los años comprendidos entre 1995 y 2013 así como para el año promedio. 
Como se pone de manifiesto en la figura 19, el 2005 y el 2006 fueron los dos años más secos de toda la serie observada. No obstante, las mayores diferencias de precipitación de dichos años con el año medio se produjeron en los dos primeros tercios del año, mientras que la precipitación del último tercio se aproximó bastante a la media de la serie. Por su parte, el año 2004 presenta la tercera precipitación acumulada más alta de toda la serie al inicio del período estival, como consecuencia, principalmente, de la elevada precipitación del mes de mayo $(215 \mathrm{~mm})$. Sin embargo, dado que con posterioridad a mayo la precipitación se produjo a menor ritmo, especialmente durante los meses de septiembre y diciembre, la precipitación total anual es ligeramente inferior a la media.

El comportamiento térmico mensual de la zona de estudio se muestra a continuación en las figuras 20, 21 y 22 y se resume, junto con la pluviometría, en la tabla 16.

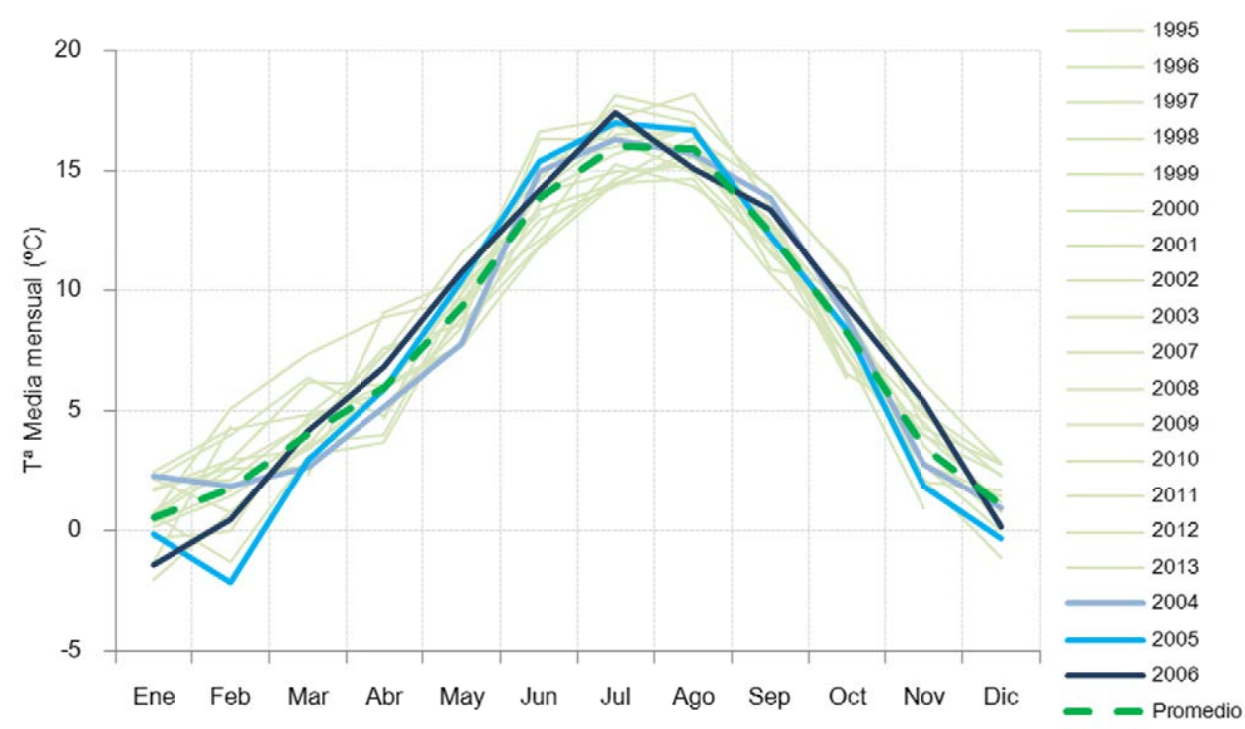

Fig. 20. Representación gráfica de la temperatura media mensual a lo largo del año para todos los años comprendidos entre 1995 y 2013 así como en el año promedio.

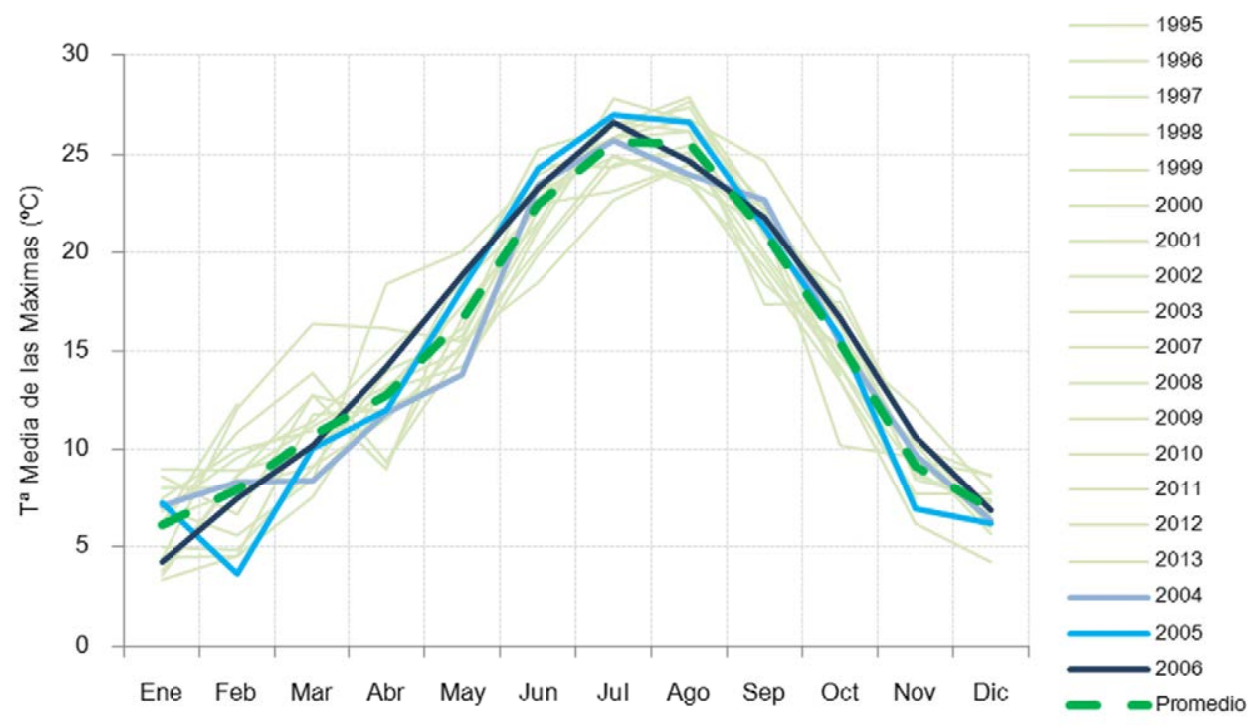

Fig. 21. Representación gráfica de la temperatura media mensual de las máximas diarias a lo largo del año para todos los años comprendidos entre 1995 y 2013 así como en el año promedio. 


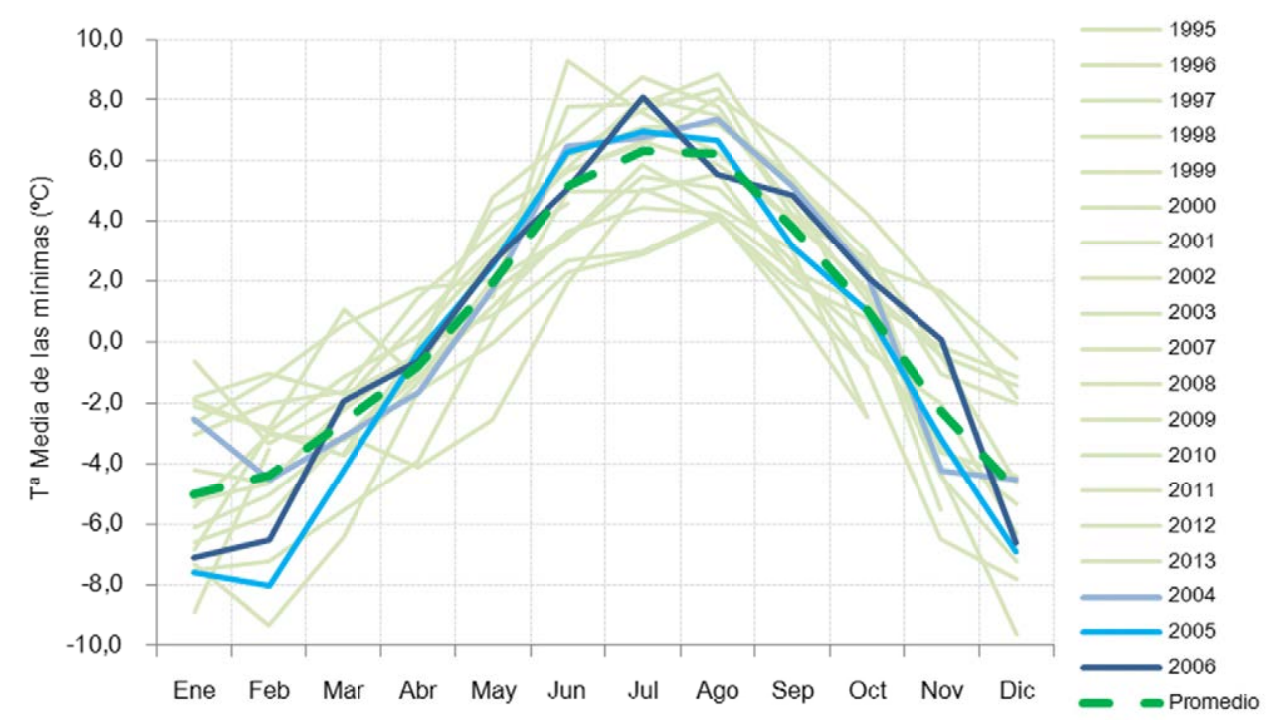

Fig. 22. Representación gráfica de la temperatura media mensual de las mínimas diarias para todos los años comprendidos entre 1995 y 2013 así como en el año promedio.

Tabla 16. Régimen termo-pluviométrico mensual en la zona de estudio durante los años de muestreo de regeneración (2004-2006) en comparación con el año medio de la serie 1995-2013.

\begin{tabular}{|c|c|c|c|c|c|c|c|c|c|c|c|c|c|}
\hline & & Ene & Feb & Mar & Abr & May & Jun & Jul & Ago & Sep & Oct & Nov & Dic \\
\hline $\mathrm{P}$ & 2004 & 138,6 & 146,2 & 151,9 & 65,0 & 215,3 & 33,1 & 3,0 & 38,5 & 11,9 & 159,9 & 40,0 & 92,5 \\
\hline \multirow[t]{3}{*}{$(\mathrm{mm})$} & 2005 & 2,5 & 129,3 & 50,0 & 60,6 & 50,6 & 32,5 & 0,0 & 6,0 & 18,1 & 174,9 & 99,3 & 242,4 \\
\hline & 2006 & 51,9 & 100,0 & 103,1 & $38 i, 1$ & 44,4 & 108,7 & 8,5 & 7,0 & 53,7 & 100,7 & 164,3 & 106,8 \\
\hline & Promedio & 155,5 & 112,8 & 109,5 & 119,1 & 106,1 & 51,5 & 13,2 & 23,8 & 51,7 & 98,3 & 137,9 & 174,3 \\
\hline $\mathrm{T}^{\mathrm{a}}$ & 2004 & 2,3 & 1,9 & 2,7 & 5,2 & 7,8 & 15,0 & 16,3 & 15,7 & 13,9 & 8,9 & 2,8 & 1,0 \\
\hline \multirow[t]{3}{*}{$\left({ }^{\circ} \mathrm{C}\right)$} & 2005 & $-0,1$ & $-2,1$ & 3,0 & 5,9 & 10,4 & 15,4 & 17,0 & 16,7 & 12,3 & 8,4 & 1,9 & $-0,3$ \\
\hline & 2006 & $-1,4$ & 0,5 & 4,2 & 6,8 & 10,8 & 14,2 & 17,4 & 15,1 & 13,4 & 9,4 & 5,4 & 0,2 \\
\hline & Promedio & 0,6 & 1,8 & 4,0 & 6,0 & 9,3 & 13,9 & 16,0 & 15,9 & 12,4 & 8,2 & 3,5 & 1,1 \\
\hline$\underline{M}$ & 2004 & 7,1 & 8,3 & 8,4 & 11,9 & 13,8 & 23,5 & 25,7 & 24,0 & 22,7 & 15,4 & 9,8 & 6,4 \\
\hline \multirow[t]{3}{*}{$\left({ }^{\circ} \mathrm{C}\right)$} & 2005 & 7,3 & 3,7 & 10,1 & 12,0 & 18,2 & 24,3 & 27,0 & 26,6 & 21,3 & 15,7 & 7,0 & 6,2 \\
\hline & 2006 & 4,3 & 7,5 & 10,2 & 14,2 & 18,9 & 23,3 & 26,6 & 24,7 & 21,8 & 16,7 & 10,7 & 6,9 \\
\hline & Promedio & 6,1 & 7,9 & 10,7 & 12,7 & 16,6 & 22,5 & 25,6 & 25,6 & 21,0 & 15,4 & 9,2 & 7,0 \\
\hline M & 2004 & 12,0 & 15,0 & 17,5 & 21,5 & 22,5 & 30,0 & 31,0 & 30,0 & 25,5 & 25,0 & 16,0 & 12,0 \\
\hline \multirow[t]{3}{*}{$\left({ }^{\circ} \mathrm{C}\right)$} & 2005 & 15,0 & 12,0 & 18,0 & 22,5 & 26,5 & 29,0 & 31,5 & 33,0 & 28,5 & 23,0 & 13,0 & 11,5 \\
\hline & 2006 & 12,5 & 15,0 & 18,0 & 19,5 & 26,5 & 28,0 & 31,0 & 29,5 & 31,5 & 23,0 & 17,5 & 10,5 \\
\hline & Promedio & 17,5 & 19,5 & 22,5 & $26 ;, 0$ & 27,5 & 33,0 & 35,5 & 34,0 & 31,5 & 27,0 & 20,0 & 18,5 \\
\hline$\underline{\mathrm{m}}$ & 2004 & $-2,5$ & $-4,5$ & $-3,1$ & $-1,6$ & 1,8 & 6,5 & 6,8 & 7,4 & 5,2 & 2,3 & $-4,2$ & $-4,5$ \\
\hline \multirow[t]{3}{*}{$\left({ }^{\circ} \mathrm{C}\right)$} & 2005 & $-7,6$ & $-8,0$ & $-4,2$ & $-0,3$ & 2,6 & 6,3 & 7,0 & 6,7 & 3,2 & 1,1 & $-3,2$ & $-6,9$ \\
\hline & 2006 & $-7,1$ & $-6,5$ & $-1,9$ & $-0,6$ & 2,7 & 5,1 & 8,1 & 5,6 & 4,9 & 2,2 & 0,1 & $-6,6$ \\
\hline & Promedio & $-5,0$ & $-4,4$ & $-2,6$ & $-0,8$ & 2,0 & 5,2 & 6,3 & 6,2 & 3,8 & 1,1 & $-2,3$ & $-4,9$ \\
\hline M & 2004 & $-10,0$ & $-9,5$ & $-18,0$ & $-7,0$ & $-4,0$ & 0,0 & 0,0 & 2,0 & 0,0 & $-4,5$ & $-10,5$ & $-9,5$ \\
\hline \multirow[t]{3}{*}{$\left({ }^{\circ} \mathrm{C}\right)$} & 2005 & $-17,0$ & $-17,0$ & $-21,0$ & $-8,0$ & $-4,5$ & 3,0 & 3,0 & $-1,0$ & $-5,5$ & $-5,0$ & $-8,0$ & $-12,0$ \\
\hline & 2006 & $-13,0$ & $-14,5$ & $-14,0$ & $-5,5$ & $-5,0$ & $-5,0$ & 3,5 & $-1,0$ & $-0,5$ & $-3,0$ & $-7,0$ & $-11,0$ \\
\hline & Promedio & $-18,0$ & $-17,0$ & $-21,0$ & $-10,5$ & $-7,0$ & $-5,0$ & $-2,0$ & $-5,5$ & $-6,5$ & $-11,0$ & $-13,0$ & $-17,0$ \\
\hline
\end{tabular}

$\mathrm{P}=$ precipitación $(\mathrm{mm}) ; \mathrm{T}^{\mathrm{a}}=$ temperatura media $\left({ }^{\circ} \mathrm{C}\right) ; \mathrm{M}=$ temperatura máxima absoluta $\left({ }^{\circ} \mathrm{C}\right) ; \underline{\mathrm{M}}=$ temperatura media de las máximas $\left({ }^{\circ} \mathrm{C}\right) ; \underline{m}=$ temperatura media de las mínimas $\left({ }^{\circ} \mathrm{C}\right) ; m=$ temperatura mínima absolutta $\left({ }^{\circ} \mathrm{C}\right)$;

De las anteriores gráficas de temperaturas, así como de la tabla resumen del régimen termo-pluviométrico mensual para el período de muestreo en la zona de estudio (tabla 16), se deduce que: 1) el año 2004 presentó una primavera (marzo-abril-mayo) más fría que la media $\left(-1,2{ }^{\circ} \mathrm{C}\right)$, seguida de un periodo estival 
(junio-julio-agosto-septiembre) ligeramente más cálido que ésta $\left(+0,6^{\circ} \mathrm{C}\right) ; 2$ ) el año 2006 fue en general más cálido que el año promedio de tal forma que, salvo agosto, todos los meses entre marzo y noviembre fueron más calurosos que los correspondientes del año medio $\left(+0,8^{\circ} \mathrm{C}\right)$; 3 ) el año 2005 presentó un comportamiento intermedio con temperaturas más bajas que el promedio sólo durante los meses de marzo y abril $\left(-0,6^{\circ} \mathrm{C}\right)$ y más altas entre mayo y septiembre $\left(+0,8^{\circ} \mathrm{C}\right)$.

A partir de los valores de la tabla 16 se han elaboradosendas fichas hídricas para analizar el balance hídrico durante los años 2004, 2005 y 2006. Al igual que en el apartado anterior, dichos balances se han llevado a cabo a través del método de Thornthwaite (1948).

Tabla 17. Sequía fisiológica $(\mathrm{mm})$ durante el período de estudio (ficha hídrica de Thornthwaite)

\begin{tabular}{lccc|c}
\hline & \multicolumn{4}{c}{ Período } \\
\cline { 2 - 5 } Mes & 2004 & 2005 & 2006 & $1995-2013$ \\
\hline Enero & 0 & 0 & 0 & 0 \\
Febrero & 0 & 0 & 0 & 0 \\
Marzo & 0 & 0 & 0 & 0 \\
Abril & 0 & 0 & 0,003 & 0 \\
Mayo & 0 & 1,0 & 2,1 & 0 \\
Junio & 12,3 & 19,1 & 0,0 & 4,9 \\
Julio & 55,8 & 66,8 & 30,3 & 40,0 \\
Agosto & 42,8 & 77,1 & 53,8 & 50,6 \\
Septiembre & 52,4 & 42,7 & 13,0 & 12,9 \\
Octubre & 0 & 0 & 0 & 0 \\
Noviembre & 0 & 0 & 0 & 0 \\
Diciembre & 0 & 0 & 0 & 0 \\
\hline Total & 163,3 & 206,8 & 99,2 & 108,4 \\
\hline
\end{tabular}

En la tabla 17 se muestran los valores encontrados para la sequía fisiológica (derivados de las correspondientes fichas hídricas) durante el período de estudio. Teniendo en cuenta dichos valores es posible concluir que: 1) a pesar de la elevada precipitación de la primavera de 2004, la escasez de precipitaciones durante el período estival en ese año provocó que la sequía en los meses de verano fuese sensiblemente superior que la observada en el año medio. El año 2004 presentó, por lo tanto, una primavera húmeda y templada seguida de un verano seco en el que la sequía se prolongó hasta el mes de septiembre. 2) el año 2005, por su parte, presentó aún mayores niveles de déficit estival que el 2004, con un período de sequía fisiológica que se extendió al mes de mayo (en el que la sequía encontrada fue baja pero distinta de 0); 3) durante el año 2006, debido a las escasas precipitaciones y a las temperaturas más elevadas durante la primavera, la sequía fisiológica comenzó durante el mes de abril; aparentemente, con niveles de intensidad bajos, pero superiores a 0 , durante los meses de abril y mayo. Durante los meses de julio, agosto y septiembre los niveles de sequía encontrados fueron, sin embargo, similares a los del año medio. Hay que destacar, por último, que el mes de junio de ese año no presentó sequía, de acuerdo con la información derivada de la ficha hídrica anual.

Llegado este punto del análisis, hay que hacer hincapié en el hecho de que el balance de la ficha hídrica se realiza mes a mes, lo que, dependiendo del patrón de distribución de las precipitaciones y las temperaturas, puede no resultar adecuado para la descripción de las condiciones a las que realmente se ve sometida la vegetación durante los períodos considerados. Indirectamente se asume que los valores mensuales acumulados de precipitación se reparten de forma más o menos homogénea a lo largo de los 30 días que aglutinan, pero esto no siempre se ajusta suficientemente a la realidad. Tampoco la distribución de temperaturas tiene por qué presentar la homogeneidad requerida.

En el caso que nos ocupa, si analizamos la distribución de las precipitaciones diarias en el período comprendido entre el 15 de abril y el 15 de junio (fig. 23) se pone de manifiesto que, si biendurante los años 2004 y 2005 la precipitación se produjo de forma escalonada pero suficientemente repartida en todo el 
período, en el año 2006 las precipitaciones se concentraron antes del 8 de mayo y después del 8 de junio; pero a lo largo de los treinta días entre ambas fechas no hubo precipitación alguna.

Este hecho, de baja probabilidad de ocurrencia, no se detecta mediante la ficha hídrica, que supone las precipitaciones ocurridas hasta el 8 de mayo y las producidas a partir del 8 de junio homogéneamente repartidas a lo largo del mes correspondiente.

Sin embargo, de cara a la germinación y supervivencia del regenerado, ambos escenarios no son equivalentes, porque los niveles de déficit que producen no son los mismos. Por este motivo, para este caso concreto (que no se produce en ninguno de los otros años de estudio durante los períodos de primavera y verano críticos para el regenerado), se ha recalculado el balance hídrico del período conflictivo.

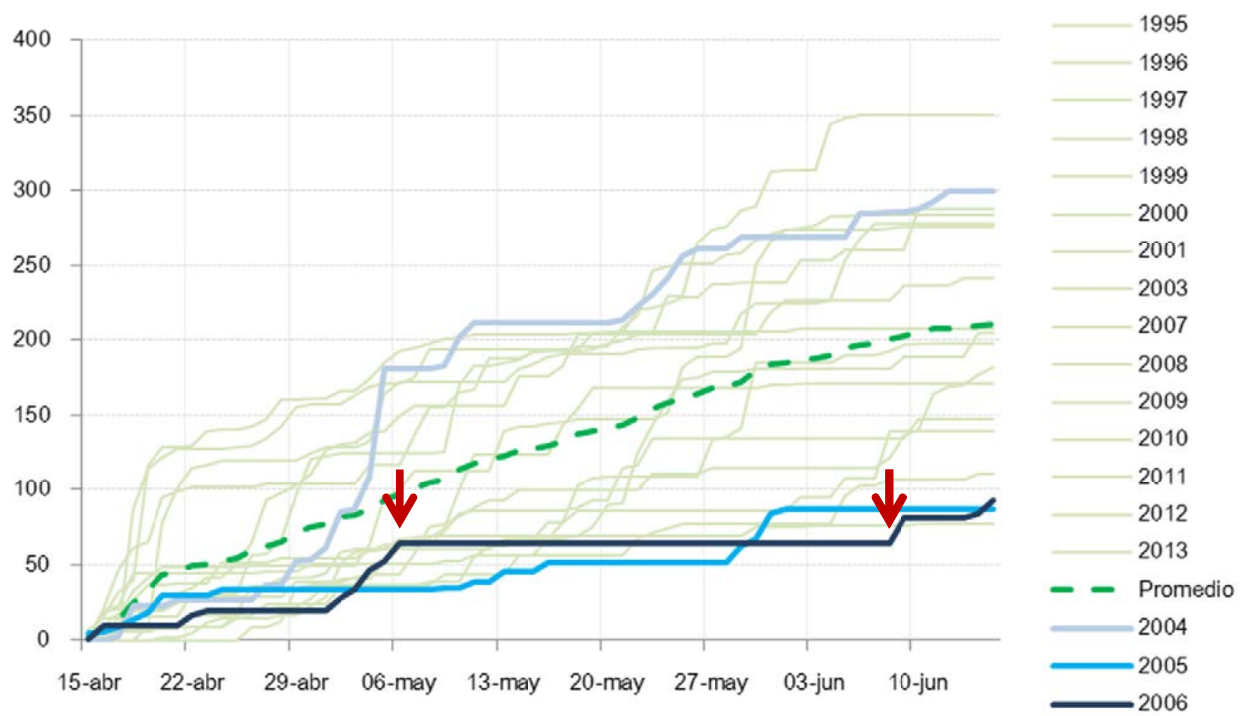

Fig. 23. Representación gráfica de la precipitación acumulada en el período comprendido entre el 15 de abril y el 15 de junio para todos los años comprendidos entre 1995 y 2013 así como en el año promedio

Para ello, se ha determinado el estado de las reservas de agua del suelo a fecha 7 de mayo y, a continuación, se han calculado la evapotranspiración y el resto de parámetros necesarios para definir el déficit del período a partir de los valores medios estimados para los treinta días comprendidos entre el 7 de mayo y el 7 de junio.

Tal y como puede verse en la tabla 18, el nivel de sequía calculado para este período en el año 2006 es prácticamente 10 veces el que se obtenía previamente calculando por meses. En el resto de años, en los que la precipitación se repartio de forma más homogénea, no se dan apenas cambios en los riesultados.

Tabla 18. Balance hídrico para la zona de estudio entre el 8 de mayo y el 8 de junio de los años 2004, 2005 y 2006, así como en el año promedio

\begin{tabular}{|c|c|c|c|c|c|c|c|c|c|}
\hline $\begin{array}{l}\text { Período } \\
\text { 8May-8Jun }\end{array}$ & $\begin{array}{l}\mathrm{T}^{\mathrm{a}} \\
\left({ }^{\circ} \mathrm{C}\right)\end{array}$ & $\begin{array}{c}\mathrm{P} \\
(\mathrm{mm})\end{array}$ & $\begin{array}{l}\text { ETP } \\
(\mathrm{mm})\end{array}$ & $\begin{array}{c}\mathrm{S} \\
(\mathrm{mm})\end{array}$ & $\begin{array}{c}\mathrm{D} \\
(\mathrm{mm})\end{array}$ & $\begin{array}{c}\mathrm{R} \\
(\mathrm{mm})\end{array}$ & $\begin{array}{c}\text { ETRMP } \\
(\mathrm{mm})\end{array}$ & $\begin{array}{c}\text { SF } \\
(\mathrm{mm})\end{array}$ & $\begin{array}{l}\text { DRJ } \\
(\mathrm{mm})\end{array}$ \\
\hline 2004 & 10,2 & 103,7 & 67,4 & 36,3 & 0 & 150 & 67,4 & 0,0 & 36,3 \\
\hline 2005 & 12,0 & 54,4 & 78,5 & 0,0 & 24,1 & 127,7 & 76,6 & 1,8 & 0,0 \\
\hline 2006 & 11,9 & 0 & 76,6 & 0 & 76,6 & 90,0 & 60,0 & 16,6 & 0,0 \\
\hline Promedio & 10,8 & 92,3 & 71,9 & 20,4 & 0 & 150 & 71,9 & 0,0 & 20,4 \\
\hline
\end{tabular}

$\mathrm{T}=$ temperatura media $\left({ }^{\circ} \mathrm{C}\right) ; \mathrm{P}=$ precipitación acumulada $(\mathrm{mm}) ; \mathrm{ETP}=$ evapotranspiración potencial; $\mathrm{S}=$ superávit $(\mathrm{mm}) ; \mathrm{D}=$ déficit $(\mathrm{mm}) ; \mathrm{R}=$ reserva de agua en el suelo al final del período $(\mathrm{mm})$; ETRMP: evapotranspiración real $(\mathrm{mm}) ; \mathrm{SF}=$ sequía fisiológica $(\mathrm{mm}) ; \mathrm{DRJ}=$ drenaje del suelo $(\mathrm{mm})$ sequía fisiológica superior a cero. 


\subsubsection{CONCLUSIONES PARCIALES}

A modo de resumen se destacan, a continuación, las características principales del régimen termopluviométrico del período de estudio con respecto al clima medio de la zona:

2004

- Año ligeramente más seco que el promedio (- $5 \%$ en precipitación total anual) y con similar temperatura media anual.

- Primavera (marzo - mayo) más fría de lo normal $\left(-2^{\circ} \mathrm{C}\right)$ y más húmeda, particularmente el mes de mayo, en el que la precipitación mensual ascendió a los $215,3 \mathrm{~mm}$.

- Período estival (junio - septiembre) muy seco y más caluroso que la media en el caso del mes de junio $\left(+1,1^{\circ} \mathrm{C}\right)$. Particularmente seco el mes de septiembre, con un déficit hídrico 4 veces superior a la media que se prolongó hasta la primera mitad de octubre. Segunda mitad de octubre más húmeda (con precipitación suficiente para recargar las reservas del suelo).

- Total de sequía fisiológica anual mayor que la media (+50\% en $\mathrm{mm}$ según la ficha hídrica), prolongada entre junio y septiembre, pero especialmente intensa durante el mes de septiembre (4 veces la sequía correspondiente del año medio).

- Año marcadamente más seco $\left(-25 \%\right.$ en precipitación total anual), aunque más frío $\left(-0,7^{\circ} \mathrm{C}\right.$ en media anual, salvo en los meses de junio y agosto $\left(+1,4{ }^{\circ} \mathrm{C}\right.$ en media mensual)) que el promedio.

- Primavera y verano secos (marzo a septiembre con -50\%), especialmente los meses de julio y agosto, en los que tan sólo hubo $4 \mathrm{~mm}$ de precipitación. Durante la primavera, no obstante, las precipitaciones fueron escasas pero bien repartidas.

- Otoño húmedo y fresco que permitió que se recuperaran las reservas hídricas del suelo a lo largo del mes de octubre.

- Total de sequía fisiológica casi doble que la del año medio ( $+90 \%$ en $\mathrm{mm}$ según la ficha hídrica), que comenzó un mes antes de lo habitual y se prolongó entre mayo y septiembre y de forma especialmente intensa durante todo ese período (más de 4 veces la sequía normal para los meses de junio y septiembre).

- Año marcadamente más seco que el promedio (-23\% en precipitación total anual) y algo más cálido, particularmente entre marzo y noviembre $\left(+1^{\circ} \mathrm{C}\right)$ con excepción del mes de agosto que fue ligeramente más frío de lo normal.

- Primavera seca con un período de 30 días consecutivos, entre el 8 de mayo y el 8 de junio, sin precipitaciones.

- Verano seco a excepción de semana de lluvias, concentrada a primeros del mes de junio. Muy pocas precipitaciones en julio y agosto. Septiembre, mejor que los años anteriores, con precipitaciones similares a la media.

- Otoño no seco, con precipitaciones similares a las del año promedio. Las reservas hídricas se recuperaron a principios del mes de noviembre.

- Total de sequía fisiológica anual aparentemente menor que el de la serie promedio. Efecto elevado sobre los cálculos de las tormentas ocurridas a primeros de junio. Sequía primaveral muy marcada en el período comprendido entre el 8 de mayo y el 8 de junio, en el que no hubo precipitación alguna. 

4.2.

CARACTERIZACIÓN DE LA MASA EN LAS UNIDADES

EXPERIMENTALES 



\subsubsection{CARACTERÍSTICAS GENERALES DE LA MASA EN LOS BLOQUES DE EXPERIMENTACIÓN}

A partir de las mediciones obtenidas en el inventario pie a pie ya descrito anteriormente en el correspondiente apartado de Material y Métodos, se calculan a continuación los índices más habituales para caracterizar la masa en las seis grandes zonas (bloques) en las que se agrupan las parcelas de muestreo de regeneración (cuatro para la Red de muestreo I y dos para la Red de muestreo II). La caracterización de la masa se lleva a cabo por separado para las dos fracciones siguientes (Bravo Fernández y Serrada, 2007): 1) masa inventariable $(\mathrm{dn}>10 \mathrm{~cm})$ y 2$)$ regenerado $(\mathrm{dn}<10 \mathrm{~cm})$.

Con respecto a esta caracterización general, hay que poner de manifiesto que la irregularidad de la masa en estudio no se manifiesta necesariamente pie a pie, sino que es consecuencia, en la mayoría de los casos, de la agregación de bosquetes internamente regulares o semirregulares y en distinto estado de desarrollo. Además de presentar forma principal de masa irregular, los bloques de experimentación se caracterizan por la notable irregularidad de la distribución espacial de los pies, que se manifiesta en la alternancia de zonas espesas con claros de dimensión variable. Por todo ello, los valores medios observados a nivel de bloque, que se resumen a continuación, pueden ser útiles para proporcionar una orientación general sobre las existencias medias de las distintas zonas de estudio, pero no son representativos de toda la variedad de situaciones de espesura presentes en cada una de ellas.

\subsubsection{MASA INVENTARIABLE}

Dado que, en algunas zonas, el pino silvestre se encuentra acompañado por un subpiso de rebollo, en este apartado se consideran ambas especies. Sus índices de espesura se calculan por separado y para cada una de ellas se distingue, a su vez, entre pies menores $(10 \mathrm{~cm}<\mathrm{dn}<20 \mathrm{~cm})$ y pies mayores $(\mathrm{dn}>20 \mathrm{~cm})$.

\section{A) DENSIDAD}

Para el cálculo de densidades por clase diamétrica se considera un ancho de clase de $5 \mathrm{~cm}$ para el pino silvestre y de $4 \mathrm{~cm}$ para el rebollo, tal y como se recomienda en la $3^{\mathrm{a}}$ revisión del proyecto de ordenación del monte en estudio (Bravo Fernández y Serrada, 2007), a partir de sus respectivos crecimientos y rangos diamétricos.

A continuación, en las tablas 19 a 21 y en las figuras 24 a 26, se resumen los datos correspondientes a la densidad de los distintos bloques de experimentación de las Redes de Muestreo I y II, tanto por clases diamétricas como en promedio; para pies menores, mayores y totales; para pino silvestre y para rebollo.

Tabla 19. Densidad media de pino silvestre (pies/ha) por clase diamétrica en los distintos bloques de experimentación (las clases diamétricas se indican por la marca de clase en $\mathrm{cm}$ ).

\begin{tabular}{|c|c|c|c|c|c|c|c|c|c|c|c|c|c|c|c|}
\hline \multirow{2}{*}{ Bloque } & \multicolumn{15}{|c|}{ Densidad de pino silvestre (pies/ha) por clase diamétrica $(\mathrm{cm})$} \\
\hline & 12,5 & 17,5 & 22,5 & 27,5 & 32,5 & 37,5 & 42,5 & 47,5 & 52,5 & 57,5 & 62,5 & 67,5 & 72,5 & $>75$ & Total \\
\hline \multicolumn{16}{|l|}{ RedM I } \\
\hline NE & 65,9 & 54,2 & 58,6 & 44,7 & 41,8 & 38,1 & 28,6 & 24,9 & 11,0 & 4,4 & 3,7 & 0,7 & 0,0 & 0,7 & 377,3 \\
\hline NW & 31,7 & 30,4 & 27,7 & 21,6 & 29,7 & 23,6 & 10,8 & 16,9 & 4,7 & 4,0 & 8,8 & 2,0 & 0,7 & 6,1 & 218,5 \\
\hline SE & 61,5 & 29,9 & 25,6 & 15,4 & 13,7 & 22,2 & 19,6 & 23,9 & 15,4 & 17,1 & 6,8 & 6,0 & 1,7 & 1,7 & 260,4 \\
\hline$S$ & 8,2 & 6,7 & 8,2 & 10,5 & 3,7 & 11,2 & 22,5 & 27,7 & 27,7 & 17,2 & 18,7 & 9,0 & 5,2 & 12,0 & 188,6 \\
\hline \multicolumn{16}{|c|}{ Red M II } \\
\hline NEn & 38,8 & 28,7 & 32,0 & 28,7 & 28,7 & 23,6 & 32,0 & 23,6 & 16,9 & 8,4 & 1,7 & 0,0 & 1,7 & 0,0 & 264,7 \\
\hline SWn & 24,9 & 22,4 & 12,5 & 20,0 & 37,4 & 42,4 & 24,9 & 39,9 & 32,4 & 22,4 & 7,5 & 2,5 & 0,0 & 0,0 & 289,3 \\
\hline
\end{tabular}


La densidad media de pino silvestre en los bloques de experimentación oscila entre los 188 (S) y los 377 pies/ha (NE). La distribución diamétrica encontrada en el estrato de pino silvestre en todos ellos se corresponde con la de una masa irregular, aunque la distribución de pies entre las distintas clases diamétricas no sea siempre la misma. Así, mientras la zona NE presenta una distribución diamétrica bastante equilibrada, el $S$ y el $S W n$ muestran una mayor abundancia de los pies de diámetros medios $(30-60 \mathrm{~cm})$ en detrimento de los más pequeños $(10-30 \mathrm{~cm})$.

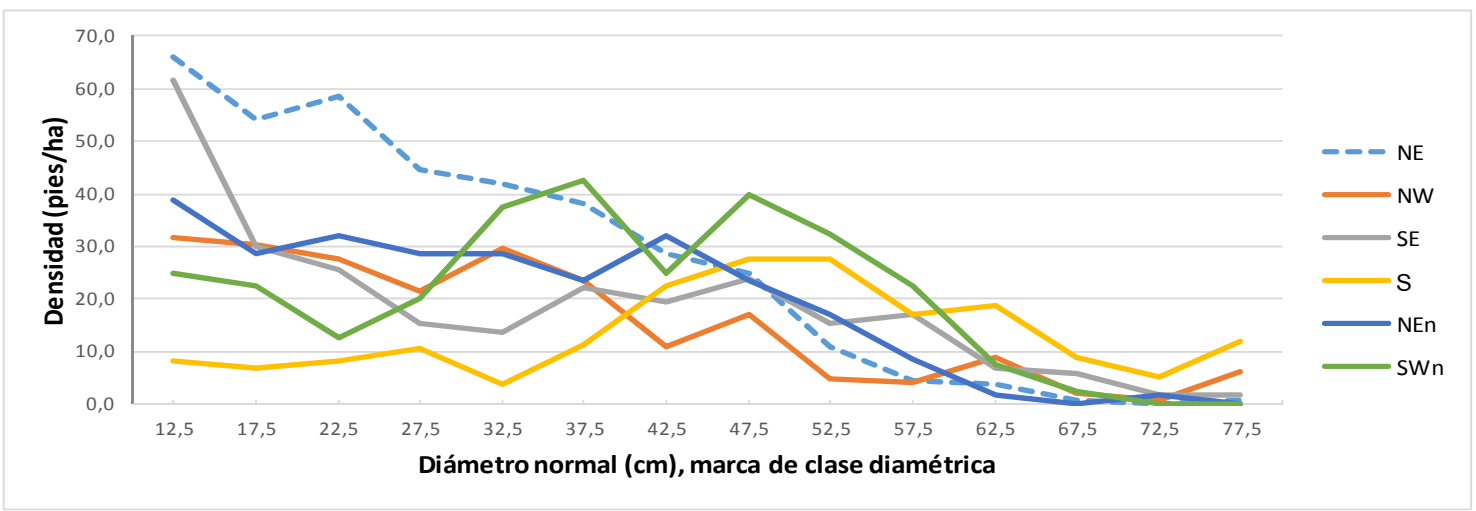

Fig. 24. Representación gráfica de la distribución diamétrica del pino silvestre para los distintos bloques de experimentación.

La densidad del sotobosque de rebollo, por su parte, presenta notables variaciones entre bloques: oscila entre los 499 pies/ha del bloque SE y los 0 pies/ha del SWn. Tal y como puede apreciarse a continuación (tabla 20), en líneas generales encontramos dos bloques con bastante sotobosque de rebollo (SE y S); tres con escasa presencia de esta especie (NE, NW y NEn); y uno del que el rebollo está ausente por completo $(\mathrm{SWn})$. En todos los casos los pies tienen, en su mayoría, diámetros inferiores a $25 \mathrm{~cm}$. Así mismo, cabe destacar que la distribución espacial de los pies de rebollo en las áreas de experimentación no es homogénea: presenta un claro patrón en agregados de amplio radio, como corresponde a pies procedentes mayoritariamente de rebrote de raíz.

Tabla 20. Densidad media de rebollo (pies/ha) por clase diamétrica en los distintos bloques de experimentación (las clases diamétricas se indican por la marca de clase en $\mathrm{cm}$ ).

\begin{tabular}{|c|c|c|c|c|c|c|c|c|c|c|c|c|c|}
\hline \multirow{2}{*}{ Bloque } & \multicolumn{13}{|c|}{ Densidad de rebollo (pies/ha) por clase diamétrica $(\mathrm{cm})$} \\
\hline & 12 & 16 & 20 & 24 & 28 & 32 & 36 & 40 & 44 & 48 & 56 & 60 & Total \\
\hline \multicolumn{14}{|l|}{ RedM I } \\
\hline NE & 34,4 & 11,0 & 5,9 & 3,7 & 2,9 & 0,0 & 2,2 & 0,0 & 0,0 & 0,7 & 0,0 & 0,0 & 60,8 \\
\hline NW & 8,8 & 9,4 & 8,8 & 6,1 & 3,4 & 5,4 & 2,7 & 1,3 & 1,3 & 0,7 & 0,0 & 0,0 & 47,9 \\
\hline SE & 211,7 & 139,1 & 96,5 & 37,6 & 8,5 & 0,9 & 0,0 & 0,0 & 0,0 & 0,9 & 1,7 & 1,7 & 498,5 \\
\hline S & 106,3 & 52,4 & 28,4 & 12,7 & 3,0 & 0,0 & 0,0 & 0,0 & 0,0 & 0,0 & 0,0 & 0,0 & 202,8 \\
\hline \multicolumn{14}{|c|}{ Red M II } \\
\hline NEn & 8,4 & 11,8 & 13,5 & 0,0 & 1,7 & 3,4 & 0,0 & 0,0 & 0,0 & 0,0 & 0,0 & 0,0 & 38,8 \\
\hline SWn & 0,0 & 0,0 & 0,0 & 0,0 & 0,0 & 0,0 & 0,0 & 0,0 & 0,0 & 0,0 & 0,0 & 0,0 & 0,0 \\
\hline
\end{tabular}

Si resumimos las anteriores tablas agrupando los pies en pies menores $(10 \mathrm{~cm}<\mathrm{dn}<20 \mathrm{~cm}$ ) y pies mayores ( $\mathrm{dn}>20 \mathrm{~cm}$ ), tal y como se muestra en la tabla 21, encontramos que en el estrato de silvestre predominan, en todos los casos, los pies mayores, en un porcentaje que ronda el $80 \%$, mientras que en el rebollo son los pies menores los dominantes, en proporción muy similar (fig. 26). En cuanto al número total de pies (silvestre+rebollo), cabe destacar que el bloque con mayor abundancia de pies - bloque SE, con 759 pies/ha duplica de largo al NW, que presenta tan sólo 266,4 pies/ha. Esta importante variabilidad del número total de pies por hectárea en los distintos bloques se debe, en su mayor parte, a los cambios en la densidad del subpiso de rebollo (con mayoría de diámetros $<25 \mathrm{~cm}$ ) (fig. 25). 
Tabla 21. Densidad media (pies/ha) de pies menores $(10 \mathrm{~cm}<\mathrm{dn}<20 \mathrm{~cm})$ y mayores $(\mathrm{dn}>20 \mathrm{~cm})$ ) de pino silvestre y rebollo en los bloques de experimentación.

\begin{tabular}{|c|c|c|c|c|c|c|c|}
\hline \multirow[b]{2}{*}{ Bloque } & \multicolumn{3}{|c|}{ Pino silvestre (pies/ha) } & \multicolumn{3}{|c|}{ Rebollo (pies/ha) } & \multirow[b]{2}{*}{ TOTAL } \\
\hline & $\begin{array}{l}\text { Pies menores } \\
10<\mathrm{dn}<20 \mathrm{~cm}\end{array}$ & $\begin{array}{c}\text { Pies mayores } \\
\mathrm{dn}>20 \mathrm{~cm}\end{array}$ & Total & $\begin{array}{l}\text { Pies menores } \\
10<\mathrm{dn}<20 \mathrm{~cm}\end{array}$ & $\begin{array}{l}\text { Pies mayores } \\
\mathrm{dn}>20 \mathrm{~cm}\end{array}$ & Total & \\
\hline \multicolumn{8}{|l|}{ RedM I } \\
\hline $\mathrm{NE}$ & 120,2 & 257,2 & 377,3 & 49,8 & 11,0 & 60,8 & 438,1 \\
\hline NW & 62,0 & 156,5 & 218,5 & 24,3 & 23,6 & 47,9 & 266,4 \\
\hline SE & 91,3 & 169,0 & 260,4 & 410,6 & 87,9 & 498,5 & 758,9 \\
\hline S & 15,0 & 173,6 & 188,6 & 177,4 & 25,4 & 202,8 & 391,4 \\
\hline \multicolumn{8}{|l|}{ RedM II } \\
\hline NEN & 67,5 & 197,3 & 264,7 & 30,4 & 8,4 & 38,8 & 303,5 \\
\hline SWN & 47,4 & 241,9 & 289,3 & 0,0 & 0,0 & 0,0 & 289,3 \\
\hline
\end{tabular}

En las figuras 25 y 26, a continuación, se resumen gráficamente los totales de densidad encontrados para pino silvestre y rebollo en los distintos bloques de experimentación y su distribución relativa entre pies mayores y pies menores.

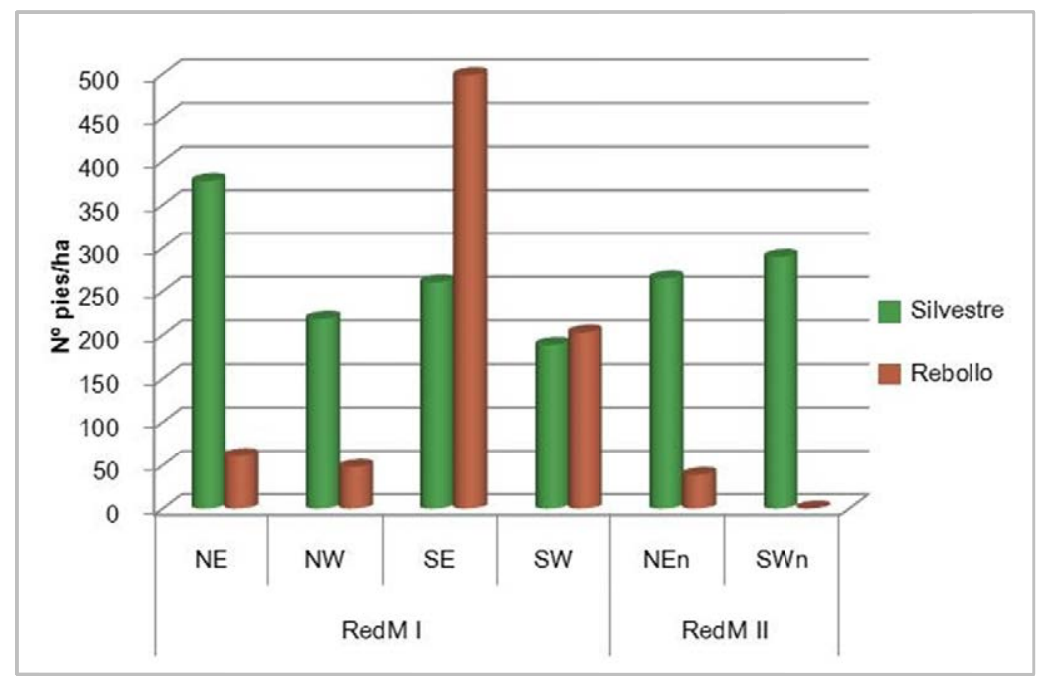

Fig. 25. Densidad total de pino silvestre y rebollo (pies/ha) en los distintos bloques de experimentación.

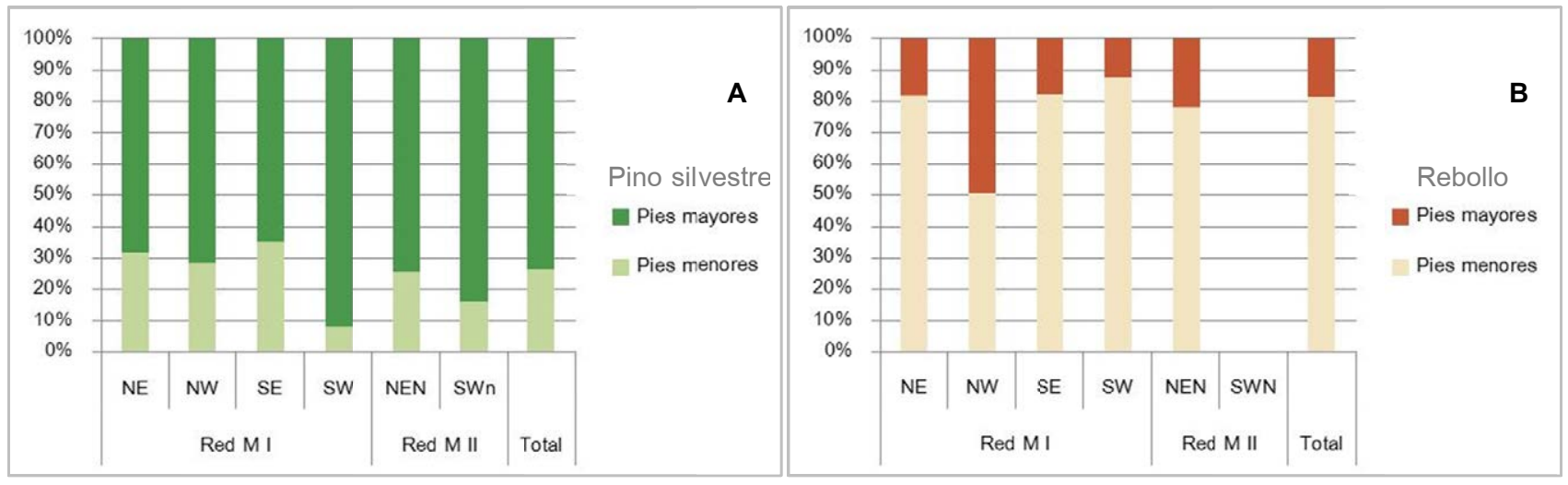

Fig. 26. Porcentajes de pies menores y mayores en el total de pies/ha para cada bloque de experimentación para A) Pino silvestre y B) Rebollo. 


\section{B) ÁREA BASIMÉTRICA Y DIÁMETRO MEDIO CUADRÁTICO}

Como complemento a las distribuciones diamétricas, se resumen a continuación el área basimétrica por hectárea (tabla 22) y el diámetro medio cuadrático (tabla 23) correspodientes al pino silvestre y al rebollo en los distintos bloques de experimentación.

Tabla 22. Área basimétrica por hectárea $\left(\mathrm{m}^{2} / \mathrm{ha}\right)$ de los pies menores $(10<\mathrm{dn}<20 \mathrm{~cm})$, mayores $(\mathrm{dn}>20 \mathrm{~cm})$ y totales de pino silvestre y rebollo en los distintos bloques de experimentación.

\begin{tabular}{|c|c|c|c|c|c|c|c|}
\hline \multirow[b]{2}{*}{ Bloque } & \multicolumn{3}{|c|}{ AB Pino silvestre $\left(\mathrm{m}^{2} / \mathrm{ha}\right)$} & \multicolumn{3}{|c|}{ AB Rebollo ( $\left.\mathrm{m}^{2} / \mathrm{ha}\right)$} & \multirow[b]{2}{*}{ TOTAL } \\
\hline & $\begin{array}{c}\text { Pies } \\
\text { menores }\end{array}$ & $\begin{array}{c}\text { Pies } \\
\text { mayores }\end{array}$ & Total & $\begin{array}{c}\text { Pies } \\
\text { menores }\end{array}$ & $\begin{array}{c}\text { Pies } \\
\text { mayores }\end{array}$ & Total & \\
\hline \multicolumn{8}{|l|}{ RedM I } \\
\hline $\mathrm{NE}$ & 2,2 & 26,5 & 28,7 & 0,7 & 0,8 & 1,5 & 30,2 \\
\hline NW & 1,1 & 21,5 & 22,6 & 0,5 & 1,8 & 2,2 & 24,8 \\
\hline SE & 1,5 & 26,3 & 27,7 & 6,8 & 4,7 & 11,4 & 39,1 \\
\hline$S$ & 0,3 & 38,8 & 39,0 & 2,8 & 1,1 & 3,9 & 42,9 \\
\hline \multicolumn{8}{|l|}{ RedM II } \\
\hline NEn & 1,2 & 23,7 & 24,9 & 0,6 & 0,5 & 1,1 & 26 \\
\hline SWn & 0,9 & 36,2 & 37,1 & 0,0 & 0,0 & 0,0 & 37,1 \\
\hline
\end{tabular}

Tabla 23. Diámetro medio cuadrático $(\mathrm{cm})$ de los pies menores $(10<\mathrm{dn}<20 \mathrm{~cm})$, mayores $(\mathrm{dn}>20 \mathrm{~cm})$ y totales de silvestre y rebollo en los distintos bloques de experimentación.

\begin{tabular}{|c|c|c|c|c|c|c|}
\hline \multirow{3}{*}{ Bloque } & \multicolumn{6}{|c|}{ Diámetro medio cuadrático $(\mathrm{cm})$} \\
\hline & \multicolumn{3}{|c|}{ Pino silvestre } & \multicolumn{3}{|c|}{ Rebollo } \\
\hline & Pies menores & Pies mayores & Total & Pies menores & Pies mayores & Total \\
\hline \multicolumn{7}{|l|}{ RedM I } \\
\hline NE & 15,2 & 36,2 & 31,1 & 13,6 & 29,8 & 17,7 \\
\hline NW & 15,2 & 41,8 & 36,3 & 15,5 & 31,1 & 24,5 \\
\hline SE & 14,3 & 44,5 & 36,8 & 14,5 & 26,0 & 17,1 \\
\hline S & 14,9 & 53,3 & 51,3 & 14,1 & 23,3 & 15,6 \\
\hline \multicolumn{7}{|l|}{ RedM II } \\
\hline NEn & 14,9 & 39,1 & 34,6 & 16,1 & 26,4 & 18,8 \\
\hline SWn & 15,4 & 43,6 & 40,4 & & & \\
\hline
\end{tabular}

Las $A B$ medias observadas oscilan entre los 25 y los $42 \mathrm{~m}^{2} /$ ha. Salvo en el bloque $S E$ (en que el porcentaje se triplica), el rebollo apenas supone un $5-10 \%$ del $A B$ total. Los bloques con mayores $A B$ por hectárea son el $\mathrm{S}\left(42,9 \mathrm{~m}^{2} / \mathrm{ha}\right)$, el SE $\left(39,1 \mathrm{~m}^{2} / \mathrm{ha}\right)$ y el SWn $\left(37,1 \mathrm{~m}^{2} / \mathrm{ha}\right)$, frente al NW y Nen que, con 24,8 y $26 \mathrm{~m}^{2} / \mathrm{ha}$, respectivamente, presentan los valores más bajos. Los bloques $S$ y SWn presentan, además, los mayores diámetros medios cuadráticos de silvestre con $51,3 \mathrm{~cm}$ y $40,4 \mathrm{~cm}$ respectivamente. En el resto de bloques los diámetros medios cuadráticos del silvestre oscilan entre 31 y $36 \mathrm{~cm}$. El rebollo presenta diámetros medios cuadráticos muy inferiores a los del pino: oscilan, en su mayoría, entre los 15 y los $18 \mathrm{~cm}$, por lo que destaca por su relativa entidad el diámetro medio cuadrático de $24,5 \mathrm{~cm}$ del NW, del que ya se ha hablado antes.

\section{C) Alturas}

Las alturas medias de los pies de silvestre son bastante similares en todos los bloques: : oscilan entre 9,3 y 10,8 m para los pies menores y entre 19,2 y 20,9 m para los pies mayores (tabla 24). Sólo el bloque NW presenta una altura media de los pies mayores considerablemente inferior al resto: 15,7 m. Y ello, a pesar de que su diámetro medio cuadrático y su densidad son similares a la media. 
Las alturas medias totales (pies menores y pies mayores) en las áreas de experimentación presentan mayores oscilaciones, como consecuencia de la proporción variable de pies menores y mayores presente en los distintos bloques. Así, frente al 1,5 m de oscilación en las alturas de menores y mayores por separado, la altura media total varía en más de $6 \mathrm{~m}$ entre los $20 \mathrm{~m}$ del $\mathrm{S}$ y los 13,9 del NW.

Por su parte, la razón de copa media de la masa oscila entre el 55 y el 67\%, con una altura de inicio de copa entre los 4,5m y los 8,6 m. En general los pies menores presentan mayores razones de copa que los pies mayores. Destacan por su singularidad los pies menores del NE, cuya razón de copa es muy inferior a la media, y los pies mayores del NW, con una razón de copa mucho mayor que la de los demás bloques.

En la tabla que se inserta a continuación se ha hecho constar también la altura dominante, aunque esta variable sólo tenga sentido, como indicadora de la calidad de estación junto con la edad de la masa, cuando se analizan masas regulares. En este caso sirve para reflejar la altura de los pies más altos encontrados (que van a pertenecer a diferentes clases de edad) - que se encuentran en los bloques $S$ y $N E$ - y pone claramente de manifiesto que el bloque NW presenta una masa de menor altura que el resto de bloques.

Tabla 24. Alturas medias $(\mathrm{m})$, alturas de la primera rama viva $(\mathrm{m})$ y razón de copa de los pies menores $(10<\mathrm{dn}<20$ $\mathrm{cm}$ ), mayores $(\mathrm{dn}>20 \mathrm{~cm}$ ) y totales de pino silvestre en los distintos bloques de experimentación. Altura dominante (m) por bloque.

\begin{tabular}{|c|c|c|c|c|c|c|c|c|c|c|}
\hline \multirow[b]{2}{*}{ Bloque } & \multicolumn{3}{|c|}{ Pies menores } & \multicolumn{3}{|c|}{ Pies mayores } & \multicolumn{4}{|c|}{ Total } \\
\hline & Hmedia & Hсора & $\begin{array}{c}\text { Razón } \\
\text { de copa }\end{array}$ & Hmedia & Hсора & $\begin{array}{l}\text { Razón } \\
\text { de copa }\end{array}$ & Hmedia & Hсора & $\begin{array}{l}\text { Razón } \\
\text { de copa }\end{array}$ & Hdom \\
\hline $\mathrm{NE}$ & 10,5 & 4,9 & 53,3 & 19,2 & 7,7 & 59,9 & 16,4 & 6,8 & 58,5 & 24,6 \\
\hline NW & 9,3 & 3,1 & 66,7 & 15,7 & 5,0 & 68,2 & 13,9 & 4,5 & 67,6 & 18,7 \\
\hline SE & 9,4 & 3,5 & 62,8 & 18,9 & 7,5 & 60,3 & 15,6 & 6,1 & 60,9 & 22,4 \\
\hline $\mathrm{S}$ & 9,6 & 3,7 & 61,5 & 20,9 & 9,0 & 56,9 & 20,0 & 8,6 & 57,0 & 24,7 \\
\hline NEn & 10,8 & 4,1 & 62,0 & 19,2 & 8,5 & 55,7 & 17,0 & 7,4 & 56,5 & 20,3 \\
\hline SWn & 9,4 & 3,5 & 62,8 & 20,6 & 9,2 & 55,3 & 18,7 & 8,3 & 55,6 & 20,3 \\
\hline
\end{tabular}

Hmedia: altura media (m); Hcopa: altura de inserción de la primera rama viva del árbol (m), Hdom: altura dominante (m); Razón de copa (\%)

En la tabla 25 se aportan las alturas medias, las alturas de inicio de copa y las fracciones de copa del rebollo. Tal y como era de esperar, las alturas de los pies mayores son inferiores a las del silvestre (media de aproximadamente $13 \mathrm{~m}$ frente a los 19 del silvestre), mientras que las de los pies menores son muy similares en ambas especies. Las fracciones de copa son mucho más elevadas que las del silvestre, especialmente en los pies mayores, debido a que el rebollo presenta alturas de inicio de copa mucho menores que las del pino (3,3 m frente a 6,9 m).

Tabla 25. Alturas medias y alturas de la primera rama viva $(\mathrm{m})$ de los pies menores $(10<\mathrm{dn}<20 \mathrm{~cm})$, mayores $(\mathrm{dn}>20 \mathrm{~cm})$ y totales de rebollo en los distintos bloques de experimentación.

\begin{tabular}{|c|c|c|c|c|c|c|c|c|c|}
\hline \multirow[b]{2}{*}{ Bloque } & \multicolumn{3}{|c|}{ Pies menores } & \multicolumn{3}{|c|}{ Pies mayores } & \multicolumn{3}{|c|}{ Total } \\
\hline & Hmedia & Hcopa & $\begin{array}{c}\text { Razón } \\
\text { de copa }\end{array}$ & Hmedia & Hcopa & $\begin{array}{c}\text { Razón } \\
\text { de copa }\end{array}$ & Hmedia & Hcopa & $\begin{array}{l}\text { Razón } \\
\text { de copa }\end{array}$ \\
\hline NW & 9,4 & 2,5 & 73,4 & 14,6 & 2,8 & 80,8 & 11,9 & 2,6 & 78,2 \\
\hline SE & 9,9 & 4,0 & 59,6 & 14,2 & 4,8 & 66,2 & 10,7 & 4,1 & 61,7 \\
\hline NEn & 10,3 & 2,9 & 71,8 & 12,8 & 2,5 & 80,5 & 10,8 & 2,8 & 74,1 \\
\hline SWn & & & & & & & & & \\
\hline
\end{tabular}

Hmedia: altura media $(\mathrm{m})$; Hcopa: altura de inserción de la primera rama viva del árbol (m), Hdom: altura dominante $(\mathrm{m})$. 


\subsubsection{ReGENERACIÓN}

La regeneración se valora únicamente para el pino silvestre. Para su cuantificación se consideran las siguientes categorías, tomadas de Bravo Fernández y Serrada (2007):

$$
\begin{aligned}
& \cdot h<0,30 \mathrm{~m} \\
& \cdot 0,30<\mathrm{h}<1,30 \mathrm{~m} \\
& \cdot \mathrm{h}>1,30 \mathrm{~m} \text { y dn }<5 \mathrm{~cm} \\
& \cdot \mathrm{h}>1,30 \mathrm{~m} \text { y } 10>d \mathrm{c}>5 \mathrm{~cm}
\end{aligned}
$$

La densidad de regenerado encontrada en los bloques de experimentación se resume a continuación numérica (tabla 26) y gráficamente (fig. 27). Los datos obtenidos son, en general, algo escasos, aunque varían considerablemente entre zonas. Básicamente encontramos dos bloques con niveles de regeneración un poco más abundantes (NEn y SWn, con 1200 y 1028 pies/ha); tres con niveles bajos (NE, NW y SE, con regeneración en torno a los 230 pies/ha); y uno con regenerado muy escaso (S, con menos de 50 pies/ha).

Con respecto a los dos bloques en los que la regeneración es marcadamente más elevada (NEn y SWn, correspondientes a la Red de Muestreo II), ,cabe destacar que: 1) la mayoría de la regeneración encontrada en el bloque NEn estaba concentrada en un lateral de su superficie, sobre unas líneas de decapado realizadas, a modo de prueba, dos años atrás con la pala del skider que habitualmente trabaja en el monte; 2) el bloque SWn linda en un lateral con el límite de un rodal en el que se habían realizado cortas poco tiempo antes de los ensayos y mediciones, por lo que la presencia de cierta cantidad de diseminado recién instalado en la franja colindante con el rodal puede explicarse como consecuencia de la mayor insolación lateral en ese área. Ambas zonas quedaban, en cualquier caso, lejos de las zonas de influencia de las parcelas de estudio, pero ponen de manifiesto los efectos que los tratamientos sobre el suelo y la mayor puesta en luz parecen tener sobre la aparición de regenerado.

En cuanto al bloque que apenas presenta regeneración (S), reúne una serie de características que podrían contribuir a esta circunstancia: 1) distribución diamétrica del silvestre desplazada hacia las clases de edad de fustal medio y fustal viejo con baja densidad de pies, elevado diámetro medio cuadrático y elevada área basimétrica; 2) considerable presencia de rebollo de baja talla (se trata del segundo bloque con mayor densidad de esta especie); 3) orientación solana pura.

Tabla 26. Densidad media del regenerado (pies/ha) de pino silvestre en los distintos bloques de experimentación.

\begin{tabular}{lccccc}
\hline & \multicolumn{5}{c}{ Densidad del regenerado (pies/ha) } \\
\cline { 2 - 6 } Bloque & $\mathrm{h}<0,3 \mathrm{~m}$ & $0,3<\mathrm{h}<1,3 \mathrm{~m}$ & $\begin{array}{c}\mathrm{h}<1,3 \mathrm{~m}, \\
\mathrm{dn}<5 \mathrm{~cm}\end{array}$ & $\begin{array}{c}\mathrm{h}>1,3 \mathrm{~m} \\
5<\mathrm{dn}<10 \mathrm{~cm}\end{array}$ & Total \\
\hline RedM.I & & & & & \\
NE & 75,5 & 92,3 & 68,1 & 50,6 & 287,5 \\
NW & 83,6 & 16,2 & 34,4 & 43,2 & 177,4 \\
SE & 89,6 & 15,4 & 58,9 & 56,3 & 220,2 \\
S & 5,2 & 5,2 & 17,2 & 20,2 & 47,9 \\
\hline Red M II & & & & & \\
NEn & 811,1 & 283,3 & 65,8 & 40,5 & 1200,6 \\
SWn & 663,5 & 149,7 & 164,6 & 49,9 & 1027,6 \\
\hline
\end{tabular}

Sup: superficie total inventariada en cada bloque de experimentación (ha); h: altura total (m); dn: diámetro normal $(\mathrm{cm})$ 


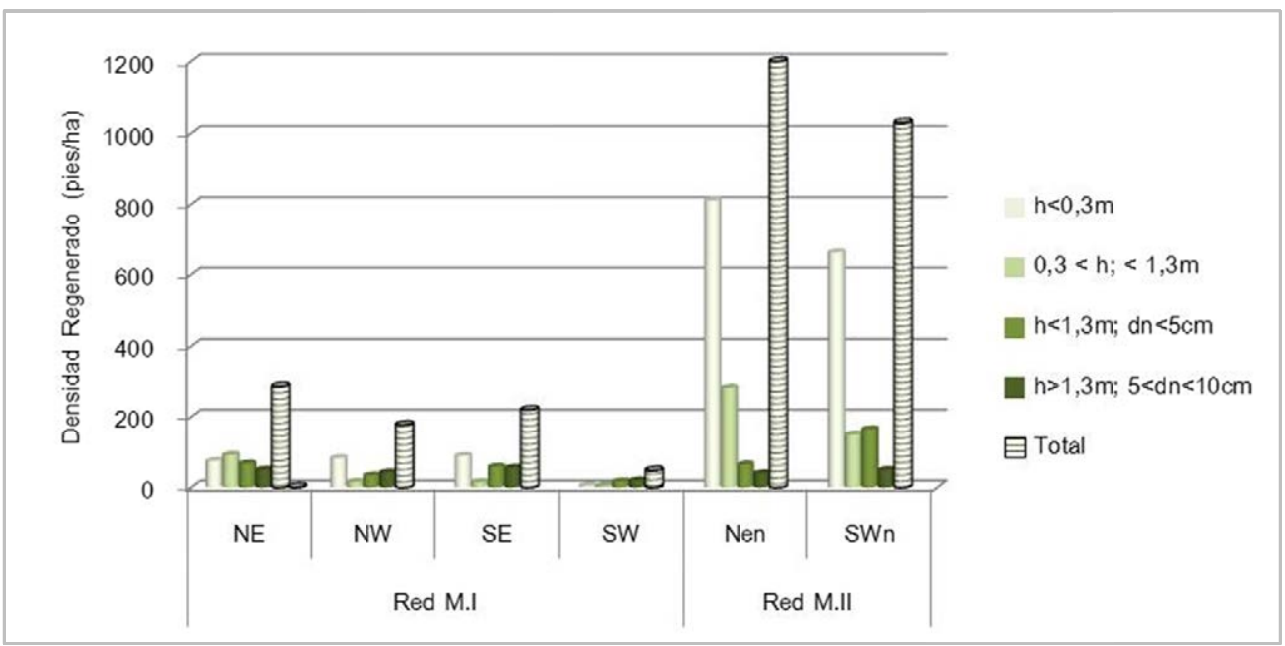

Fig. 27. Densidad media del regenerado de pino silvestre (pies/ha) en los bloques de experimentación de las dos Redes de muestreo (Red M I y Red M II).

\subsubsection{SínTESIS DEL ESTAdO DE LA MASA EN LOS BLOQUES DE EXPERIMENTACIÓN}

En definitiva y como resumen general de la caracterización de la masa en la zona de estudio hay que decir que:

1) En cinco de los seis bloques experimentales nos encontramos con un monte medio irregular de pino silvestre y rebollo. El estrato superior de pino domina claramente en la mayoría de ellosi, pero el rebollo está presente también en todos, excepto en el SWn. El bloque SE es el que cuenta con un subpiso de rebollo más desarrollado, como refleja su elevada área basimétrica. En general, el rebollo presenta una distribución espacial en agregados.

2) La distribución diamétrica del pino silvestre se corresponde en todos los casos con una masa irregular, no necesariamente pie a pie sino por mezcla de bosquetes, en cuyo interior podemos encontrar masas regulares o semirregulares de diferentes edades.

3) Los valores de regeneración parecen, en general, escasos.

A continuación se describen, a título orientativo, las particularidades de la masa en cada uno de los bloques de experimentación contemplados. Una vez más hay que poner de manifiesto que, dado que la masa presenta irregularidad por agregación de boquetes en distinto estado de desarrollo, los valores medios no son representativos de las condiciones particulares de cada bosquete, que se tratarán en el apartado siguiente.

NE

- Distribución equilibrada de clases de edad en el estrato de pino silvestre, con mayor densidad de las clases inferiores en detrimento de las clases superiores. Es el bloque con mayor densidad de pino silvestre (377 pies/ha).

- Presencia escasa de rebollo, con predominio de pies menores (80\%).

- Densidad total, área basimétrica y diámetro medio cuadrático próximos a la media inter-bloques.

- Altura dominante del silvestre superior a la de la mayoría de bloques $(24,3 \mathrm{~m})$.

- Existencia de regenerado, pero con baja densidad (287 pies/ha). 
- Distribución equilibrada de clases de edad para el pino silvestre, aunque con escasa presencia de los pies más finos $(10-15 \mathrm{~cm})$.

- Presencia escasa de rebollo, pero con un porcentaje de pies mayores de la especie superior al del resto de bloques (cerca del 50\%).

- Es el bloque con menores densidad total (tanto en pino como en rebollo), AB/ha y altura dominante, a pesar de presentar un diámetro medio cuadrático en torno a la media interbloque. En definitiva, está poblado por menos pies, de diámetros medios similares a los de otros bloques pero de menor altura.

- Existencia de regenerado, pero con baja densidad (177,4 pies/ha).

SE

- Distribución equilibrada de clases de edad para el pino silvestre, con densidad en torno a la media (260 pies/ha).

- Es el bloque con mayor densidad total (758 pies/ha), debida a la elevada presencia de rebollo (casi 500 pies/ha). Entre los pies de rebollo hay un $80 \%$ de menores.

- Elevada $A B /$ ha media (casi $39 \mathrm{~m} 2 / \mathrm{ha}$ ), debida a los $11,4 \mathrm{~m}^{2} /$ ha de rebollo. Diámetro medio cuadrático y alturas en torno a la media interbloque, tanto para silvestre como para rebollo.

- Existencia de regenerado, pero con baja densidad (220 pies/ha).

S

- Distribución diamétrica del silvestre bastante desplazada hacia los diámetros altos $(>40 \mathrm{~cm})$. Presenta un bajo número de pies/ha de pino (el menor de todos los bloques), pero de grandes dimensiones (diámetro medio cuadrático de $51,3 \mathrm{~cm}$ ), de forma que el $A B /$ ha de pino es la más alta de todos los bloques (39 $\mathrm{m} 2 / \mathrm{ha})$.

- Presencia abundante de rebollo de baja talla (202 pies/ha, con 90\% de menores).

- Regeneración prácticamente inexistente (48 pies/ha).

NEn

- Distribución diamétrica equilibrada para el silvestre. Densidad y resto de parámetros cercanos al comportamiento medio interbloques.

- Baja presencia de rebollo ( $80 \%$ de pies menores).

- Regeneración más alta que en los bloques de la RM I (1200 pies/ha).

SWn

- Distribución diamétrica del silvestre bastante desplazada hacia los diámetros altos. Elevados diámetro medio cuadrático $(40 \mathrm{~cm})$ y $\mathrm{AB} / \mathrm{ha}\left(37 \mathrm{~m}^{2} / \mathrm{ha}\right)$.

- Ausencia de rebollo.

- Regeneración mucho mayor que en los bloques de la RM I (1028 pies/ha), como ocurre en el NEn. 


\subsubsection{CARACTERIZACIÓN DE LA ESPESURA EN TORNO A LOS PUNTOS DE MEDICIÓN}

El área basimétrica es uno de los parámetros de uso habitual para la toma de decisiones selvícolas así como para la definición de las actuaciones a realizar. Caracteriza apropiadamente la espesura a nivel de rodal y resulta por tanto adecuada para gestionar las masas a esta escala incluyendo, claro está, la regeneración de las mismas.

Cuando medimos áreas basimétricas para un rodal en un determinado estado de desarrollo y manejamos la espesura mediante tratamientos selvícolas para fomentar la regeneración, lo que conseguimos es aumentar el número de puntos en los que se dan las condiciones de luz, temperatura y disponibilidad hídrica para que comience la instalación del regenerado. Eso no quiere decir que todos los puntos sean viables, quiere decir que hay una serie de ellos que sí lo son y que su densidad en el conjunto es suficiente. Qué hueco necesitan las semillas y plántulas para instalarse no está claro cómo ha de medirse. No está claro qué radio de parcela debe considerarse cuando lo que queremos no es caracterizar la media de espesura de un rodal a fin de saber si permitirá o no la existencia de un número suficiente de puntos viables para el regenerado, sino saber si en un punto concreto el hueco es suficiente o no.

¿Qué es un hueco suficiente? ¿Importa sólo el hueco por encima y en el entorno cercano al punto o importa también la masa que tiene alrededor?

Cuando lo que se pretende valorar, como en el presente estudio, es el modo en que la espesura afecta a las condiciones ambientales de un punto en concreto (y no la media general de una zona), cabe plantearse si el área basimétrica resulta o no un parámetro adecuado y, caso de serlo, cuál es el tamaño de parcela en torno al punto en el que sería idóneo valorarla.

Gran parte de los efectos del dosel arbóreo sobre las condiciones ambientales en cada punto concreto bajo cubierta están ligadas a la intercepción de la luz y de la precipitación incidente en dicho punto, lo que viene, a su vez, determinado por la cantidad, tamaño y disposición espacial de los huecos en el hemisferio por encima del punto. Se considera, por tanto, que una buena forma de determinar la idoneidad del área basimétrica para describir las condiciones puntuales bajo cubierta y establecer su radio óptimo de medición es comprobar el grado de correlación de sus mediciones con las correspondientes mediciones de huecos en el dosel.

En los apartados siguientes se analizan las mediciones de espesura realizadas sobre la masa en torno a cada unidad experimental, junto con la caracterización de la estructura de huecos del dosel y su comportamiento lumínico - obtenida a partir de fotografías de ojo de pez -, a fin de seleccionar un radio óptimo de evaluación del $A B$ que permita caracterizar adecuadamente la masa de cara al estudio de los procesos de regeneración en dichas unidades experimentales. 


\subsubsection{RELACIÓN DEL ÁREA BASIMÉTRICA EN TORNO A UN PUNTO CON LA PROPORCIÓN DE HUECOS EN EL DOSEL POR ENCIMA DE ÉL.}

Para cada una de las unidades experimentales de la Red de muestreo I se calcularon:

1) el porcentaje de huecos en el dosel (\%HD) por encima de cada una de ellas en 40 casquetes esféricos de ángulo cenital creciente (explicaciones detalladas en el apartado 3.4.1. Esquema de análisis de resultados) entre 0 y $90^{\circ}$. Dado que para cada punto se realizaron dos fotografías hemisféricas, una en verano y otra en primavera, antes de la foliación del rebollo, los porcentajes de huecos se calcularán estos porcentajes para ambos períodos (\%HDverano y \%HDprimavera).

2) el área basimétrica de pino, rebollo y total (ABpino, ABrebollo y ABtot) en torno al centro de la unidad experimental y en radios de $5,10,15,20$ y $25 \mathrm{~m}$.

Por lo tanto, en cada punto de los 192 de la Red de muestreo I se obtuvieron 80 porcentajes de huecos del dosel (dos - primavera y verano - para cada tamaño de casquete esférico) y 15 áreas basimétricas (tres ABtot, ABpino y ABrebollo - para cada radio de parcela entre 5 y $25 \mathrm{~m}$ ). A partir de esas mediciones, se calcularon los coeficientes de correlación entre los valores de área basimétrica y los de los porcentajes de huecos en cada tamaño de casquete, a fin de encontrar en los hemisferios situados sobre cada punto de muestreo el ángulo de influencia de los pies ubicados a las distintas distancias del punto.

A priori, los pies más cercanos ocupan el casquete esférico que queda casi en la vertical del punto y, a medida que los pies van estando más lejos, sus copas sombrean en ángulos cenitales más bajos (figura 28). No obstante, estas relaciones dependen de la estructura horizontal y vertical de la masa (particularmente, de la altura total de los árboles y de la altura de inicio de copa), por lo que la distancia variará en función de las características generales de la masa.

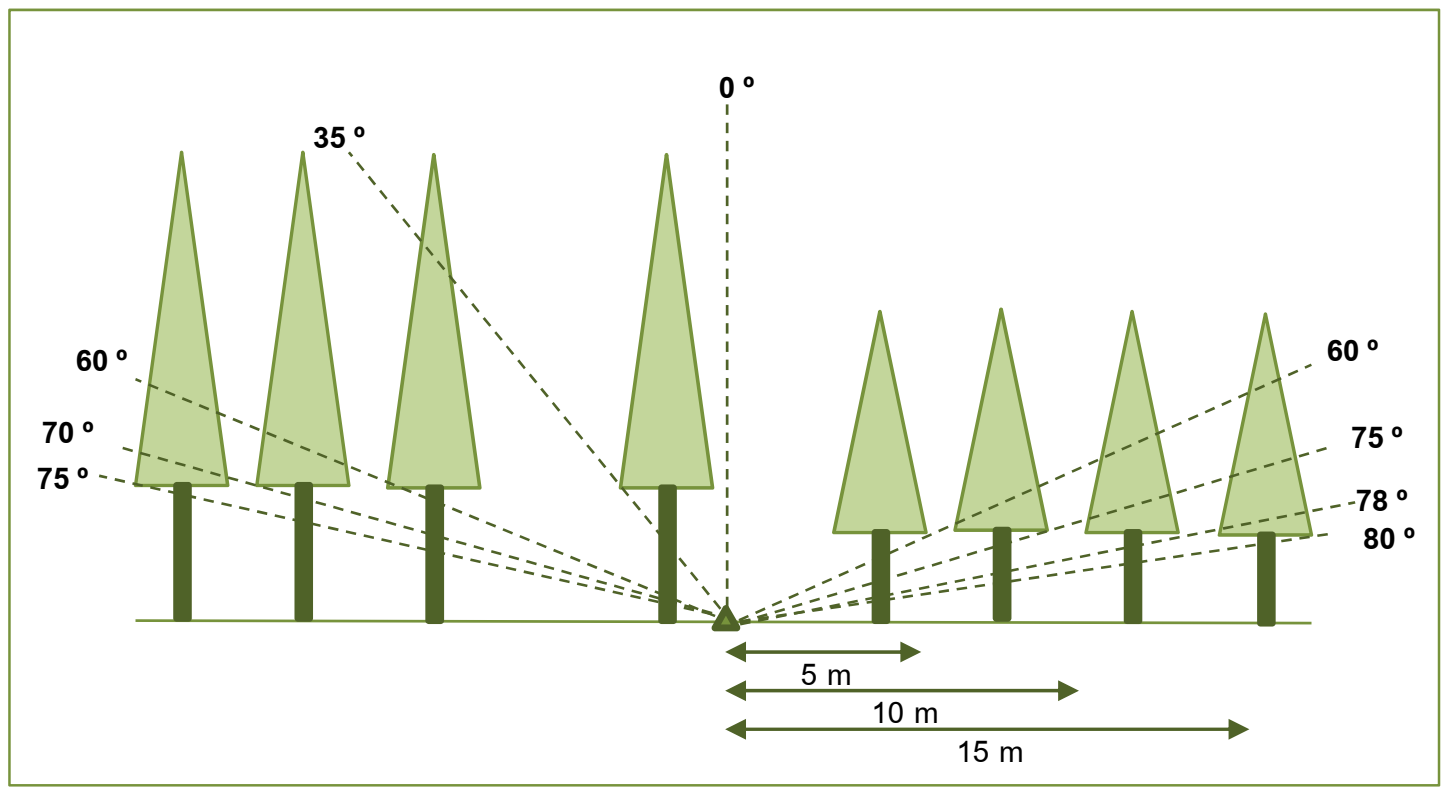

Fig. 28. Influencia de los pies en el índice de huecos en el hemisferio sobre un punto bajo cubierta en función de su distancia horizontal al mismo. 
Los resultados obtenidos muestran que, tal y como cabía esperar, la máxima correlación entre el área basimétrica (ya sea ABtot, ABpino o ABrebollo) y el porcentaje de huecos se produce en ángulos cenitales mayores a medida que aumenta el radio de estimación del $A B$ en torno al punto. Es decir: a medida que se van tomando árboles más lejanos al punto de muestreo, su influencia en el hemisferio sobre el punto se produce en un ángulo más bajo. Así mismo, tal y como puede verse en la figura 29 - en la que se representan los coeficientes de correlación entre las $A B$ totales y los porcentajes de huecos del dosel correspondientes al verano -, el coeficiente máximo alcanzado para cada radio de estimación del $A B$ va siendo más elevado a medida que aumenta dicho radio. Este incremento se produce hasta una cierta distancia, a partir de la cual meter árboles más lejanos ya no mejora las estimaciones del índice de huecos del dosel, por mucho que aumentemos el ángulo cenital considerado (el máximo coeficiente de correlación empieza a decrecer). Cabe suponer que los árboles ubicados por encima de esa distancia contabilizan en $A B$, pero sus copas apenas tienen influencia sobre el punto de muestreo. En el caso del ABtotal frente al \%Hdverano, el máximo de correlación es prácticamente el mismo para la parcela de 15 y 20 metros, aunque en el primer caso dicho máximo corresponde a un ángulo cenital de $55^{\circ}$, mientras que en el segundo tendría lugar con el \%HD correspondiente al casquete esférico de $66^{\circ}$.

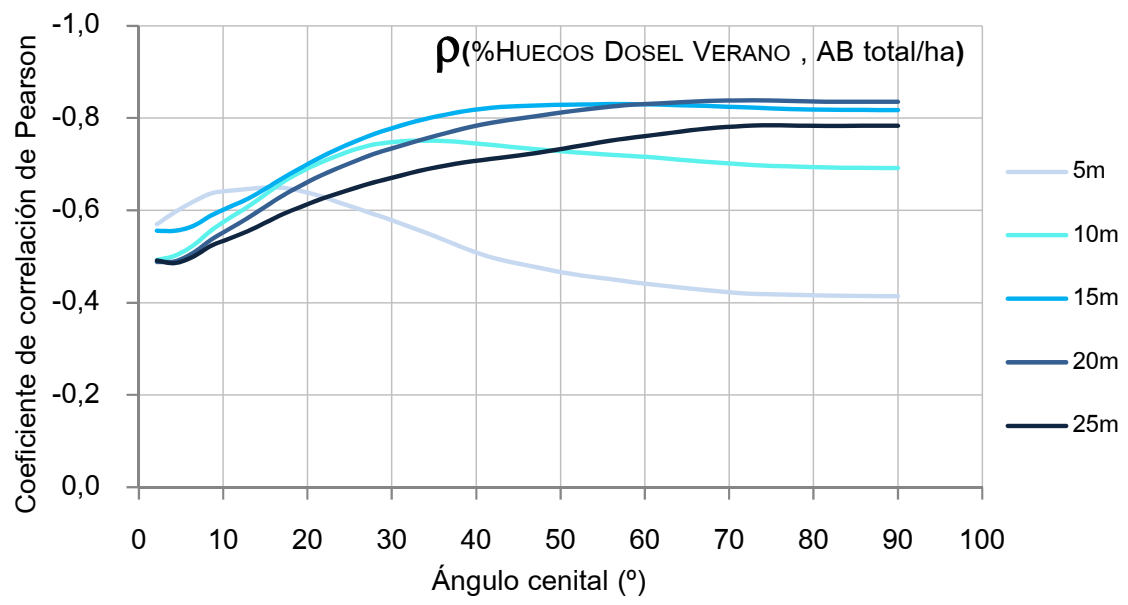

Fig. 29. Coeficientes de correlación lineal entre el porcentaje de huecos del dosel (Sky fraction) en casquetes de ángulo cenital creciente durante la primavera y el $A B / h a$ de pino en torno al punto medida en parcelas de radio creciente $(5,10,15,20$ y $25 \mathrm{~m})$.

Con respecto a los tipos de área basimétrica calculados y a los distintos períodos de muestreo del índice de huecos del dosel (primavera/verano), hay que decir que el $A B$ total mostró mejores correlaciones con el \%HD del verano (que tiene en cuenta tanto el rebollo como el pino), mientras que el $A B$ del pino se correlacionó ligeramente mejor con el \%HD de primavera. Por último, el $\mathrm{AB}$ del rebollo, que es claramente minoritaria en prácticamente todos los puntos de muestreo, presentó correlaciones mucho más bajas que las otras dos tanto con el \%HD de primavera como con el de verano. Su mejor correlación se dio, precisamente, con la diferencia entre ambas (\%HD verano - \%HDprimavera); lo que resulta muy lógico, ya que esta diferencia refleja, precisamente, la incorporación de las hojas del rebollo al dosel tras su caída durante el invierno. Las combinaciones de radio y ángulo cenital con máximo coeficiente de correlación absoluto para cada especie y época de muestreo se muestran en la tabla 27.

Los radios de muestreo a los que se consiguieron los máximos absolutos de correlación oscilaron, por lo general, entre los 15 y los $20 \mathrm{~m}$. En cuanto a los ángulos cenitales, únicamente hay que señalar que, a igualdad de radio de muestreo del área basimétrica, los máximos para el rebollo se produjeron siempre en ángulos cenitales más bajos que para el pino, lo que podría tener relación con la menor altura de inicio de copa del rebollo (altura de inserción de la primera rama de 3,3, m frente a los 6,95 m del silvestre). 
Tabla 27 Coeficientes de correlación máximos entre el porcentaje de huecos en el dosel (\%HD) y el AB para cada tipo de área basimétrica (rebollo, pino o ambas) y tipo de \%HD en función del período de muestreo (primavera, verano, verano-primavera). Para cada combinación se indican el valor del coeficiente máximo y el radio de estimación de $\mathrm{AB}$ y ángulo cenital en el que se produce.

\begin{tabular}{|c|c|c|c|c|c|c|c|c|c|}
\hline & \multicolumn{3}{|c|}{$\rho$} & \multicolumn{3}{|c|}{ Radio (m) } & \multicolumn{3}{|c|}{${ }^{\circ}$ Cenital } \\
\hline & $\% \mathrm{HDp}$ & $\% \mathrm{HDV}$ & $\% H D(v-p)$ & $\% H D p$ & $\% \mathrm{HDV}$ & $\% H D(v-p)$ & $\% H D p$ & $\% \mathrm{HDV}$ & $\% H D(v-p)$ \\
\hline Rebollo & $-0,317$ & $-0,595$ & $-0,720$ & 10 & 25 & 15 & 62,1 & 79,3 & 81,4 \\
\hline Pino & $-0,748$ & $-0,714$ & $-0,178$ & 15 & 15 & 5 & 55,7 & 47,1 & 12,9 \\
\hline \multirow{2}{*}{ Total } & $-0,786$ & $-0,838$ & \multirow{2}{*}{$-0,415$} & 20 & 20 & \multirow{2}{*}{25} & 66,4 & 72,9 & \multirow{2}{*}{45} \\
\hline & $-0,782$ & $-0,830$ & & 15 & 15 & & 55,7 & 55,7 & \\
\hline
\end{tabular}

$\rho$ :máximo coeficiente de correlación de Pearson encontrado entre el $A B$ y el \%HD que se indican; Radio: radio de estimación del correspondiente AB (en m); ${ }^{\circ}$ Cenital: ángulo cenital de estimación de los \%HD; \%HDp: porcentaje de huecos del dosel en primavera; \%HDv: porcentaje de huecos del dosel en verano; \%HD(v-p): diferencia entre el porcentaje de huecos del dosel de verano y primavera.

En cualquier caso, los coeficientes del rebollo presentan unas tendencias mucho más difusas debido a su irregular y muchas veces escasa presencia en la masa. Los coeficientes de correlación entre el área basimétrica de pino y rebollo y los correspondientes \%HDprimavera y \%HDverano-primavera se aportan en las figuras 30 y 31 .

Como puede observarse en la figura 30, cada radio de muestreo de AB representa de forma óptima el \%HD de un ángulo cenital: radios mayores pueden mejorar el coeficiente de correlación absoluto, pero no la estimación para ese ángulo cenital concreto. Ello implica que, dependiendo del ángulo cenital al que se produzcan los procesos que queramos representar, tendrá más sentido realizar las estimaciones de área basimétrica en un radio u otro. Por ejemplo: en el caso de la intercepción de la precipitación, el área basimétrica más adecuada sería la del entorno de $5 \mathrm{~m}$, mientras que para radiación difusa lo adecuado será, probablemente, tomar el radio con el coeficiente a mayor ángulo cenital, que en este caso sería el r=20m.

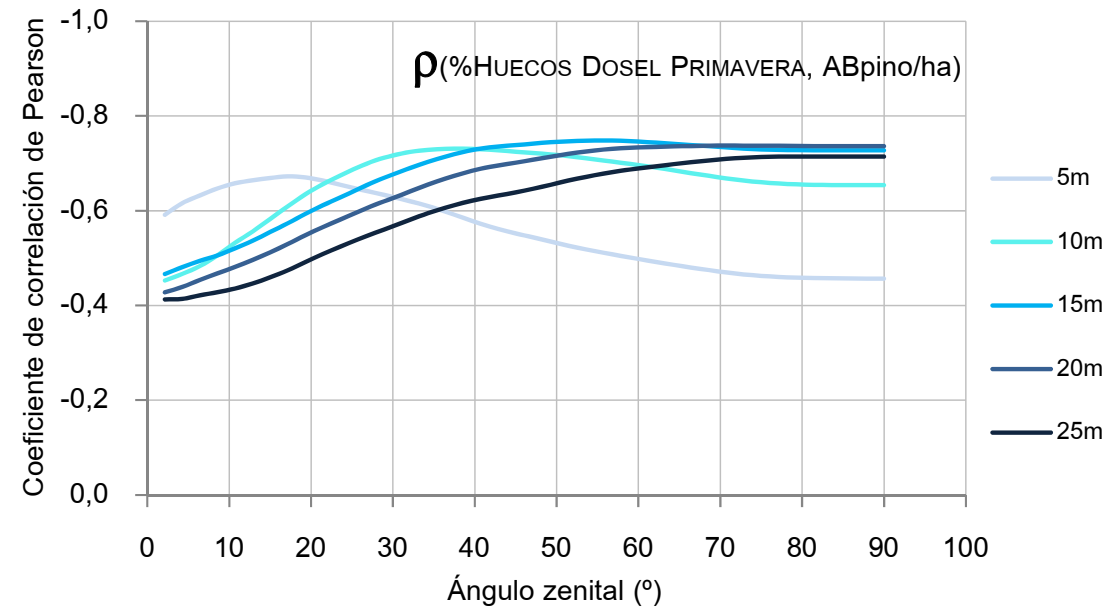

Fig. 30. Coeficientes de correlación lineal entre el porcentaje de huecos del dosel durante la PRIMAVERA en casquetes de ángulo cenital creciente y el $\mathrm{AB} /$ ha de $\mathrm{PINO}$ en torno al punto, medida en parcelas de radio creciente $(5,10,15,20$ y $25 \mathrm{~m})$. 


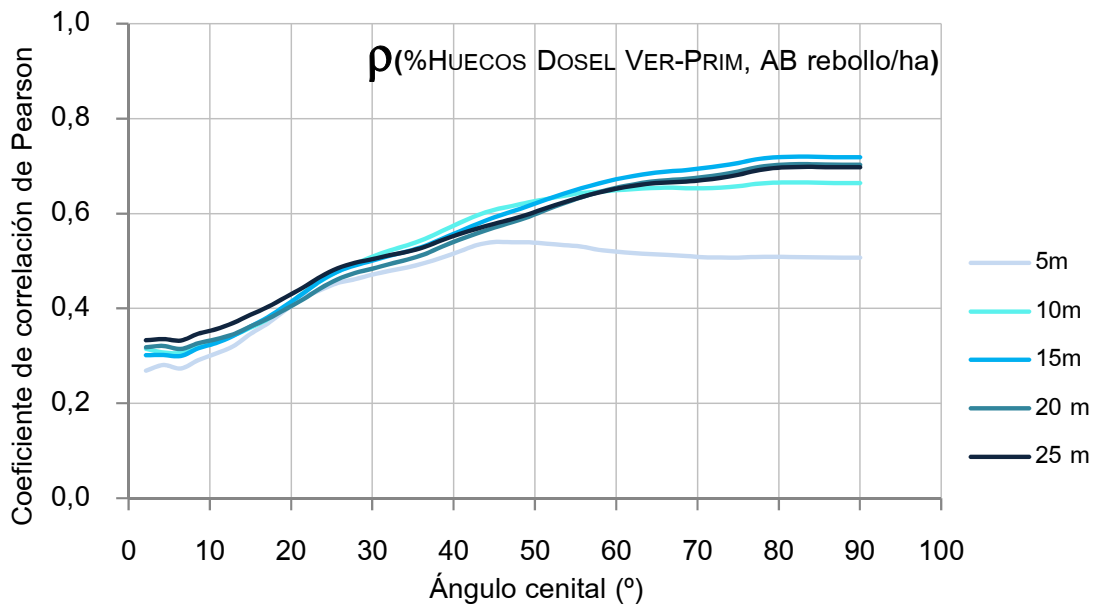

Fig. 31. Coeficientes de correlación lineal entre la diferencia en porcentaje de huecos del dosel (\%HD) entre VERANO y PRIMAVERA en casquetes de ángulo cenital creciente y el AB/ha de REBOLLO en torno al punto, medida en parcelas de radio creciente $(5,10,15,20$ y $25 \mathrm{~m})$.

Como se puede apreciar en la figura 31, en el caso del rebollo el comportamiento es mucho más estable, salvo para el tamaño de parcela más pequeño de los analizados (radio de $5 \mathrm{~m}$ ). A la vista de este resultado se puede concluir que, independientemente del ángulo cenital que nos interese, se podría trabajar con el área basimétrica de rebollo estimada en cualquiera de las parcelas de radios entre 10 y $25 \mathrm{~m}$.

En el apartado siguiente se analizan brevemente los ángulos a los que tienen lugar los procesos de intercepción de radiación que nos interesa caracterizar para ser capaces de seleccionar el radio más adecuado para el cálculo del $A B$ en torno a los puntos de muestreo.

\subsubsection{RELACIÓN DEL PORCENTAJE DE HUECOS DEL DOSEL CON LA RADIACIÓN BAJO CUBIERTA}

El porcentaje medio de huecos encontrado en el dosel en la zona de estudio fue de $21,4 \%$. No obstante, como la mayor parte de los bloques experimentales presentaba una cierta proporción de pies de rebollo, dicho porcentaje varió entre el $23,0 \%$ del inicio de la primavera (frondosa sin hojas) y el $19,8 \%$ del verano (frondosa con hojas). El porcentaje de huecos en el dosel en función del ángulo cenital considerado para las dos épocas de muestreo se representa, junto con la diferencia entre los datos de ambas épocas, en la figura 32. Como puede verse, la mayor parte de los huecos del dosel se encuentran entre los 0 y los $80^{\circ}$ de ángulo cenital; a partir de los $80^{\circ}$ no hay, prácticamente, más incorporaciones de huecos y el parámetro pasa a ser casi constante (en ese ángulo tan bajo se solapan las sombras de muchos más árboles en cada visual)

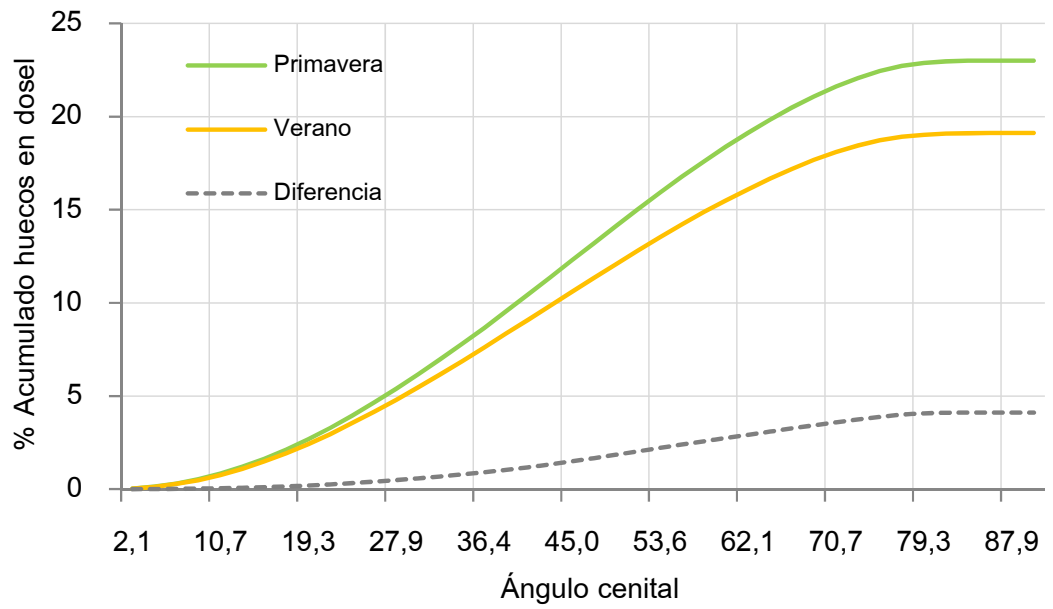

Fig. 32. Evolución del porcentaje acumulado de huecos del dosel en casquetes esféricos de ángulo cenital creciente. Se representan en distintos colores los valores de primavera y verano y la diferencia entre ambos. 
Tal y como se señaló en el correspondiente apartado de material y métodos, en el presente trabajo se ha optado por tener en cuenta, de entre los posibles parámetros de luz derivados de las fotografías hemisféricas, el porcentaje de luz directa transmitida en verano y primavera, el porcentaje de luz difusa transmitida en verano y primavera y la duración primaveral, estival y total anual de los sunfleks (sumatorio total de los minutos en los que el punto de muestreo está recibiendo radiación directa). Los efectos sobre estos parámetros de los huecos de dosel ubicados en distintos ángulos cenitales varían según el tipo de parámetro. Por eso, para cada parcela de la Red de muestreo I se estimaron siete valores de radiación (\%Luz directa en primavera y verano, \% de luz difusa en primavera y verano, Sunflecks en primavera, verano y total anual) y para cada uno de ellos se calcularon los coeficientes de correlación con los correspondientes \%HD en casquetes esféricos crecientes. Los resultados se representan en las figuras 33 (\% de luz directa y difusa para las distintas épocas del año) y 34 (Sunflecks).

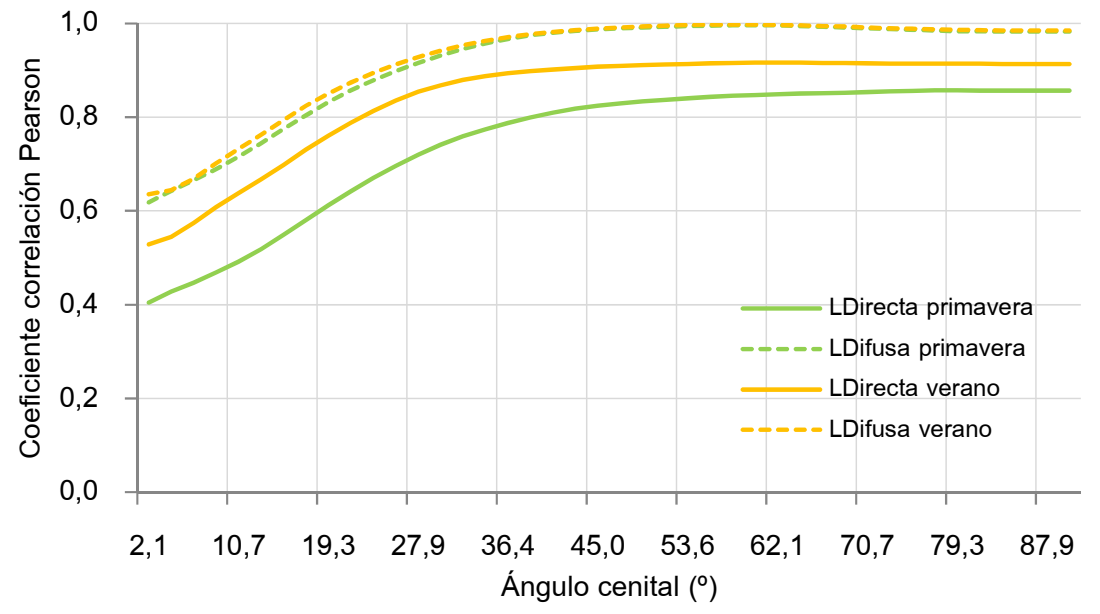

Fig. 33. Coeficientes de correlación entre la radiación incidente en cada punto y el porcentaje de huecos del dosel $(\% \mathrm{HD})$ en casquetes esféricos de ángulo cenital creciente.

El porcentaje de luz difusa se correlaciona con el \%HD mejor que el de la luz directa, porque la luz difusa tiene que ver con los huecos de todo el casquete esférico y la luz directa sólo con los situados en el camino del sol. Así mismo, la luz directa de primavera se correlaciona con el \%HD peor que la de verano, ya que en verano el camino del sol va más alto, lo que implica que el casquete esférico que contiene el camino del sol es más pequeño y contiene, por tanto, menos huecos de más. Lo mismo se observa para los sunflecks.

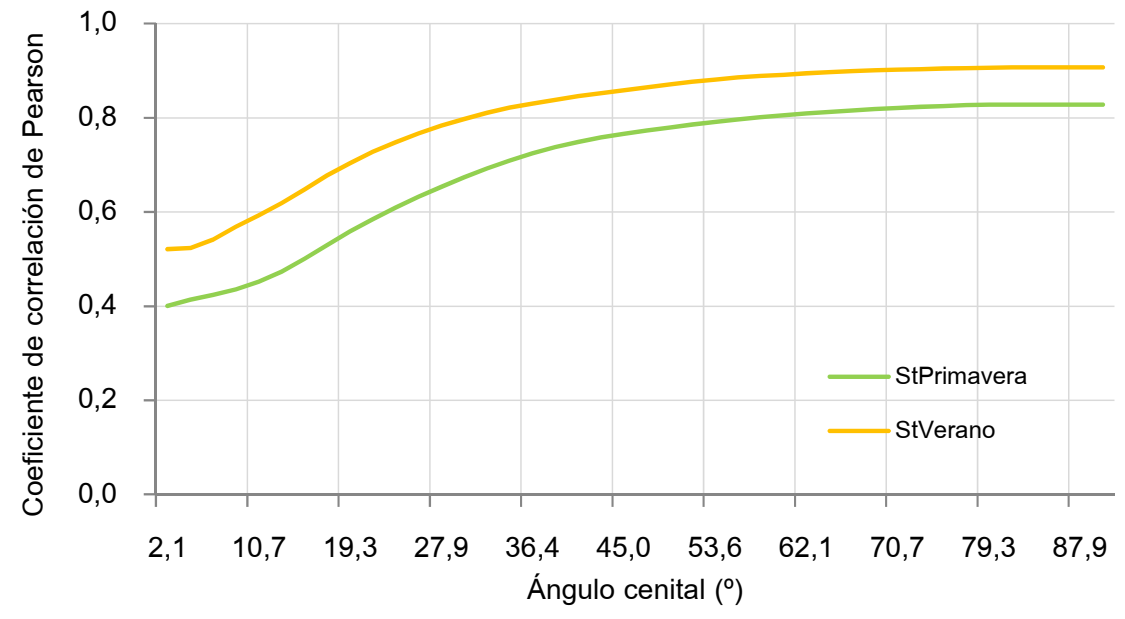

Fig. 34. Coeficientes de correlación entre la duración total de sunflecks para cada punto y el porcentaje de huecos del dosel $(\% \mathrm{HD})$ en casquetes esféricos de ángulo cenital creciente 
Con respecto a los ángulos a los que se produce el coeficiente de correlación máximo (tabla 28), puede decirse que, en general, la radiación de primavera, al incidir en un ángulo más bajo, tiene sus máximos en ángulos cenitales mayores en todos los casos. El comportamiento de los sunflecks fue muy diferente al del porcentaje de transmisión de la luz directa - pese a ser ambas mediciones de luz directa - por razones que no resultan evidentes, pero que pueden estar relacionadas con el hecho de que, a diferencia del $\%$ de transmisión, los sunflecks sean valores acumulativos en lugar de medias.

Tabla 28. Ángulos cenitales a los que se producen los máximos coeficientes de correlación de Pearson entre los parámetros de luz indicados y los porcentajes de huecos $(\% \mathrm{HD})$ de los correspondientes casquetes esféricos.

\begin{tabular}{lc}
\hline Variable & Ángulo $(\rho$ max $)$ \\
\hline $\begin{array}{l}\text { \%Luz Directa } \\
\text { Primavera }\end{array}$ & $79,3^{\circ}$ \\
Verano & $62,1^{\circ}$ \\
\%Luz Difusa & \\
Primavera & $60,0^{\circ}$ \\
Verano & $57,9^{\circ}$ \\
Sunfleks & \\
Primavera & $90,0^{\circ}$ \\
Verano & $90,0^{\circ}$ \\
\hline
\end{tabular}

En cualquier caso, al margen de los valores máximos, en la figura 33, se aprecia que los coeficientes de correlación para todos los tipos de radiación se estabilizan entre 45 y $55^{\circ}$, de tal forma que, aunque luego sigan aumentando hasta alcanzar su máximo, los cambios a partir de ese ángulo son ya muy leves.

\subsubsection{Radio óptimo de muestreo del Área basimétrica. Selección de parámetros para la CARACTERIZACIÓN DEL EFECTO DE LA MASA EN TORNO A LOS PUNTOS DE MUESTREO}

Teniendo en cuenta los ángulos cenitales que han resultado relevantes para los porcentajes de transmisión de la radiación, cabe esperar que los radios de estimación del $A B$ más adecuados para representarlos sean de 15 ó 20 (radios a los que el área basimétrica representa de forma óptima los ángulos cenitales requeridos). Sin embargo, los Sunflecks parecen necesitar radios mayores.

Este hecho se confirma cuando se calculan directamente los coeficientes de correlación entre el $A B$ y los parámetros de luz, como refleja la tabla 29. En general, el radio de $15 \mathrm{~m}$ es el que resulta más adecuado para representar el efecto del $A B$ sobre el porcentaje de radiación (directa y difusa) sobre el suelo. Por el contrario, los sunflecks parecen estar mejor representados por las parcelas de $20 \mathrm{~m}$, aunque el coeficiente de correlación entre $A B$ y sunflecks tan sólo desciende en 0,050 unidades al considerar la parcela de $15 \mathrm{~m}$.

Se confirma, por tanto, que hay una cierta variación en el radio óptimo de estimación del área basimétrica en función del parámetro a estimar, aunque las parcelas de $15 \mathrm{~m}$ resultan suficientemente adecuadas para todos ellos en la mayoría de los casos en la masa en estudio. Por lo tanto, éste será el tamaño de parcela en el que se realizarán las estimaciones del área basimétrica para el posterior análisis de la influencia de la masa sobre el proceso de regeneración.

Por último: dado que estos resultados dependen de la estructura vertical y horizontal que presente la masa y de las alturas medias y de inicio de copa, no cabe plantearlos como norma de muestreo. La distancia necesaria habrá de variar en función de la masa que se desee caracterizar. 
Tabla 29. Coeficientes de correlación máximos entre el $A B$ para cada tipo de área basimétrica (rebollo, pino o ambas) y cada tipo de parámetro lumínico (y período de medición). Para cada uno se indican el valor del coeficiente máximo y el radio de estimación de $A B$ y al que se produce

\begin{tabular}{|c|c|c|c|c|c|c|}
\hline & \multicolumn{2}{|c|}{ AB Pino } & \multicolumn{2}{|c|}{ AB Total } & \multicolumn{2}{|c|}{ AB Rebollo } \\
\hline & Radio (m) & $\rho$ & Radio (m) & $\rho$ & Radio (m) & $\rho$ \\
\hline \multicolumn{7}{|l|}{ Sunflecks } \\
\hline Total & 20 & $-0,577$ & 20 & $-0,636$ & 20 & $-0,636$ \\
\hline Primavera & 25 & $-0,537$ & 20 & $-0,558$ & 20 & $-0,558$ \\
\hline Verano & 20 & $-0,582$ & 20 & $-0,693$ & 20 & $-0,693$ \\
\hline \multicolumn{7}{|l|}{ \%Luz Directa } \\
\hline Primavera & 15 & $-0,616$ & 20 & $-0,620$ & 25 & $-0,174$ \\
\hline Verano & 15 & $-0,670$ & 15 & $-0,739$ & 10 & $-0,402$ \\
\hline \multicolumn{7}{|l|}{ \%Luz difusa } \\
\hline Primavera & 15 & $-0,746$ & 15 & $-0,774$ & 10 & 0,297 \\
\hline Verano & 15 & $-0,733$ & 15 & $-0,822$ & 10 & $-0,490$ \\
\hline
\end{tabular}

$\rho:$ máximo coeficiente de correlación de Pearson encontrado entre el $A B$ y los parámetros de luz que se indican; Radio: radio de estimación del correspondiente $A B$ (en m);

Si lo que se desea caracterizar no es la llegada de luz al punto sino la llegada de precipitaciones verticales, lo que debe valorarse es el porcentaje de huecos del dosel únicamente en el casquete esférico que queda por encima de la parcela del suelo en la que se quiere valorar el efecto. El tamaño de dicho casquete esférico vendrá determinado por el tamaño de la parcela de regeneración sobre el suelo y por la altura media total y de inicio de la copa en los pies en torno a ella. Teniendo en cuenta el tamaño de la parcela $(1,5 \times 1,5$ más un margen de $0,5 \mathrm{~m}$ ) y las alturas medias de inicio de copa y total de la masa circundante en la zona de estudio, se considera que un ángulo adecuado de estimación de la precipitación serían los $15^{\circ}$.

En el caso de un ángulo cenital de $15^{\circ}$, el radio de muestreo más adecuado para el $A B$ sería de $5 \mathrm{~m}$. No obstante, como en este caso el coeficiente de correlación no es tan adecuado porque la variabilidad en la estimación del $A B$ en parcelas tan pequeñas es muy elevada, se opta por utilizar directamente el porcentaje de huecos del dosel en el casquete esférico de $15^{\circ}$ (\%HD15) para caracterizar la mayor o menor intercepción de la lluvia por parte de la cubierta arbórea.

Para todo lo demás se tendrán en cuenta tanto el $A B$ estimada en parcelas de $15 \mathrm{~m}$ como los parámetros de luz ya mencionados: \%Luz transmitida directa, \% Luz transmitida difusa y Sunflecks. En un caso la utilidad será obtener valores que sean interpretables desde el punto de la gestión; en el otro, interpretar de una forma más directa la importancia de las distintas fracciones de la luz sobre el proceso analizado. Con respecto a los períodos de medición de las variables de radiación, dado que los coeficientes de correlación entre los valores de primavera y los de verano superan el 0,9 en todos los casos, se opta por utilizar únicamente los valores de verano, que son los más completos y los que, en realidad, afectan a la mayor parte del período de estudio de regeneración. Para los sunflecks - al tratarse de un valor acumulado y no una media - se consideran los valores totales. 


\subsubsection{CONCLUSIONES PARCIALES DEL CAPÍTULO}

El inventario pie a pie de la masa en el área de estudio permitió caracterizar los bloques de estudio en cuanto a espesura, distribución diamétrica, alturas y presencia de regeneración. Como resumen general de la caracterización de la masa en la zona de estudio hay que decir que:

1) En cinco de los seis bloques experimentales nos encontramos con un monte medio irregular de pino silvestre y rebollo. En la mayoría de ellos domina claramente el estrato superior de pino, y es el bloque SE el que cuenta con un subpiso de rebollo más desarrollado, como refleja su elevada área basimétrica. En general, el rebollo presenta una distribución espacial en agregados. El único bloque sin rebollo es el SWn.

2) La distribución diamétrica del pino silvestre se corresponde en todos los casos con una masa irregular, no necesariamente pie a pie sino por mezcla de bosquetes, en cuyo interior podemos encontrar masas regulares o semirregulares de diferentes edades.

3) Los valores de regeneración observados resultan, en general, algo escasos.

Las características particulares de cada uno de los bloques de experimentación se resumen a grandes rasgos en el apartado 4.2.1.3. Síntesis del estado de la masa en los bloques de experimentación.

El porcentaje de huecos en el dosel (\%HD) por encima de cada punto de muestreo de regeneración se correlacionó significativamente tanto con el área basimétrica $(A B)$ medida en radios concéntricos en torno al punto como con los parámetros lumínicos contemplados (\%Luz directa transmitida, \%Luz difusa transmitida y duración de sunflecks).

Los mayores coeficientes de correlación del ABtotal se produjeron con el \%HD de verano, mientras que para el $A B$ de pino fueron mayores con el \%HD de primavera (cuando el rebollo no tiene hojas). El $A B$ de rebollo, por su parte, mostró en general correlaciones mucho más bajas debido a su menor presencia en la masa, pero su óptimo se produjo con la diferencia entre los \% $\mathrm{HD}$ de verano y primavera (que corresponderían precisamente a las hojas incorporadas por el rebrote tras la primavera).

Las máximas correlaciones de los procesos de transmisión de la luz con los \%HD variaron en ángulo cenital en función de la época del año (mayores ángulos cenitales en invierno que en verano) y del tipo de luz considerada (mayores para la luz directa y los sunflecks que para la luz difusa).

Las correlaciones máximas entre área basimétrica y porcentaje de huecos del dosel se produjeron en ángulos cenitales mayores a medida que aumentaba el radio de estimación del área basimétrica en torno al punto. Dependiendo del ángulo cenital en el que se produzca el proceso que se desee caracterizar mediante el $A B$, su radio de muestreo deberá ser mayor o menor. Cuando lo que se quiere caracterizar es el efecto del dosel arbóreo sobre la luz bajo cubierta, se calcula que en la masa de estudio el radio óptimo de muestreo del área basimétrica en torno a cada unidad experimental es de $15 \mathrm{~m}$.

Por el contrario, cuando lo que interesa es el efecto de intercepción de la precipitación del dosel, el casquete esférico a caracterizar es el ubicado inmediatamente por encima de la parcela de muestreo, por lo que el radio óptimo de estimación del $A B$ se reduciría a $5 \mathrm{~m}$. No obstante en este caso, debido a la elevada variabilidad del área basimétrica estimada en parcelas tan pequeñas, resulta más adecuado el uso del \%HD. En concreto en el área de estudio, dadas las características de la masa (altura media, altura media de inicio de copa) y las dimensiones de las parcelas de muestreo $(1,5 \times 1,5 \mathrm{~m})$, se estima adecuado caracterizar el nivel de intercepción de las precipitaciones por la cubierta arbórea a partir del porcentaje de huecos del dosel en el casquete esférico de ángulo cenital $15^{\circ}$. 

4.3.

RED DE MUESTREO I: GERMINACIÓN, SUPERVIVENCIA Y ESTABLECIMIENTO DEL REGENERADO BAJO DISTINTAS CONDICIONES DE CUBIERTA VEGETAL 



\subsubsection{GERMINACIÓN Y SUPERVIVENCIA INICIAL EN EL ÁREA DE ESTUDIO (AÑO I)}

\subsubsection{CRonograma del PROCESo de REgeneración duRANTE EL PRIMER PERÍodo Vegetativo}

\section{A. GERMINACIÓN}

La emergencia del regenerado en las parcelas de experimentación tras la siembra llevada a cabo durante el mes de febrero comenzó de forma esporádica durante la última semana del mes de abril pero no se generalizó hasta la tercera semana del mes de mayo. En términos generales el $85 \%$ de la germinación contabilizada en todo el período vegetativo se produjo entre mediados de mayo y mediados de junio, aunque concentrada mayoritariamente $(70 \%)$ entre el 15 de mayo y el 5 de junio (figura 35 ). Este período coincide en términos generales con lo encontrado por Castro et al. (2004) y (Castro et al., 2005a) en masas de silvestre de Sierra Nevada.

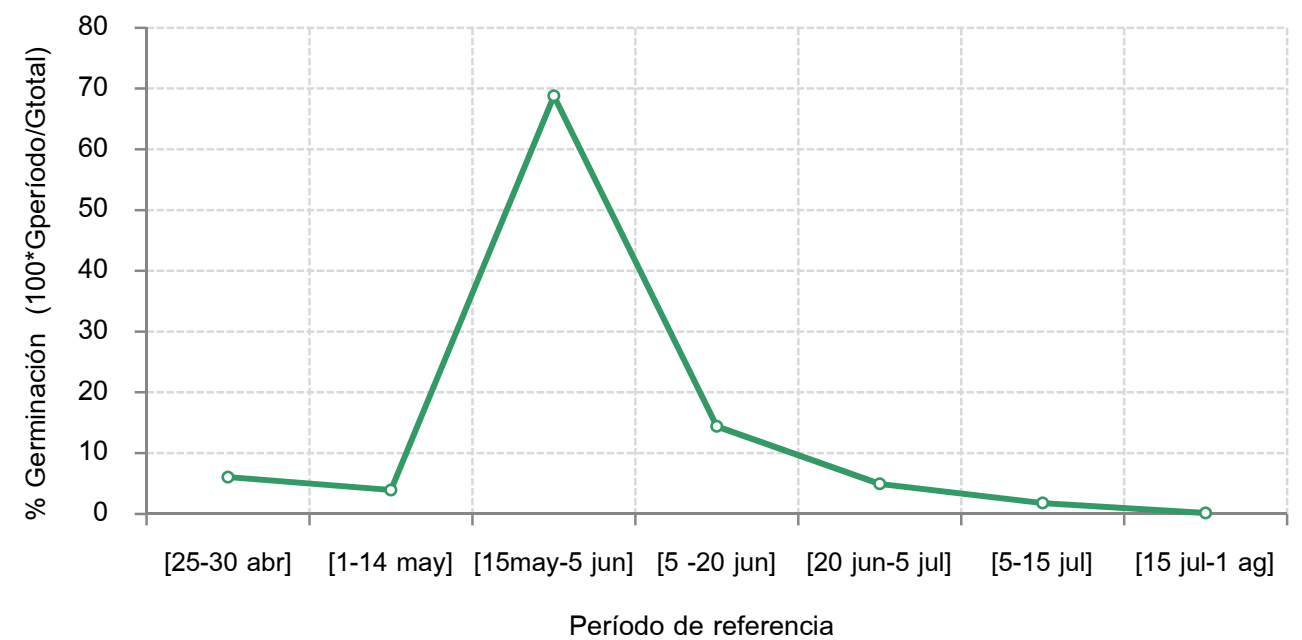

Fig. 35. Cronograma medio del proceso de germinación en la zona de estudio durante el año 2004: porcentajes de germinación en los períodos indicados con respecto al total del período vegetativo

La primera zona en empezar a germinar fue el bloque NE (el de menor altitud con $1.340 \mathrm{~m}$ y exposición de umbría pura) a finales de abril, mientras que el bloque más tardío fue el $\mathrm{S}$ (la zona de mayor altitud media con $1.530 \mathrm{~m}$ y exposición de solana) en donde no se detectó prácticamente ninguna plántula hasta la segunda mitad de mayo. Los bloques NW y SE presentaron un comportamiento intermedio. Las diferencias en la fecha de inicio de la germinación no repercutieron en las fechas en las que se produjo el máximo de incorporaciones que en todos los casos coincidió con el período indicado en el párrafo anterior.

Las semillas del pino silvestre no presentan durmancia y su emergencia tiene lugar cuando se alcanzan niveles suficientes de humedad y temperatura (Castro, 1999; Castro et al., 2002). En el caso que nos ocupa los bloques con orientación de umbría [NE y NW] se encuentran ubicados a menor altitud que los de orientación de solana [SE y S] (apdo. 3.2.2.2. Replanteo de la red de parcelas), por lo que la altitud y la orientación van a tener efectos contrapuestos sobre la temperatura y la humedad de dichas zonas.

Teniendo en cuenta el comportamiento de los bloques ubicados en orientaciones extremas (NE y S), cabría decir que el efecto de la altitud sobre la temperatura $\left(1,3^{\circ} \mathrm{C}\right.$ de variación media esperada entre ellos según la corrección altitudinal propuesta por Gandullo (1994)) predomina sobre el de la orientación posibilitando que sea en el bloque NE en el que más rápidamente se alcancen las temperaturas mínimas para la emergencia. Con respecto a la humedad edáfica, según la ficha hídrica, en el año 2004 existió superávit en el suelo en todo el período entre enero y mayo, tanto si se considera el efecto de la altitud sobre las precipitaciones como 
si no, por lo que la disponibilidad hídrica del suelo sería suficiente en todos los casos. Por su parte, la humedad del aire, y particularmente la humedad del aire a ras de suelo, se relaciona más directamente con orientación que con la altitud (McCutchan y Fox, 1986) - que es sobre la temperatura ambiente sobre la que ejerce una influencia más clara sobre la temperatura ambiente. Por todo ello, caso de establecerse diferencias en la influencia de este parámetro, se confirmaría la mejor y más temprana disposición del bloque NE para la germinación frente al bloque $\mathrm{S}$ en el caso concreto de nuestro diseño

Aun así, las causas orográficas podrían explicar las diferencias encontradas entre en el momento de germinación del NE y el $S$ (que son las más marcadas), pero difícilmente pueden explicar los cambios (menores pero existentes) entre SE y S, que presentan apenas $30^{\circ}$ de cambio de orientación y $20 \mathrm{~m}$ de diferencia altitudinal. Al margen de las tendencias señaladas, cabe esperar por tanto que esté actuando una combinación de factores fisiográficos, de cobertura vegetal cercana al suelo, de espesura de la masa arbolada... de difícil modelización.

El único hecho que resulta claro con respecto a los bloques es que el momento de inicio de la germinación parece relacionarse con la idoneidad del bloque para la germinación, de tal forma que los bloques que presentaron mayor número de individuos germinados durante el período de máxima germinación (15 mayo 15 de junio) fueron también los que empezaron a germinar más temprano (y viceversa) (figura 36).

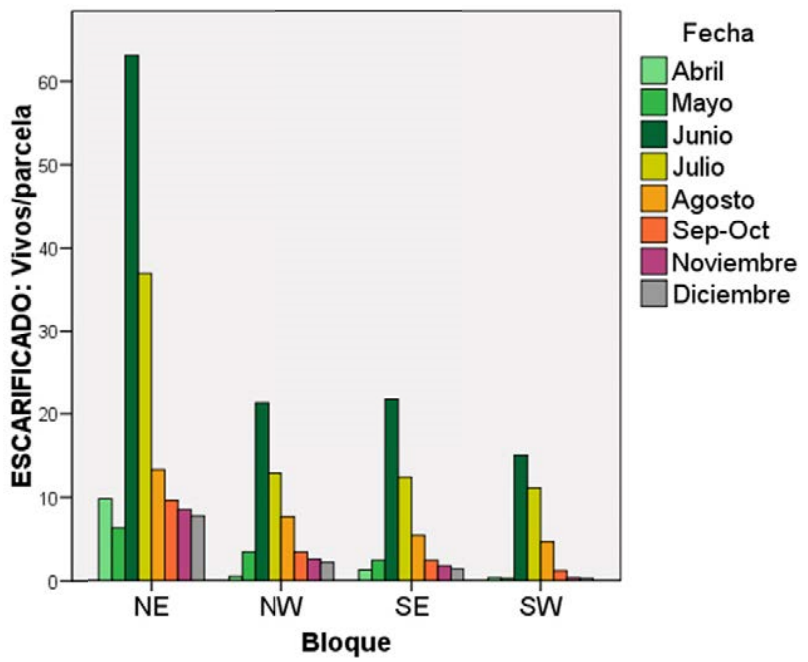

Fig. 36. Número medio de plántulas por parcela detectadas en las parcelas escarificadas de los distintos bloques durante el período de muestreo (finales de abril a mediados de diciembre).

Con respecto a la cobertura vegetal superficial a ras de suelo, las primeras parcelas en germinar fueron las que habían sido tratadas con escarificación. Este tipo de tratamientos de laboreo en los que queda expuesto el suelo mineral mejoran el contacto suelo-semilla lo que a su vez 1) aumenta la humedad en el entorno de las semillas tras la eliminación de todo tipo de cobertura vegetal con menor capacidad de retención de agua que el suelo mineral (Castro et al., 2002; Oleskog y Sahlén, 2000a); 2) aumenta el trano útil de la radícula emitida que no se ve obligada a atravesar una capa de material orgánico hasta llegar a un sustrato viable para las funciones de anclaje y absorción de agua y nutrientes (Borchert et al., 1989; Castro et al., 2002). Así mismo se consigue disminuir la dureza del suelo lo que permite una mayor velocidad de elongación de las raíces a través del suelo (Bengough et al., 2006; Eavis, 1972). Por todo ello parece lógico esperar que este tipo de tratamiento anticipe la emergencia de las semillas con todo lo que ello puede conllevar de cara a la supervivencia posterior por el mayor tiempo disponible para el desarrollo radical. En cuanto a la espesura de la masa en pie, no se observan tendencias significativas con respecto a la velocidad de emergencia de las semillas. 


\section{B. MORTALIDAD}

Si bien la mortalidad del regenerado es inherente al proceso de germinación, su nivel se mantuvo en niveles bajos (máximo del 5-9\% del total de germinados) hasta la primera mitad del mes de junio. Durante las siguientes semanas se elevó notablemente hasta una tasa máxima del $65 \%$ y no volvió a reducirse a niveles bajos hasta el mes de noviembre (figura 37). La mayoría de las muertes de las plántulas se produjo entre la última semana de junio y finales del mes de julio.

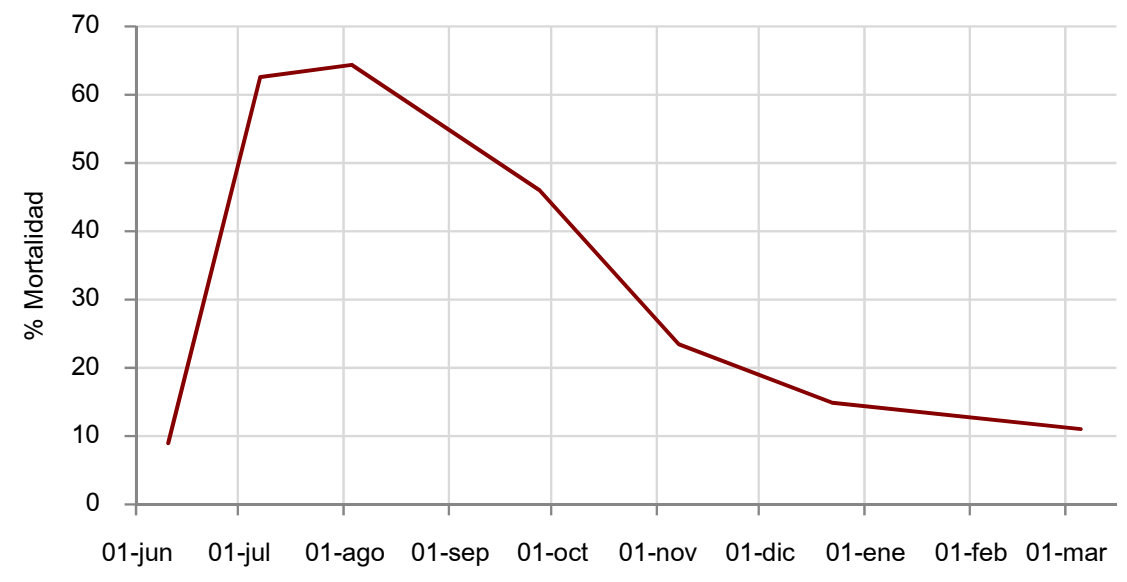

Fig. 37. Variación del porcentaje de mortalidad de las plántulas germinadas a lo largo del período de estudio (\%Mortalidad $=100 \times n^{\circ}$ plántulas muertas contabilizadas en una fecha $/ \mathrm{n}^{\circ}$ plántulas vivas en la fecha anterior).

Durante el mes de agosto se redujo sensiblemente la mortalidad con respecto al mes de julio, lo que pudiera estar ligado a la precipitación registrada en dicho mes ya que fue un $50 \%$ mayor que la media normal para agosto en el año medio. Ese aumento de precipitación supuso a su vez una reducción del 15\% en la sequía fisiológica correspondiente. Dado que estuvo ligada a unas condiciones climáticas atípicas, no cabe esperar que la mortalidad observada durante el mes de agosto de 2004 sea la característica de la zona sino más bien un hecho puntual.

Resulta así mismo llamativo que la mortalidad se prolongue durante los meses de septiembre y octubre en lugar de concentrarse más en los meses centrales del período estival tal y como suele mencionarse para la franja meridional de la distribución del silvestre(Castro et al., 2005b). Al contrario que en el caso anterior, el año 2004 presentó un mes de septiembre particularmente seco en el que el que la sequía fisiológica acumulada alcanzó valores cuatro veces mayores que la media normal $(52,4 \mathrm{~mm}$ frente a los 12,9 del promedio interanual) superando incluso la sequía registrada durante el mes de agosto, lo que podría explicar la mortalidad elevada durante dicho mes. Durante la segunda mitad del mes de octubre se produjeron abundantes precipitaciones que permitieron recuperar las reservas de agua en el suelo. Sin embargo, dado que la exposición a condiciones hídricas y térmicas adversas genera en las plántulas una serie de alteraciones fisiológicas y metabólicas que las debilitan (Gómez-Sánz y Elena, 1997) y las hacen más susceptibles a morir con posterioridad al período crítico, cabe esperar que algunos de los pimpollos supervivientes, debilitados por el largo período de sequía, fueran muriendo durante las semanas posteriores a dicho período. En todo caso, hay que considerar que los porcentajes calculados de mortalidad (figura 36) se establecen sobre el número de plántulas vivas en la fecha previa de control, de modo que el hecho de que dichos porcentajes de mortalidad se mantengan altos o relativamente altos reflejan una reducción muy considerable en valor absoluto en relación con la regeneración conseguida. 
En definitiva, durante el primer año de estudio, la cronología de los procesos de germinación y mortalidad, así como la de la población de brinzales vivos resultante del balance de ambas, es la que se resume en la figura 38.

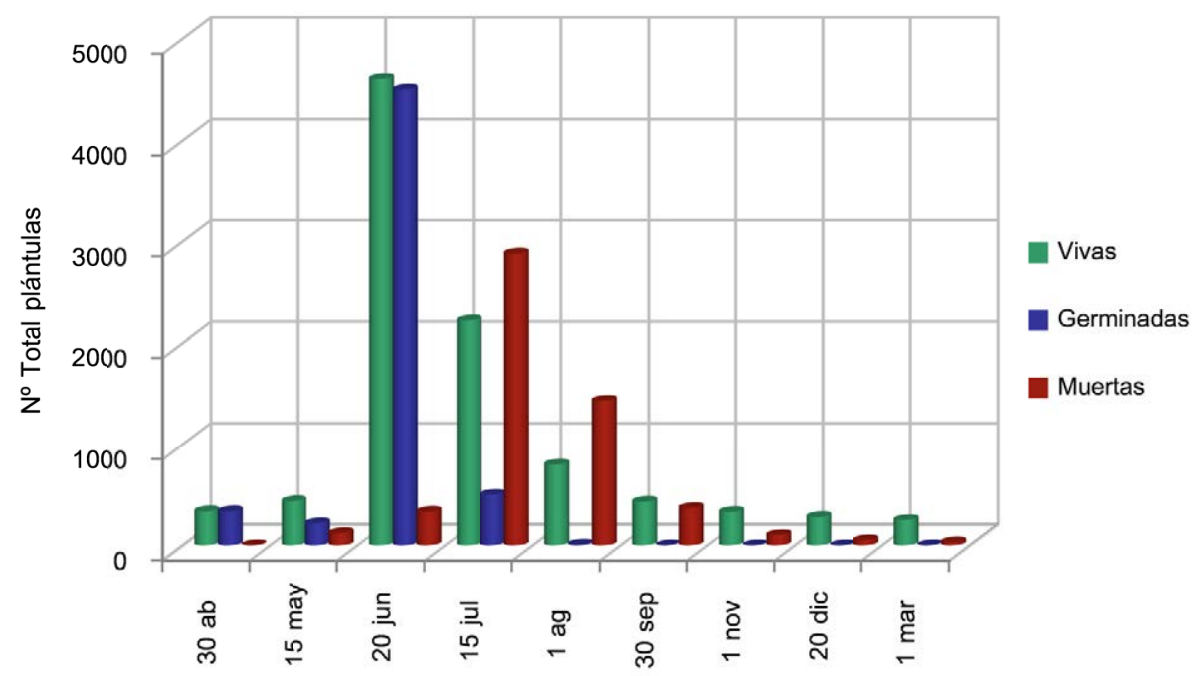

Fig. 38. Cronograma del proceso de germinación en la zona de estudio durante el primer año de experimentación. Las barras representan el total de plántulas vivas, germinadas o muertas contabilizadas en el período comprendido entre la fecha indicada bajo la barra y la fecha anterior a ella.

Dado que los procesos de germinación y supervivencia dependen del régimen termo-pluviométrico, va a existir variabilidad interanual en el cronograma de ambos procesos aunque a rasgos generales sí se espera que se mantengan las tendencias observadas.

\subsubsection{CuANTIFICACIÓN DE LOS PROCESOS DE GERMINACIÓN Y SUPERVIVENCIA TRAS EL PERÍOdO ESTIVAL}

Una vez definido el cronograma observado para el primer período vegetativo del regenerado, a continuación se cuantifican a grandes rasgos tanto la germinación total observada como la supervivencia tras el período estival de ese primer año.

Para la evaluación de la tasa total de germinación en las parcelas de estudio se toma como referencia el valor total acumulado de germinados hasta mediados de julio, coincidiendo con último conteo con incorporación de nuevos pimpollos. Para la supervivencia tras el período estival se toma como referencia el valor de supervivencia de finales del mes de septiembre.

Tal y como puede apreciarse en la tabla 30 , el $17,3 \%$ de las 24.000 semillas sembradas germinaron y sobrevivieron el tiempo suficiente como para ser detectadas en un conteo, lo que supone una densidad media de emergencia en torno a las 96.000 plántulas/ha que se repartió prácticamente entre el $100 \%$ de las parcelas de estudio. Se considera por tanto que la germinación fue suficiente tanto por cantidad como por distribución.

La precipitación registrada durante el mes de mayo de 2004 fue la mayor de todo el período 1995-2013 alcanzando un valor superior al doble de la precipitación media interanual para dicho mes, por lo que los resultados observados sólo permiten deducir que en la zona de estudio, con un suministro suficiente de semilla, la germinación no resulta problemática en años de primavera húmeda. 
Tabla 30. Valores medios de germinación y supervivencia estival durante el primer período vegetativo del regenerado en los distintos bloques de experimentación así como en el conjunto de todos ellos.

\begin{tabular}{|c|c|c|c|c|c|c|c|c|}
\hline \multirow[b]{2}{*}{ Bloque } & \multicolumn{3}{|c|}{ Totales } & \multicolumn{3}{|c|}{ Porcentajes } & \multicolumn{2}{|c|}{ \%Parcelas } \\
\hline & Siembra & $G$ & Sup & $\% G$ & $\%$ Sup & \%Éxito & $P G$ & PSup \\
\hline NE & 6.000 & 1802 & 214 & 30,0 & 11,9 & 3,6 & 97,9 & 57,4 \\
\hline NW & 6.000 & 732 & 57 & 12,2 & 7,8 & 1,0 & 97,9 & 29,8 \\
\hline SE & 6.000 & 1075 & 44 & 17,9 & 4,1 & 0,7 & 97,9 & 36,2 \\
\hline S & 6.000 & 532 & 17 & 8,9 & 3,2 & 0,3 & 97,9 & 21,3 \\
\hline Total & 24.000 & 4141 & 332 & 17,3 & 8,0 & 1,4 & 97,9 & 35,6 \\
\hline
\end{tabular}

Totales: Siembra $=n^{\circ}$ total de semillas sembradas por zona; $\mathbf{G}=n^{\circ}$ total de individuos germinados por zona; Sup=n ${ }^{\circ}$ total de individuos vivos tras el período estival por zona; Porcentajes: $\% \mathbf{G}=100^{*} \mathrm{~N}^{\circ}$ germinados a mediados de julio / TotalSiembra; \%Sup=100*Superv. a finales de septiembre/Ngerminados; \%Éxito=100*Superv/TotalSiembra; \%Parcelas: $\mathbf{P G}=\%$ de parcelas que presentan individuos vivos al finalizar la fase de germinación; PSup=Porcentaje de parcelas que presentan individuos vivos tras el período estival con respecto a las parcelas que presentaron germinación.

De los individuos germinados y contabilizados, el 8,0 \% sobrevivieron al período estival, lo que supone un $1,4 \%$ de supervivientes frente al total sembrado. La densidad media de plántulas vivas al final del primer verano fue por tanto de 7.500 pies/ha. Esta densidad general no se repartió de forma uniforme por todo el abanico de escenarios contemplados en las unidades experimentales ya que en dos de cada tres parcelas no sobrevivió ningún pimpollo.

Teniendo en cuenta que la tasa de mortalidad del regenerado de pino silvestre suele ser alta hasta el tercer o cuarto año (Castro et al., 2004) la supervivencia media observada tras el primer verano es escasa. No obstante, como el reparto de la misma fue irregular, es necesario analizar las características de las unidades experimentales en que tiende a concentrarse para poder establecer qué situaciones son las que deben abundar a nivel de rodal para asegurar un establecimiento suficiente.

En todo caso, para contextualizar los resultados observados hay que señalar que tras la primavera húmeda, el año 2004 fue muy seco durante los meses de junio y julio (total de precipitaciones inferior a la mitad de las del año medio), por lo que en este caso estaríamos ante un 'año malo' para la supervivencia a pesar de haber sido bueno para la germinación.

Dentro de los cuatro bloques en los que se organizó el diseño experimental, el bloque correspondiente a la orientación NE (umbría pura) es el que presentó mejores tasas de germinación y supervivencia, mientras que el $S$ (el de más solana) fue el de peor comportamiento en ambos procesos. Es un hecho comúnmente aceptado que la regeneración del pino silvestre en la Península lbérica se ve favorecida por exposiciones de umbría (González Vázquez, 1948; Montero et al., 2008), y que lógicamente dicha tendencia se acentúa cuanto más meridional es la localización. Sin embargo, a pesar de la coincidencia, en el presente estudio la variación en las tasas de germinación y supervivencia no se puede atribuir con certeza estadística al efecto de la orientación ya que, tal y como se ha visto en apartados anteriores, las diferencias entre bloques no se limitan a un tema de exposición dominante.

\subsubsection{INFLUENCIA DE LA COBERTURA VEGETAL}

De los valores medios resumidos en la tabla 30 se deduce que en las parcelas que sí presentaron germinación, el número medio germinados fue de 20 plántulas/parcela mientras que en el caso de las parcelas con supervivencia este número bajó a 5 plántulas/parcela. En cada una de ellas se habían sembrado 125 semillas y, dado su reducido tamaño, en cada una se habían supuesto constantes las condiciones fisiográficas (altitud, orientación, pendiente...) y de cobertura vegetal (estratos arbóreo, arbustivo, herbáceo y 
capa de restos sobre el suelo). Sin embargo, los resultados indican que, cuando una parcela es adecuada para la supervivencia del regenerado, por término medio sólo lo es para 5 de los pinitos sembrados. Para el resto no, a pesar de que las semillas sobreviven en un $96 \%$ en condiciones de laboratorio.

Se pone de manifiesto por tanto que las condiciones directas de las que depende el éxito en la regeneración tienen una escala de funcionamiento aún más pequeña que la considerada (1,5x1,5 m). En este sentido, a la hora de evaluar la influencia de la cobertura vegetal sobre el éxito del proceso de regeneración, habrá que tener en cuenta que lo que se espera de las distintas condiciones de espesura en los distintos estratos vegetales es que aumenten o disminuyan la probabilidad de que se den puntos de condiciones micrometeorológicas adecuadas para la germinación o la supervivencia, pero que, a pesar de la aparente homogeneidad tanto de cobertura como de disponibilidad de semilla, dicha homogeneidad no es tal de cara a la regeneración. Probablemente también por la influencia de factores ajenos a la vegetación o la fisiografía como la predación de semillas o la acción del ganado.

Tal y como se indicó en el apartado de material y métodos, se considera el efecto de la cubierta vegetal dividido en dos grupos: por un lado se valora la influencia de masa arbórea en torno a cada unidad experimental (caracterizada en función de su espesura y densidad de huecos del dosel) y por otro se considera el tipo de cubierta vegetal sobre el suelo de la parcela distinguiendo entre hierba, matorral, hierba o escarificado.

\section{A. Cobertura Vegetal del suelo}

En tabla 31 se resumen los resultados de regeneración para los distintos tipos de recubrimiento vegetal del suelo considerados.

Tabla 31. Éxito en la regeneración durante el primer período vegetativo para las distintas combinaciones de Orientación y Tipo de Cobertura vegetal (E: Escarificado, H: Hierba, M: Matorral, R: Restos).

\begin{tabular}{|c|c|c|c|c|c|c|c|c|c|c|c|c|}
\hline \multirow{2}{*}{ Bloque } & \multicolumn{3}{|c|}{$E$} & \multicolumn{3}{|c|}{$\mathrm{H}$} & \multicolumn{3}{|c|}{$\mathrm{M}$} & \multicolumn{3}{|c|}{$\mathrm{R}$} \\
\hline & $\% G$ & \%Sup & \%Éxito & $\% G$ & \%Sup & \%Éxito & $\% G$ & $\%$ Sup & \%Éxito & $\% G$ & $\%$ Sup & \%Éxito \\
\hline $\mathrm{NE}$ & 34,4 & 15,1 & 5,2 & 23,5 & 2,8 & 0,7 & 26,7 & 17,0 & 4,5 & 35,5 & 10,9 & 3,9 \\
\hline NW & 18,7 & 14,3 & 2,7 & 8,4 & 0,8 & 0,1 & 11,0 & 2,4 & 0,3 & 10,7 & 7,5 & 0,8 \\
\hline SE & 18,5 & 9,7 & 1,8 & 17,5 & 1,5 & 0,3 & 18,7 & 3,9 & 0,7 & 16,9 & 0,8 & 0,1 \\
\hline$S$ & 12,3 & 7,6 & 0,9 & 10,1 & 1,3 & 0,1 & 5,9 & 0,0 & 0,0 & 7,1 & 0,9 & 0,1 \\
\hline Total & 21,0 & 12,6 & 2,7 & 14,9 & 1,9 & 0,3 & 15,6 & 8,9 & 1,4 & 17,6 & 6,9 & 1,2 \\
\hline
\end{tabular}

$\% \mathrm{G}=100 * \mathrm{~N}^{\circ}$ germinados/TotSiembra; \%Sup=100*Superviviente/Ngerminados; \%Éxito=100*Supervivientes/TotSiembra

Las parcelas sometidas a tratamiento de escarificación presentaron tasas de germinación y supervivencia medias más altas que las del resto de coberturas consideradas. Teóricamente la remoción superficial del suelo mejora el contacto entre la semilla y el sustrato, elimina competencia con otras especies de pequeña talla (Rojo y Montero, 1996) y disminuye la resistencia a penetración del suelo como consecuencia de su efecto de mullido. Todo ello en conjunto puede justificar un mayor éxito en la germinación mientras la disponibilidad hídrica sea suficiente (Montero, 1987). No obstante, la escarificación genera un aumento del tamaño y la densidad de poros, lo que disminuye la inercia térmica del suelo y contribuye a aumentar la velocidad y profundidad de desecación del mismo durante los meses de calor (Kubin y Kemppainen, 1994; Örlander, 1986). Por este motivo cabría esperar que, tras una buena germinación, tuviera lugar una elevada mortalidad en este tipo de sustratos; sin embargo también la supervivencia parece mejorar como consecuencia del tratamiento sobre el suelo. Posiblemente este hecho pueda ser debido a que, tal y como se ha visto, los individuos germinados sobre parcelas sometidas a escarificación germinan antes y desarrollan más rápidamente la raíz (mejor contacto con el substrato y menor resistencia al avance radical), lo que posibilita que las plántulas estén más asentadas y presenten un desarrollo radical más profundo, cuando las condiciones ambientales comienzan a endurecerse durante el período estival. 
Las parcelas clasificadas como Hierba son, al contrario que las anteriores, las que presentan peor tasa de supervivencia con respecto a siembra $(0,3 \%)$. El problema en este tipo de parcelas no es sin embargo la germinación, que pese a presentar el valor más pequeño en todos los casos, ronda el $15 \%$, sino la supervivencia, ya que por término medio sólo 1,9 individuos de cada cien germinados con éxito logran sobrevivir al período estival. Esta elevada tasa de mortalidad se atribuye normalmente al aumento del estrés hídrico efectivo como consecuencia de la competencia que se establece con los sistemas radicales de las herbáceas (Montero et al., 2008), así como a la predación y pisoteo frecuente en el caso de presencia abundante de ungulados silvestres y/o ganado. En la zona en estudio se suman ambos efectos puesto que tal y como ya se ha comentado existe una elevada presencia de ganado doméstico (mayoritariamente vacuno) que desde hace décadas viene generando en la masa daños por sobrepastoreo (Bravo et al., 2010).

Los otros dos tipos de cobertura presentan un comportamiento intermedio y de tendencia algo más variable entre bloques. En relación con la influencia del matorral, aparece citada como negativa para el establecimiento de nuevas plántula en ambientes templados (Buckley et al., 1998; Kolb y Robberecht, 1996; Lorimer et al., 1994), y sin embargo su efecto es positivo en ambiente marcadamente mediterráneo para la supervivencia del regenerado de pino silvestre (Castro et al., 2004), de modo que se podría entender su citado comportamiento intermedio en el monte de estudio. Por otro lado, resulta llamativo el comportamiento de los restos, habitualmente citados en este entorno como limitantes para la supervivencia (Barbeito et al., 2011; Rojo y Montero, 1996), pero cuyo comportamiento en la zona de estudio es similar al del matorral y mucho mejor que el de la hierba tanto en germinación como en supervivencia. No obstante, dentro de la categoría de restos existe una gran diferencia en el comportamiento de bloque NE en el que la germinación y la supervivencia son buenas, y el comportamiento de los bloques sur (SE y S) en los que, tras una germinación razonable, prácticamente no hay supervivencia.

Partiendo de los datos adquiridos dos años después, se calcula para las unidades experimentales tipificadas como 'Restos' el porcentaje medio de recubrimiento, el espesor medio de la capa de restos frescos y el espesor medio de la capa total de restos sobre el suelo (frescos + parcialmente descompuestos) en cada uno de los bloques de experimentación. Dado que no ha habido cambios en la masa ni tratamientos sobre el suelo (sólo se analizan las parcelas de restos) no se espera que las tendencias generales en estas profundidades se hayan visto especialmente alteradas en esos dos años por lo que se considera que dichas mediciones pueden reflejar adecuadamente las líneas generales de comportamiento. En la tabla 32 a continuación se resumen los valores medios calculados así como el resultado del contraste de igualdad de las mismas mediante un Anova unifactorial con el bloque experimental como factor. Dichos resultados ponen de manifiesto que: 1) no existen diferencias significativas entre bloques en el porcentaje de recubrimiento superficial; 2) sí existen diferencias significativas en el espesor de la capa total (horizonte $O$ al completo) ( $p$ valor $=0,003$ ), de tal forma que los bloques SE y $S$ presentan un horizonte $O$ significativamente mayor que el NE (el bloque NW presenta un comportamiento intermedio entre ambos); 3) el espesor de los restos frescos presenta cierta diferencia entre Sur y Norte pero menos consistente que la de los restos totales ( $p$-valor $=0,018$ ).

Tabla 32. Características medias de la capa de restos (recubrimiento superficial y espesor de restos frescos y totales) en las parcelas tipo "Restos" de los cuatro bloques experimentales. Significación asociada a los test ANOVA sobre la influencia del factor "Bloque experimental" en las variables contempladas.

\begin{tabular}{|c|c|c|c|c|c|}
\hline \multirow[b]{2}{*}{ Variable } & \multicolumn{4}{|c|}{ Bloque experimental } & \multirow{2}{*}{$\begin{array}{l}\text { ANOVA } \\
\text { p-valor }\end{array}$} \\
\hline & NE & NW & SE & SW & \\
\hline$\%$ Recubrimiento restos & $89,4^{a} \pm 21,2$ & $89,6^{a} \pm 19,1$ & $98,8^{a} \pm 3,1$ & $90,4^{a} \pm 28,6$ & 0,625 \\
\hline Espesor restos no descompuestos $(\mathrm{cm})$ & $3,3^{a} \pm 2.0$ & $3,5^{b} \pm 1,3$ & $6,3^{b} \pm 4,5$ & $6,2^{b} \pm 3,1$ & 0,018 \\
\hline Espesor total de restos (cm) & $5,4^{a} \pm 1,8$ & $7,6^{\mathrm{ab}} \pm 2,1$ & $9,3^{b} \pm 4,0$ & $10,4^{b} \pm 4,0$ & 0,003 \\
\hline
\end{tabular}


Teniendo en cuenta los resultados obtenidos, lo que determina el perjuicio de los restos sobre la instalación del regenerado no parece ser el grado de recubrimiento superficial de los mismos sino más bien el espesor de la capa. Esta tendencia coincide con lo encontrado por otros autores para esta misma especie cuando las temperaturas son altas y hay limitaciones por sequía (Cañellas et al., 2005).

Aunque habitualmente a las exposiciones de solana se les asocian condiciones climáticas que promueven mayores tasas de mineralización de la materia orgánica acumulada sobre el suelo en el caso que nos ocupa los bloques Sur y Sureste y son con diferencia los bloques cuya masa arbolada presenta mayor espesura y los que tienen una mayor densidad de rebollo. Al margen del comportamiento de las variables meteorológicas (que ya se discutió al principio de este apartado), la mayor tasa de incorporación de restos asociada a la espesura y a la presencia de la frondosa son en sí mismos suficientes para explicar el aumento de espesor de la capa de restos en las orientaciones $\mathrm{S}$.

En definitiva, si analizamos los porcentajes de éxito (que sintetizarían germinación y supervivencia) observamos que en todos los casos las mayores tasas corresponden a las parcelas del bloque NE o aquellas que fueron tratadas con escarificación. Fuera de este la mejor tasa de éxito para el NW se produciría en las parcelas de restos mientras que en el SE se producirían bajo matorral. El SW, por el contrario, sólo mejora levemente su nivel de éxito cuando las parcelas son escarificadas siendo el resto de niveles apenas del $0,1 \%$.

\section{B. DOSEL ARBÓREO}

Como primera aproximación al análisis de la influencia del dosel arbóreo sobre el proceso de regeneración, se calculan los coeficientes de correlación entre las variables de masa y las tasas de germinación y supervivencia tras el período estival observadas. Para la tasa de supervivencia los coeficientes de correlación se calculan tanto para el conjunto de parcelas que presentaron germinación (188 de las 192 iniciales) como exclusivamente para las que además presentaron supervivencia tras el período estival (67 de 192). Los valores obtenidos se resumen en la tabla 33.

Tabla 33. Coeficientes de correlación de Pearson entre las variables de masa y las tasas de germinación y supervivencia tras el período estival calculada para: a) conjunto de parcelas que presentaron germinación $(\mathrm{N}=188)$ y b) Parcelas que además presentaron supervivencia (eliminamos parcelas con sup $=0)(\mathrm{N}=67)$.

\begin{tabular}{|c|c|c|c|}
\hline \multirow{2}{*}{ Variable } & \multirow{2}{*}{$\begin{array}{c}\text { Germinados } \\
N=188\end{array}$} & \multicolumn{2}{|c|}{ Supervivientes } \\
\hline & & a) $N=188$ & b) $N=67$ \\
\hline AB Ps ( $\left.m^{2} / h a\right)$ & 0,100 & $-0,141$ & $-0,440^{* * *}$ \\
\hline$A B$ QP (m²/ha) & $-0,062$ & $-0,115$ & $-0,163$ \\
\hline AB Tot $\left(\mathrm{m}^{2} / \mathrm{ha}\right)$ & 0,079 & $-0,165^{*}$ & $-0,476^{* * *}$ \\
\hline$\% H D 15^{\circ}$ & $-0,114$ & $0,256^{\star \star \star *}$ & $0,489^{\star * *}$ \\
\hline SunFlecks (min) & $-0,317^{* * *}$ & $-0,036$ & 0,282 * \\
\hline \% Luz Directa & $-0,284^{* * *}$ & 0,014 & $0,367^{* *}$ \\
\hline$\%$ Luz Difusa & $-0,214^{* *}$ & 0,135 & $0,469^{\star * *}$ \\
\hline
\end{tabular}

ABPs // ABQp // ABTot: áreas basimétricas de pino, rebollo y total respectivamente en un radio de $15 \mathrm{~m}$ en torno a cada parcela; \%HD15: porcentaje de huecos en el dosel en el casquete esférico correspondiente a un ángulo cenital de 15\%; Sunflecks: tiempo total en minutos de exposición de cada parcela a la luz directa del sol a lo largo del año. \%LuzDirecta // \%LuzDifusa: porcentajes de luz directa y difusa respectivamente que llegan al suelo con respecto al total incidente por encima del dosel de copas. p-valor: $<0.001$ : ${ }^{* *} ;<0.01$ : ${ }^{* *} ;<0.05:{ }^{*} ;<0.1:$ p-valor: $<0.001$ : $^{* * *} ;<0.01$ : $^{* *} ;<0.05$ : $^{*} ;<0.1$ : * 
La tasa de germinación únicamente presenta correlación significativa con los parámetros de luz, especialmente con la duración de los Sunflecks. No se correlaciona con el área basimétrica ni con el porcentaje de huecos del dosel en el casquete esférico de $15^{\circ}$.

Dentro de que los niveles de correlación observados son bajos, lo único que se pone de manifiesto con respecto a la germinación, es que los lugares con una excesiva insolación van a germinar peor que aquellos que reciben menos cantidad de radiación, particularmente de radiación directa. El resto de efectos colaterales de la masa (mejor caracterizados por el área basimétrica) no parecen tener una influencia lo bastante directa en la emergencia como para reflejarse en el coeficiente de correlación.

Las correlaciones de la tasa de supervivencia varían considerablemente en función de que se considere toda la muestra de parcelas con germinación o que sólo se evalúen las parcelas con supervivencia. Cuando se considera toda la muestra las correlaciones observadas son bajas y la mayoría no significativas. Sin embargo, cuando el análisis se realiza exclusivamente sobre las parcelas con supervivencia distinta de cero, todas las variables de masa (a excepción del área basimétrica de rebollo) se correlacionan significativamente con la tasa de supervivencia. Este hecho pone de manifiesto que la espesura de la masa (ya sea valorada a través del área basimétrica o de la luz transmitida) influye significativamente en la abundancia de supervivientes, pero no es el único factor cuello de botella para la supervivencia o al menos en la muestra analizada y durante el período analizado no ha sido una de los principales. Incluir en el grupo de análisis las parcelas en las que no sobrevive ninguna plántula disminuye o anula los coeficientes de correlación porque la ocurrencia de parcelas sin supervivencia en la muestra analizada no depende lo suficiente de los parámetros de luz.

Así, si distinguimos únicamente entre parcelas viables (tasa de supervivencia $>0$ ) y no viables (tasa de supervivencia $=0$ ) sin entrar a valorar abundancia, y analizamos sus frecuencias en función del área basimétrica total, encontramos que la proporción de parcelas sin supervivientes es independiente del rango de área basimétrica que se considere (test de la $\mathrm{Chi}^{2}$ sobre asociación de variables, $\mathrm{p}$-valor $=0,962$ )

Tabla 34: Tabla de contingencia Área Basimétrica Total x Viabilidad para la supervivencia

\begin{tabular}{llc}
\hline & \multicolumn{2}{c}{$\%$ Parcelas } \\
\cline { 2 - 3 } AB total (m2/ha) & SupNo & SupSí \\
\hline $0-15$ & $69,2 \%$ & $30,8 \%$ \\
$15-35$ & $61,5 \%$ & $38,5 \%$ \\
$35-50$ & $64,3 \%$ & $35,7 \%$ \\
$>50$ & $63,2 \%$ & $36,8 \%$ \\
\hline TOTAL & $63,5 \%$ & $36,5 \%$ \\
\hline \multicolumn{2}{c}{ Chi $^{2}$ Pearson (p-valor) } & 0,962 \\
\hline
\end{tabular}

SupSí // SupNo: \% de parcelas en las que hubo y no hubo supervivencia tras el período estival (30 septiembre)

De todos modos, aunque se intensifiquen notablemente al restringir la muestra y quitar ruido, las tendencias observadas en ambos casos (considerando o no las parcelas sin supervivencia) son las mismas: más supervivencia cuanto menor es la espesura de la masa y mayor la cantidad de luz, y un marcado efecto positivo del porcentaje de huecos en el dosel en el casquete esférico que queda justo por encima de la parcela (ángulo cenital de $15^{\circ}$ ). Llama la atención que no exista una tendencia tipo unimodal de la espesura sobre la supervivencia con efecto negativo tanto de los valores muy bajos de esta como de los muy altos, pero la complejidad del diseño experimental puede estar complicando que se detecten ciertos efectos en presencia de otros de mayor intensidad.

Al contrario que en el caso de la germinación, el porcentaje de huecos que quedan en el dosel justo por encima de la parcela de muestreo tiene mucha influencia sobre la supervivencia. Dicho porcentaje $\left(\% \mathrm{HD} 15^{\circ}\right)$ se entiende que representa el mayor o menor efecto de intercepción de la lluvia por parte de la cubierta arbórea, además de estar relacionado con la luz incidente. Lo observado pone de manifiesto que durante la germinación la humedad no es un factor limitante pero que sí lo es durante la supervivencia. 
Debido al régimen termopluviométrico de la zona de estudio, la sequía fisiológica tiende a concentrarse en el período estival por lo que es en este período (en el que fundamentalmente se produce o no la supervivencia (Castro et al., 2005a, 2002)) en el que el nivel de intercepción de la lluvia por la precipitación va a ser más importante, por la escasez de las mismas. Pero además, la intercepción en este período pasa a ser especialmente importante debido a que las precipitaciones del período estival la mayoría de las veces no tienen la cuantía suficiente como para empapar y traspasar la cubierta vegetal, con lo que el efecto de sombra seca se intensifica en cuantía y trascendencia.

Hay que destacar así mismo que entre los parámetros lumínicos, para la supervivencia parece ser más importante (y positivo) el efecto la luz difusa que el de la luz directa. Este hecho podría deberse a que en nuestras latitudes la luz difusa se relaciona más directamente con la actividad fotosintética mientras que la luz directa (y los sunflecks) implican también sobrecalentamiento por su mayor carga energética, por lo que su exceso podría resultar perjudicial para el regenerado durante el período estival.

En definitiva con respecto a la importancia de las características del dosel arbóreo en el primer período vegetativo del regenerado hay que decir: 1) influyen significativa pero levemente en la germinación principalmente debido a su efecto sobre el tiempo de radiación directa sobre el suelo, lo que a su vez podría ser indicativo de calentamiento, de tal forma que a mayor tiempo de insolación directa, menor número de germinados; 2) influye en la abundancia de supervivientes aunque no parece ser el principal factor cuello de botella para la misma, en este caso su efecto está más ligado a la mayor o menor intercepción de las precipitaciones $\left(\% \mathrm{HD}^{\circ} 5^{\circ}\right.$ ) así como a la disponibilidad de luz difusa por parte del regenerado: a mayor proporción de huecos justo por encima de la parcela y a mayor disponibilidad de luz (y menor área basimétrica), mayor abundancia de supervivientes cuando el resto de factores no impiden esa supervivencia.

Señalamos por último que en general la influencia de la espesura sobre la supervivencia es mayor que la ejercida sobre la germinación y de signo contrario a esta, por lo que aparentemente espesuras intermedias podrían ser el mejor compromiso entre ambas.

\section{MODELO MULTIVARIANTE}

Lo señalado hasta el momento se ha basado en el análisis de relaciones univariantes pero, dado que lo esperable es que todos los estratos vegetales actúen de forma conjunta sobre el proceso de regeneración y que esta actuación pueda variar en función de la zona de experimentación (NE, NW, SE, S), finalmente es necesario también analizar de forma multivariante su efecto sobre la germinación y la supervivencia.

Todos los parámetros considerados hasta el momento se han medido sobre un entorno común y la situación que describen en cada punto es fruto de la interacción entre todos ellos, por lo que la mayoría de las veces muchos de los efectos de unos y otros se solapan y no es tarea sencilla definir qué parámetros son causa o causa principal en cada caso y cuáles acompañan o son consecuencia de esas causas.

Dado que en ambos casos la variable de interés es binomial (éxito/fracaso) se plantea un análisis mediante regresión logística. No obstante, la elevada correlación existente entre las variables regresoras que se contemplan (el solape del que hablábamos en el párrafo anterior), hace inviable utilizar técnicas convencionales para el ajuste del modelo. En estos casos, el uso de regresión penalizada tipo LASSO con validación cruzada o bootstrap permite detectar mejor la estructura subyacente de las variables regresoras así como la selección de aquellas que presentan una relación más directa con la variable objetivo.

Se llevan por tanto a cabo regresiones logísticas mediante regresión penalizada tipo LASSO para la tasa de germinación con respecto al total sembrado así como para la tasa de supervivencia al final del período estival (30 septiembre) y la tasa de éxito (supervivientes al final del período estival con respecto al total sembrado) en función de: - bloque (4 niveles: NE, NW, SE, S); - tipo de cobertura vegetal sobre el suelo (4 niveles: 
Escarificado, Hierba, Matorral y Restos), - área basimétrica total, de pino y de rebollo $\left(\mathrm{m}^{2} / \mathrm{ha}\right)$; - porcentaje de huecos del dosel en el casquete esférico de ángulo cenital 15\%; -porcentajes de trasmisión de luz directa y difusa por el dosel arbóreo; - Total anual de exposición a radiación directa, o Sunflecks (minutos).

Los coeficientes obtenidos para el nivel de penalización óptimo $\left(\lambda_{c}\right)$ calculado mediante validación cruzada se presentan en la tabla 35. La categoría de referencia para las variables cualitativas son el NE para el bloque y el Escarificado para la cobertura vegetal sobre el suelo. Esto implica que los coeficientes que se hacen constar en el resto de categorías corresponden a lo que añade o resta una parcela por el hecho de pertenecer a la combinación de bloque y tipo de cobertura que corresponda, con respecto a la media de los Escarificados del NE. La bondad de ajuste se mide a través de la devianza que es el equivalente al ' $R$ ' ajustado' en las regresiones por mínimos cuadrados.

Se destaca por último que la discusión de los resultados de este análisis se va a dirigir a los aspectos que no han sido detectados y comentados con anterioridad en los análisis univariantes. Básicamente se trata de identificar las variables más importantes en cada uno de los procesos analizados (germinación, supervivencia y éxito) que se manifiesta al manejarlas todas a la vez.

Tabla 35. Coeficientes de los modelos de regresión logística calculados mediante LASSO para las variables Germinación, Supervivencia y Éxito en función de las variables regresoras que se indican (Términos del modelo). Las categorías de referencia para las variables categóricas son el 'NE' para el Bloque y el 'Escarificado' para el Tipo de cobertura vegetal. Se marcan en negrita los coeficientes de valor absoluto $>0,5$.

\begin{tabular}{|c|c|c|c|}
\hline \multirow[b]{2}{*}{ Términos } & \multicolumn{3}{|c|}{ Variable objetivo } \\
\hline & Germinación & Supervivencia & Éxito \\
\hline T.Independiente & $-1,17$ & $-2,04$ & $-3,11$ \\
\hline \multicolumn{4}{|c|}{ Bloque Experimental } \\
\hline NW & $-0,78$ & $-0,45$ & $-1,15$ \\
\hline SE & $-0,66$ & - & $-0,80$ \\
\hline$S$ & $-1,03$ & $-0,30$ & $-1,68$ \\
\hline \multicolumn{4}{|l|}{ Cobertura vegetal } \\
\hline Hierba & $-0,12$ & $-1,40$ & $-1,57$ \\
\hline Matorral & $-0,10$ & $-0,76$ & $-0,94$ \\
\hline Restos & $-0,08$ & - & - \\
\hline \multicolumn{4}{|c|}{ Orientación x Cobertura } \\
\hline Hierba NW & $-0,11$ & $-0,20$ & - \\
\hline Hierba SE & - & - & - \\
\hline Hierba S & - & - & - \\
\hline Matorral NW & - & - & $-0,32$ \\
\hline Matorral SE & - & $-0,29$ & $-0,22$ \\
\hline Matorral S & $-0,41$ & $-0,40$ & - \\
\hline Restos NW & $-0,05$ & - & - \\
\hline Restos SE & - & $-1,26$ & $-0,92$ \\
\hline Restos S & - & $-0,56$ & $-0,04$ \\
\hline \multicolumn{4}{|l|}{ Espesura } \\
\hline $\mathrm{HD} 15^{\circ}$ & - & 0,64 & 0,68 \\
\hline ABT & 0,06 & $-0,09$ & - \\
\hline ABR & - & $-0,11$ & $-0,10$ \\
\hline \multicolumn{4}{|l|}{ Luz } \\
\hline Sunflecks & $-0,14$ & $-0,02$ & $-0,10$ \\
\hline \%Luz directa & $-0,16$ & $-0,31$ & $-0,49$ \\
\hline \%Luz difusa & - & - & - \\
\hline DEVIANZA & 0,489 & 0,528 & 0,549 \\
\hline
\end{tabular}


Los coeficientes de regresión para la tasa de germinación ponen de manifiesto que la variable que más influye en el éxito de este proceso es el bloque experimental. En mucha menor medida contribuirían también el tipo de cobertura vegetal sobre el suelo y la luz directa. Pero si realizamos un ajuste considerando únicamente el bloque, encontramos que esta variable por sí sola explica el $30 \%$ de la variabilidad desplazando en importancia a las variables que describen las características de la vegetación en cada punto. Todo parece indicar que las diferentes condiciones de altitud y orientación (ligadas a la posición del bloque) afectan al régimen térmico y a la humedad de las distintas zonas y que esta influencia se va a ver matizada por las condiciones de vegetación, pero no tanto por los matices singulares de cada punto sino en mayor medida por las condiciones de masa más generales del rodal (o lo que es lo mismo de cada zona experimental).

Tal y como se describe en el apartado 4.2. Caracterización de la masa en las unidades experimentales, al margen de las variaciones puntuales, la masa en los bloques experimentales tiene unas generalidades peculiares en cada caso (más o menos presencia de rebollo de mayor o menor talla, mayor o menor densidad de silvestre y con mayor o menor densidad de pies menores etc.). La combinación entre fisiografía y condiciones generales de masa es única para cada bloque. Las condiciones específicas de cada punto pueden matizar esta información pero su capacidad explicativa de cara a las condiciones ambientales generales que son las que afectan al comienzo de la germinación y a su posterior desarrollo es mucho menor tal y como refleja su respectivo coeficiente.

En todo caso el porcentaje de variabilidad explicada en este caso es menor que en el resto de procesos poniendo de manifiesto que la germinación durante el período estudiado ha resultado ser un proceso menos dependiente de la cubierta vegetal en sus distintos estratos de lo que lo es la supervivencia posterior.

Para la supervivencia, por el contrario, lo fundamental va a ser el tipo de cobertura sobre el suelo y el hueco del dosel para la incorporación de lluvia al sistema. El bloque importa también pero mucho menos que para la germinación. Aunque todos los tipos de cobertura sobre el suelo son peores que la escarificación resultan especialmente malos la hierba y los restos en las orientaciones sur y particularmente en el SE (tal y como ya se explicó con anterioridad). Con respecto a la hierba resulta especialmente perjudicial en el NW que es donde la presión del ganado es mayor ( $\mathrm{y}$ donde por otro lado el nivel de empradecimiento es también más elevado).

El éxito final del proceso de regeneración con respecto a la siembra es consecuencia de la concatenación de los dos procesos anteriores (que no están afectados exactamente por los mismos factores conceptos ni en los mismos sentidos) por lo que se ve afectado tanto por el bloque como por la cobertura vegetal en todos los estratos alcanzando una devianza de 0,55 que para un proceso natural tan complejo es bastante elevada. Llama particularmente la atención en lo referente al éxito el comportamiento de los restos de modo que, cuando el espesor no es excesivo (todos los bloques menos el SE), se pueden llegar a conseguir tasas de éxito similares a las del escarificado.

Tal y como hemos visto en los apartados univariantes el área basimétrica está significativamente correlacionada con las distintas etapas del proceso de regeneración (no vamos a repetir las tendencias); no obstante, al considerar todos los parámetros juntos sus coeficientes disminuyen mucho debido a que su efecto queda reflejado en parte por el bloque (que proporcionaría la tendencia general, de tal forma que si lo eliminamos el $A B$ sube en importancia) y la luz (que refleja con más precisión el comportamiento puntual). Algo parecido ocurre con las proporciones de luz directa y luz difusa. Todas estas variables entran en el modelo como complemento a las de coeficientes mayores (e influencia más directa) por lo que sus coeficientes sólo tienen sentido como complemento a los coeficientes de las variables principales (pero no como indicadores de relación directa, ya descrita mediante los modelos univariantes). 
Cabe destacar por último que las tasas de supervivencia observadas no están necesariamente correlacionadas con sus respectivas tasas de germinación, a diferencia de lo que ocurre en otros trabajos con la misma especie y estación similar (Pardos et al., 2007). Es decir, tal y como ocurre en el caso de las parcelas de hierba, una elevada tasa de germinación en una parcela no implica que la supervivencia también lo sea y viceversa, una germinación escasa (aunque no nula, claro está) puede ir seguida de una tasa moderada de supervivencia como es el caso de las parcelas tipo Restos del bloque NW. Así, el coeficiente de correlación entre la tasa de germinación y la de supervivencia resulta significativo pero bajo $(\rho=0,297)$ lo que confirma que los lugares aptos para la germinación no siempre son los más adecuados para la supervivencia posterior (Battaglia y Reid, 1993). 


\subsubsection{ESTABLECIMIENTO DE LAS PLÁNTULAS DE PINO SILVESTRE EN EL ÁREA DE ESTUDIO (SUPERVIVENCIA EN AÑOS 2 Y 3)}

A continuación en las tablas 36 y 37 y en la figura 39 se muestra la evolución de individuos vivos a lo largo de los tres períodos vegetativos considerados agrupando tanto por bloques como por tipos de cobertura vegetal sobre el suelo (Escarificado, Hierba, Matorral, Restos).

En valor absoluto, de las 24.000 semillas inicialmente colocadas tan solo 39 brinzales sobreviven al cabo de tres años, valor extremadamente bajo que, además, se puede matizar distinguiendo incluso casos especialmente extremos. Así, de las 6.000 semillas sembradas por orientación al cabo de tres años solo sobrevive 1 planta en orientación NW, repitiéndose el resultado en la orientación S; en cuanto a la cobertura, en el caso de la hierba aparecen tan solo 3 plantas vivas a los tres años, también a partir de 6.000 piñones sembrados.

En definitiva, lo observado equivaldría a decir que por cada 1.000 semillas viables de pino silvestre que llegan al suelo, en torno a 170 consiguen germinar, 14 superan el primer período estival, 2 el segundo y menos de 2 el tercero. Las cifras de supervivencia y establecimiento observadas corresponden al período $2004-2006$ que, tal y como se describió en el apartado 4.1.2. Caracterización termo-pluviométrica del período de estudio, son tres años de los denominados 'malos' para el regenerado. El 2004, tras una primavera húmeda presentó un verano con un 50\% más de déficit que el año medio (tabla 17), el 2005 y el 2006 directamente fueron dos de los años más secos de toda la serie analizada entre 1995 y 2014 (figura 19).

Estos datos ponen de manifiesto las dificultades iniciales para la instalación de la regeneración de pino silvestre en medio mediterráneo, y la enorme dependencia que el éxito del proceso de establecimiento inicial del regenerado presenta en relación con las condiciones del período estival. Se confirma que para lograr una instalación masiva del diseminado, es imprescindible que coincidan un año de abundante disponibilidad de semilla con varios veranos suaves (no extremadamente caluroso y con algunas tormentas) que permitan el establecimiento de las plántulas. En la medida en que esto no ocurre, la instalación se produce aisladamente y reducida a aquellos puntos en los que el microambiente resulta favorable para la germinación y la posterior supervivencia.

Aunque la mayor tasa de mortalidad se produce durante el primer período vegetativo, siguen muriendo brinzales al menos hasta el tercer año de medición. En este último período, no obstante la supervivencia aumenta considerablemente llegando hasta el 50\%. Esta tasa decreciente de mortalidad es razonable: los individuos que van progresivamente sobreviviendo lo hacen desarrollando a su vez un sistema radical y una parte aérea cada vez mayores que aumentarán sus posibilidades de supervivencia.

Tabla 36. Porcentajes de germinación inicial (junio 2004), y Supervivencia y Éxito de establecimiento durante el mes de octubre de los tres años considerados para cada uno de los bloques experimentales.

\begin{tabular}{|c|c|c|c|c|c|c|c|c|}
\hline \multirow{2}{*}{ Bloque } & \multirow{2}{*}{$\%$ G } & \multicolumn{2}{|c|}{ Oct - Año1 } & \multicolumn{2}{|c|}{ Oct - Año 2} & \multicolumn{3}{|c|}{ Oct - Año 3} \\
\hline & & $\%$ Sup & \%Éxito & $\%$ Sup & \%Éxito & $\%$ Sup & \%Éxito & Total plantas vivas \\
\hline NE & 30,0 & 9,3 & 3,48 & 21,1 & 0,69 & 50,8 & 0,35 & 30 \\
\hline NW & 11,8 & 7,8 & 0,95 & 1,7 & 0,01 & 100,0 & 0,01 & 1 \\
\hline SE & 18,1 & 3,8 & 0,70 & 20,0 & 0,11 & 77,8 & 0,08 & 7 \\
\hline S & 8,8 & 3,0 & 0,27 & 5,9 & 0,01 & 100,0 & 0,01 & 1 \\
\hline Total & 17,2 & 7,3 & 1,35 & 17,5 & 0,20 & 55,7 & 0,11 & 39 \\
\hline
\end{tabular}


Así mismo, y en relación con las orientaciones estudiadas (tabla 31), se detectan grandes diferencias en el comportamiento de los bloques, tanto en la germinación como en la posterior supervivencia., obteniéndose los mejores resultados en NE, y los peores en S y NW. No obstante, la tasa de éxito al cabo de los tres años fue tan baja que las diferencias en número de pies resultan irrisorias, y seguramente sin trascendencia alguna a efectos prácticos.

Tabla 37. . Porcentajes de Supervivencia y Éxito de establecimiento (total vivos sobre total sembrados) durante el mes de octubre de los tres años considerados para los distintos tipos de cobertura considerados.

\begin{tabular}{|c|c|c|c|c|c|c|c|c|}
\hline \multirow{2}{*}{ Cobertura } & \multirow{2}{*}{$\%$ G } & \multicolumn{2}{|c|}{ Oct - Año1 } & \multicolumn{2}{|c|}{ Oct - Año 2} & \multicolumn{3}{|c|}{ Oct - Año 3} \\
\hline & & $\%$ Sup & \%Éxito & $\%$ Sup & \%Éxito & \%Sup & \%Éxito & Total plantas vivas \\
\hline Escarificado & 20,4 & 11,1 & 2,65 & 12,1 & 0,27 & 39,1 & 0,11 & 9 \\
\hline Hierba & 15,2 & 1,8 & 0,28 & 21,1 & 0,05 & 75,0 & 0,04 & 3 \\
\hline Matorral & 15,5 & 7,6 & 1,28 & 23,6 & 0,25 & 61,9 & 0,15 & 13 \\
\hline Restos & 17,6 & 6,7 & 1,18 & 21,6 & 0,26 & 63,6 & 0,16 & 14 \\
\hline Total & 17,2 & 7,3 & 1,35 & 17,5 & 0,20 & 55,7 & 0,11 & 39 \\
\hline
\end{tabular}

Las distintas coberturas también presentaron un comportamiento desigual a lo largo del tiempo. Destaca particularmente la Hierba por ser la que peores tasas de germinación, supervivencia y éxito presenta; en cualquier caso, sus peores resultados al final del periodo de estudio parecen explicarse por la bajísima supervivencia en el primer verano, ya que las tasas de supervivencia en los dos años siguientes son similares o incluso mejores que los del resto de casos analizados. Matorral y Restos por el contrario, se mantienen en un comportamiento similar y constante a lo largo de todo el período considerado.

Fig. 39. Evolución del número total de brinzales vivos durante el período de estudio para los distintos tipos de cobertura considerados frente al total germinado en el año inicial (2004)

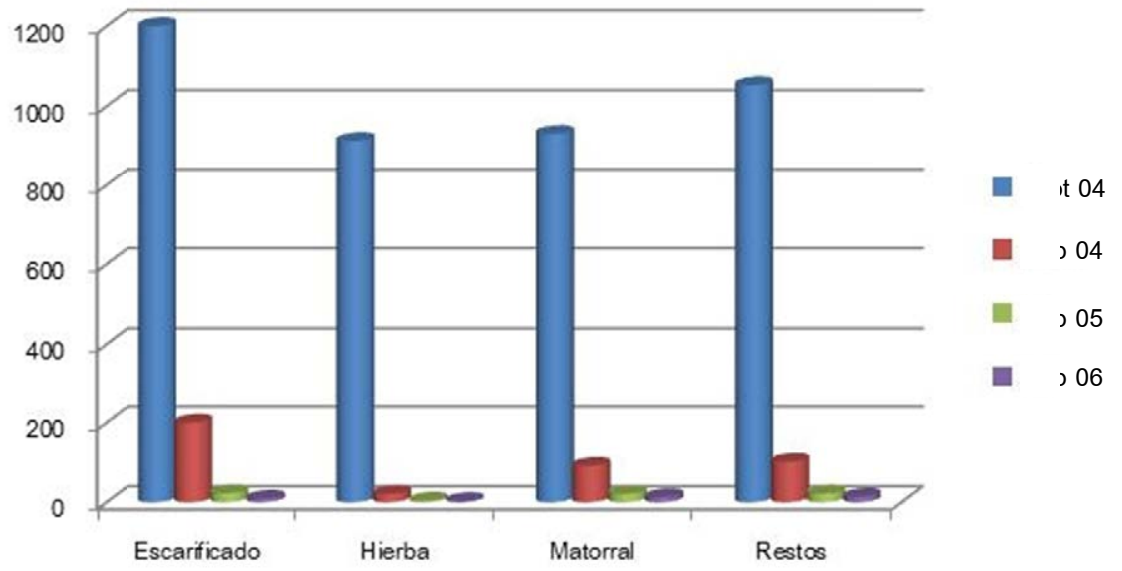

Gtot: $n^{\circ}$ total de germinados durante el primer período vegetativo (2004); Sup04 // Sup05 // Sup06: $n^{\circ}$ total de plántulas vivas tras los períodos estivales de 2004, 2005 y 2006 respectivamente

Con respecto a las parcelas en las que se llevó a cabo un escarificado, hay que destacar que tras una sensible mejoría de los resultados de germinación y supervivencia durante el primer período estival, el comportamiento de estas parcelas empeora, motivo por el cual el resultado del tratamiento sobre la supervivencia al final del período de tres años no resulta significativo. Dado que este tratamiento afectó a los $10 \mathrm{~cm}$ superficiales del suelo, nuestra hipótesis es que la escarificación sí consiguió aumentar de manera muy 
clara las tasas de germinación y supervivencia del primer año por la acción combinada de varios de sus efectos, presentes o no en función de la situación de partida: eliminación de estrato herbáceo o capa superficial de restos sin descomponer, con lo que ello supone de anulación de sus efectos negativos sobre germinación y primer desarrollo del sistema radical de las plántulas de pino ya analizados en otros puntos; aumento de la permeabilidad, etc. Sin embargo, si los sistemas radicales no consiguen atravesar el horizonte afectado los efectos posiblemente pasen a ser negativos básicamente en relación con la menor capacidad de retención del agua en el mismo. $Y$ desde luego en un año los sistemas radicales de los pinitos recién instalados no van a crecer esos $10 \mathrm{~cm}$ de profundidad. 


\subsubsection{CONCLUSIONES PARCIALES}

La mayor parte de la germinación de pino silvestre en la zona de estudio durante el año 2004 se concentró en la segunda mitad del mes de mayo y la primera mitad de junio, iniciándose el proceso en las parcelas escarificadas antes que en el resto. La fase de establecimiento inicial, tres años después de la siembra, presenta una tasa de éxito muy baja de aproximadamente el $0,11 \%$ de los sembrados. Dicha tasa es provocada por una elevada mortalidad durante el primer período estival $(>92 \%)$ tras una tasa de germinación en torno al $17 \%$ de las semillas viables que llegan al suelo.

Aunque el mayor número de pérdidas se produce durante el primer verano, la mortalidad sigue siendo elevada hasta el tercer período vegetativo, en que comienza a reducirse mucho descendiendo hasta menos del $50 \%$, si bien el número de individuos que sobrevive hasta ese punto es ya apenas del $0,1 \%$ sobre el total sembrado inicialmente. De hecho, el número de plántulas de pino silvestre que sobrevive al tercer año es tan reducido que, a efectos prácticos, se puede considerar irrelevante en cualquiera de los casos. Seguramente las bajísimas tasas de éxito se deben, al menos en parte, a las circunstancias concretas de los años de estudio, de veranos especialmente secos.

La orientación parece influir en el proceso, obteniéndose mejores resultados en la umbría pura. En cuanto a la cobertura vegetal, influye en el proceso de establecimiento del regenerado de pino silvestre en el monte "Cabeza de Hierro". Así: la escarificación del suelo consigue mejorar tanto la germinación como la supervivencia del regenerado en el primer año, si bien después (años dos y tres) parecen ir especialmente peor en las parcelas así tratadas. La presencia de tapiz herbáceo, aunque no afecta en exceso a la germinación, sí empeora notablemente la tasa de supervivencia. En efecto, entre todos los tipos de cubierta observados la cobertura de herbáceas es la que presenta peores tasas de supervivencia tanto a corto como a medio plazo. La cobertura de matorral y de restos a pesar de no presentar las mejores tasas de germinación ni de supervivencia tras el primer verano, mantienen un buen comportamiento a medio plazo $\left(2^{\circ}\right.$ y $3^{\circ}$ períodos vegetativos).

La mortalidad se concentra en el mes de julio y final del mes de junio, aunque se mantiene en niveles relativamente elevados incluso hasta septiembre y octubre si en dichos meses la precipitación es escasa. La espesura de masa arbolada no parece influir en el momento de inicio de la germinación, y lo hace sobre las tasas de germinación a través de las variables directamente relacionadas con la luz incidente en el suelo (sunflecks, porcentajes de luz directa y difusa) en el sentido de que la germinación es peor con excesiva insolación; el efecto de la espesura sobre la germinación no aparece recogido por el área basimétrica o la fracción de huecos. La relación es mucho más evidente con la supervivencia, que aumenta significativamente cuanto menor es la espesura (el área basimétrica ahora sí sirve como indicador al respecto) y mayor la cantidad de luz (especialmente la difusa), tomando mucho peso la fracción de huecos situada inmediatamente encima del lugar posiblemente por su relación con la cantidad de agua disponible en el suelo tras las precipitaciones estivales.

Las tasas de germinación y supervivencia manifiestan una baja correlación lineal. Los lugares idóneos para la germinación no siempre son los más adecuados para la supervivencia posterior, y viceversa. 

4.4.

RED DE MUESTREO I: PERSISTENCIA DE LOS EFECTOS DEL

TRATAMIENTO DE ESCARIFICACIÓN 



\subsubsection{ESTADO GENERAL DE LA CUBIERTA VEGETAL Y LA CAPA SUPERFICIAL DEL SUELO DOS AÑOS DESPUÉS DEL TRATAMIENTO DE ESCARIFICACIÓN}

Tanto en la cubierta vegetal superficial como en el propio suelo todos los parámetros analizados presentaban, dos años después del escarificado, una notable recuperación, observándose valores próximos a los niveles medios de las parcelas no escarificadas (tabla 38).

Tabla 38. Efectos de la escarificación sobre el estado de la cubierta vegetal superficial y la capa superior del suelo dos años después del tratamiento: valores medios y diferencias de medias entre grupos analizadas mediante el test de la tStudent, tasa de recuperación en parcelas escarificadas en relación con los niveles medios de las parcelas no escarifcadas.

\begin{tabular}{lccccc}
\hline & No-Esc. & Esc. & $\Delta_{\text {Esc- No-Esc }}$ & $\begin{array}{c}p \text {-valor } \\
\text { (t-test })\end{array}$ & $\begin{array}{c}\text { Tasa de recuperación (\%) } \\
{\left[100 \times\left(\bar{X}_{\text {Esc }} / \bar{X}_{\text {No Esc }}\right)\right]}\end{array}$ \\
\hline Cobertura vegetal en superficie & & & & & \\
Matorral (\%) & 14.2 & 8.3 & -6.0 & $0.049^{*}$ & 58.1 \\
Herbáceas (\%) & 35.9 & 22.9 & -12.9 & $0.019^{*}$ & 64.0 \\
Restos ND (\%) & 80.3 & 69.6 & -10.7 & $0.036^{*}$ & 86.7 \\
Espesor restos ND [cm] & 3.4 & 1.7 & -1.7 & $0.001^{* *}$ & 50.6 \\
Espesor restos total [cm] & 6.9 & 7.6 & +0.7 & 0.170 & a \\
\hline Suelo & & & & & a \\
\% humedad & 11.8 & 13.8 & +1.9 & $0.079 \cdot$ & $\mathrm{a}$ \\
RP 0-10cm [kPa] & 945.8 & 871.0 & -74.8 & 0.245 & $\mathrm{a}$ \\
RP 10-20cm [kPa] & 1835.7 & 1708.2 & -127.6 & 0.125 & \\
\hline
\end{tabular}

No-Esc.: parcelas no escarificadas; Esc: parcelas escarificadas; Espesor restos ND [cm]: espesor de los restos sin descomponer en cm; Espesor restos total [cm]: espesor total de restos en suelo, en $\mathrm{cm}$. $\boldsymbol{\Delta}_{\text {Esc-No Esc: diferencia de }}$ medias entre parcelas escarificadas y no escarificadas; p-valor: nivel de significación para la comparación de medias en la muestra $\left(\mathrm{H}_{0}: \mu_{\text {esc }}=\mu_{\text {no esc }}\right)$; p-valor: $<0.001$ : *** $;<0.01$ : ** $;<0.05$ : * $;<0.1$ : $;$ RP: resistencia a la penetración en las profundidades especificadas; ${ }^{a}$ Tasa de recuperación no calculada para estos parámetros porque no se encontraron diferencias significativas.

a) Cobertura vegetal en superficie

Según las tasas de recuperación observadas (calculadas como se describe en el apartado 3.4. Análisis y tratamiento de datos), todos los tipos de cubierta vegetal contemplados recuperaron más de la mitad de los niveles medios no perturbados, pese a su total eliminación inicial (porcentajes de recuperación superiores al $50 \%$ en todas las características de vegetación consideradas).

La mayor tasa de recuperación (valor medio superior al $85 \%$ ) se produjo para la cobertura superficial de restos sin descomponer,lo que se explica por el aporte de restos por el dosel arbóreo y el matorral circundante, no alterado en modo alguno por el tratamiento. El porcentaje de recuperación del espesor de esta capa de restos frescos fue sin embargo mucho menor $(50,5 \%)$, ya que el aumento del espesor se produce por acumulación de capas sucesivas y ello requiere más tiempo que el recubrimiento superficial. El nivel de recuperación de las herbáceas, por su parte, resultó menor que el del \% de restos pero más elevado que el del matorral, lo que resulta lógico teniendo en cuenta la mayor rapidez de las dinámicas de regeneración de las herbáceas.

A fin de contrastar si, tras el proceso de recuperación, los niveles medios observados en las parcelas escarificadas difieren o no de forma significativa de los de las parcelas no alteradas, se han llevado a cabo tests de comparaciones de medias t-Student (tabla 38). 
A partir de los resultados, puede afirmarse que los niveles medios de las variables de cobertura vegetal de las unidades experimentales 'con' y 'sin' escarificación presentan diferencias significativas al 95\% de significación en todos los casos, con excepción del Espesor total de restos ( $p$-valor= 0,171 ). Dentro de las variables con diferencias significativas, los p-valores observados son muy variables de tal forma que, entre todas ellas, el Espesor de los restos sin descomponer es la única que presenta diferencias fuertemente significativas ( $p$-valor $<0,001)$. Por el contrario, la significación para los porcentajes de cubierta de matorral, herbáceas y restos varía entre 0,01 y 0,05 , lo que revela diferencias más débiles entre parcelas escarificadas y no escarificadas en relación con estos parámetros.

Resulta llamativo que, a pesar de las tendencias detectadas en relación con el espesor y el porcentaje de recubrimiento de restos no descompuestos, el espesor total de los mismos (restos sin descomponer + restos parcialmente descompuestos) no muestre cambios significativos como resultado de la escarificación ( $p$-valor= $0,170)$.

b) Suelo

Con respecto al comportamiento del suelo, el escarificado no afectó significativamente a los niveles de resistencia a la penetración encontrados ( $p$-valor >> 0,05 para las diferencias entre medias de parcelas escarificadas y no escarificadas). Dado que la escarificación aplicada afectó a una profundidad aproximada de $15 \mathrm{~cm}$, parece obvio que, inicialmente, debió alterar la resistencia a la penetración, parcialmente en el horizonte sub-superficial $(10-20 \mathrm{~cm})$ y completamente en el superficial $(0-10 \mathrm{~cm})$. Sin embargo, según estos resultados, dos años parecen haber sido tiempo suficiente para anular los efectos del escarificado sobre los niveles de compactación del suelo tanto hasta los $10 \mathrm{~cm}$ de profundidad como entre 10 y $20 \mathrm{~cm}$.

Los niveles medios de humedad encontrados fueron ligeramente superiores en las parcelas escarificadas, aunque con una significación muy débil ( $p$-valor=0,079). Además, los valores observados corresponden a un único momento de medición durante el mes de mayo, por lo que no informan sobre la evolución de la tasa de humedad durante el período posterior de mayor déficit hídrico (aptdo. 4.1.2. Caracterización termopluviométrica del período de estudio). Aun así, durante el mes de mayo ya está en marcha el proceso de germinación y primer desarrollo de los nuevos brinzales y la humedad disponible resulta clave para ambos procesos desde sus inicios. Por este motivo, a pesar de sus limitaciones (baja significación y época concreta) este resultado implicaría que, dos años después, la aplicación del escarificado aún seguiría siendo positiva para el regenerado en este sentido. 


\subsubsection{INFLUENCIA DE LA MASA EN LA EVOLUCIÓN POST-ESCARIFICADO}

Tanto la fracción de huecos del dosel (\%HD) como el área basimétrica (AB) mostraron correlación significativa con la mayoría de los parámetros de suelo y cobertura vegetal analizados en las parcelas escarificadas y en las no escarificadas (tabla 39). Lo cual es muy razonable, teniendo en cuenta que la luz incidente sobre el suelo es consecuencia directa de la estructura de la cubierta (Catovsky y Bazzaz, 2002b) y que, a su vez, el efecto de dicha luz juega un papel trascendental en las condiciones del suelo, de gran importancia porque, en última instancia, permitirán o no la germinación, supervivencia y crecimiento de las nuevas plantas (Catovsky y Bazzaz, 2002a; Emborg, 1998; Messier y Puttonen, 1995; Montgomery y Chazdon, 2002; Pardos et al., 2007).

El hecho de que el estado del suelo y la cobertura vegetal de las parcelas tratadas muestre correlación significativa con las condiciones de la masa a pesar de la completa eliminación de la vegetación superficial y de la remoción de los primeros centímetros del sustrato dos años antes, pone de manifiesto que esa masa circundante influyó en el proceso de recuperación de suelo y cobertura.

El signo y magnitud de las correlaciones encontradas varía en función del parámetro considerado; pero el tratamiento de escarificación no invirtió en ningún caso el tipo de tendencia encontrada en condiciones de noescarificación. Las correlaciones encontradas fueron siempre las esperables.

Tabla 39. Coeficientes de correlación de Pearson entre las variables de espesura de masa y las relativas a suelo y cobertura vegetal en superficie.

\begin{tabular}{|c|c|c|c|c|c|c|c|c|c|c|c|c|c|}
\hline & \multicolumn{3}{|c|}{$\mathrm{HD} 15^{\circ}(\%)$} & \multicolumn{3}{|c|}{$\operatorname{HD} 90^{\circ}(\%)$} & \multicolumn{3}{|c|}{ ABTot $\left(m^{2} / h a\right)$} & \multicolumn{2}{|c|}{ ABPs $\left(m^{2} / h a\right)$} & \multicolumn{2}{|c|}{ ABQp (m²/ha) } \\
\hline & No-Esc & Esc & & No-Esc & Esc & & No-Esc & Esc & & No-Esc & Esc & No-Esc & Esc \\
\hline Herbáceas (\%) & $0.442^{* * *}$ & 0.484 & $* *$ & $0.282^{* *}$ & 0.401 & $* *$ & $-0.290^{* *}$ & -0.385 * & ** & $-0.232^{* *}$ & $-0.319 *$ & $-0.247^{* *}$ & -0.272 \\
\hline Matorral (\%) & $0.203^{*}$ & 0.233 & & 0.122 & -0.019 & & -0.145 & -0.178 & & -0.155 & -0.178 & -0.011 & -0.041 \\
\hline Restos ND (\%) & $-0.413^{* * *}$ & -0.762 & $* * *$ & $-0.465^{\star * *}$ & -0.800 & $* * *$ & $0.444^{* * *}$ & 0.721 & $* * *$ & $0.407^{* * *}$ & $0.660^{* * *}$ & $0.230^{* *}$ & $0.336^{*}$ \\
\hline Restos ND (cm) & $-0.521^{* * *}$ & -0.460 & $* *$ & $-0.408^{* * *}$ & -0.338 & & $0.399^{* * *}$ & 0.268 & & 0.340 & 0.224 & $0.279^{* *}$ & 0.183 \\
\hline Restos Total (cm) & $-0.436^{* * *}$ & -0.551 & $* * *$ & $-0.369^{* * *}$ & -0.577 & $* * *$ & $0.459^{* * *}$ & 0.474 & ** & $0.399^{* * *}$ & $0.413^{* *}$ & $0.299^{* * *}$ & 0.279 \\
\hline Humedad (\%) & $0.510^{* * *}$ & 0.617 & $* * *$ & $0.324^{* * *}$ & 0.550 & $* * *$ & $-0.334^{* * *}$ & -0.527 & $* * *$ & $-0.244^{\star *}$ & $-0.360^{*}$ & $-0.351^{* * *}$ & $-0.579^{* * *}$ \\
\hline $\mathrm{RP}_{0-10}(\mathrm{kPa})$ & $0.366^{* * *}$ & 0.581 & $* * *$ & $0.387^{* * *}$ & 0.385 & ** & $-0.380^{* * *}$ & -0.459 & ** & $-0.325^{\star \star *}$ & $-0.465^{* *}$ & $-0.264^{* *}$ & -0.091 \\
\hline $\mathrm{RP}_{10-20}(\mathrm{kPa})$ & $0.330^{* * *}$ & 0.419 & ** & $0.418^{* * *}$ & 0.437 & ** & $-0.362^{* * *}$ & -0.311 & * & $-0.242^{* *}$ & -0.159 & $-0.443^{* * *}$ & $-0.489^{* *}$ \\
\hline
\end{tabular}

No-Esc: parcelas no escarificadas; Esc: parcelas escarificadas; ABPs // ABQp // ABTot: áreas basimétricas de pino, rebollo y total respectivamente en un radio de $15 \mathrm{~m}$ en torno a cada parcela; $\mathbf{H D}^{\circ} \mathbf{5}^{\circ} \%$ ) $/ / \mathrm{HD}^{\circ}(\%)$ :porcentaje de huecos del dosel en casquete esférico de ángulo cenital $15^{\circ}$ por encima de cada parcela y en todo el hemisferio $\left(90^{\circ}\right)$ respectivamente; Restos ND (\%): cobertura superficial de restos no descompuestos; Restos ND (cm): espesor de la capa de restos no descompuestos acumulada sobre el suelo; Restos Total (cm): espesor de la capa total de material orgánico acumulado sobre el suelo (no descompuesto y en diferentes grados de descomposición); RP: resistencia a penetración del suelo en las profundidades indicadas; p-valor: $<0.001:{ }^{* *} ;<0.01:{ }^{* *} ;<0.05:{ }^{*} ;<0.1$ :

A continuación se analizan las relaciones encontradas entre la espesura y las variables de suelo y cobertura vegetal estudiadas, intentando destacar en su caso el efecto del tratamiento de escarificación aplicado.

a) Cobertura vegetal en superficie

Todas las variables de cobertura vegetal en superficie, a excepción del porcentaje de recubrimiento de matorral, muestran correlación significativa con las condiciones de masa tanto en las parcelas escarificadas como en las no escarificadas. 
Los niveles de correlación están próximos en ambos grupos, salvo en el caso del \% de recubrimiento de restos, en el que la correlación prácticamente se duplica en el grupo de parcelas tratadas. En efecto: aunque la acumulación de restos fue siempre significativamente mayor bajo cubierta en el caso del \% de recubrimiento de restos no descompuestos, esta tendencia fue mucho más clara para las parcelas escarificadas que para las no escarificadas (coeficiente de correlación en torno al 0,77 frente al 0,45). Este hecho es fácil de entender si se tiene en cuenta que, tras la aplicación del tratamiento, la cobertura de restos no descompuestos adquirió valor cero y que el tiempo transcurrido hasta el momento de las mediciones sólo fue suficiente para recubrir en mayor o menor medida la capa superficial (dependiendo del nivel de espesura) pero no permitió, en la mayoría de los casos, la acumulación de capas sucesivas que borrase el efecto en superficie (cosa que sí ocurre con mucha mayor frecuencia en las parcelas no escarificadas).

En lo referente a las herbáceas, el \% de recubrimiento resultó siempre menor cuanto mayor fue la espesura, ya que las herbáceas se desarrollan mejor en los claros que bajo cubierta. Esta correlación es significativa en relación tanto con el área basimétrica de la masa arbolada circundante como con la densidad de huecos del dosel sobre las parcelas (justo por encima de los puntos de muestreo $\left(\mathrm{HD} 15^{\circ}\right)$ o en todo el hemisferio sobre el punto $\left(\mathrm{HD} 90^{\circ}\right)$.

Hay que destacar, por último que, entre todas las variables analizadas, la única que no ha resultado estár significativamente correlacionada con la espesura de la masa arbolada es la cobertura de matorral, respecto a la cuál todos los coeficientes de correlación son bajos y de significación muy débil o nula. A la hora de interpretar este comportamiento, debemos recordar que en "matorral" se incluyen especies que soportan en grado variable vivir bajo sombra de arbolado por lo que no es sorprendente la ausencia de relación. Este hecho es extensible tanto a las parcelas no escarificadas como a las escarificadas, que sólo recuperaron el recubrimiento arbustivo si ya lo tenían previamente (o si eran limítrofes), sin que la distribución espacial o la composición específica de tal recubrimiento resultaran alteradas en modo alguno, por lo que resulta lógico que no alteren tampoco su coeficiente de correlación con la espesura de la masa.

b) Suelo

La humedad edáfica y la resistencia a la penetración mostraron valores más altos cuanto menor era la cubierta arbolada, tanto en las parcelas escarificadas como en las no escarificadas (correlación negativa y, en general, fuertemente significativa con la espesura).

En el caso de la resistencia a la penetración este hecho se fundamenta esencialmente en: I) la presencia bajo cubierta de un mayor espesor de acumulación de restos en distintos estados de descomposición pero, en cualquier caso, con una resistencia inferior a la del suelo mineral; II) la menor incidencia y efecto bajo cubierta de los agentes compactadores (tanto de origen climático como antrópico).

Con respecto a la humedad edáfica, la tendencia a valores menores en las zonas localizadas bajo cubierta es debida al proceso denominado "sombra seca": como consecuencia de la intercepción de la precipitación (y no sólo de la luz) por las copas de los árboles, se genera por debajo de ellas una zona de baja recepción de agua de Iluvia. Este hecho es especialmente acusado con lluvias de baja intensidad, pero pierde relevancia durante los períodos de lluvias abundantes (que sobrepasan la capacidad de intercepción de la cubierta). Durante los períodos cálidos y secos la tendencia puede llegar a invertirse cuando las precipitaciones sean tan escasas que no compensen la mayor pérdida de humedad generada por evapotranspiración en las zonas de baja espesura arbórea debido a las elevadas temperaturas alcanzadas.

A este respecto debemos recordar que las mediciones de humedad se llevaron a cabo en el mes de mayo, momento en el que sí se puede considerar como dominante el proceso de "sombra seca" por no contar ya con abundantes lluvias pero tampoco estar aún en el periodo cálido y seco que llega más adelante. 
En definitiva y a modo de resumen sobre el efecto de la escarificación con respecto a las variables de masa: hay que destacar que el tratamiento realizado no altera excesivamente las tendencias originales de las parcelas escarificadas, de tal forma que los problemas asociados a las distintas zonas en función de su espesura, dado que ésta no se modifica con el tratamiento, van a tender a repetirse. La mayor o menor eficacia del tratamiento dependerá, por tanto, de la velocidad con que se produzca la recuperación en cada tipo de cubierta superficial, pero no cabe esperar cambios de vegetación predominante. 


\subsubsection{IMPLICACIONES PARA LA REGENERACIÓN}

Una vez descritas las tendencias generales observadas en las variables edáficas y de cobertura vegetal transcurridos dos años tras la escarificación, reviste especial interés valorar, en función de ellas, qué eficacia cabe esperar del tratamiento aplicado en relación con la mejora de la regeneración. Diado el corto período contemplado, dentro del proceso de regeneración, procede valorar el modo en que los cambios observados pueden modificar la eficacia del tratamiento sobre la mejora de la germinación y el establecimiento inicial de las plántulas.

Los tres principales aspectos que pretende mejorar la escarificación en estas etapas iniciales del proceso de regeneración natural son: a) el contacto semilla-suelo; b) el desarrollo radical de las plántulas (velocidad y extensión); y c) la disponibilidad hídrica del suelo. Su funcionalidad se valora, por tanto en función de esos tres aspectos:

\section{a) Contacto semilla-suelo}

En lo referente al contacto semilla-suelo mineral, la alta tasa de recuperación observada en los parámetros de cobertura vegetal $(>50 \%)$ parece implicar que la eficacia del tratamiento en este aspecto tiene una duración muy limitada. No cabe duda de que la existencia de diferencias significativas a los dos años permite suponer que los piñones que hayan caído hasta ese momento habrán tenido mayor probabilidad de contactar adecuadamente con el suelo mineral. No obstante, dada la vecería de la especie y la dependencia de adecuadas condiciones climatológicas para asegurar una abundante regeneración (Mast y Veblen, 1999) todo parece indicar que se trata de un plazo excesivamente corto.

$\mathrm{Si}$, además de fijarnos en los valores medios, tenemos en cuenta también las distribuciones de frecuencias de los valores observados en las parcelas escarificadas y no escarificadas (figura 40), se pone de manifiesto que, a pesar de que los valores medios de recuperación de cubierta encontrados fueron altos, en el caso del porcentaje de hierba y matorral las diferencias más marcadas entre distribuciones se producen en la frecuencia de parcelas con alto recubrimiento ( $>75 \%$ para hierba y $>50 \%$ para matorral). Así, la frecuencia de parcelas con cobertura completa de estos tipos vegetales, que son precisamente las susceptibles de generar dificultades para el contacto semilla-suelo (Modrý et al., 2004) aún es limitada en la muestra de parcelas escarificadas ( $<10 \%$ para hierba y $<1 \%$ para matorral frente a un $30 \%$ de no escarificadas con cobertura completa de hierba y un $10 \%$ con cobertura completa de matorral).

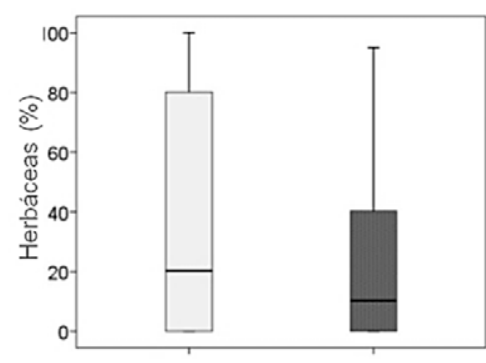

NO ESCARIF.

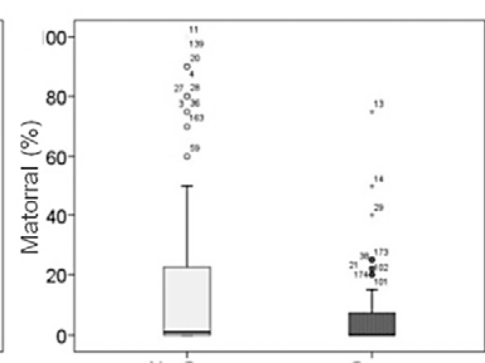

NO ESCARIF. ESCARIF

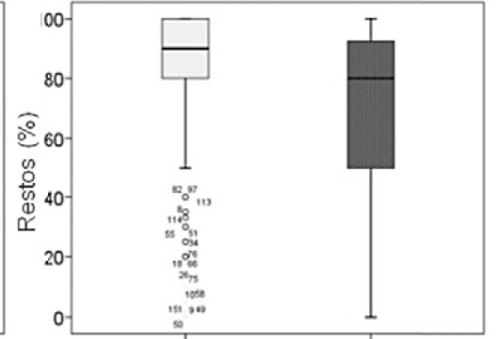

NO ESCARIF.

ESCARIF

Fig. 40. Diagramas de caja para las variables relativas a la cobertura vegetal del suelo, para parcelas escarificadas y no escarificadas.

En el caso de la cobertura de los restos no descompuestos - factor transcendental en el proceso de regeneración (Caccia y Ballaré, 1998) transcurridos dos años tras el tratamiento -, la mayoría de las parcelas presentó un recubrimiento superficial de restos superior al $75 \%$ tanto en la muestra escarificada como en la no escarificada (figura 40). Si añadimos esta cifra al elevado porcentaje de recuperaciónı del 86,7\% de este 
parámetro, ya señalado anteriormente (tabla 39), todo parece indicar que, previsiblemente, el primer factor susceptible de volver a dificultar el contacto suelo-semilla tras la escarificación en la zona de estudio es el recubrimiento de restos vegetales.

No obstante, se destaca una vez más que la tasa de recuperación del recubrimiento de restos está ligada a la espesura colindante, por lo que estas dificultades tendrán menos relevancia cuando la espesura sea baja (o cuando se disminuya mediante la aplicación de cortas de regeneración).

Así mismo, hay que tener en cuenta que, más que del recubrimiento superficial, la trascendencia del efecto de los restos vegetales depende del espesor de la capa que se acumule (Caccia y Ballaré, 1998; GonzálezMartínez y Bravo, 1999). Los cambios provocados por la escarificación favorecen la descomposición de los restos vegetales (Johansson, 1994). Por otro lado la recuperación de dicho espesor requiere la acumulación de capas sucesivas de restos y es, por tanto, más lenta que la recuperación de la cobertura superficial (que, en cierta medida, equivale a la recuperación de la primera de esas capas). Por este motivo, en las parcelas escarificadas, a pesar de la rápida velocidad de recuperación superficial, el espesor de lla capa de restos no descompuestos fue la variable que menos se recuperó de entre todas las contempladas: se limitó a un espesor medio de $1,7 \mathrm{~cm}$ frente a los $3,4 \mathrm{~cm}$ originales (tabla 38 ).

Este hecho habría resultado muy adecuado para las semillas de cara a su contacto con el suelo de no ser porque, a pesar de la reducción de la capa de restos no descompuestos, el espesor total de restos (no descompuestos + parcialmente descompuestos) no varió significativamente tras el tratamiento (figura 41).
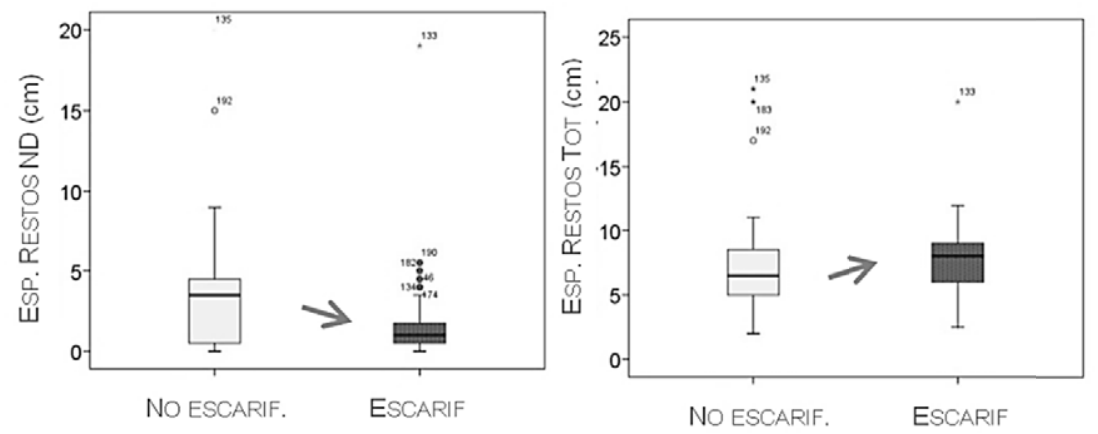

Fig. 41. Diagramas de caja para el espesor de restos no descompuestos y el del total de restos para las parcelas escarificadas y no escarificadas.

Si llevamos a cabo una regresión lineal entre el espesor total de restos (no descompuestos y parcialmente descompuestos) y el espesor de la parte no descompuesta, se pone de manifiesto que el total de material orgánico acumulado sobre el suelo está integrado por un espesor fijo común a todas las parcelas y que no depende de la incorporación de nuevo material (término independiente $=4,1 \mathrm{~cm}$ ) y un espesor variable función de esa incorporación de restos frescos que se sitúa en torno al $80 \%$ del espesor de éstos. Además, en los casos en los que la parcela se escarifica, el modelo encuentra que la profundidad total resulta ser $2,05 \mathrm{~cm}$ mayor que lo estimado a partir del espesor de la capa no descompuesta acumulada con posterioridad al tratamiento (tabla 40).

Tabla 40. Modelo de regresión para el espesor total de restos en función del espesor de restos no descompuestos y del tratamiento aplicado en el suelo (escarificación).

\begin{tabular}{lllll}
\hline Fuente & Coef. & Error St. & $\mathrm{t}$ valor & $\operatorname{Pr}(>\mathrm{t})$ \\
\hline Término Independiente & $4.13^{* * * *}$ & 0.224 & 18.4 & $<0.001$ \\
RND $(\mathrm{cm})$ & $0.81^{* * *}$ & 0.048 & 17.0 & $<0.001$ \\
ESC & $2.05^{* * *}$ & 0.320 & 6.4 & $<0.001$ \\
\hline
\end{tabular}

RND =espesor de restos no descompuestos $(\mathrm{cm})$. ESC = variable dicotómica que indica si la escarificación ha sido o no aplicada (1: sí; 0: no). ${ }^{* * *}$ : p-valor $<0,001$. 
Si transformamos la ecuación del modelo anterior tomando como espesor de restos no descompuestos (RND) de las parcelas escarificadas el espesor previo al tratamiento [RND+1.7·ESC] tenemos que, en la nueva ecuación (equivalente a la anterior), la primera parte del modelo correspondería al espesor total que se estima tendría la parcela antes de escarificar $[4.1+0.81 \cdot(R N D+1.70 \cdot E S C)]$, mientras que el nuevo término independiente $[2.05-1.70 / 0.81=0.70]$ correspondería al aumento de espesor de la capa como consecuencia del tratamiento de escarificación. La ecuación correspondiente se indica a continuación (Ec.2.). El aumento de $0.7 \mathrm{~cm}$ estimado por el modelo para el espesor total de restos coincide con el incremento observado en la media de la muestra escarificada con respecto a la no escarificada.

$$
\begin{aligned}
& \boldsymbol{R} \boldsymbol{T}_{\boldsymbol{i}}=4.13+0.81 *\left(\boldsymbol{R N} \boldsymbol{D}_{i}\right)+\underline{2.05} \cdot \boldsymbol{E S C _ { i }}+e_{i j} \\
& \boldsymbol{R} \boldsymbol{T}_{\boldsymbol{i}}=4.13+0.81 *\left(\boldsymbol{R N} \boldsymbol{D}_{i}+1.70 \cdot \boldsymbol{E S} \boldsymbol{C}_{\boldsymbol{i}}\right)+0.7 \cdot \boldsymbol{E S} \boldsymbol{C}_{i}+e_{i j}
\end{aligned}
$$

$\mathbf{R} \mathbf{T}_{\mathrm{i}}=$ Espesor de restos totales en la parcela 'i'; $\mathbf{R N D}_{\mathbf{i}}=$ Espesor de restos no descompuestos en la parcela 'i'. $\mathbf{E S C}_{\mathbf{i}}$

= variable dicotómica asociada a la aplicación o no de escarificación (1: sí; 0: no).

Todo parece indicar, por tanto, que el tratamiento realizado no alteró el equilibrio acumulación-transformación de restos en la masa (ESC no afecta a la pendiente del modelo) y que, lejos de generar una disminución del espesor total de restos acumulados en las parcelas, la escarificación generó un ligero incremento de esta variable, como consecuencia de la incorporación a la capa de restos más humificados que los restos nodescompuestos que había acumulados en el momento del laboreo.

Según lo señalado en bibliografía, dentro de la capa de material orgánico que se acumula sobre el suelo minerallo que más entorpece la germinación y el arraigo de las semillas son los restos no alterados, entre otras cosas por su menor capacidad de retención de agua (Hui et al., 2012), baja inercia térmica (Oleskog y Sahlén, 2000b) y escasa capacidad para proveer un anclaje adecuado para las raíces en su avance por el suelo (Bengough y Mullins, 1990). No obstante, una excesiva profundidad de la capa más humificada también puede suponer, aunque en menor medida, una barrera para las semillas en ambientes secos y calurosos (Oleskog y Sahlén, 2000b).

En la zona geográfica contemplada, la principal limitación que tienen que superar los nuevos individuos, tanto en la germinación como en la posterior supervivencia inicial, son, precisamente. la sequía y las altas temperaturas, por lo que cabe esperar que tanto el espesor de restos no descompuestos como el espesor total constituyan una barrera efectiva para el contacto de la semilla con el suelo mineral. Este hecho ya ha sido citado en entornos mediterráneo para otras especies de pino (Adili et al., 2013). Pero también ha sido señalado en el pasado, en relación con el propio monte de estudio, en los documentos técnicos de gestión (Montero, 1987). El efecto del escarificado sobre la temperatura del suelo ha sido estudiado en Kubin y Kemppainen (1994), aunque en un medio muy distinto al del presente trabajo.

Dado que el tratamiento de escarificación ensayado no consigue reducir el espesor total de la capa de material orgánico acumulado sobre el suelo, parece lógico pensar que su eficacia en la mejora de la germinación y la supervivencia se va a ver seriamente comprometida en las zonas de mayor acumulación de restos vegetales. Como se ha señalado con anterioridad, estas zonas son las de mayor espesura, tanto por el mayor ritmo de aporte de hojarasca como por el menor ritmo de mineralización y humificación asociado a las condiciones bajo cubierta (Gómez Sanz, 2002). Cabe esperar, por tanto, que en las parcelas de estudio tanto el efecto inicial del tratamiento sobre el contacto suelo-semilla como su duración posterior se vean especialmente limitadas bajo cubierta.

Al margen de estos resultados, en principio, cuando en especies de luz o media luz surge la necesidad de conseguir regeneración natural en escenarios de arbolado adulto en espesura completa o trabada (lo más 
habitual), se considera que es precisamente el exceso de espesura el que impide en primer término la aparición de nuevos brinzales (Emborg, 1998; Messier y Puttonen, 1995; Montgomery y Chazdon, 2002; Rojo y Montero, 1996), por lo que los tratamientos sobre el suelo, caso de existir, van siempre precedidos por o simultaneados con cortas de regeneración para reducir la espesura.

Teniendo en cuenta las características de partida de la masa, puede ocurrir que en estas situaciones el recubrimiento y el espesor de restos sean muy elevados. Sin embargo, a la hora de evaluar los efectos esperados de un eventual tratamiento de escarificación, hay que tener en cuenta la puesta en luz que suele acompañarlos. Dicha puesta en luz reduce la tasa posterior de incorporación de restos al sistema, al disminuir la espesura, y aumenta las tasas de mineralización de tales restos por el cambio de las condiciones microestacionales (mayor aireación, incidencia de radiación solar y temperatura) (Gómez: Sanz, 2002), con lo que cabe esperar que la reducción de la superficie y espesor de la capa de restos sea más efectiva y duradera que la observada en la zona de estudio. No obstante, dependiendo de las características del tratamiento, esta puesta en luz también va a aumentar la velocidad de entrada de herbáceas y matorral.

Al margen de todo esto y teniendo en cuenta todo lo visto hasta el momento, parece claro que, para mejorar el contacto suelo-semilla inicial generado por el tratamiento de escarificación en las zonas de gran acumulación de restos se requerirá, en cualquier caso, que la profundidad de la labor asegure la mezcla de los restos con el suelo mineral y no su mera remoción.

\section{b. Desarrollo radical}

La resistencia mecánica al desarrollo radical es uno de los factores determinantes en el desarrollo de la vegetación (Letey, 1985). La resistencia del suelo está relacionada negativamente con el crecimiento y la extensión de los sistemas radicales en ausencia de otras limitaciones (Miller et al., 2004; Zou et al., 2001). El segundo de los objetivos del tratamiento de escarificación es mullir el suelo, aumentando su porosidad y disminuyendo su dureza, de tal forma que las raíces puedan expandirse más y más rápidiamente. Se pretende asegurar que el regenerado logre alcanzar un desarrollo radical suficiente (profundidad y volumen prospeccionado) para maximizar su probabilidad de supervivencia cuando se produzcan las condiciones de baja humedad y elevada temperatura del período estival.

Tal y como se ha indicado en el apartado anterior, la resistencia a penetración edáfica de las parcelas escarificadas entre 0 y $20 \mathrm{~cm}$ de profundidad se recuperó hasta no mostrar diferencias significativas con las parcelas no tratadas en tan solo dos años. En todos los casos, los niveles medios encontrados tendieron a ser más elevados en los claros que bajo cubierta y más elevados en profundidad que en superficie (figura 42)
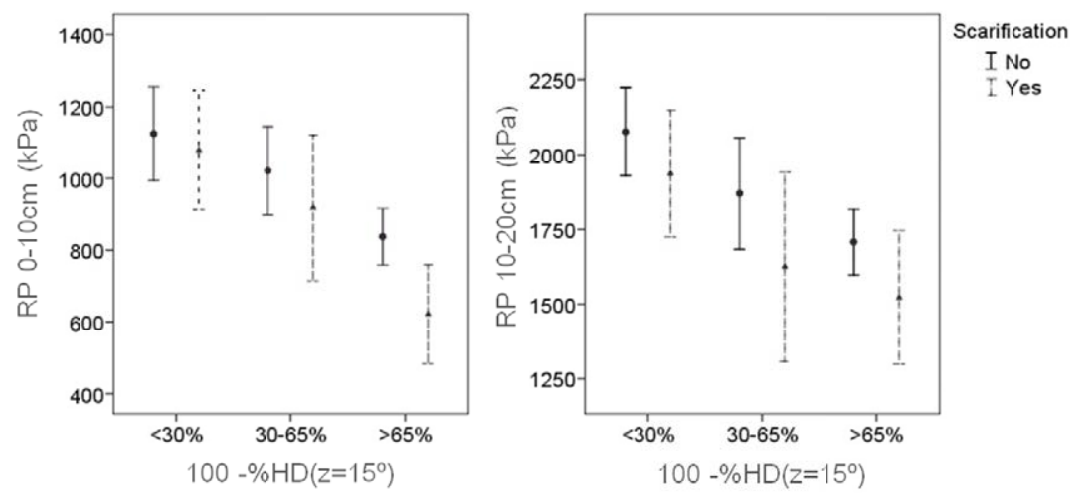

Fig. 42. Gráficos de intervalos de confianza para la resistencia a la penetración del suelo entre 0-10 $\mathrm{cm}$ de profundidad (izquierda) y 10-20 cm de profundidad (derecha), en función de la fracción de huecos y del tratamiento de escarificación aplicado. 
En el conjunto del área experimental, aproximadamente un $60 \%$ de los puntos muestreados presentaron valores de resistencia a la penetración en la capa superficial del suelo $(0-10 \mathrm{~cm})$ menores de $1000 \mathrm{kPa}$ y se alcanzaron niveles máximos en torno a los $1600 \mathrm{kPa}$. Estos valores están muy por debajo de los 2000-3000 $\mathrm{kPa}$ habitualmente señalados en bibliografía como limitantes para el desarrollo radical en suelos arenosos y franco-arenosos (Ampoorter et al., 2011; A. Gomez et al., 2002; Greacen y Sands, 1980; Powers, 1999; Powers et al., 2005), por lo que no cabe esperar que el exceso de dureza del suelo sea un problema verdaderamente limitante para el enraizamiento inicial del regenerado en la zona de estudio.

Si tenemos en cuenta los rangos de dureza asociados a las distintas condiciones de espesura de la masa, se pone de manifiesto que el tratamiento de mullido sólo sería de más utilidad en lo relativo a la elongación radical en los claros donde la resistencia a penetración es un poco más alta. No obstante, a la vista de la elevada velocidad con la que los suelos parecen recompactarse, el tratamiento tampoco resultaría rentable en estas zonas desde el punto de vista de la dureza del suelo salvo, como mucho, en los dos años iniciales.

\section{c. Disponibilidad hídrica}

La tercera y última de las mejoras perseguidas con el tratamiento de escarificación es el incremento de la disponibilidad hídrica para el regenerado. La humedad disponible durante su instalación es clave tanto para la germinación de las plántulas como para su posterior supervivencia. Concretamente, este factor es señalado de forma habitual en entornos mediterráneos como el principal limitante en esta parte del proceso de regeneración (Aussenac, 2000).

Mediante el tratamiento de escarificación planteado se pretendía conseguir un aumento de la disponibilidad hídrica en los primeros centímetros del perfil basado en tres efectos: el aumento de la capacidad de infiltración del suelo debido al incremento de su porosidad (especialmente de la proporción de poros de gran tamaño); el aumento de la capacidad de retención de agua derivada también del incremento de la porosidad; y la eliminación de la vegetación competidora y consumidora de agua, entre otros recursos.

Con respecto a estos tres efectos, hay que poner de manifiesto que los suelos de texturas gruesas - como la predominante en la zona de estudio (franco-arenosa) - no suelen presentar problemas de infiltración, salvo en casos de compactación extrema, debido a su elevada proporción de poros grandes.

En cuanto a la capacidad de retención de agua de este tipo de suelos, sus limitaciones suelen estar relacionadas precisamente con el exceso de porosidad de gran tamaño, que no es capaz de retener eficazmente el agua infiltrada en el perfil y evitar su rápida pérdida por gravedad (o por evaporación en las zonas más próximas a la superficie, cuando las temperaturas exteriores son elevadas).

La mejora de la disponibilidad hídrica en suelos arenosos precisa, por tanto, de un aumento de la proporción de poros de tamaño intermedio, lo que a priori puede conseguirse a través de una mejora de la estructura (adecuada incorporación de materia orgánica humificada al perfil, acción equilibrada de micro y macroorganismos edáficos, raíces e hifas..). O incluso, en ocasiones por un aumento de la compactación superficial que, al provocar un mayor empaquetamiento de las partículas edáficas, reduzca el tamaño medio de poro (Agrawal, 1991; G. A. Gomez et al., 2002).

Los tratamientos de laboreo superficial como el que se realiza en la escarificación destruyen, al menos parcialmente, la estructura preexistente en la profundidad de perfil afectada por el tratamiento, aumentando aún más la proporción de poros de gran tamaño en detrimento de los medianos. No es esperable por tanto una excesiva mejora de la disponibilidad hídrica del perfil en este sentido. 
Así mismo, en las zonas en las que el tratamiento alcance suelo mineral, tanto la aireación generada por la remoción del suelo como la puesta en luz derivada de la eliminación de la cubierta vegetal incentivan los procesos de mineralización de la materia orgánica humificada presente en el suelo, lo que disminuye la presencia de sustancias húmicas (generadoras de estructura) en los horizontes superficiales.

Por todo ello, la eventual mejora de las condiciones hídricas del perfil derivada de la escarificación tendría que venir mayoritariamente asociada a la disminución de la competencia inter-específica como consecuencia de la eliminación de la cobertura vegetal del suelo, principalmente de la cobertura de herbáceas. Así mismo, podría esperarse una cierta mejoría en el comportamiento hídrico de las zonas en las que exista una importante acumulación de restos y en las que la remoción generada por el tratamiento de escarificación consiga incorporar a dicha capa (carente de estructura y con peores características hídricas y térmicas que el suelo mineral) un cierto porcentaje de suelo mineral.

Tal y como se ha señalado en el apartado anterior, los valores de humedad encontrados en el área de estudio ponen de manifiesto que el efecto de la escarificación sobre la disponibilidad hídrica era débilmente significativo dos años después del tratamiento, lo que podría estar relacionado con todo lo indicado anteriormente.

Los datos de humedad de los que se dispone fueron tomados en mayo. En consecuencia, reflejan la humedad correspondiente al proceso de germinación, que no tiene por qué ser indicativa del comportamiento hídrico de las parcelas durante el período estival (supervivencia), en el que, debido al efecto cambiante de la cobertura vegetal y el suelo en función de las condiciones termo-pluviométricas reinantes, no tienen por qué mantenerse las mismas tendencias observadas durante la primavera.

Aun así, para tratar de definir un poco más las variables que resultan clave en la humedad edáfica en el entorno considerado, se ha analizado la influencia de todas las variables consideradas (escarificación sí/no incluida) sobre el estado de humedad del suelo en el momento de medición. En dicho análisis, la influencia del área de experimentación se ha simplificado en una única variable dicotómica, distinguiendo solana (bloques $\mathrm{S}$ y SE) y umbría (boques NE y NW) para tener en cuenta la orientación de los bloques de muestreo.

Debido al elevado grado de correlación entre las variables regresoras consideradas, el análisis de regresión se ha llevado a cabo mediante regresión penalizada vía LASSO (Tibshirani, 1996). Esta técnica, combinada con herramientas de validación cruzada para la selección del nivel de penalización $(\lambda)$, permite identificar las variables que más directamente afectan y explican la variable regresora y obtener un modelo de regresión más robusto que el que proporcionan los métodos convencionales. La evolución de los coeficientes estimados para los diferentes parámetros considerados en función del nivel de penalización aplicado se representa en la figura 43.

Tal y como puede observarse en el gráfico de la página siguiente, las variables más directamente relacionadas con el comportamiento de la humedad han resultado ser: I) la orientación del área experimental (con el previsible aumento de la humedad en las zonas de umbría); II) el $100-\% \mathrm{HD}^{15^{\circ}}$ que, teniendo en cuenta que evalúa únicamente la cobertura por encima de las parcelas, está directamente correlacionado con la mayor o menor intercepción de lluvia por parte del dosel de copas y, por tanto, con la mayor o menor entrada de agua en el sistema (coeficiente negativo: a mayor cobertura, menor humedad en el suelo, debido al efecto de 'sombra seca' que podemos considerar dominante en el mes de mayo y que ya fue comentado en apartados previos); III) los coeficientes relativos a la capa de restos: en orden decreciente de trascendencia, (1) espesor de restos no descompuestos - RNDcm - (la capa más superficial y la de menor CRA), (2) profundidad total de la capa de material orgánico - RTcm- y (3) recubrimiento superficial de restos RND \%, este último con un peso mucho menor. Los tres parámetros presentan coeficientes negativos, lo que indica que una mayor acumulación de restos se relaciona con una menor disponibilidad hídrica durante la germinación. 


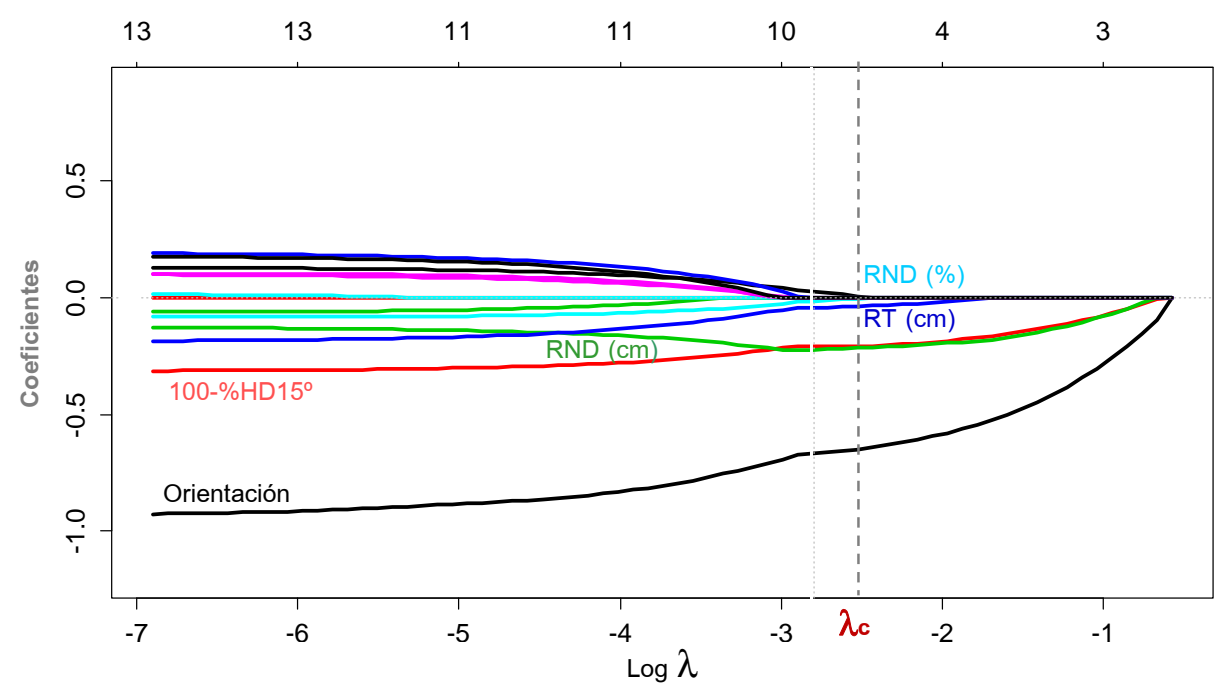

Fig. 43. Representación de la evolución de los coeticientes estimados en la regresión penalizada para via LASSU (\% de humedad edáfica estimada en función del resto de variables), en función del nivel de penalización aplicado $(\lambda)$. RND $(\mathrm{cm})=$ espesor de restos no descompuestos en $\mathrm{cm}$; $\mathrm{RND}(\%)=\%$ de recubrimiento de restos no descompuestos; $\mathrm{RT}(\mathrm{cm})=$ espesor total de restos en cualquier estado de humificación; 100-\%HD15 = $100-$ fracción de huecos del dosel en el casquete esférico correspondiente a un ángulo cenital de $15^{\circ}$ (obtenida mediante fotografía hemisférica); Orientación: variable dicotómica 1 :solana, $0=$ Umbría

Los coeficientes del modelo en el punto de corte determinado por el nivel de penalización $\lambda$ seleccionado por validación cruzada se muestran a continuación en la tabla 41. La contribución del resto de parámetros considerados a la explicación de la variable regresora resulta irrelevante y subordinada a lo aportado por los cinco parámetros ya señalados.

Tabla 41. Coeficientes estandarizados del modelo de regresión en el punto de corte determinado por el nivel de penalización $\lambda_{c}$ seleccionado.

\begin{tabular}{ll}
\hline Término & $\begin{array}{l}\text { Coeficiente stand. } \\
\text { Estimado }\end{array}$ \\
\hline Término independiente & 0.3233 \\
Orientación & $-0,6395$ \\
100-\%HD15 & $-0,2078$ \\
RND $(\mathrm{cm})$ & $-0,2118$ \\
RT $(\mathrm{cm})$ & $-0,0336$ \\
RND $(\%)$ & $-0,0001$ \\
$\%$ Herbáceas & $\cdot$ \\
$\%$ Matorral & $\cdot$ \\
RP 0-10cm (kPa) & $\cdot$ \\
RP 10-20cm (kPa) & $\cdot$ \\
ABT $\left(\mathrm{m}^{2} / \mathrm{ha}\right)$ & $\cdot$ \\
ABQp $\left(\mathrm{m}^{2} / \mathrm{ha}\right)$ & $\cdot$ \\
$100-\% H D 90^{\circ}$ & $\cdot$ \\
ESCAR & $\cdot$ \\
\hline $\mathrm{R}^{2}$ & 0,4915 \\
\hline
\end{tabular}

Orientación: variable dicotómica 1:solana, 0=Umbría; 100-\%HD15 $=100$ - fracción de huecos del dosel en el casquete esférico correspondiente a un ángulo cenital de $15^{\circ}$ (obtenida mediante fotografía hemisférica); $100-\% H D 90^{\circ}=100$ fracción de huecos del dosel todo el hemisferio por encima del punto de muestreo -ángulo cenital de $90^{\circ}$ - (obtenida mediante fotografía hemisférica); RND $(\mathrm{cm})=$ espesor de restos no descompuestos en $\mathrm{cm}$; $\mathrm{RT}(\mathrm{cm})=$ espesor total de restos en cualquier estado de humificación; $\mathrm{RND}(\%)=\%$ de recubrimiento de restos no descompuestos; RP: resistencia a penetración edáfica en las profundidades indicadas; $\mathrm{ABT}\left(\mathrm{m}^{2} / \mathrm{ha}\right)$ : Área basimétrica total en torno al punto expresada en $\mathrm{m}^{2} / \mathrm{ha}$; ABQp $\left(\mathrm{m}^{2} / \mathrm{ha}\right)$ : Área basimétrica de rebollo en torno al punto expresada en $\mathrm{m}^{2} / \mathrm{ha}$; ESCAR: variable dicotómica que indica la existencia o no de tratamiento previo de escarificación sobre la parcela $-1=$ sí, $-0=$ no. 
Dada la complejidad de las relaciones entre las variables estudiadas no es posible predecir con certeza a partir de lo observado la evolución de su efecto sobre la humedad durante el período estival. No obstante, el análisis realizado sí permite detectar los factores clave para la disponibilidad hídrica en el momento de medición, en pleno período de crecimiento vegetativo. Evidentemente, mediante la escarificación no podemos intervenir sobre los más relevantes de entre esos factores - orientación y espesura de la masa arbolada. Sin embargo, sí podemos incidir sobre los siguientes en importancia.

De entre éstos, el aspecto clave para la disponibilidad hídrica con respecto a la cobertura ha resultado ser el espesor de acumulación de restos sobre la superficie del suelo, seguido de otros parámetros que han demostrado tener menor trascendencia, como la cobertura de herbáceas o de matorral. Este resultado es similar al encontrado en otros estudios (Pardos et al., 2007).

Recapitulando lo visto en apartados previos: dos años después de escarificar el espesor de los restos no descompuestos era menor con diferencias fuertemente significativas; el espesor de los restos totales no presentaba diferencias significativas debidas al tratamiento; la cobertura de restos no descompuestos, aunque con una tasa de recuperación muy elevada, sí presentaba valores significativamente inferiores en las parcelas tratadas. Por tanto, y desde este punto de vista, el efecto de la escarificación debe considerarse como positivo en relación con la humedad en el mes en el que se realizaron las medidas. 


\subsubsection{CONCLUSIONES PARCIALES}

Los resultados obtenidos muestran que las condiciones previas a la escarificación se recuperan rápidamente cuando el tratamiento se aplica en parcelas de reducido tamaño $(1,5 \times 1,5 \mathrm{~m})$. Hay que destacar que la recuperación de la cobertura vegetal (herbáceas y matorral, con coberturas medias significativamente menores en las parcelas escarificadas), es algo más lenta que la de las variables de los horizontes superficial y subsuperficial del suelo (resistencia a la penetración y humedad), las cuáles no mostraban diferencias significativas dos años después del tratamiento en el caso de la resistencia a la penetración, o las mostraban débilmente en el caso de la humedad (con valores superiores tras la escarificación). De entre todas las variables relacionadas con la cobertura del suelo que se consideraron, el espesor de los restos sin descomponer parece ser el más lento en recuperarse, mientras que el espesor de los restos totales (sin descomponer y parcialmente descompuestos) parece haberse recuperado completamente dos años después de la escarificación; el porcentaje de cobertura de restos no descompuestos presenta la tasa de recuperación más elevada, si bien aún muestra valores medios significativamente inferiores en las parcelas escarificadas.

Los índices de espesura de la masa arbolada considerados (dosel arbolado, como complementario a la fracción de huecos, y área basimétrica) influyeron sobre las variables de suelo analizadas (cubierta vegetal y características de los horizontes superficial y subsuperficial), de modo que el valor que tomaron dichas variables y su recuperación tras la escarificación demostraron depender en gran medida de la espesura de la masa colindante. El sentido de dicha influencia fue siempre el previsible: cuanto mayor era la espesura, menores resultaron ser la cobertura de herbáceas y de matorral, la humedad (por el efecto de "sombra seca" dominante en mayo) y la resistencia a la penetración; y mayores fueron todas las variables relacionadas con los restos vegetales. Esta correlación no fue alterada en ningún caso por la aplicación de la escarificación.

A partir de los resultados anteriores se resumen, a continuación los principales efectos de la escarificación, dos años después de ser aplicada, sobre los siguientes aspectos:

a) Contacto semilla-suelo

El factor más limitante es, en condiciones de elevada espesura, la presencia de restos vegetales; y, en zonas abiertas, la cobertura de herbáceas y matorral. El escarificado es efectivo en relación con la creación de nuevas condiciones que permiten el contacto de las semillas con el suelo, pero su efecto en este sentido parece durar muy poco tiempo. Por ello, su aplicación debería llevarse a cabo inmediatamente después de ejecutar las cortas de regeneración y coincidiendo con buenas producciones de semilla.

b) Desarrollo radical

Los valores encontrados de resistencia a la penetración se sitúan por debajo de los propuestos como limitantes para el desarrollo radical. En todo caso, los principales problemas desde el punto de vista de resistencia a la penetración elevada se sitúan en claros y zonas abiertas, asociadas también a la presencia de herbáceas. En estas situaciones el escarificado sí puede resultar útil, si bien de nuevo hay que señalar la especialmente rápida recuperación de los valores de partida en comparación con lo que ocurre con otras variables analizadas.

c) Disponibilidad hídrica

Si bien en suelos franco-arenosos, como los estudiados, la infiltración no suele ser un problema, la escarificación puede mejorar la disponibilidad hídrica tanto con presencia abundante de herbáceas (situación dominante en claros y zonas abiertas) como con presencia de abundantes restos vegetales sin descomponer (situación dominante con espesuras altas), aunque de nuevo hay que recordar la rápida recuperación de los 
valores iniciales. Sin embargo, la alteración que la escarificación genera en la estructura del suelo y, en consecuencia, su efecto sobre la capacidad de retención hídrica y la inercia térmica de dicho suelo podrían empeorar aún más las condiciones estivales para el regenerado.

Por todo ello, cabe plantearse en estas zonas la posibilidad de aplicar otros tratamientos sobre el suelo que, como el decapado, eliminen competencia y mejoren el contacto de las semillas con el suelo mineral sin alterar la estructura edáfica (dado que los efectos positivos de disminución de la dureza del escarificado no perduran). Así mismo, podría resultar interesante la formación de caballones en líneas de nivel para tratar de acumular infiltración en líneas (y aumentar localmente la disponibilidad hídrica). Incluso la eliminación de restos de corta mediante quema parece, en este tipo de suelos, un procedimiento que no genera problemas edáficos y sí favorece la regeneración posterior en las pequeñas superficies donde se realizó la quema (Bravo Fernández et al., 2010). 

4.5.

RED DE MUESTREO I: LA COMPACTACIÓN EN LA MASA EN ESTUDIO 



\subsubsection{LA RESISTENCIA A PENETRACIÓN COMO ÍNDICE DE COMPACTACIÓN EDÁFICA: TÉRMINOS Y CONDICIONES DE USO}

Tal y como se ha indicado anteriormente, los efectos de la compactación sobre el suelo en la zona de estudio se han valorado a través de mediciones de Resistencia a Penetración (RP), que es un parámetro frecuentemente utilizado para valorar compactación en las masas forestales (Lipiec y Hatano, 2003; Miller et al., 2004).

Teniendo en cuenta que la estructura del suelo es lo que realmente se ve alterado en primer término como consecuencia de la compactación edáfica, lo más adecuado para valorar los efectos de la compactación sería estimar de forma directa e inequívoca los cambios generados en la estructura del suelo (tanto cuantitativa como cualitativamente). En su defecto, también resultaría idóneo poder evaluar simultáneamente los cambios inducidos en la capacidad del suelo para proporcionar adecuadas condiciones para el crecimiento radical en todos los parámetros físicos clave (disponibilidad hídrica, aireación, temperatura y resistencia a penetración).

Lamentablemente, por el momento no se han encontrado parámetros de fácil y barata medición que proporcionen esta información, por lo que determinados parámetros parciales (que sólo valoran los cambios derivados de la compactación en alguna de las propiedades edáficas), como la resistencia a penetración, se consideran una buena alternativa, especialmente cuando se pretende valorar grandes áreas (Lipiec y Hatano, 2003). No obstante, cuando se utilizan estos parámetros parciales se deben tener en cuenta sus limitaciones tanto en el muestreo como en el análisis de resultados. En el caso de la Resistencia a Penetración debe valorarse:

1. Alcance: la dureza del suelo es el único de los parámetros físicos que controlan el desarrollo radical que está directamente ligado a la resistencia a penetración. La RP estima adecuadamente la resistencia mecánica del suelo en un momento puntual y con las condiciones reinantes en ese instante. Pero, si no se dispone de más datos, no permite extraer conclusiones fiables acerca de la estructura porosa subyacente ni del comportamiento hídrico, térmico y gaseoso esperado en el suelo (Manoel et al., 2001; Dec et al., 2011).

2. Precisión: la RP, cuando se valora mediante un penetrómetro de cono, cuantifica la fuerza que opone el suelo al avance de una barra rígida de metal de diámetro muy superior al de las raíces que penetra en el suelo a una velocidad muy superior a la velocidad de crecimiento de éstas (Whiteley et al., 1981). Pero, al contrario que la barra del penetrómetro de cono, las raíces de las plantas pueden zigzaguear aprovechando los caminos de mínimo esfuerzo (en ocasiones a través de grietas y poros de mayor tamaño sin ni siquiera tener que expandir el sustrato) y presentan adaptaciones para disminuir la fricción con el suelo (Bengough y McKenzie, 1997; MCKENZIE et al., 2013). Todo ello provoca que las fuerzas de fricción y de expansión del sustrato que debe vencer la barra metálica para avanzar sean mayores que las que realmente experimentan las raíces en esas mismas circunstancias. El coeficiente de sobrestimación será mayor o menor en función del sustrato (mayor o menor presencia de macroporos y grietas, naturaleza de las partículas del suelo, humedad en el momento de la medida...) y de la especie (diámetro radical, estrategias de adaptación a la compactación edáfica...). De acuerdo con Bengough and Mullins (1990) los penetrómetros experimentan en su avance una resistencia entre dos y ocho veces mayor que la experimentada por las raíces de las plantas. Por todo ello, la RP es, aparentemente, un estimador fiable de la dureza del suelo, pero genera mucha incertidumbre a la hora de valorar la mayor o menor penetrabilidad por parte de las raíces.

3. Valores límite: cambios en propiedades edáficas como la textura, la concentración de materia orgánica, la pedregosidad o la humedad, pueden generar diferentes estimaciones de RP con independencia de la estructura de poros subyacente. (Smith, 1997). Por este motivo, si se establecen valores límite de RP para el correcto desarrollo radical, éstos sólo pueden referirse de forma fiable a limitaciones debidas a la impenetrabilidad del suelo. Si las limitaciones generadas por la compactación son debidas en primer término a aireación, encharcamiento/sequía o Ta ${ }^{\mathrm{a}}$, la RP por sí sola no es un indicador válido de la idoneidad del suelo 
para el desarrollo radical. Incluso en el caso de que la variable cuello de botella sea la RP, aún hay que tener en cuenta que su efecto final sobre la vegetación va a depender de lo buenas o lo malas que sean las condiciones en el resto de variables, que pueden compensar parcialmente o incrementar su efecto perjudicial. Por lo tanto, los valores límite de RP tan sólo son válidos para restricciones debidas a la dureza del suelo y, salvo en casos de dureza extremadamente elevada, varían en función del entorno.

4. Efecto acumulado vs efecto puntual: todo lo dicho anteriormente es importante para valorar cuánto de limitante es la fuerza del suelo en un momento puntual. No obstante, si lo que se pretende conocer es el efecto real del suelo sobre los sistemas radicales, es necesario tener en cuenta el efecto acumulado durante todo el período vegetativo. Dado que la resistencia a penetración de un suelo varía a lo largo del año en función de las fluctuaciones de su contenido de humedad y viceversa, la parte del período vegetativo en la que la fuerza del suelo afecta al crecimiento radical no depende exclusivamente de las características del sustrato, sino de las características del sustrato en relación con el régimen termopluviométrico de la zona correspondiente. Cuando no se dispone de información suficiente sobre la evolución anual de RP y humedad edáfica, como en el caso que nos ocupa, parece lógico pensar que el régimen termopluviométrico o, como mínimo, el tipo de clima y el tipo de restricciones que impone a la vegetación (sequía, encharcamiento, bajas/altas temperaturas, heladas...) debería ser tenido en cuenta a la hora de seleccionar valores críticos de RP y valorar el daño esperado por compactación (Gomez et al., 2002).

En definitiva, la RP es, aparentemente, una medición bastante grosera e imprecisa de la resistencia del suelo al crecimiento radical que tan solo permite valorar una de las posibles causas de ralentización o estancamiento de dicho crecimiento. No obstante, su interés radica en que es una medición rápida y sencilla que permite muestrear muchos puntos con bajo coste así como en el hecho de que, aunque no informe de forma precisa sobre la penetrabilidad real del suelo por las raíces, sí proporciona un dato innegable acerca de la dureza del suelo en un determinado momento (con la humedad, concentración de materia orgánica, estructura de poros... etc que correspondan). Dado que la capacidad de empuje de las raíces es limitada, la dureza del suelo, en ausencia de otro tipo de restricciones, mantiene una correlación negativa con la elongación radical (Miller et al., 2004; Zou et al., 2001). Debido a la presencia de multitud de factores muy intercorrelacionados, esto no implica taxativamente que en un suelo duro las raíces no vayan a desarrollarse o que en uno blando vayan a hacerlo. Sin embargo, a grandes rasgos tiene sentido esperar que, llevando a cabo un muestreo suficientemente intenso de RP (asequible, teniendo en cuenta la facilidad de medición), sea posible caracterizar la superficie de un monte en un momento puntual de acuerdo con un gradiente de idoneidad para el crecimiento radical en relación con su estado de compactación (Miller et al., 2001; Schmalz et al., 2013; Steber et al., 2007). Si el muestreo se lleva a cabo durante el período en el que el crecimiento de la masa debería ser máximo, la imagen obtenida nos proporciona una idea de la idoneidad real del suelo en cuanto a dureza para el crecimiento radical. Sin entrar a valorar las causas de la mayor o menor dureza en cada punto (si es por causa directa de la estructura o indirecta de la humedad o materia orgánica, etc.), la imagen obtenida nos indica dónde la resistencia es más alta y más baja en el momento en el que se debería estar produciendo el pico de crecimiento de la vegetación. Este tipo de muestreo comparativo resulta también adecuado si lo que se desea es analizar el efecto de agentes compactadores sobre el suelo (Dec et al., 2011; Schmalz et al., 2013).

Por el contrario, como ya se ha indicado, establecer límites absolutos de RP para el desarrollo radical parece menos viable. La incertidumbre asociada a las mediciones es tan alta que los límites han de ser tomados como referencia general, pero no como puntos de inflexión en el comportamiento radical. En cualquier caso, dado que se señala que una parte importante de estas oscilaciones son debidas a la especie y a las condiciones del suelo, parece lógico tener en cuenta estos aspectos a la hora de seleccionar límites de entre los propuestos en bibliografía para disminuir la incertidumbre. Así, habrán de considerarse las características del clima y sus limitaciones asociadas. 


\subsubsection{VALORES MEDIOS DE RESISTENCIA A PENETRACIÓN EN EL MONTE: ¿POTENCIALMENTE NOCIVOS?}

Los valores medios de Resistencia a Penetración encontrados en la capa superficial $(0-10 \mathrm{~cm})$ y sub-superficial $(10-20 \mathrm{~cm})$ del suelo fueron respectivamente $927 \pm 372$ y $1.804 \pm 482 \mathrm{kPa}$. La humedad edáfica media durante el muestreo fue de $12,2 \pm 6,4 \%$.

Como se mencionó en el apartado anterior, establecer si unos determinados niveles de RP deben ser considerados nocivos no es trivial. Tanto los valores críticos de RP como los efectos que se les atribuyen presentan una enorme variabilidad en bibliografía. Así, pueden encontrarse referencias a límites desde 800 a $5.000 \mathrm{kPa}$ (Greacen \& Sands, 1980) con efectos asociados que van desde la ralentización del crecimiento de los sistemas radicales hasta el completo detenimiento del crecimiento de la parte aérea.

Teniendo en cuenta las características de la zona de estudio (suelo franco arenoso en clima mediterráneo de montaña), cabe esperar que el primer parámetro con virtualidad para causar restricciones como consecuencia de la compactación sea la dureza del suelo. En principio, en los suelos de texturas arenosas y franco arenosas, debido a su tendencia hacia poros de mayor tamaño, el comportamiento hídrico y térmico del suelo no suele empeorar como consecuencia de compactaciones leves a moderadas, sino todo lo contrario, y rara vez se presentan problemas de aireación. Por tanto, en la medida en que la dureza parece ser el parámetro físico del suelo más vulnerable, se considera que la RP puede ser un indicador aceptable del inicio de los problemas por compactación en la zona de estudio.

Los valores límite de RP más comúnmente mencionados en bibliografía para coníferas en suelos arenosos y franco-arenosos oscilan entre los $2000 \mathrm{kPa}$ para el inicio de las reducciones de la elongación radical hasta los 2500-3000 kPa, que suelen asociarse en mayor medida al total detenimiento de dicha elongación. Los impactos sobre la parte aérea son enormemente variables en función de la fuente consultada (Ampoorter et al., 2011).

Se han evaluado los valores de RP encontrados en la zona de estudio en función de los límites mencionados (tabla 42) y los resultados evidencian que ninguno de los puntos muestreados superó dichos valores críticos en la capa superficial $(0-10 \mathrm{~cm})$. Sin embargo, en la capa sub-superficial $(10-20 \mathrm{~cm})$ dependiendo del límite considerado $(2.000,2.500$ ò 3.000$)$ el porcentaje de puntos cuyo nivel de compactación puede considerarse nocivo varió entre el 0 y el $37 \%$.

Tabla 42. Porcentaje de observaciones que exceden los valores umbral de resistencia a la penetración encontrados en bibliografía en los niveles superficial $(0-10 \mathrm{~cm})$ y sub-superficial $(10-20 \mathrm{~cm})$ del suelo.

\begin{tabular}{lccc}
\hline \multirow{2}{*}{ Capa de suelo } & \multicolumn{3}{c}{ Resistencia a Penetración $(\mathrm{kPa})$} \\
& $>2000$ & $>2500$ & $>3000$ \\
\hline $0-10 \mathrm{~cm}$ & $0 \%$ & $0 \%$ & $0 \%$ \\
$10-20 \mathrm{~cm}$ & $37,8 \%$ & $7,2 \%$ & $0 \%$ \\
\hline
\end{tabular}

A pesar de que los porcentajes de puntos con niveles nocivos son enormemente variables en función del límite considerado, cabría esperar que el suelo del área de muestreo presentase ciertas restricciones al crecimiento radical - insuficientes, sin embargo, para detenerlo por completo - en un porcentaje considerable de superficie. No obstante hay que tener en cuenta que las mediciones de RP que se analizan se llevaron a cabo en un único momento a mitad del período vegetativo con el objetivo de comprobar las limitaciones reales debidas a la compactación en pleno período de crecimiento de la masa de estudio. Sólo podemos concluir, 
por tanto, que en ese momento, con las condiciones reales y variables de cada punto, el 37,8\% del área de muestreo presentó valores de RP que podrían implicar la ralentización del crecimiento radical. El efecto global esperado sobre el crecimiento a lo largo de todo el período vegetativo es, sin embargo, incierto.

Si analizamos el contenido de humedad durante el muestreo en función de la dureza del suelo (figura 44), se pone de manifiesto que los suelos más compactados parecen conservar niveles de humedad más altos que las zonas menos compactadas (0-500 kPa). En particular, los niveles de humedad encontrados en los suelos menos compactados fueron en la mayoría de los casos lo suficientemente bajos como para implicar la parada vegetativa por sequía, a pesar de que el muestreo fue llevado a cabo en el mes de mayo al inicio del período vegetativo (véase climodiagrama de Walter-Lieth aptdo. 4.1.1.), tras los meses de más precipitación del año y antes de que se produjese un excesivo aumento de las temperaturas.

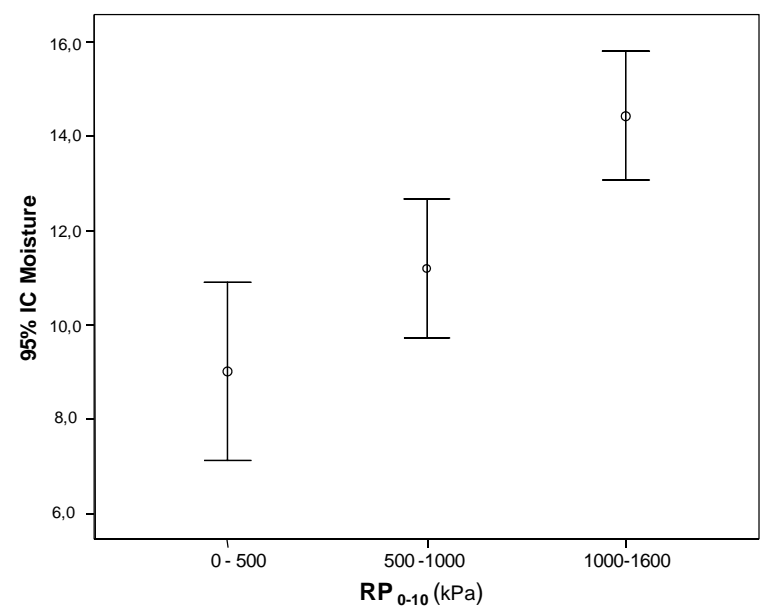

Fig. 44. Humedad del suelo en función de la resistencia a la penetración $(\mathrm{kPa})$ en el momento del muestreo.

En este sentido, niveles de compactación moderados podrían estar incrementando la duración del periodo vegetativo en la zona de estudio. Este tipo de tendencia ya ha sido mencionada con anterioridad por Gomez et al. (2002), que encontraron que un aumento de los niveles de compactación en suelos arenosos y francoarenosos de entornos mediterráneos incrementaba el período de disponibilidad hídrica para la vegetación en el suelo en 86 y 48 días a las profundidades de $1-15 \mathrm{~cm}$ y $15-30 \mathrm{~cm}$, respectivamente. La mejora del balance hídrico del suelo estaría compensando las restricciones de la dureza del suelo al desarrollo vegetal: los sistemas radicales crecerían más despacio en las áreas moderadamente compactadas, pero podrían hacerlo durante un período mayor de tiempo por la mejora del comportamiento hídrico del suelo.

En resumen: los valores de RP encontrados no eran alarmantes, pero sí moderadamente altos, en la capa sub-superficial del suelo $(10-20 \mathrm{~cm})$ para $1 / 3$ de los puntos muestreados. No obstante, existe una elevada incertidumbre acerca del efecto acumulado de la RP cuando se considera el año completo, debido a la compensación de efectos (dureza del suelo vs. disponibilidad hídrica) que puede producirse en suelos de tendencia arenosa bajo climas mediterráneos.

Dado que los valores observados no eran lo suficientemente altos ni lo suficientemente bajos como para determinar si habíay o no un problema de compactación en el monte, para evaluar hasta qué punto la gestión que se estaba realizando resultaba o no perjudicial para la calidad de estación fue necesario establecer: 1) si los usos del monte susceptibles de generar compactación (mayormente los aprovechamientos mecanizados y la explotación ganadera) estaban produciendo o no aumentos significativos de los niveles de compactación en el monte. 2) si habían tenido lugar cambios significativos en la productividad de la masa forestal en estudio durante las décadas de actuación de los agentes compactadores. Ambos aspectos son tratados en los siguientes apartados. 


\subsubsection{INFLUENCIA DE LOS AGENTES COMPACTADORES: GANADO Y MAQUINARIA}

A cada punto de muestreo de la red I se le asignó un nivel de intensidad de tránsito tanto de ganado como de maquinaria. En general, resulta complicado establecer con fiabilidad una clasificación excesivamente detallada de niveles de tránsito cuando ésta se hace a posteriori. Es posible determinar las zonas de máximo impacto con relativa certeza, pero resulta complicado valorar el nivel de acumulación del tránsito más esporádico fuera de estas áreas. Por este motivo, para el análisis de la compactación en el monte se consideraron únicamente dos niveles: 'áreas de máxima intensidad de tránsito' vs. 'todas las demás áreas'.

En relación con la maquinaria, se consideraron puntos de máximo tránsito los situados sobre vías de saca y cargaderos. De acuerdo con los Planes de Aprovechamiento del monte, no se había realizado ningún tratamiento selvícola mecanizado en los bloques de experimentación durante los diez años anteriores al desarrollo del muestreo. Por el contrario, las vías de saca y los cargaderos presentes en algunos de ellos sí habían sido transitados con mayor o menor frecuencia durante los dos años previos al muestreo en el curso de operaciones en rodales próximos.

Teniendo en cuenta así mismo que lo habitual en el monte es que la periodicidad de intervención selvícola mecanizada sea de unos quince años y que cuando las intervenciones se producen la mayoría del tránsito mecanizado se centra en las vías secundarias de saca, la clasificación establecida para determinar el impacto de la maquinaria distinguió entre dos tipos de puntos: a) puntos transitados por última vez durante los 1-2 años previos al muestreo, en los que el período de descanso entre intervenciones no solía superar los tres años y que recibían un elevado número de pasadas de maquinaria en cada intervención mecanizada; b) puntos transitados por última vez como mínimo diez años antes del muestreo, en los que el período de descanso entre intervenciones era de 15 años y cuya frecuencia de pisada en el curso de cada intervención era reducida.

Respecto al ganado, los niveles de impacto fueron asignados de acuerdo a la cobertura de herbáceas encontrada en las parcelas de 1,5×1,5 m donde se evaluó la resistencia a penetración del suelo. Todos los bloques de experimentación contemplados están situados en zonas de paso habitual del ganado, que circula libremente por el monte. No obstante, dentro de las zonas de paso, las superficies cubiertas de hierba son mucho más frecuentadas por el ganado para alimentarse ( $\mathrm{y}$, por tanto, más pisoteadas) que aquellas cubiertas mayoritariamente de matorral u hojarasca (Sigua y Coleman, 2009). Así, se consideraron puntos de "máximo tránsito" del ganado los situados en parcelas que presentaban un porcentaje de cobertura de herbáceas $\geq$ $90 \%$.

El análisis de los efectos de maquinaria y ganado sobre los niveles de resistencia a penetración del suelo se realizó en dos etapas sucesivas: 1 . impacto sobre los primeros centímetros de suelo $(0-29 \mathrm{~cm})$; y 2 . impacto en profundidad $(0-50 \mathrm{~cm})$.

\subsubsection{CAPA SUPERficial del SUelo}

Los valores medios marginales de RP en función del tipo de perturbación (bajo tránsito, alto tránsito de maquinaria, alto tránsito de ganado) encontrados en las capas superficial $(0-10 \mathrm{~cm})$ y sub-superficial $(10-20 \mathrm{~cm})$ del suelo son los que se muestran a continuación en la tabla 43. 
Tabla 43. Valores medios de resistencia a penetración ( $₫$ desviación estándar) en función del nivel y tipo de tránsito en los 20 primeros $\mathrm{cm}$ de suelo.

\begin{tabular}{lcccccccc}
\hline \multirow{2}{*}{ Tipo de Perturbación } & & \multicolumn{2}{c}{$\mathrm{RP}_{0-10 \mathrm{~cm}}$} & & \multicolumn{3}{c}{$\mathrm{RP}_{10-20 \mathrm{~cm}}$} \\
\cline { 3 - 4 } \cline { 7 - 9 } & $\mathrm{N}$ & Media & $\Delta(\mathrm{abs})$ & $\Delta(\%)$ & & Media & $\Delta(\mathrm{abs})$ & $\Delta(\%)$ \\
\hline Bajo tránsito & 134 & $830 \pm 341$ & - & - & & $1.694 \pm 453$ & - & - \\
Alto tránsito maquinaria & 19 & $1.176 \pm 324$ & $347^{* * *}$ & $42 \%$ & & $2.171 \pm 369$ & $478^{* * *}$ & $28 \%$ \\
Alto tránsito ganado & 34 & $1.260 \pm 297$ & $431^{* *}$ & $52 \%$ & & $2.143 \pm 420$ & $449^{* * *}$ & $27 \%$ \\
\hline
\end{tabular}

$\Delta$ (abs): diferencias medias absolutas con respecto a los niveles medios de "Bajo tránsito". $\Delta$ (\%): diferencias medias relativas con respecto a los niveles de "Bajo tránsito". Significación de las diferencias de medias: * $p$-valor < $0.05,{ }^{* *}$ p-valor $<0.01,{ }^{* * *} p$-valor $<0.001$.

Tanto maquinaria como ganado generaron niveles de resistencia a penetración significativamente diferentes en los primeros $20 \mathrm{~cm}$ de suelo de las zonas de alto y bajo tránsito. Concretamente, el tránsito elevado de ambos agentes compactadores acarreó incrementos de RP del mismo orden de magnitud y en torno a los 400 $\mathrm{kPa}(\mathrm{p}$-valor $<0,01)$.

La resistencia a penetración del suelo observada tendió a aumentar en profundidad en todos los casos, de tal forma que los niveles de dureza encontrados en superficie en las zonas de alto tránsito fueron similares a los encontrados 5 ó $10 \mathrm{~cm}$ más abajo en las zonas de bajo tránsito.

Tanto los valores medios de resistencia a penetración de las áreas de alto tránsito de maquinaria y ganado como las diferencias encontradas con respecto a las áreas de bajo tránsito entran dlentro de los rangos mencionados en bibliografía para este tipo de perturbaciones en suelo franco-arenoso. No obstante, resulta más habitual encontrar valores más altos para suelos afectados por maquinaria y más bajos para los afectados por ganado.
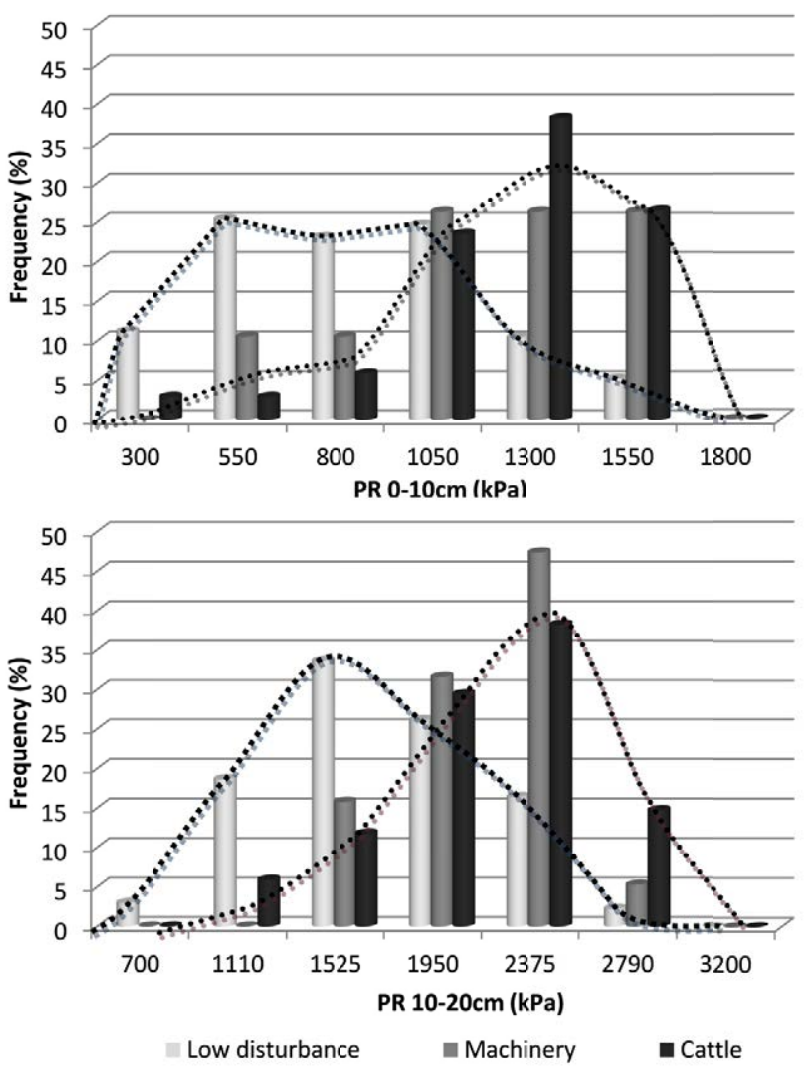

Fig. 45. Histogramas de frecuencia de la PR en función del tipo de perturbación y de la profundidad considerada.
Si se analizan en la muestra las distribuciones de frecuencias (\%) de los valores medios de RP por punto y profundidad $([0-10 \mathrm{~cm}],[10-20 \mathrm{~cm}])$ para los distintos tipos de tránsito, se pone de manifiesto que en ambas profundidades los puntos de alto tránsito constituyen poblaciones claramente diferenciadas de la de bajo tránsito. Especialmente en el horizonte sub-superficial

Por el contrario, dentro de las zonas de alto tránsito no parecen apreciarse grandes diferencias entre las distribuciones de ganado y maquinaria.

En lo concerniente a los límites de referencia para el inicio de las restricciones para la vegetación aludidos en el apartado anterior hay que mencionar que, aunque en ningún caso se superan los 3000 $\mathrm{kPa}$, los porcentajes de puntos cuyas $\mathrm{RP}_{10-20}$ superan los 2000 y $2500 \quad \mathrm{kPa}$ son significativamente superiores en las zonas de alta perturbación que en las dle baja ( $X_{\text {square }} p$ valor $<<0,01$ ) (tabla 44). 
Todo parece indicar que el impacto de los agentes compactadores en los primeros $\mathrm{cm}$ de suelo se ha concentrado mayoritariamente en las zonas de alto tránsito. La acumulación de tránsito esporádico en el resto de superficie durante los largos períodos en los que llevan produciéndose los aprovechamientos (> 50 años en el caso de la maquinaria y > 150 años en el ganado) no ha igualado en absoluto ambas poblaciones. Esta tendencia se manifiesta con mayor intensidad en profundidad donde se requiere un mayor número de pasadas para generar compactación y los procesos de recuperación son más lentos.

Tabla 44. Frecuencia de puntos de muestreo (\%) en los que la resistencia a penetración supera los límites que se indican $(2000,2500 \& 3000 \mathrm{kPa})$ en el horizonte subsuperficial $(10-20 \mathrm{~cm})$ en función del tipo de perturbación sufrida.

\begin{tabular}{|c|c|c|c|c|}
\hline \multirow{2}{*}{ Tipo de Perturbación } & \multirow[b]{2}{*}{$\mathrm{N}$} & \multicolumn{3}{|c|}{$\mathrm{RP}_{10-20 \mathrm{~cm}}(\mathrm{kPa})$} \\
\hline & & $>2000$ & $>2500$ & $>3000$ \\
\hline Alto tránsito ganado & 34 & $68 \%$ & $24 \%$ & $0 \%$ \\
\hline Alto tránsito maquinaria & 19 & $63 \%$ & $21 \%$ & $0 \%$ \\
\hline Bajo tránsito & 134 & $28 \%$ & $3 \%$ & $0 \%$ \\
\hline Todos $_{10-20 \mathrm{~cm}}$ & 180 & $38 \%$ & $7 \%$ & $0 \%$ \\
\hline
\end{tabular}

Numerosos autores defienden la necesidad de concentrar las perturbaciones de los agentes compactadores como medio para minimizar su efecto pernicioso a nivel de monte (Ampoorter et al., 2010, 2007; Horn et al., 2007, 2004). Consideran que pocas pasadas de maquinaria son suficientes para compactar irreversiblemente el suelo debido a la baja (o nula, en ocasiones) velocidad de recuperación de los horizontes edáficos. Otros autores, por el contrario, postulan que en algunos casos es mejor no establecer esas redes permanentes y repartir el daño tanto como sea posible, y apuestan por la recuperación entre pasadas sucesivas (Brais y Camiré, 1998).

En el monte que nos ocupa, la maquinaria realiza el mayor número de pasadas por una red de skid trails bastante fija, pero también recorre, aunque con menos frecuencia y con muchas menos pasadas por aprovechamiento, el resto de la superficie. El ganado, por su parte, no tiene ningún tipo de acotado, por lo que es libre para circular por toda la superficie del monte. No obstante, tal y como se ha descrito anteriormente, tiende claramente a frecuentar más las zonas empradizadas y los puntos de agua y de suplementación alimenticia por parte de los ganaderos (Bravo et al., 2010). El resto del territorio es pisado mucho más esporádicamente en los viajes de camino entre las zonas de querencia. Este reparto de tránsito "dentro y fuera de calles" parece haber sido suficiente para concentrar el daño en una parte de la superficie del monte y dejar el resto con niveles de compactación claramente inferiores. Ello implicaría que la compactación no se ha producido con tan poco número de pasadas y/o que los procesos de recuperación están siendo suficientemente efectivos. En cualquier caso, a la hora de valorar la viabilidad del sistema, sería necesario comprobar si la intensidad y superficie afectada en la actualidad a nivel de monte, es o no suficiente como para generar un daño perceptible en la calidad de estación del conjunto.

\subsubsection{NIVEL PROFUNDO}

El análisis del comportamiento de la RP en profundidad se ha realizado a partir del ajuste de un modelo lineal mixto para todo el rango de profundidades muestreado $(0-50 \mathrm{~cm})$. Dicho modelo se ha ajustado tomando la profundidad como covariable; las perturbaciones (maquinaria y ganado), como factor fijo; y el punto de muestreo, como factor aleatorio.

En la tabla 35 se muestran los resultados de la comparación de modelos con diferente estructura de efectos fijos, de menor $\left(M_{0}\right)$ a mayor complejidad $\left(M_{5}\right)$. La bondad de ajuste de cada modelo se ha valorado con base en su verosimilitud a partir de los índices AIC (Akaike Information Criterion) y el Logaritmo de la verosimilitud (Log Likelihood). Se ha seleccionado el modelo más sencillo de entre los que no suponen una disminución significativa de la verosimilitud (partiendo de $M_{5}$, se han comparado, en orden decreciente, sucesivos $M_{i}$ hasta el primer $i$ en el que $p$-value $\left(M_{i}\right.$ vs $\left.M_{i-1}\right)<0,05$. 
Tabla 45. Comparación de modelos de efectos fijos. Criterios de selección: Índice de Akaike (AIC), logaritmo de la verosimilitud (log Likelihood), p-valor asociado al cociente de verosimilitudes (L-ratio para $M_{i}$ vs $M_{i-1}$ ).

\begin{tabular}{|c|c|c|c|c|c|c|c|c|}
\hline & Efectos fijos & $\begin{array}{c}\text { Efectos } \\
\text { aleatorios }\end{array}$ & $\mathrm{Gl}$ & $A / C$ & $\log L i k$ & Test & L-ratio & $\mathrm{p}$-valor \\
\hline$M_{0}$ & Int & X*Bloque/Punto & 5 & 71265,0 & $-35627,5$ & & & \\
\hline$M_{1}$ & $\operatorname{lnt}+\left(x+x^{2}+x^{3}+x^{4}\right)$ & X*Bloque/Punto & 9 & 70434,6 & $-35208,30$ & M1 vs M0 & 838.440 & $<0.001$ \\
\hline $\mathrm{M}_{2}$ & $\operatorname{lnt}+\left(x+x^{2}+x^{3}+x^{4}\right)+(A T)$ & X*Bloque/Punto & 10 & 70385.5 & -35182.75 & M2 vs M1 & 51.103 & $<0.001$ \\
\hline$M_{3}$ & $\operatorname{lnt}+\left(x+x^{2}+x^{3}+x^{4}\right)^{*}(\mathrm{AT})$ & $x^{\star}$ Bloque/Punto & 14 & 70380.4 & -35176.22 & M3 vs M2 & 13.058 & 0.011 \\
\hline $\mathrm{M}_{4}$ & Int $+\left(x+x^{2}+x^{3}+x^{4}\right)^{*}\left(A T_{M a q}+A T_{C a t}\right)$ & x*Bloque/Punto & 19 & 70380,2 & $-35171,1$ & $M_{4}$ vs $M_{3}$ & 10,225 & 0,069 \\
\hline$M_{5}$ & Int $+\left(x+x^{2}+x^{3}+x^{4}\right)^{*} A T_{M a q}^{*}{ }^{*} T_{\text {Cat }}$ & $x^{*}$ Bloque/Punto & 24 & 70388,1 & $-35170,0$ & $\mathrm{M}_{5}$ vs $\mathrm{M}_{4}$ & 2,163 & 0,826 \\
\hline
\end{tabular}

Int= término independiene; $x=$ profundidad de muestreo; $A T M a q=$ alto transito de maquinaria $(\mathrm{Si}=1, \mathrm{No}=0) ; \mathrm{ATCat}=$ alto tránsito de ganado $(\mathrm{S} i ́=1, \mathrm{No}=0) ; \mathrm{AT}=$ Alto tránsito de Maquinaria o Ganado (Sí=1, No=0); Punto=Punto de muestreo; Símbolo indicadores de tipos de estructura en el modelo: '+' = Sólo se consideran los efectos principales, ' * '= se consdieran tanto los efectos principales como las interacciones. ' $A / B$ '= efectos anidados (B anidado en $A)$.

En el caso que nos ocupa, el modelo que resulta más adecuado (máxima sencillez sin pérdida significativa de capacidad explicativa) es el $\mathrm{M}_{3}$ cuya expresión desarrollada se hace constar a continuación (Ec.1):

Ec.1.

$$
\begin{gathered}
\mathbf{P R}_{i j}=\beta_{0}+\left[\beta_{1} x_{i j}+\beta_{2} x_{i j}^{2}+\beta_{3} x_{i j}^{3}+\beta_{4} x_{i j}^{4}\right]+\mathbf{A T} \cdot\left[\beta_{5} x_{i j}+\beta_{6} x_{i j}^{2}+\beta_{7} x_{i j}^{3}+\beta_{8} x_{i j}^{4}\right]+\beta_{9} \mathbf{A T}+\delta_{i} \\
+\tau_{i} x_{i j}+\alpha_{i j}+\gamma_{i j} x_{i j}+e_{i j}
\end{gathered}
$$

$x i j=$ profundidad de muestreo en el punto 'j' del bloque 'i'; $A T=$ alto tránsito de maquinaria o ganado ( $S i=1, N o=0)$; $\beta \_n=$ coeficientes estimados para los efectos fijos; $\delta \_i=$ coeficiente estimado para el efecto aleatorio del bloque ' $i$ ' sobre el término independiente; $T_{-} \mathrm{i}=$ coeficiente estimado para el efecto aleatorio del bloque i sobre la pendiente. $\alpha_{-} \mathrm{ij}=$ coeficiente estimado para el efecto aleatorio del punto de muestreo ' $\mathrm{j}$ ' (del bloque 'i') sobre el término independiente; $Y_{-} \mathrm{i}=$ coeficiente estimado para el efecto aleatorio del punto de muestreo ' $\mathrm{j}$ ' (en el bloque 'i') sobre la pendiente.

Este modelo sólo distingue entre puntos de alto impacto y de bajo impacto de perturbación $(A T=1 / 0)$ y descarta la necesidad de tener en cuenta si la fuente de perturbación es maquinaria o ganado. El factor AT influye tanto en el término independiente como en la pendiente de la relación entre la resistencia a penetración y la profundidad.

Los coeficientes correspondientes a la parte fija del modelo (que es la que describe la relación entre la RP y la Profundidad una vez descontado el efecto aleatorio del bloque y el punto de muestreo) son los que se muestran a continuación en la tabla 46 . El modelo descrito equivale a dos ecuaciones para la RP, una para las zonas de bajo tránsito $(A T=0)$ y otra para las zonas de alto tránsito, ya sea por ganado, por maquinaria o por ambos $(A T=1)$. La representación gráfica de ambas curvas y de sus intervalos de predicción se muestra en la figura 46 , en la página siguiente.

Tabla 46. Coeficientes de los efectos fijos del modelo ajustado para la estimación de la Resistencia a Penetración ( $\mathrm{kPa}$ ) en función de la profundidad (modelo polinómico) y el nivel de tránsito de maquinaria y ganado.

\begin{tabular}{lccccc}
\hline & T.Ind. & $\mathbf{x}$ & $\mathbf{x}^{2}$ & $\mathbf{x}^{3}$ & $\mathbf{x}^{4}$ \\
\hline Alto tránsito & -82.51 & 208.67 & -8.87 & $20.07 \cdot 10^{-2}$ & $-17.34 \cdot 10^{-4}$ \\
Bajo tránsito & 159.03 & 225.79 & -9.07 & $18.20 \cdot 10^{-2}$ & $-14.54 \cdot 10^{-4}$ \\
\hline
\end{tabular}

$\mathrm{x}=$ profundidad de muestreo; T.Ind.=Término independiente

A la luz de la estructura de efectos fijos obtenida para el modelo óptimo y de las curvas estimadas y sus correspondientes intervalos de predicción (figura 26), podemos afirmar que en los datos analizados se cumple que: 1) maquinaria y ganado generan un perfil de Resistencia a Penetración en las zonas de alto tránsito 
significativamente diferente del de las zonas de bajo tránsito;2) dentro de las zonas de alto tránsito no se encuentran diferencias significativas entre los efectos medios de ambos agentes compactadores; 3) si calculamos la función diferencia entre los modelos 'Alto' y 'Bajo' tránsito, encontramos que la variación de RP inducida por maquinaria o ganado va en aumento desde la superficie hasta los $16,8 \mathrm{~cm}$, punto en el que se produce la perturbación máxima en valor absoluto; 4) a partir de los $16,8 \mathrm{~cm}$, la diferencia entre modelos disminuye hasta dejar de ser significativa lo que, teniendo en cuenta los intervalos de predicción, se produce en torno a los $36,8 \mathrm{~cm}$ de profundidad.

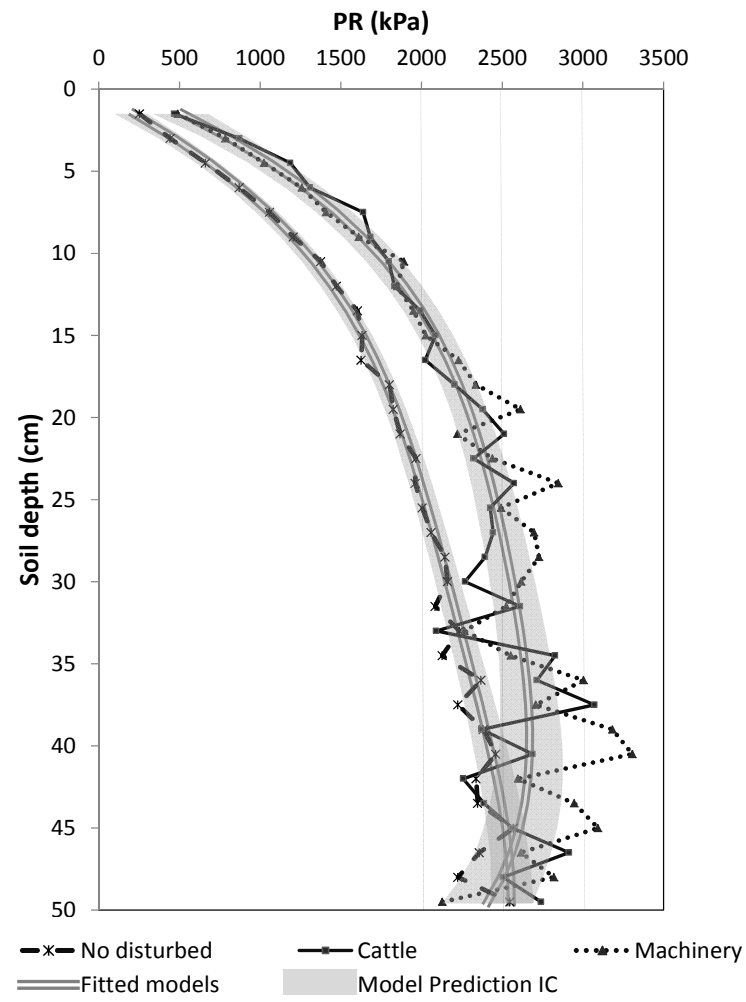

Fig. 46. Resistencia a penetración en función del tipo de perturbacion: A) Bajo Tránsito, B) Alto tránsito de maquinaria, C) Álto tránsito de ganado. Se representan así mismo los valores medios de RP predichos por el modelo mixto ajustado (tablas 45 y 46) así como los intervalos de confianza para estas predicciones.

Aunque, al igual que en la capa superficial, las tendencias descritas para los perfiles de compactación de maquinaria y ganado entran dentro de lo encontrado en bibliografía, lo más habitual es que se atribuya a maquinaria y ganado diferente comportamiento en profundidad. La mayoría de las veces la maquinaria acarrea niveles de compactación marcadamente más intensos y más profundos que los observados en la zona de estudio, mientras que el efecto del ganado suele ser, en teoría, más suave y superficial (algunos autores postulan incluso que su efecto en ningún caso supera los primeros $10-15 \mathrm{~cm}$ de suelo).

\subsubsection{COMPARACIÓN DE LOS EFECTOS GENERADOS POR MAQUINARIA Y GANADO}

Al margen de tendencias generales, a la hora de comparar el efecto compactador de maquinaria y ganado tanto en la zona de estudio como en la bibliografía de referencia y establecer sus causas, hay que tener en cuenta que el estado de compactación que encontramos en un determinado momento y lugar no siempre corresponde al máximo que puede ocasionar la carga que vemos actuar. Los mismos perfiles de compactación pueden haber sido ocasionados por diferentes combinaciones de intensidad de carga y frecuencia de paso, de tal forma que cargas susceptibles de compactar intensa y profundamente el terreno pueden generar el mismo efecto que otras mucho más ligeras sólo por llevar menos tiempo actuando y viceversa (Jorajuria et al., 1997). En cada caso, la combinación de tipo de carga y frecuencia de paso 
existente nos sitúa en un escenario distinto y condiciona tanto el riesgo del sistema y la necesidad de intervención como el tipo y probabilidad de éxito de las medidas a tomar.

En este sentido, a la hora de valorar los efectos de maquinaria y ganado habrá que tener en cuenta tanto las características de la carga que ejercen como las del régimen perturbaciones con el que actúan sobre el terreno.

En lo referente a las características de la carga, frecuentemente se menciona en bibliografía que maquinaria y ganado ejercen presiones similares sobre el terreno, aunque la maquinaria tiene un efecto más intenso y más profundo, debido a que ejerce la presión sobre una superficie mayor en cada pasada. No obstante, tanto maquinaria como ganado presentan mucha variabilidad en sus dimensiones. El tamaño de la hembra adulta de vaca puede oscilar entre 400 y $900 \mathrm{~kg}$ en función de la raza y, si no restringimos por edad y sexo, la variación llega a ser entre 30 y 110 okg. En el caso de la maquinaria, los mismos tratamientos selvícolas pueden ser realizados (dependiendo del nivel de mecanización) por máquinas entre 3000 y $30000 \mathrm{~kg}$ y aun cuando nos limitamos a un solo tipo de máquina (ej. Skidder John Deere 540-D), encontramos que la presión estática sobre el suelo puede variar en más de un $75 \%$ tan sólo en función del tipo de neumáticos utilizado y de su presión de hinchado (Deschênes, 1989; Hakansson y Reeder, 1994; McDonald et al., 1995). Las generalizaciones medias son, por tanto, poco precisas en algunos casos, por lo que a la hora de estimar y comparar efectos máximos es importante tener en cuenta las características reales de las cargas en cada caso concreto.

Con respecto régimen de perturbación hay que destacar la trascendencia que tiene en su repercusión final sobre el terreno el diferente patrón espacial de compactación de maquinaria y ganado. Así, mientras que la maquinaria compacta linealmente por bandas, el ganado compacta por puntos del tamaño de las pezuñas distribuidos de forma aleatoria dentro de la zona de pasto. Por este motivo, es corriente que el paso de la maquinaria se produzca reiteradamente por las mismas líneas generando un área de compactación fácil de identificar y con una intensidad de tránsito bastante homogénea. Sin embargo, la relación entre la carga pastante asignada a una zona de pasto y el número de pisadas sufridas por cada punto concreto es mucho más variable y, salvo en casos de daño elevado, es muy complicado distinguir de visu en el suelo un gradiente de frecuencia de pisada. Por todo ello, la incertidumbre y la variabilidad en el error a la hora de asignar frecuencias reales de pisada a los puntos de muestreo seleccionados dentro de un área alterada es mucho mayor en el caso del ganado que en el de la maquinaria.

Señalar por último que, teniendo en cuenta la superficie total media pisada por una vaca al día (Greenwood y McKenzie, 2001) y el número de pisadas necesarias para conseguir compactación máxima ( $\mathrm{n} \geq 100$ según Lei (2004)), todo parece indicar que hacen falta cargas pastantes y/o tiempos de permanencia elevados (elevados con respecto a las cargas pastantes habituales en ganadería extensiva) para que se alcancen los niveles potenciales máximos. Por este motivo, en el caso del ganado es especialmente importante tener en cuenta el historial de perturbaciones (carga pastante + período total de permanencia del ganado), puesto que la probabilidad de encontrarnos por debajo del potencial máximo de perturbación de las cargas es mayor que en la maquinaria.

En el caso de la maquinaria, debido a ese patrón de compactación por bandas y mayor índice de reiteración de paso, se alcanzan niveles máximos durante el transcurso de las operaciones forestales normales con mayor frecuencia, por lo que las características de la carga y, con ella, el máximo potencial de compactación, son más importantes de cara a definir la compactación que va a producirse.

En una parte importante de la bibliografía asociada a ganado en extensivo, los niveles que se mencionan corresponden a cargas pastantes bajas y/o de corta duración lo que implica que la compactación observada corresponde a niveles bajos dentro del espectro de los posibles. Eso no implica que los sistemas no sean 
potencialmente dañinos, sino que ese máximo potencial está aún lejos de materializarse. Sin embargo, a partir de los daños observados podría llegar a concluirse de forma imprecisa que el ganado pastante no puede generar daño más profundo o más intenso que el observado.

En el caso del monte en estudio, las características de las cargas ejercidas por maquinaria y ganado en la zona de estudio son las que se detallan a continuación (tablas 47 y 48 ).

Tabla 47. Características del ganado pastante en el área de estudio.

\begin{tabular}{llll}
\hline Raza & $\begin{array}{l}\text { Peso hembra } \\
\text { adulta }(\mathrm{kg})\end{array}$ & $\begin{array}{l}\text { Estimación } \\
\text { superficie pezuña } \\
\left(\mathrm{cm}^{2}\right)\end{array}$ & $\begin{array}{l}\text { Presión } \\
\text { estática } \\
(\mathrm{kPa})\end{array}$ \\
\hline Negra Avileña & $500-600^{*}$ & 382.7 & 143.7 \\
Limousin & $650-850^{*}$ & 467.0 & 160.6 \\
Charolés & $700-950^{*}$ & 498.6 & 165.5
\end{tabular}

*Fuente: Federación Española de Asociaciones de Ganado Selecto (FEAGAS) http://feagas.com/

** Área de pezuña estimada en base a un ajuste lineal sobre los datos peso-área de pezuña proporcionados por Greenwood y McKenzie (2001)

Tabla 48. Especificaciones técnicas de la maquinaria empleada en el área de estudio.

\begin{tabular}{lcccc}
\hline Marca y modelo & Peso (vacío) & Neumáticos & \multicolumn{2}{c}{ Presión estática (kPa) } \\
\hline $\begin{array}{c}\text { TimberJack Cable } \\
\text { Skidder 240A }\end{array}$ & $7441 \mathrm{~kg}$ & $23.1-26$ & $\begin{array}{c}47 \text { (Front) }-30 \\
\text { (Rear) }\end{array}$ & 59 (Rear) \\
\hline
\end{tabular}

Deschênes (1989)

Teniendo en cuenta los rangos de valores posibles mencionados anteriormente estaríamos ante ganado de tamaño medio alto, mientras que la maquinaria sería tamaño medio bajo.

En lo referente al historial de perturbación, en el caso del monte de estudio la carga pastante media anual teórica es baja $\left(0,007\right.$ Animal Unit Month per ha [AUM ha $\left.\left.{ }^{-1}\right]\right)$. No obstante, la carga real sobre las zonas de concentración es mucho más elevada. Tal y como indican Bravo et al. (2010) en su estudio sobre el sobrepastoreo en el monte Cabeza de Hierro, a pesar de disponer de 2000 ha, el ganado concentra su actividad mayoritariamente en un $10-15 \%$ de la superficie del mismo. Por otro lado Moorefield y Hopkins (1951) señalan que habitualmente por término medio el ganado pasa prácticamente la mitad del tiempo en menos de un $10 \%$ del área de pasto, por lo que cabe esperar que dentro de ese $10-15 \%$ del monte, el pisoteo del ganado se reparta de nuevo de forma desigual concentrándose especialmente las zonas de mayor querencia.

Este uso del territorio tan variable se explica en el monte de estudio por su propia estructura (irregular por bosquetes), ya comentada. A pequeña escala se presenta una mezcla de situaciones bastante distintas, de modo que se entremezclan en forma de mosaico: 1) zonas abiertas, dominadas por pastos herbáceos, sin presencia de leñosas o con muy poca cobertura de éstas; 2) zonas dominadas por leñosas (arbolado o matorral), con el suelo poco iluminado y poca o nula presencia de pastos herbáceos con valor pastoral.

Si tenemos todo esto en cuenta, la carga real esperada en las zonas que han sido consideradas "de alto impacto" rondaría las $3,75 \mathrm{AUM}^{-1} \mathrm{~h}^{-1}$, lo que puede considerarse una carga elevada. Dado que hay constancia de que el pastoreo lleva produciéndose con estas cargas pastantes desde hace más de cien años de forma ininterrumpida y, como mínimo, 7 de los 12 meses cada año, se puede considerar que la presión ganadera ha sido alta, tanto por carga como por tiempo total. En definitiva, todo parece indicar que el efecto del ganado está cercano a su potencial de compactación en las zonas de alto tránsito y de ahí los valores profundos y elevados observados. 
Por el contrario, para los aprovechamientos mecanizados, la frecuencia (tiempo de retorno de aproximadamente 15 años) y el modo de ejecución de las operaciones (fuste completo, apeo y desramado manual con motosierra en pequeñas superficies y arrastre con skider de tamaño medio), minimizan viajes e intensidad de la alteración máxima en cada operación forestal y podrían estar permitiendo un cierto nivel de recuperación durante los períodos de descanso (Angima et al., 2011; Blanco, 2012). Especialmente, teniendo en cuenta la elevada tasa de acumulación de materia orgánica y los rápidos procesos relacionados con ella en este monte (Aroca-Fernández et al., 2015). A priori, en cada rodal se han realizado en promedio tres intervenciones desde el inicio de los aprovechamientos mecanizados, a lo que hay que añadir que las zonas de alto tránsito analizadas (arrastraderos y cargaderos) dan servicio a los rodales que atraviesan, pero también a otros adyacentes, por lo que cabe esperar que las zonas de alto tránsito superen sobradamente las 100 pasadas citadas por Lei (2004), a partir de las cuales la compactación se equilibra y aumenta ya muy poco aunque continúe el tránsito, por lo que sí debería haberse alcanzado ese potencial máximo de carga. No obstante, el hecho de que el estado de compactación no corresponda a los niveles máximos esperados implica que existe una cierta recuperación efectiva en el perfil y que tanto la forma de realizar los aprovechamientos como las condiciones de la estación (suelo arenoso profundo y bien estructurado con presencia de abundante materia orgánica y un entramado radical adulto bastante denso y profundo) están consiguiendo reducir los daños producidos. 


\subsubsection{EFECTOS DE LA COMPACTACIÓN SOBRE LA PRODUCTIVIDAD DEL MONTE}

La masa en estudio (monte "Cabeza de Hierro") lleva ordenada desde 1957. Desde esa fecha se han realizado revisiones de la ordenación y/o inventarios cada diez años. La información sobre existencias contenida en las sucesivas Revisiones de la Ordenación de la masa desde 1957 hasta la actualidad (Bravo Fernández y Serrada, 2007), se resume a continuación en la tabla 49 y se sintetiza en la figura 47 . No se dispone de información sobre edades medias de la masa forestal asociada a unidades de inventario, debido a su estructura irregular. Tampoco se midieron alturas dominantes en los inventarios anteriores a 1997. Por todo ello, el presente análisis se basa en la evolución a lo largo del tiempo de densidades, volúmenes y crecimientos.

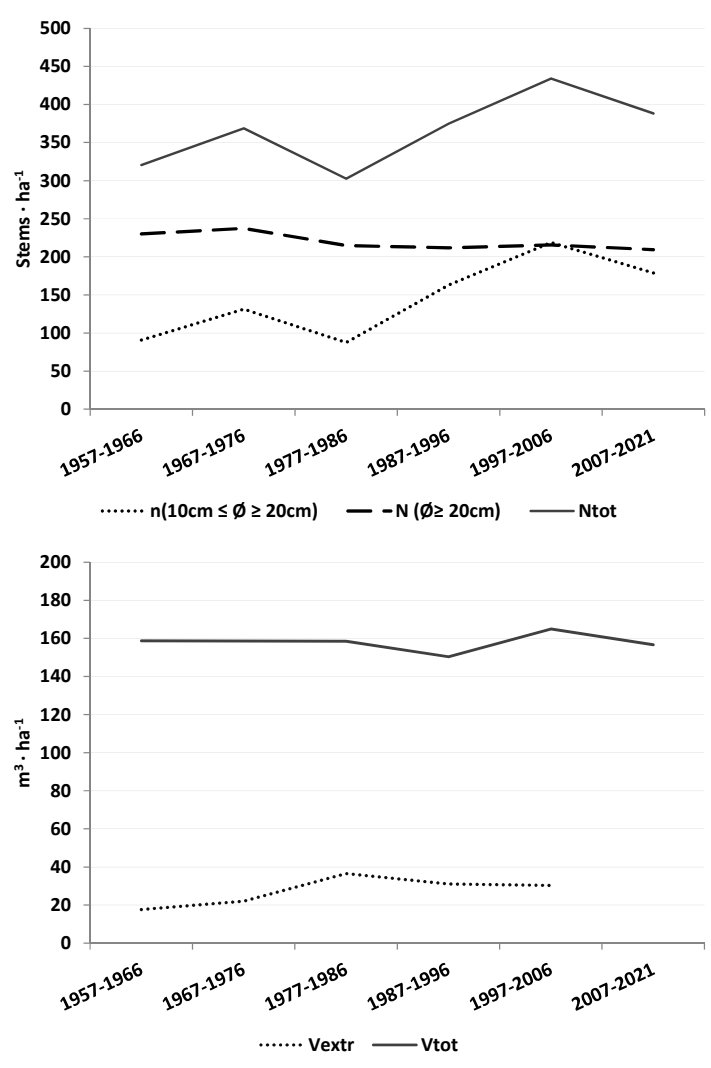

Fig. 47. Evolución de la densidad y el volumen de la masa arbolada de pino silvestre entre 1957 y 2007. "n": densidad de pies menores. "N": densidad de pies mayores. "Vextr": volumen extraído por hectárea.
Tal y como puede observarse en la figura 47, tanto la densidad de pies mayores como el volumen total de la masa en pie se han mantenido prácticamente constantes durante todo el período en estudio, a pesar de que el volumen extraído ha ido ligeramente en aumento. El crecimiento en volumen de la masa tampoco ha variado sustancialmente (tabla 49).

La densidad de pies menores presenta más oscilaciones que los pies mayores pero ha seguido una tendencia general ascendente. Así, entre 1957 y 2007 se produjo un ligero descenso de pies mayores (extracción de los pies más viejos) a cambio de un claro aumento de pies menores, cuya densidad prácticamente se duplicó.

De la comparación de inventarios se deduce una estabilización de existencias y densidad en la masa durante las últimas cínco décadas, a pesar de que en ese tiempo se ha llevado a cabo la extracción del $87 \%$ de las existencias iniciales. Cabe destacar así mismo que la gestión realizada ha permitido un mayor equilibrio de clases de edad.

La mayoría de los estudios a largo plazo se basa en el crecimiento de las especies objetivo para evaluar los cambios en la productividad de la estación (Miller et al., 2004). Para este fin, lo ideal es emplear parámetros exclusivamente dependientes de la calidad de estación como el índice de sitio.

Sin embargo, ya se han indicado la dificultad de usar edades medias en este caso y la ausencia de información sobre alturas dominantes en los primeros inventarios, que obligan a basar el análisis de los posibles cambios en la productividad en las variables de masa mencionadas en los párrafos previos (figura 47 y tabla 49). Por tanto, hay que ser especialmente cuidadoso al extraer conclusiones, ya que los cambios en dichas variables de masa podrían ser debidos a cambios en la calidad de estación, pero también podrían haber sido provocados por la propia gestión aplicada. 
En el caso que nos ocupa, a partir de los resultados obtenidos tan sólo podemos afirmar que la gestión realizada durante los últimos 50 años no ha impedido que la masa mantenga existencias y presente un ritmo suficiente de incorporación de pies menores.

Tras ese período de aprovechamientos mecanizados y más de 150 años de ganado, la masa presenta en la actualidad una distribución de clases de edad equilibrada, renta maderable sostenida, buen estado sanitario y un adecuado cumplimiento de sus funciones ambientales y protectoras. $Y$ todo ello ha sido compatible con la extracción, desde el primer plan de gestión, de un volumen muy similar al que actualmente hay en pie (Bravo Fernández y Serrada, 2007). Por supuesto, con los datos disponibles no es posible descartar que la compactación causada por el aprovechamiento mecanizado de madera y el ganado hayan provocado un deterioro en la calidad de la estación; pero sí se puede afirmar que no hay indicio alguno de dicho deterioro. Eso es sostenibilidad y buena práctica según Burger y Kelting (1999).

Tabla 49. Evolución de la densidad y las existencias de la masa entre 1957 y 2005.

\begin{tabular}{|c|c|c|c|c|c|c|c|}
\hline \multirow[b]{2}{*}{$\begin{array}{c}\text { Fecha } \\
\text { Inventario }\end{array}$} & \multirow[b]{2}{*}{ Validez } & \multicolumn{3}{|c|}{ Densidad [pies $\left.\cdot \mathrm{ha}^{-1}\right]$} & \multicolumn{3}{|c|}{ Volumen $\left[\mathrm{m}^{3} \cdot \mathrm{ha}^{-1}\right]$} \\
\hline & & $\begin{array}{c}\text { Pies menores } \\
{[10 \mathrm{~cm} \leq \varnothing \geq 20 \mathrm{~cm}]}\end{array}$ & $\begin{array}{c}\text { Pies mayores } \\
{[\varnothing \geq 20 \mathrm{~cm}]}\end{array}$ & Total & Vextr & Vtot & Crecimiento \\
\hline 1957 & $1957-1966$ & 90,7 & 230,0 & 320,6 & 17,7 & 158,7 & \\
\hline 1967 & 1967-1976 & 131,2 & 237,4 & 368,6 & 22,1 & 158,7 & \\
\hline 1977 & $1977-1986$ & 87,6 & 214,9 & 302,5 & 36,5 & 158,6 & 37,4 \\
\hline 1987 & $1987-1996$ & 163,0 & 211,8 & 374,8 & 31,0 & 150,4 & 36,6 \\
\hline 1997 & $1997-2006$ & 218,7 & 215,5 & 434,3 & 30,3 & 165,0 & 37,4 \\
\hline 2005 & $2007-2021$ & 178,8 & 209,4 & 388,2 & & 156,7 & 37,7 \\
\hline
\end{tabular}

En la bibliografía de referencia no existe uniformidad de criterio acerca del efecto de la compactación edáfica sobre la productividad forestal (Ampoorter et al., 2011; Tarpey et al., 2008). Algunos artículos de revisión se refieren al enorme peligro que suponen los largos períodos de recuperación de la compactación subsuperficial y la previsible acumulación de efectos en los aprovechamientos mecanizados (Kozlowski, 1999). Pero dentro de las experiencias reales encontramos resultados de todo signo (Fox, 2000; Grigal, 2000).

Una vez más no es posible, aparentemente, generalizar y a la hora de asignar riesgos a este tipo de perturbaciones es imprescindible especificar adecuadamente tanto las características de la perturbación como las del contexto. Tal y como indican Curran et al. (2005), los resultados de los estudios a corto y largo plazo existentes han demostrado que todos los tipos de efecto sobre la productividad son posibles y que la repercusión final depende de los factores limitantes que hayan sido afectados por la perturbación. Particularmente, los efectos encontrados parecen variar en función de: las características de la perturbación (severidad, extensión y patrón superficial del daño); las características de la estación (suelo + clima); las características de la formación vegetal (especies implicadas, edad; forma de masa); y el horizonte temporal contemplado.

En suelos arenosos o franco-arenosos como los de la zona de estudio, la mayor parte de los trabajos encuentran que niveles no excesivamente elevados de compactación no disminuyen la productividad forestal (Ampoorter et al., 2011; Powers et al., 2005), especialmente en climas donde la sequía es un factor limitante (A. Gomez et al., 2002; Powers, 1999).

En cualquier caso, tras el historial de aprovechamientos ya descrito actuando en una masa de pino silvestre semirregular sobre suelo franco-arenoso, se comprueba que la masa no ha variado su rendimiento (madera, ganado, setas, funciones protectoras, recreativas y ambientales). Confirmar con certeza que es debido a un mantenimiento de la productividad del sitio requería mediciones más exhaustivas y a un plazo aún mayor, pero lo observado hasta el momento pone de manifiesto que, en el contexto descrito, el efecto a nivel de monte y a largo plazo no es lo suficientemente perjudicial como para alterar la funcionalidad de la masa. 


\subsubsection{CONCLUSIONES PARCIALES}

En una masa semirregular de pino silvestre asentada sobre suelo franco arenoso y clima mediterráneo de montaña como la estudiada, se comprueba que más de 50 años de aprovechamientos madereros mecanizados tipo fuste entero mediante skider con cable y más de 100 años de pastoreo mediante ganado doméstico en extensivo (carga media $\cong 0.007 \mathrm{AUM} \cdot \mathrm{ha}^{-1}$, cargas zonas alto tránsito $\cong 3.75 \mathrm{AUM} \cdot \mathrm{ha}^{-1}$ ), no han disminuido las existencias de la especie principal, su crecimiento en volumen o el ritmo de incorporación de pies menores a la masa.

Aunque no se detecten consecuencias sobre la productividad a nivel del monte considerado en su totalidad, se constata que tanto los aprovechamientos mecanizados como el ganadero generan un aumento significativo de los niveles medios de resistencia a penetración en los primeros $20 \mathrm{~cm}$ del suelo de las zonas de máximo tránsito (zonas de querencia alimenticia del ganado y arrastraderos, cargaderos y vías principales de saca). La compactación generada por el tránsito de la maquinaria es del mismo orden de magnitud que la observada como consecuencia del efecto del ganado en las zonas del monte con alta querencia por alimentación entre 0-50 cm de profundidad. En ambos casos el máximo de compactación se produce entre los 15 y los $20 \mathrm{~cm}$ de profundidad y los efectos dejan de ser significativos entre los 35 y los $40 \mathrm{~cm}$.

La ausencia de influencia sobre la productividad a nivel de monte de los niveles locales de compactación observados tanto en las zonas de alto tránsito como en las de bajo tránsito, a pesar de superarse en un elevado porcentaje de los puntos muestreados los $2000 \mathrm{kPa}(65 \%$ y $25 \%$ de los puntos muestreados en las zonas de alto y bajo tránsito respectivamente), pone de manifiesto la importancia de valorar el impacto de un aprovechamiento no sólo en función de la intensidad y profundidad de la compactación generada, sino también por la cantidad de superficie afectada y su patrón de distribución en el conjunto de la masa. Así mismo, teniendo en cuenta la mejora de las condiciones hídricas asociada al aumento de la compactación edáfica en la zona de estudio, se confirma la importancia de tener en cuenta el clima a la hora de valorar los efectos de la compactación sobre las formaciones vegetales (especialmente en suelos de tendencia arenosa bajo climas con limitaciones por sequía como el Mediterráneo).

En cualquier caso, El límite de $2000 \mathrm{kPa}$, comúnmente citado en bibliografía para el inicio de las limitaciones al desarrollo vegetal, si bien podría estar afectando al crecimiento radical, no se manifiesta sobre la parte aérea de la masa al considerar su efecto a escala monte.

Existen muchas incertidumbres a la hora de predecir cómo evolucionará la intensidad y extensión del daño en el caso de continuar con los aprovechamientos. No obstante, todo parece indicar que el tiempo y la acumulación de pasadas en ambos casos han sido suficientes para asegurar niveles de equilibrio en las zonas de alto tránsito de ambos agentes compactadores.

Por este motivo, dado que con los niveles máximos alcanzados en las zonas de alto tránsito no parece haberse visto alterada significativamente la calidad de estación, la principal recomendación de gestión llegado este punto sería mantener el tránsito prioritario por las zonas ya alteradas y tratar de mantener el resto de superficie con los niveles de tránsito esporádico realizados hasta el momento.

Se recomienda así mismo mantener un cierto control a largo plazo sobre la evolución (intensidad y superficie) de la compactación en las áreas de bajo tránsito. 

4.6.

RED DE MUESTREO II: GERMINACIÓN Y SUPERVIVENCIA. DECAPADO VS. ESCARIFICADO 



\subsubsection{CUANTIFICACIÓN GENERAL DEL PROCESO}

La emergencia del regenerado en las parcelas de experimentación tras la siembra llevada a cabo durante la última semana del mes de marzo de 2006 empezó durante la segunda semana del mes de mayo y se concentró casi exclusivamente en los siguientes veinte días. A partir de ese momento prácticamente no se produjeron nuevas incorporaciones. La espesura influyó en el inicio del proceso de tal forma que en los claros la germinación fue más temprana que en las zonas más espesas.

La muerte de plántulas comenzó al mismo tiempo que la emergencia aunque su máximo se produjo entre finales de mayo y finales de junio. A fecha de 26 de junio se habían producido casi el $80 \%$ de las muertes del período vegetativo; el $20 \%$ restante se produjo casi íntegramente durante el mes de agosto mientras que en septiembre la población se mantuvo prácticamente estable.

La evolución a lo largo del período de muestreo del porcentaje de plántulas vivas con respecto al total sembrado (resultado del balance entre germinación y mortalidad en cada fase) se representa en función del bloque de experimentación (NE o SW) en las figuras 48 y 49.

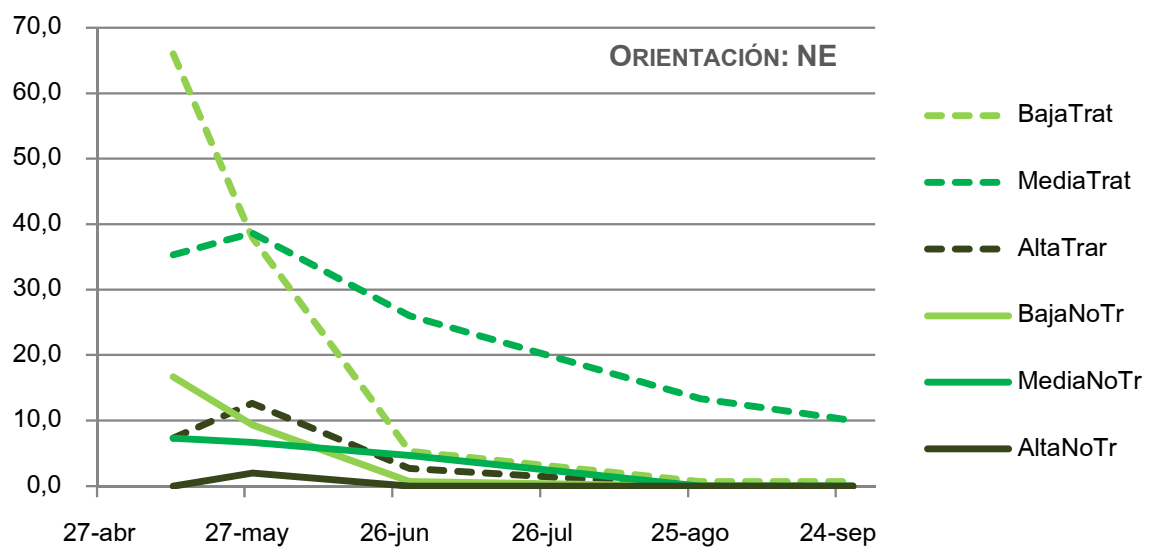

Fig. 48. Porcentaje medio de plántulas vivas con respecto al total sembrado en el BLOQUE NE en función de la espesura (baja, media o alta) y la existencia o no de tratamiento edáfico de ayuda a la regeneración: Trat: parcelas tratadas con Decapado+Acaballonado, NoTr: parcelas no tratadas.

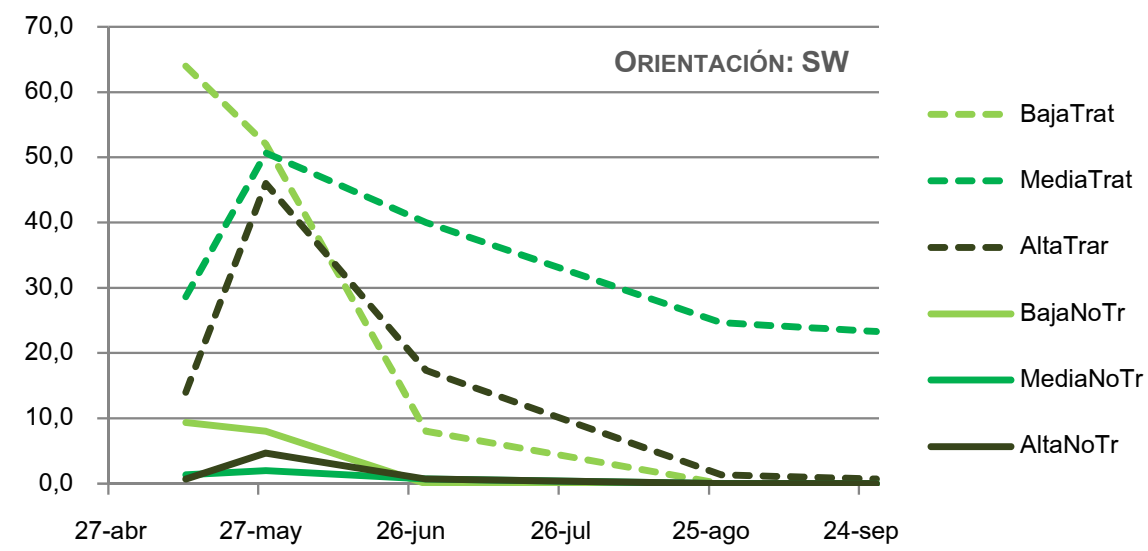

Fig. 49. Porcentaje medio de plántulas vivas con respecto al total sembrado en el BLOQUE SW en función de la espesura (baja, media o alta) y la existencia o no de tratamiento edáfico de ayuda a la regeneración: Trat: parcelas tratadas con Decapado+Acaballonado, NoTr: parcelas no tratadas. 
El año 2006 fue por tanto un año de germinación temprana (inicio de la emergencia en torno a 10 días antes de lo observado en el 2004) seguida de una elevadísima tasa de mortalidad que, en las parcelas sin tratamiento edáfico, alcanzó el $100 \%$ de los germinados en todos los casos con independencia de su espesura u orientación (tabla 50).

El tratamiento de preparación del suelo por decapado+acaballonado afectó notablemente a la tasa de germinación (48,2\% frente al 9,2\% de germinación en parcelas no tratadas) pero su efecto fue definitivo en la supervivencia ya que sólo lograron sobrevivir plántulas en las parcelas con tratamiento de preparación del suelo.

La tasa de germinación fue mayor en los claros que bajo cubierta tanto en las parcelas tratadas como en las no tratadas y mayor y ligeramente más temprana en umbría que en solana. Sin embargo, el tratamiento de preparación del suelo tuvo un efecto mayor en solana que en umbría tanto en germinación como en supervivencia por lo que la tasa final de éxito fue prácticamente el doble en el bloque SW. Una vez más hay que poner de manifiesto que la orientación no es la única característica que varía entre bloques por lo que atribuir a la orientación las tendencias observadas requeriría ampliar la red de muestreo incluyendo un mayor número de zonas de muestreo en cada tipo de orientación.

Tabla 50. Resultado del ensayo de regeneración de la Red de muestreo II. Tasas de germinación (\%Germ) y supervivencia (\%Sup) para las parcelaa tratadas con Decapado+Acaballonado (DEC+ACABALLONADO) y para las no tratadas (SIN TRATAMIENTO), en función de la orientación y la espesura.

\begin{tabular}{|c|c|c|c|c|c|c|}
\hline \multirow[b]{2}{*}{ Orientación } & \multirow[b]{2}{*}{ Espesura } & \multicolumn{2}{|c|}{ SIN TRATAMIENTO } & \multicolumn{3}{|c|}{ DEC + ACABALLONADO } \\
\hline & & \%Germ & $\%$ Sup & \%Germ & $\%$ Sup & \% Éxit \\
\hline \multirow[t]{4}{*}{ NE } & Baja & 21,3 & 0 & 70,0 & 1,0 & 0,7 \\
\hline & Media & 8,7 & 0 & 38,7 & 25,9 & 10,0 \\
\hline & Alta & 10,0 & 0 & 12,7 & 0,0 & 0,0 \\
\hline & Total & 13,3 & 0 & 40,4 & 8,8 & 3,6 \\
\hline \multirow[t]{4}{*}{ SW } & Baja & 8,7 & 0 & 65,3 & 0,0 & 0,0 \\
\hline & Media & 2,0 & 0 & 53,3 & 42,5 & 22,7 \\
\hline & Alta & 4,7 & 0 & 49,3 & 1,4 & 0,7 \\
\hline & Total & 5,1 & 0 & 56,0 & 13,9 & 7,8 \\
\hline Total & & 9,2 & 0,0 & 48,2 & 11,8 & 5,7 \\
\hline
\end{tabular}

\%Germ: tasa de germinación (porcentaje de plántulas emergidas sobre el total de siembra); \% Sup: Tasa de supervivencia (porcentaje de plántulas que sobreviven sobre el total de germinadas);

La regeneración natural durante esta fase del muestreo tanto en fechas como en tasas de germinación, supervivencia y éxito, difiere notablemente de lo observado durante el año 2004. Si analizamos el comportamiento meteorológico del año 2006 encontramos que las diferencias observadas encajan perfectamente con las diferencias termopluviométricas entre ambos períodos. Así: a) el año 2006 presentó durante los meses de marzo a mayo (al contrario que el 2004), una media mensual entre 1 y $1,5^{\circ} \mathrm{C}$ mayor que la correspondiente al año medio, lo que se relaciona con el adelantamiento del inicio de la germinación observado. b) Aunque entre los meses de mayo y junio de 2006 se produjeron más de $150 \mathrm{~mm}$ de precipitación, el desigual reparto de las mismas generó una sequía fisiológica media de 16,6 mm entre el 8 de mayo y el 8 de junio (período en el que no suele producirse sequía en un año medio normal). c) A mediados de junio de 2006 se produjo un breve período de tormentas al que siguió otro largo período de escasez de precipitaciones durante los meses de julio y agosto (menos de la mitad de precipitaciones que la serie media) que acabó de desplomar las tasas de supervivencia que antes de ese período ya alcanzaban, como se ha dicho anteriormente, el $80 \%$. 
Se pone por tanto de manifiesto la enorme fragilidad del proceso de supervivencia durante el primer período vegetativo y su marcada dependencia del régimen termopluviométrico existente. Concretamente, durante el período estudiado, la ocurrencia de cuatro semanas sin precipitaciones durante el momento crítico de emergencia y enraizamiento, fue suficiente para acabar con casi el $90 \%$ de las plántulas en ausencia de tratamientos de ayuda a la regeneración.

Se señala así mismo que dicho período crítico, al producirse a caballo entre dos meses, no habría sido detectado por los resúmenes meteorológicos convencionales que promedian por mes. $\mathrm{Y}$ tampoco en el caso habitual de proporcionar como indicador de bondad del año la precipitación total de período estival o la de la primavera. Por lo que se deduce la importancia de tener en cuenta que la sensibilidad del proceso tiene una escala menor o diferente que la proporcionada por este tipo de resúmenes, de modo que deberían reducirse esos períodos promedio a la hora de caracterizar este tipo de procesos.

En este contexto de año 'malo' resulta especialmente llamativa la abrumadora eficacia del tratamiento de decapado+acaballonado aplicado. Este hecho confirma lo encontrado por otros autores en clima mediterráneo (Barbeito et al., 2011; Castro et al., 2002) fundamentalmente por la mejoría del contacto suelo-semilla (mayor velocidad y eficacia del desarrollo radical) y la mejoría del comportamiento hídrico del suelo gracias a la eliminación de la capa de restos y la concentración de los aportes hídricos en la línea de siembra generada por los caballones. La importancia de la cubierta vegetal en el régimen hídrico resultante para el regenerado se pone especialmente de manifiesto en años secos como el del presente estudio en los que cada milímetro de agua disponible cuenta.

No obstante, también resulta llamativo el hecho de que dicho tratamiento sólo resulta eficaz cuando la espesura de la masa en pie es intermedia. A pesar de la existencia de germinación suficiente, en un año de escasez hídrica, el tratamiento de decapado+acaballonado sólo resulta efectivo en esas zonas con independencia de la orientación.

A partir de los datos del inventario georreferenciado se calcula (tabla 51) el área basimétrica real por hectárea (estimada en parcelas de $15 \mathrm{~m}$ de radio) en torno a cada subzona de orientación y espesura constantes (cada subzona está integrada por cuatro parcelas de regeneración, dos con tratamiento edáfico y dos sin él). En la Red de Muestreo II las parcelas de muestreo de cada subzona están tan próximas que es correcto asignar un área basimétrica común por subzona (Aptdo. 3.2.3.2. Replanteo del experimento).

En contra de lo establecido de visu, las dos subzonas de espesura "Media", no presentaron los mismos niveles de área basimétrica; en concreto la espesura de la subzona SW-Media resultó muy similar a la de las subzonas de espesura "Alta" mientras que la NE-Media sí presentó esos niveles intermedios. A pesar de todo, la tasa de éxito del SW-media en la regeneración fue del 22,7\% mientras que las de las de "Alta", con la misma área basimétrica que ella, presentaron una tasa de éxito nula.

Tabla 51. Espesura media de la masa en torno a las parcelas de muestreo de regeneración. Como las parcelas de cada tipo de espesura en cada bloque están lo bastante cerca como para suponerles espesura común, se les asigna un único valor de área basimétrica por grupo

\begin{tabular}{cccc}
\hline Espesura & Bloque & ABT $\left(\mathrm{m}^{2} \cdot \mathrm{ha}^{-1}\right)$ & \% Éxito \\
\hline \multirow{2}{*}{ Baja } & NE & 8,6 & 0,7 \\
& SW & 12,2 & 0,0 \\
\multirow{2}{*}{ Media } & NE & 31,5 & 10,0 \\
& SW & $\mathbf{5 1 , 4}$ & $\mathbf{2 2 , 7}$ \\
\multirow{2}{*}{ Alta } & NE & $\mathbf{4 3 , 5}$ & $\mathbf{0 , 0}$ \\
& SW & $\mathbf{5 2 , 3}$ & $\mathbf{0 , 7}$ \\
\hline
\end{tabular}

$\operatorname{ABT}\left(\mathrm{m}^{2} \cdot \mathrm{ha}^{-1}\right)$ : área basimétrica total (pino+rebollo) por hectárea estimada en parcelas de $15 \mathrm{~m}$ de radio en torno a las subzonas de bloque y tipo de espesura y constantes. 
Dado que las diferencias entre ambos grupos de parcelas no se pueden atribuir en este caso a las condiciones de suelo o cubierta vegetal, puesto que la proximidad y el tratamiento de decapado aseguran su homogeneidad, las diferencias tienen que residir en alguno de los otros parámetros de masa (que por otro lado fueron las que llevaron a clasificar de visu esta parcela como de "Espesura intermedia").

Los valores medios para las variables derivadas de las fotografías de ojo de piez en las distintas combinaciones de bloque y espesura se resumen en la tabla 52. Las variables relacionadas con la luz mantienen la misma tendencia observada en el área basimétrica. Sin embargo, el \%HID15 es muy similar para las dos subzonas de espesura media y muly distinta de los otros dos tipos de zonas.

Tabla 52. Caracterización del dosel de copas en torno a las parcelas de experimentación

\begin{tabular}{lccccc}
\hline Espesura & Bloque & \%HD15 & Sunflecks & \%LuzDirecta & \%LuzDifusa \\
\hline \multirow{2}{*}{ Baja } & NE & 3,4 & 93682,6 & 76,8 & 78,0 \\
& SW & 3,4 & 91034,3 & 81,7 & 65,4 \\
\hline \multirow{2}{*}{ Media } & NE & 1,9 & 66796,2 & 46,3 & 45,1 \\
& SW & 2,2 & 32217,0 & 31,4 & 30,9 \\
\multirow{2}{*}{ Alta } & NE & 0,5 & 34737,8 & 24,9 & 29,7 \\
& SW & 0,7 & 32288,6 & 29,6 & 21,5 \\
\hline
\end{tabular}

\%HD15: porcentaje de huecos en el dosel en el casquete esférico correspondiente a un ángulo cenital de $15^{\circ}$; Sunflecks: tiempo total en minutos de exposición de cada parcela a la luz directa del sol a lo largo del año. \%LuzDirecta // \%LuzDifusa: porcentajes de luz directa y difusa respectivamente que llegan al suelo con respecto al total incidente por encima del dosel de copa.

Si homogeneizamos la escala de medición de todas las variables del dosel calculando los porcentajes respecto al valor máximo en cada una (el de espesura Baja) y representamos juntos sus valores medios para las distintas subzonas de experimentación, se visualiza fácilmente que el \%HD15 es única variable en la que el SW-media se comporta como la otra subzona de espesura media (NW-media) y no como las correspondientes de espesura alta.

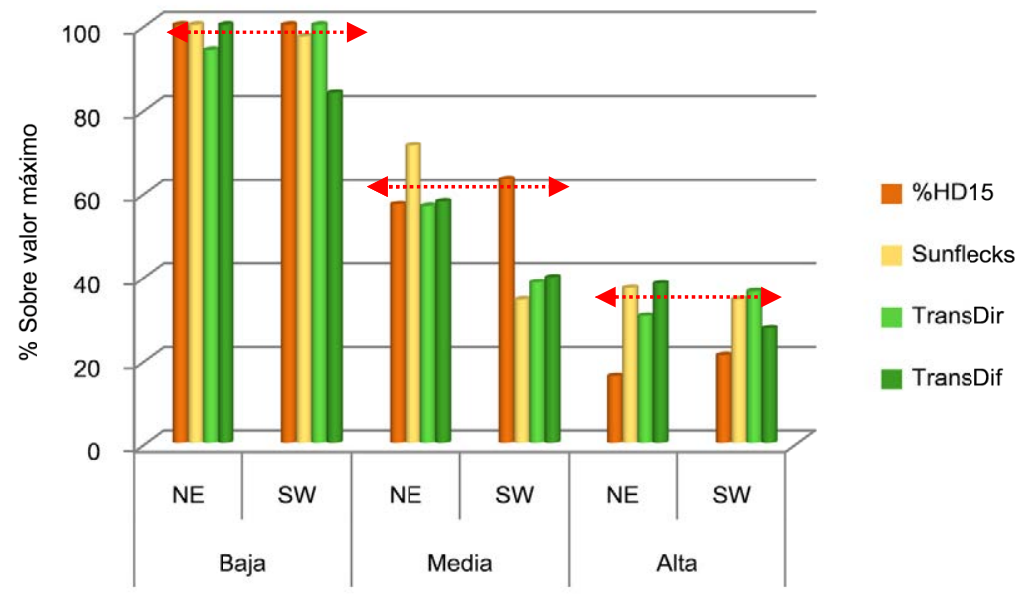

Fig. 50. Caracterización del dosel de copas en las distintas subzonas de experimentación contempladas en la Red de muestreo II. Las variables se transforman para poder representarlas juntas y medir su capacidad discriminatoria de la espesura en lo referente al proceso de regeneración. \%HD15\%: porcentaje de huecos en el dosel en el casquete esférico correspondiente a un ángulo cenital de $15^{\circ}$; Sunflecks: tiempo total en minutos de exposición de cada parcela a la luz directa del sol a lo largo del año. \%LuzDirecta // \%LuzDifusa: porcentajes de luz directa y difusa respectivamente que llegan al suelo con respecto al total incidente por encima del dosel de copa. 
Frente al resto de variables del dosel que tienen una relación más directa con la luz o el efecto térmico de la masa, el porcentaje de huecos en el casquete esférico de $15^{\circ}$ se relaciona mucho más directamente con el grado de intercepción de la precipitación del dosel arbóreo. Cuantos más huecos, menos efecto "sombra" para la precipitación que entra en el sistema.

La mejor tasa de éxito durante un año de elevada sequía fisiológica se produjo en las subzonas decapadas que, teniendo un \% $\% \mathrm{HD} 15^{\circ}$ adecuado, presentaron un área basimétrica mínima en su entorno. El área basimétrica elevada no resultó problemática cuando el hueco para la llegada de lluvia fue suficiente.

No parece por tanto que el problema de la supervivencia en esta fase de desarrollo sea en ninguno de los casos la luz sino más bien que las limitaciones van a ir asociadas en mayor media al agua y el calor. Así, las plántulas necesitarían alrededor espesura suficiente como para generar "efecto masa" de amortiguación de los valores extremos de las variables de estado (Gómez Sanz, 2002); pero al mismo tiempo requerirían un hueco suficiente en el dosel inmediatamente por encima de ellas para maximizar la entrada de agua en el sistema también cuando las precipitaciones son esporádicas y de escasa cuantía (precisamente porque en las épocas críticas esos son muchas veces los únicos aportes que van a existir). Si el hueco es excesivamente grande, el balance entre el efecto amortiguador de la masa y la entrada de agua al sistema, se desequilibra, y el aumento de las temperaturas con la consiguiente desecación de suelo y planta, deja de compensar la ausencia de intercepciones de la precipitación por el dosel.

Cañellas et al. (2005), en experimentos de germinación de silvestre en entorno controlado de vivero bajo clima mediterráneo, encuentran que el efecto de la sombra sobre la tasa de germinación es mucho menor cuando las plantas se riegan. Este hecho, que a priori nos parece evidente, ha de ser tenido en cuenta también en las masas naturales en entorno mediterráneo donde la disponibilidad de luz es mucha y la disponibilidad de agua muy poca. Parece lógico por tanto pensar que, en nuestras latitudes, el efecto del exceso de espesura sobre la intercepción de las precipitaciones incidentes es mucho más limitante que su posible efecto de sombreo. 


\subsubsection{COMPARACIÓN ESCARIFICACIÓN VS DECAPADO+ACABALLONADO}

A finales del mes de marzo de 2006 se repitieron siembras en algunas de las parcelas de la Red Experimental I, con el objetivo de poder comparar la efectividad de los tratamientos de decapado por líneas + acaballonado, y el escarificado manual con azada, bajo un régimen termo-pluviométrico común.

Teniendo en cuenta los resultados que se habían obtenido durante el año 2004 en la Red de Muestreo I, los conteos de germinación total se llevaron a cabo tras la primera semana de junio. Sin embargo, tal y como se ha explicado con anterioridad, el año 2006 la germinación comenzó más pronto de lo habitual y posteriormente se produjo un período de sequía fisiológica en pleno proceso de emergencia de las semillas (máxima fragilidad). Estas peculiaridades del régimen termo-pluviométrico generaron que la mayor parte de la mortalidad se concentrase entre mediados de mayo y mediados de junio (concretamente en las parcelas no tratadas de la Red Experimental II a finales de junio ya se habían muerto el $90 \%$ de las plántulas germinadas). Por todo ello es muy probable que los conteos realizados en las parcelas de la Red I durante el mes de junio contabilizasen sólo una parte de los pinos germinados durante todo el período vegetativo debido a la muerte y desaparición de muchos de ellos con anterioridad al conteo.

No es posible por tanto estimar con fiabilidad las tasas de germinación y supervivencia en la Red de muestreo I, pero sí se conoce con certeza la tasa de éxito ( $n^{\circ}$ de vivos*100/ total sembrado) en las dos fechas en las que se llevaron a cabo los conteos de regeneración: 10-12 junio y 28 de Septiembre de 2006. No obstante, estas tasas fueron tan bajas, que no permiten más allá de un análisis puramente descriptivo del balance final de éxito en la supervivencia.

Tal y como se puede ver en la tabla 53, de las 7200 semillas sembradas sólo germinaron y llegaron vivas hasta el conteo de junio 50 plántulas (éxito $0,7 \%$ antes de iniciar el período estival) y después del verano tan sólo quedaron 11 , lo que supone una tasa de éxito post-estival del $0,16 \%$.

La tasa de éxito observada es aproximadamente la décima parte de la correspondiente a las plántulas sembradas en 2004 después de tres períodos vegetativos. La mayor parte de supervivientes se produjeron en el bloque NE confirmando las tendencias ya observadas durante el 2004; esta tendencia se acentuó aún más tras el período estival que en la solana no hubo ni un solo superviviente.

Tabla 53. Número de plántulas supervivientes en las fechas y bloques experimentales (Red de muestreo I) que se indican

\begin{tabular}{lcc}
\hline & Junio & Septiembre \\
\hline NE & 43 & 11 \\
SW & 7 & 0 \\
\hline Total & 50 & 11 \\
\hline
\end{tabular}

Con respecto al efecto del escarificado hay que decir que a pesar de las bajas cifras de éxito, la mayor parte se produjo en las parcelas de escarificación ya que el $84 \%$ de la supervivencia tuvo lugar en parcelas en las que dos años antes se había llevado a cabo un tratamiento de escarificación. El efecto fue aún más marcado tras el verano ya que sólo sobrevivieron plántulas (aunque pocas) en este tipo de parcelas. 
Tabla 54. Número de plántulas supervivientes en las fechas y bloques experimentales (Red de muestreo I) en función de que hubiera existido o no de tratamiento de escarificación dos años antes de la siembra.

\begin{tabular}{lcc}
\hline & Junio & Septiembre \\
\hline Escarificados & $42(84 \%)$ & $11(100 \%)$ \\
No escarificados & $8(16 \%)$ & $0(0 \%)$ \\
\hline Total & 50 & 11 \\
\hline
\end{tabular}

Si bien es cierto que el año de muestreo fue muy malo para la germinación y la supervivencia, también es cierto que en ese mismo año el decapado+acaballonado consiguió unos resultados claramente mejores. Dos años después de su aplicación, el escarificado aún marcó una diferencia cualitativa en la germinación y la supervivencia puesto que en un año muy malo sólo hubo supervivencia en parcelas escarificadas. No obstante su efecto (no sabemos a ciencia cierta si por el tiempo transcurrido o por la menor eficacia de la actuación) sólo se manifestó sobre las parcelas menos problemáticas (orientación NE y todas ellas parcelas en las que también hubo germinación y supervivencia en anteriores períodos). 


\subsubsection{CONCLUSIONES PARCIALES}

Se comprueba una gran variabilidad interanual en el proceso de regeneración del pino silvestre en función de las características del régimen termo-pluviométrico en cada caso. Se ve afectado tanto el cronograma de emergencia y mortalidad, como las tasas finales de éxito de la instalación.

La preparación del suelo por decapado por líneas y acaballonado resultó ser un tratamiento muy eficaz para mejorar tanto la germinación como la supervivencia en la zona de estudio, incluso en un año con un régimen termo-pluviométrico adverso: anticipa levemente el proceso de germinación, aumenta notablemente la tasa de la misma y mejora la supervivencia tras el período estival. Sin embargo, mientras que el efecto sobre la germinación se hace patente en todos los niveles de espesura contemplados y en ambas orientaciones, la mejora de la supervivencia sólo se manifiesta en las espesuras intermedias.

Tras eliminar la heterogeneidad de la cobertura del suelo y sus correspondientes efectos mediante el decapado+acaballonado, la supervivencia manifiesta una marcada dependencia de las condiciones de masa. De los resultados observados se deduce que el regenerado requiere para su instalación una espesura mínima que consiga modificar el régimen térmico bajo cubierta (amortiguando las temperaturas extremas y la desecación asociada). No obstante, una vez que las condiciones generales están aseguradas, el regenerado va a requerir y a tender a instalarse en aquellas zonas en las que el dosel de copas presente un porcentaje de huecos suficiente en el casquete esférico de ángulo zenital $15^{\circ}$ con respecto a la vertical sobre el punto, que permita la entrada de precipitación al sistema sin excesivas intercepciones del estrato arbóreo.

En un año seco, el tratamiento de escarificación realizado dos años antes consiguió mejorar el éxito del proceso de regeneración con respecto a ausencia del mismo, no obstante esta mejoría fue muy leve tanto en número de parcelas como en plántulas vivas por parcela.

No es posible llegar a saber si el motivo de su baja eficacia fue la pronta recuperación de una buena parte de las alteraciones conseguidas el primer año de su aplicación y caso de haber sido aplicado en ese mismo año sí hubiera funcionado. Tampoco sabemos si el problema han sido las pésimas condiciones de sequía de la primavera y verano de ese años. O si quizá hubo una mezcla de todas ellas.

Lo que sí es claro es que el otro tratamiento ensayado durante el mismo período sí consiguió mejorar la supervivencia cuando la espesura de la masa fue la adecuada. Cómo cabe esperar que evolucione la efectividad del decapado con los años es algo que no vamos a poder saber tampoco a partir de las mediciones realizadas. 
5. CONCLUSIONES 

Los resultados obtenidos a partir de las experiencias realizadas en el monte "Cabeza de Hierro", sobre una masa irregular por bosquetes de pino silvestre ubicada en el Sistema Central entre los 1300 y los $1800 \mathrm{~m}$, permiten concluir sobre el proceso de regeneración natural de la especie en este tipo masa y entorno que:

La regeneración durante el primer período vegetativo presenta una enorme variabilidad interanual dependiente del régimen termo-pluviométrico, particularmente del existente entre los meses de mayo y septiembre. Dicho régimen condiciona tanto el cronograma de germinación y muerte del regenerado, como la cuantía de ambos procesos.

Aunque con la variabilidad interanual ya señalada, el grueso de la emergencia del regenerado en esta zona tiende a producirse entre la primera mitad del mes de mayo y la primera mitad de junio.

Según lo observado durante un año de condiciones meteorológicas próximas a las del año climático medio en la zona, cabe concluir que: 1) la tasa de éxito del proceso de regeneración durante el primer período vegetativo es muy baja, apenas el 1,4\% de los sembrados. 2) El bajo éxito está provocado por una elevada mortalidad durante el primer período estival (>92\%) tras una tasa de germinación en torno al $17 \%$ de las semillas viables que llegan al suelo.

Con respecto a la evolución posterior, en dos años de condiciones meteorológicas marcadamente más secas que la media, se concluye que, en estas circunstancias:1) el mayor número de pérdidas se produce durante el primer verano, pero la mortalidad sigue siendo elevada hasta el tercer período vegetativo en que comienza a reducirse significativamente descendiendo hasta el $45 \%$; 2) como consecuencia de las altas tasas de mortalidad mantenidas en el tiempo, el número de individuos que sobrevive al tercer período estival es apenas del $0,11 \%$ sobre el total sembrado inicialmente.

El modo en que las condiciones meteorológicas generales repercuten en el regenerado varía en función de las condiciones de cobertura vegetal en dosel, sotobosque y suelo. La cobertura vegetal influye significativamente tanto en el proceso de germinación como en el de supervivencia aunque ambos procesos manifiestan una baja correlación lineal, indicando que los lugares idóneos para la germinación no siempre son los más adecuados para la supervivencia.

Entre todos los tipos de cubierta observados, la cobertura de herbáceas es la que presenta peores tasas de supervivencia tanto a corto como a medio plazo. La cobertura de matorral y de restos por el contrario, a pesar de no presentar las mejores tasas de germinación ni de supervivencia tras el primer verano, mantienen un buen comportamiento a medio plazo $\left(2^{\circ}\right.$ y $3^{\circ}$ período vegetativo $)$.

El efecto de la espesura de la masa sobre el proceso de regeneración es difícil de detectar en presencia de condiciones variables de cubierta vegetal sobre el suelo debido a que éstas aúnan su efecto propio y parte del de la masa al tender a distribuirse en función de ésta (hierba en claros, restos bajo cubierta... etc.).

Cuando se analiza el proceso de regeneración eliminando el efecto de la cubierta vegetal sobre el suelo (tratamiento de decapado) se observa que el pino silvestre requiere para su instalación de una espesura mínima que amortigüe las condiciones térmicas bajo cubierta pero que, una vez asegurado ese efecto, la regeneración requiere un porcentaje mínimo de huecos en el dosel inmediatamente por encima de ella, para maximizar la entrada de precipitación en el sistema. Por lo general, la luz no parece ser el factor directo de limitación para el éxito de la instalación sino que la correlación observada aparece por estar ligada a condiciones de masa que conllevan limitaciones en la disponibilidad hídrica o las temperaturas, que son las que sí limitan directamente la instalación en el entorno de montaña mediterránea analizado. 
En masas con elevada irregularidad espacial y estructural como la masa en estudio, los índices de espesura del dosel de copas proporcionados por las fotografías hemisféricas permiten una mejor caracterización del efecto de la masa sobre el establecimiento del regenerado que los índices de espesura convencionales. En su defecto, ha de tenerese en cuenta que las correlaciones máximas entre área basimétrica y porcentaje de huecos del dosel se producen en ángulos cenitales mayores a medida que aumenta el radio de estimación del área basimétrica en torno al punto. Por este motivo, dependiendo del ángulo cenital en el que se produzca el proceso que se desee caracterizar - radiación directa, radiación difusa, entrada de precipitación - mediante el $A B$, su radio de muestreo deberá ser mayor o menor. Cuando lo que se quiere caracterizar es el efecto del dosel arbóreo sobre la luz bajo cubierta, se calcula que en la masa de estudio el radio óptimo de muestreo del área basimétrica en torno a cada unidad experimental es de $15 \mathrm{~m}$

Entre los tratamientos de ayuda a la regeneración ensayados, el tratamiento de escarificación mejora significativamente las tasas iniciales de germinación y supervivencia durante el primer período vegetativo pero su efectividad sobre la supervivencia de las plántulas de 1 y 2 años es sin embargo mucho menor. Por este motivo su efecto al final del tercer período vegetativo no supone ninguna mejoría con respecto a las parcelas no tratadas.

El tratamiento de decapado por líneas con acaballonado por su parte manifiesta una elevada eficacia en la germinación con independencia de la espesura considerada. Su efecto sobre la supervivencia durante el primer período estival, por el contrario, sólo resulta eficaz en las zonas de espesura intermedia con independencia de la orientación considerada.

Ninguno de los dos tratamientos aplicados resulta eficaz para mejorar la supervivencia estival en los claros donde tanto las temperaturas estivales como el efecto del pisoteo del ganado suelen ser máximos. Aun así, el decapado con acaballonado presenta una mayor eficacia que el tratamiento de escarificación durante el primer período vegetativo.

En cuanto a la duración de los efectos del tratamiento de escarificación en este entorno cuando su aplicación se realiza en parcelas de reducido tamaño, se comprueba que las condiciones del suelo previas a la aplicación de la escarificación se recuperan rápidamente. Hay que destacar que la recuperación de la cobertura vegetal es algo más lenta que la de las variables del suelo (resistencia a la penetración, humedad), que no muestran ningún efecto significativo dos años después del tratamiento. De entre todas las variables relacionadas con la cobertura del suelo que se consideraron, el espesor de los restos sin descomponer parece ser el más lento en recuperarse mientras que el espesor de los restos totales (sin descomponer y parcialmente descompuestos) se mantiene constante a pesar de la escarificación.

Tanto los aprovechamientos mecanizados como el ganadero generan un aumento significativo de los niveles medios de resistencia a penetración en los primeros $20 \mathrm{~cm}$ del suelo de las zonas de máximo tránsito (zonas de querencia alimenticia del ganado y arrastraderos, cargaderos y vías principales de saca). La compactación generada por el tránsito de la maquinaria es del mismo orden de magnitud que la observada como consecuencia del efecto del ganado en las zonas del monte con alta querencia por alimentación entre 0-50 $\mathrm{cm}$ de profundidad. En ambos casos el máximo de compactación se produce entre los 15 y los $20 \mathrm{~cm}$ de profundidad y los efectos dejan de ser significativos entre los $35 \mathrm{y}$ los $40 \mathrm{~cm}$.

A pesar de la existencia de estos efectos, tras más de 50 años de aprovechamientos madereros mecanizados tipo fuste entero mediante skider con cable y más de 100 años de pastoreo mediante ganado doméstico en extensivo (carga media $\cong 0.007 \mathrm{AUM} \cdot$ ha $^{-1}$, cargas zonas alto tránsito $\cong 3.75 \mathrm{AUM} \cdot \mathrm{ha}^{-1}$ ), se comprueba que no se ha producido ninguna disminución de las existencias de la especie principal, su crecimiento en volumen o el ritmo de incorporación de pies menores a la masa. 
La ausencia de influencia sobre la productividad a nivel de monte de los niveles locales de compactación observados tanto en las zonas de alto tránsito como en las de bajo tránsito a pesar de superarse en un elevado porcentaje de los puntos muestreados los $2000 \mathrm{kPa}(65 \%$ y $25 \%$ de los puntos muestreados en las zonas de alto y bajo tránsito respectivamente), pone de manifiesto la importancia de valorar el impacto de un aprovechamiento no sólo en función de la intensidad y profundidad de la compactación generada, sino también por la cantidad de superficie afectada y su patrón de distribución en el conjunto de la masa. Así mismo, teniendo en cuenta la mejora de las condiciones hídricas asociada al aumento de la compactación edáfica en la zona de estudio, se confirma la importancia de tener en cuenta el clima a la hora de valorar los efectos de la compactación sobre las formaciones vegetales (especialmente en suelos de tendencia arenosa bajo climas con limitaciones por sequía como el Mediterráneo). 

6. BIBLIOGRAFÍA 

Ackzell, L., 1994. Artificial measures and natural forces in regeneration of Pinus sylvestris L. in boreal Sweden. Invest. Agrar. Sist. Recur. For. Fuera de serie 133-140.

Adams, S.N., 1975. Sheep and cattle grazing in forest: A review. J. Appl. Ecol. 12, 143-152.

Adili, B., El Aouni, M.H., Balandier, P., 2013. Unravelling the influence of light, litter and understorey vegetation on Pinus pinea natural regeneration. Forestry 86, 297-304. doi:10.1093/forestry/cpt005

Agrawal, R.P., 1991. Water and nutrient management in sandy soils by compaction. Soil Tillage Res. 19, 121130. doi:10.1016/0167-1987(91)90081-8

AGRESTA, INCA, 2012. Criteria and indicators for sustainable forest Management, in Spanish forests 2012. Ed. Ministerio de Agricultura, Alimentación y Medio Ambiente, Madrid.

Aguirre, J., Álvarez-Jiménez, J., Bartolomé, C., Peinado, M., 1991. Distribución y ecología de plántulas de Pinus sylvestris L. Stud. Oecologica VIII, 119-125.

Agúndez, D., Galera, R.M., Martín, S., Díez, R., 1992. Emergencia supervivencia y crecimiento en vivero de 16 procedencias de Pinus sylvestris L. en vivero. Montes 28, 56-58.

Alameda, D., Villar, R., 2009. Moderate soil compaction: Implications on growth and architecture in seedlings of 17 woody plant species. Soil Tillage Res. 103, 325-331. doi:10.1016/j.still.2008.10.029

Ampoorter, E., Frenne, P. De, Hermy, M., Verheyen, K., 2011. Effects of soil compaction on growth and survival of tree saplings: a meta-analysis. Basic Appl. Ecol. 12, 394-402. doi:10.1016/j.baae.2011.06.003

Ampoorter, E., Goris, R., Cornelis, W.M., Verheyen, K., 2007. Impact of mechanized logging on compaction status of sandy forest soils. For. Ecol. Manage. 241, 162-174. doi:10.1016/j.foreco.2007.01.019

Ampoorter, E., Nevel, L. Van, Vos, B. De, Hermy, M., Verheyen, K., 2010. Assessing the effects of initial soil characteristics, machine mass and traffic intensity on forest soil compaction. For. Ecol. Manage. 260, 1664-1676. doi:10.1016/j.foreco.2010.08.002

Andrzejczyk, T., Zybura, H., 1981. Scots pine-unknown species? The possibility of utilizing old Scots pine understorey. Las-Polski 55, 8-9.

Angima, S.D., Terry, T.A., Miller, R.E., Campbell, S., 2011. Best management practices for maintaining soil productivity in the Douglas-fir region.

Aroca-Fernández, M.J., Bravo Fernández, J.A., Fernández Yuste, J.A., Serrada, R., 2015. Persistence of scarification effects in a Scots pine forest within the Spanish Central System mountains, en: Mountains Forest Management in a Changing World' IUFRO Conference. High Tatra Mountains, Slovakia.

Artigas, P., 1890. Selvicultura o cría y cultivo de los montes. Impresa Moreno y Rojas, Madrid.

Aussenac, G., 2000. Interactions between forest stands and microclimate: Ecophysiological aspects and consequences for silviculture. Ann. For. Sci. 57, 287-301. doi:10.1051/forest:2000119

Barbeito, I., Fortin, M.J., Montes, F., Cañellas, I., 2009. Response of pine natural regeneration to small-scale spatial variation in a managed Mediterranean mountain forest. Appl. Veg. Sci. 12, 488-503. doi:10.1111/j.1654-109X.2009.01043.x

Barbeito, I., Lemay, V.M., Calama, R., Canellas, I., 2011. Regeneration of Mediterranean Pinus sylvestris under two alternative shelterwood systems within a multiscale framework. Can. J. For. Res. Can. Rech. For. 41, 341-351. doi:10.1139/×10-214

Barbeito, I., Pardos, M., Calama, R., Cañellas, I., 2008. Effect of stand structure on Stone pine (Pinus pinea L.) regeneration dynamics. Forestry 81, 617-629.

Battaglia, M., Reid, J.B., 1993. The Effect of microsite variation on seed germination and seedling survival of Eucalyptus delegatensis. Aust. J. Bot. 41, 169-181.

Bengough, A., Mullins, C., 1990. Mechanical impedance to root growth: a review of experimental techniques and root growth responses. J. soil Sci. 41, 341-358. 
Bengough, A.G., Bransby, M.F., Hans, J., Mckenna, S.J., Roberts, T.J., Valentine, T.A., 2006. Root responses to soil physical conditions: growth dynamics from field to cell. J. Exp. Bot. 57, 437-447. doi:10.1093/jxb/erj003

Bengough, A.G., McKenzie, B.M., 1997. Sloughing of root cap cells decreases the frictional resistance to maize (Zea mays L.) root growth. J. Exp. Bot. 48, 885-893. doi:10.2307/23695846

Bengough, A.G., Mullins, C.E., Wilson, G., 1997. Estimating soil frictional resistance to metal probes and its relevance to the penetration of soil by roots. Eur. J. Soil Sci. 48, 603-612.

Blanco, J. a, 2012. Forests may need centuries to recover their original productivity after continuous intensive management: an example from Douglas-fir stands. Sci. Total Environ. 437, 91-103. doi:10.1016/j.scitotenv.2012.07.082

Blouin, V.M., Schmidt, M.G., Bulmer, C.E., Krzic, M., 2005. Mechanical disturbance impacts on soil properties and lodgepole pine growth in British Columbia's central interior. Can. J. Soil Sci. 85, 681-691. doi:10.4141/S04-077

Booth, T.C., 1984. Natural regeneration in the native pinewoods of Scotland. A review of principles and practice. Scottish For. 38, 33-42.

Boppe, L. Jolyet, A., 1901. Les forêts. Traité pratique de sylviculture. Librairie J.-B. Baillière et fils, Paris.

Borchert, M.I., Davis, F.W., Michaelsen, J., Oyler, L.D., 1989. Interactions of Factors Affecting Seedling Recruitment of Blue Oak (Quercus douglasii ) in California. Ecology 70, 389-404. doi:10.2307/1937544

Boudru, M., 1992. Forêt et Sylviculture: Traitemets des Forêts. Les Presses Agronomiques de Gembloux.

Brais, S., Camiré, C., 1998. Soil compaction induced by careful logging in the claybelt region of northwestern Quebec (Canada). Can. J. Soil Sci. 78, 197-206. doi:10.4141/S97-032

Bravo Fernández, J.A., Serrada, R., 2007. Tercera Revisión del Proyecto de Ordenación del monte «Cabeza de Hierro» (Rascafría, Madrid).

Bravo, J.A., Rubio, A., Aroca, M.J., Serrada, R., Roig, S., 2010. Diagnosis y distribución espacial del sobrepastoreo mediante Sig. Caso del monte «Cabeza de Hierro» (Rascafría, Madrid), en: IV Reunión Ibérica de pastos y forrajes. Zamora \& Miranda do Douro, pp. 537-542.

Buckley, D.S., Sharik, T.L., Isebrands, J.G., 1998. Regeneration of northern Red oak: positive and negative effects of competitor removal. Ecology 79, 65-78.

Burger, J.A., Kelting, D.L., 1999. Using soil quality indicators to assess forest stand management. For. Ecol. Manage. 122, 155-166.

Cabrera Bonet, M., 2003. Incidencia de la regeneración natural en los proyectos de ordenación de montes. Cuad. Soc. Esp. Cien. For. 15, 25-36.

Caccia, F.D., Ballaré, C.L., 1998. Effects of tree cover, understory vegetation, and litter on regeneration of Douglas-fir (Pseudotsuga menziesii) in southwestern Argentina. Can. J. For. Res. 28, 683-692. doi:10.1139/cjfr-28-5-683

Camarero, J.J., Gutiérrez, E., Fortin, M.J., Ribbens, E., 2005. Spatial patterns of tree recruitment in a relict population of Pinus uncinata: forest expansion through stratified difussion. J. Biogeogr. 32, 1979-1992.

Cambi, M., Certini, G., Neri, F., Marchi, E., 2015. The impact of heavy traffic on forest soils: A review. For. Ecol. Manage. 338, 124-138. doi:10.1016/j.foreco.2014.11.022

Campo, M. del, Peña, F., 1922. Estudios de absorción de luz relativos a especies forestales, Colección . ed. Gráficas Reunidas S.A., Madrid.

Canham, C.D., 1995. GLI/C: Software for calculation of light transmission through forest canopies using color fisheye photography. Millbrook, NY. 
Cañellas, I., Montes, F., Bachiller, A., Dones, J., Pardos, M., del Río, M., 2005. Influencia de la cobertura vegetal en la germinación natural de semillas de Pinus sylvestris L., en: 4o Congreso Forestal español. Zaragoza.

Capelli, M., 1988. Selvicoltura generale. Edagricole.

Carballeira, A., 1980. Phenolic inhibitors in Erica australis L. and in associated soil. J. Chem. Ecol. 6, 593-596.

Castro, J., 1999. Seed mass versus seedling performance in Scots pine: A maternally dependent trait. New Phytol. 144, 153-161. doi:10.1046/j.1469-8137.1999.00495.x

Castro, J., Zamora, R., Hódar, J.A., 2002. Mechanisms blocking Pinus sylvestris colonization of Mediterranean mountain meadows. J. Veg. Sci. 13, 725-731. doi:10.1111/j.1654-1103.2002.tb02100.x

Castro, J., Zamora, R., Hódar, J.A., Gómez, J.M., 2004. Seedling establishment of a boreal tree species (Pinus sylvestris) at its southernmost distribution limit: consequences of being in a marginal Mediterranean habitat. J. Ecol. 92, 266- 277.

Castro, J., Zamora, R., Hódar, J.A., Gómez, J.M., 2005a. Alleviation of summer drought boosts establishment success of Pinus sylvestris in a Mediterranean mountain: an experimental approach. Plant Ecol. 181, 191-202. doi:10.1007/s11258-005-6626-5

Castro, J., Zamora, R., Hódar, J.A., Gómez, J.M., 2005b. Ecology of seed germination of Pinus sylvestris L . at its southern, Mediterranean distribution range. Invest.Agr. Sist. Recur. For. 14, 143-152.

Catovsky, S., Bazzaz, F.A., 2002a. Nitrogen availability influences regeneration of temperate tree species in the understory seedling bank. Ecol. Appl. 12, 1056-1070.

Catovsky, S., Bazzaz, F.A., 2002b. Feedbacks between canopy composition and seedlings regeneration in mixed conifer broad-leaved forests. Oikos 98, 403-420.

Ceballos, L., Ruíz de la Torre, J., 1979. Árboles y arbustos de la España Peninsular. Madrid.

Chapman, N., Miller, A.J., Lindsey, K., Whalley, W.R., 2012. Roots, water, and nutrient acquisition: let's get physical. Trends Plant Sci. 17, 701-10. doi:10.1016/j.tplants.2012.08.001

Chazdon, R.L., Field, C.B., 1987. Photographic estimation of photosynthetically active radiation: evaluation of a computerized technique. Oecologia 73, 525-532.

Claverie, J., Balbuena, R., Terminiello, A., Casado, J., Manghi, E., Jorajuría, D., 2000. Compactación inducida por el tráfico de máquinas en suelo forestal. Rev. Bras. Eng. Agrícola e Ambient. 4, 286-289.

Crawley, M.J., 1997. Plant-herbivore dynamics, en: Crawley, M.J. (Ed.), Plant Ecology. Blackwell Scientific Publications, Oxford, pp. 401-474.

Crush, J.R., Thom, E.R., 2011. Review: The effects of soil compaction on root penetration , pasture growth and persistence. Pasture Persistence - Grassl. Res. Pract. Ser. 15, 73-78.

Curran, M.P., Heninger, R.L., Maynard, D.G., Powers, R.F., 2005. Harvesting effects on soils, tree growth, and long-term productivity, en: Harrington, C.A., Schoenholtz, H.S. (Eds.), Productivity of Western Forests : A Forest Products Focus. pp. 3-15.

Daniel, P.W., Helms, U.E., Baker, F.S., 1982. Principios de silvicultura. McGraw-Hill, México.

De Schepper, C., 1988. Typology of the natural regeneration in a middle-aged. Scots Pine Forest. Silva Gandav. 53, 29-60.

Dec, D., Dörner, J., Balocchi, O., 2011. Temporal and spatial variability of structure dependent properties of a volcanic ash soil under pasture in southern Chile. Chil. J. Agric. Res. 71, 293-303.

Deschênes, C., 1989. Pression exerceé sur le sol par la machinerie forestiere: repertoire. Ministere de l'Energie et des Ressources, Canada, Quebec.

Dolling, A.H.U., 1996. Interference of bracken (Pteridium aquilinum L. Kuhn) with Scots pine (Pinus sylvestris L.) and Norway spruce (Picea abies L. Karst.) seedling establishment. For. Ecol. Manage. 88, 227-235. doi:10.1016/S0378-1127(96)03846-7 
Duncan, R.P., Diez, J.M., Sullivan, J.J., Wangen, S., Miller, A.L., 2009. Safe sites, seed supply, and the recruitment function in plant populations. Ecology 90, 2129-2138.

Eavis, B.W., 1972. Soil physical conditions affecting seedling root growth. I. Mechanical impedance, aeration and moisture availability as influenced by bulk density and moisture levels in a sandy loam soil. Plant Soil $36,613-622$.

Egli, B.R., 1998. Effects of grazing on the natural forest of western Crete, en: Papanastasis, V.P., Peter, D. (Eds.), Ecological basis of livestock grazing in Mediterranean ecosystems. EUR 18308, Luxemburgo, pp. 103-106.

Emborg, J., 1998. Understorey light conditions and regeneration with respect to the structural dynamics of a near-natural temperate deciduous forest in Denmark. For. Ecol. Manag. 106, 83-95.

Fernández, M., Gil, L., Pardos, J.A., 1999. Response of Pinus Pinaster Ait. provenances at early age to water supply. I. Water relation parameters. Ann. For. Sci. 56, 179-187.

Fox, T.R., 2000. Sustained productivity in intensively managed forest plantations. For. Ecol. Manage. 138, 187202. doi:10.1016/S0378-1127(00)00396-0

Frazer, G., Canham, C., Lertzman, K., 1999. Gap Light Analyzer (GLA), Version 2.0: Imaging software to extract canopy structure and gap light transmission indices from true-colour fisheye photographs, users manual and program documentation. (c) 1999: Simon Fraser University \& Inst.Ecos.St. doi:citeulike-articleid:4887176

Friedman, J., Hastie, T., Tibshirani, R., 2010. Regularization paths for Generalized Linear Models via coordinate descent. J. Stat. Softw. 33, 22.

Froehlich, H.A., 1979. Soil compaction from logging equipment: effects on growth of young ponderosa pine. J. Soil Water Conserv. 34, 276-278.

Fron, A., 1910. Sylviculture. Paris.

Gandullo, J.M., 1994. Climatología y Ciencia del Suelo. FUCOVASA, ETSIM, Madrid.

Gandullo, J.M., Nicolás, A., 1967. Estudio ecológico de los pinares españoles. I: Pinus pinaster Aiton. IFIE.

Gandullo, J.M., Serrada, R., 1977. Mapa de productividad potencial forestal de la España peninsular. CRIDA 06-INIA, Madrid.

García, L.V., Melchiorre, G., Angulo, E., Gutiérrez-Hernández, O. Moreno López, A., Díaz-Delgado, R., Ramo, C., Domínguez, M.T., Gómez Aparicio, L., 2013. Amenazas bióticas sobre el alcornocal centenario de Doñana: ¿demasiadas para sobrevivir?, en: XI Congreso Nacional de la AEET.

García, L.V., Polo, A., Maltez-Mouro, S., Gutiérrez, E., Pérez Ramos, I.M., Martínez-Zavala, L., Marañón, T., 2007. Relación entre la composición y densidad de la cubierta vegetal leñosa y las características superficiales del suelo en bosques mixtos de Quercus al sur de la península ibérica ., en: Jordano, Bellinfante (Eds.), Tendencias actuales de la ciencia del suelo. Sevilla, pp. 522-530.

Gomez, A., Powers, R.F., Singer, M.J., Horwatha, W.R., 2002. Soil Compaction Effects on Growth of Young Ponderosa Pine Following Litter Removal in California's Sierra Nevada. Soil Sci. Soc. Am. J. 66, 13341343.

Gomez, G.A., Singer, M.J., Powers, R.F., Horwath, W.R., 2002. Soil compaction effects on water status of ponderosa pine assessed through 13C/12C composition. Tree Physiol. 22, 459-467.

Gómez Sanz, V., 2002. Micrometeorología de masas forestales de pino silvestre (Pinus sylvestris L.) y rebollo (Quercus pyrenaica Willd.) en la vertiente norte del Sistema Central (Montes de Valsaín - Segovia). Consecuencias selvícolas. Universidad Politécnica de Madrid.

Gómez-Sánz, V., Elena, R., 1997. Investigación de las marras causadas por factores ecológicos de naturaleza meteorológica. Cuad. la S.E.C.F. N4, 13-25. 
Gong, Y.L., Swaine, M.D., Miller, H.G., 1991. Effects of fencing and ground preparation on natural regeneration of native pinewood over 12 years in Glen Tanar, Aberdeenshire. Forestry 64, 157-168.

González Martínez, S.C., Bravo, F., 2001. Density and population structure of the natural regeneration of Scots Pine in the High Ebro Basin. Ann. For. Sci. 58, 277-288.

González Vázquez, E., 1945. La selvicultura española. Montes 5, 311-318.

González Vázquez, E., 1948. Selvicultura. Estudio cultural de las masas forestales y los métodos de regeneración. Residencia de profesores, Madrid.

González-Martínez, S.C., Bravo, F., 1999. Regeneración natural, establecimiento y primer desarrollo del pino silvestre (Pinus sylvestris L.). Investig. Agrar. Sist. y Recur. For. Fuera de S, 225-247.

Goutal, N., Keller, T., Défossez, P., Ranger, J., 2013. Soil compaction due to heavy forest traffic: measurements and simulations using an analytical soil compaction model. Ann. For. Sci. 70, 545-556. doi:10.1007/s13595-013-0276-x

Graae, B.J., Ejrnaes, R., Lang, S.I., Meineri, E., Ibarra, P.T., Bruun, H.H., 2011. Strong microsite control of seedling recruitment on tundra. Oecologia 166, 565-576.

Granström, A.Y., Fries, C., 1985. Depletion of viable seeds in the forest floor after clearcutting. J.For. 68, 776778.

Greacen, E.L., Sands, R., 1980. Compaction of forest soils. A review. Soil Res. 18, 163-189.

Greenwood, K.L., McKenzie, B.M., 2001. Grazing effects on soil physical properties and the consequences for pastures: a review. Aust. J. Exp. Agric. 41, 1231-1250.

Grigal, D.F., 2000. Effects of extensive forest management on soil productivity. For. Ecol. Manage. 138, 167185. doi:10.1016/S0378-1127(00)00395-9

Hakansson, I., Reeder, R.C., 1994. Subsoil compaction by vehicles with high axle load extent, persistence and crop response. Soil Tillage Res. 29, 277-304.

Harper, J.L., 1977. Population Biology of Plants. Academic Press, Inc., London.

Harrington, T.B., 2006. Five-year growth responses of Douglas-fir, western hemlock and western redcedar seedlings to manipulated levels of overstory and understory competition. Can. J. For. Res. 36, 24392453.

Hawley, R.C., Smith, D.M., 1982. Silvicultura práctica. Ediciones Omega S.A., Barcelona.

Herrera, C.M., Jordano, P., 1983. Prunus mahaleb and birds. Ecol. Monogr. 51, 203-218.

Honkanen, T., Haukioja, E., Suomela, J., 1994. Effects of simulated defoliation and debudding on needle and shoot growth in Scots pine (Pinus sylvestris): implications of plant source/sink relationships for plantherbivore studies. Funct. Ecololgy 8, 631-639.

Horn, R., Vossbrink, J., Becker, S., 2004. Modern forestry vehicles and their impacts on soil physical properties. Soil Tillage Res. 79, 207-219. doi:10.1016/j.still.2004.07.009

Horn, R., Vossbrink, J., Peth, S., Becker, S., 2007. Impact of modern forest vehicles on soil physical properties. For. Ecol. Manage. 248, 56-63. doi:10.1016/j.foreco.2007.02.037

Huberty, M.R., 1945. Compaction in cultivated soils. Am. Geophys. Union Trans. 25, 896-899.

Hui, S.R., Wang, W.J., Liu, Q., Liu, H., Chen, Z.W., 2012. A Study on the Volume and Water-Holding Properties of Litter Layer for Larix Kaempferi Forests of Eastern Region in Liaoning Province, en: Advanced Materials Research. pp. 3298-3303.

I.S.T.A., 1999. International rules for seed testing. Seed Sci. Technol. 9, 373-409.

Izhaki, I., Ne'eman, G., 1996. The effect of porcupine and bast scale on Aleppo pine recruitment after fire. Acta Oecologica 17, 97-108.

Jakobsen, B.F., Greacen, E.L., 1985. Compaction of sandy forest soils by forwarder operations. Soil Tillage Res. 5, 55-70. 
Jeansson, E., Bergman, F., Elfving, B., Falck, J., Lundqvist, L., 1989. Natural regeneration of pine and spruce. Proposal for a research program. Rapporter $n^{\circ} 25$.

Jiménez Esquilín, A.E., Stromberger, M.E., Shepperd, W.D., 2008. Soil scarification and wildfire interactions and effects on microbial communities and carbon. Soil Sci. Soc. Am. J. 72, 111-118. doi:10.2136/sssaj2006.0292

Johansson, M.-B., 1994. The influence of soil scarification on the turn-over rate of slash needles and nutrient release. Scand. J. For. Res. 9, 170-179.

Jones, A., 2000. Effects of cattle grazing on north american arid ecosystems: a quantitative review. West. North Am. Nat. 60, 155-164.

Jorajuria, D., Draghi, L., Aragon, a., 1997. The effect of vehicle weight on the distribution of compaction with depth and the yield of Lolium/Trifolium grassland. Soil Tillage Res. 41, 1-12. doi:10.1016/S01671987(96)01085-9

Jordano, P., 1993. Geographical ecology and variation of plant-seed disperser interactions: Southern Spanish junipers and frugivorous thrushes., en: Fleming, T.H. (Ed.), Frugivory and seed dispersal. Kluwer Acad. Pub, Dordrecht. The Nederlands.

Kirby, M., 2007. Whither soil compaction research? Soil Tillage Res. 93, 472-475. doi:10.1016/j.still.2006.04.008

Kolb, P.F., Robberecht, R., 1996. Pinus ponderosa seedling establishment and the influence of competition with the bunchgrass Agropyron spicatum. Int. J. Plant Sci. 157, 509-515.

Kozlowski, T.T., 1999. Soil compaction and growth of woody plants. Scand. J. For. Res. 14, 596-619. doi:10.1080/02827589908540825

Kubin, E., Kemppainen, L., 1994. Effect of soil preparation of boreal Spruce forest on air and soil temperature conditions in forest regeneration areas. For. Fenn. 244, 56.

Kuiters, A.T., Slim, P.A., 2002. Regeneration of mixed forest in a Dutch forest-heathland, following a reduction of ungulate densities. Biol. Conserv. 105, 65-74.

Kupila-Ahvenniemi, S., 1985. Wintertime changes in the fine structure and the ribosome content of the buds of Scots pine, en: Kaurin, A., Junttila, O., Nielsen, J. (Eds.), Plant Production in the North. Norw. Univ. Press, pp. 171-180.

Laguna, M., de Ávila, P., 1883. Flora forestal española. Primera parte. Imprenta del Colegio Nacional de Sordo-Mudos y de Ciegos, Madrid.

Laliberté, E., Cogliastro, A., Bouchard, A., 2008. Spatiotemporal patterns in seedling emergence and early growth of two oak species direct-seeded on abandoned pastureland. Ann. For. Sci. 65, 401-407.

Lei, S.A., 2004. Soil compaction from human trampling, biking, and off-road motor vehicle activity in a Blackbrush (Coleogyne ramossisima) shrubland. Weswtern North Am. Nat. 64, 125-130.

LePage, P.T., Canham, C.D., Coates, K.D., Bartemacci, P., 2000. Seed abundance versus substrate limitation of seedling recruitment in northern temperate forests of British Columbia. Can. J. For. Res. 30, 415427.

Leroy, P., 1961. Humus brut et régénération du pin sylvestre en forêt de Haguenauo. Rev. For. Française 4 , 251-263.

Letey, J., 1985. Relationship between soil physical properties and crop production, en: Stewart, B.A. (Ed.), Advances in Soil Science SE - 8, Advances in Soil Science. Springer New York, pp. 277-294. doi:10.1007/978-1-4612-5046-3_8

Lindstrom, M.J., Bates, D.M., 1988. Newton-Raphson and EM algorithms for linear models for repeatedmeasures data. J. Am. Stat. Assoc. 83, 1014-1022. doi:10.2307/2290128 
Lindstrom, M.J., Bates, D.M., 1990. Nonlinear mixed effects models for repeated measures data. Biometrics 46, 673-687.

Lipiec, J., Hatano, R., 2003. Quantification of compaction effects on soil physical properties and crop growth. Geoderma 116, 107-136. doi:10.1016/S0016-7061(03)00097-1

Lorimer, C.G., Chapman, J.W., Lambert, W.D., 1994. Tall understorey vegetation as a factor in the poor development of oak seedlings beneath mature stands. J. Ecol. 82, 227-237.

Lust, N., 1988. Analysis of a natural regeneration of Scots pine forest in the High Campine after a fire. Silva Gandav. 53, 3-28.

M.A.P.A., 1985. Mapa 1:200.000 de cultivos y aprovechamientos de la provincia de Madrid y memoria. Ministerio de Agricultura Pesca y Alimentación, Madrid.

Manoel, C., Vaz, P., Hopmans, J.W., 2001. Simultaneous measurement of soil penetration resistance and water content with a combined penetrometer - TDR moisture probe. Soil Sci. Soc. Am. J. 65, 4-12.

Martín, S., Agúndez, D., 1992. Crecimiento y floración de Pinus sylvestris L. en un huerto semillero clonal. Montes 28, 46-48.

Martín, S., Galera, R., Iglesias, S., de Tuero, M., 1997. El material forestal de reproducción. Cuad. la S.E.C.F. $5,19-24$

Martínez de Pisón, M., 1948. Defensa del método denominado «ordenar transformando». Escuela Especial de Ingenieros de Montes, Madrid.

Mast, J.N., Veblen, T.T., 1999. Tree spatial patterns and stand development along the pine-grassland ecotone in the Colorado Front Range. Can. J. For. Res. 29, 575-584.

Materechera, S.A., Dexter, A.R., Alston, A.M., 1991. Penetration of very strong soils by seedling roots of different plant species. Plant Soil 135, 31-41.

Mathews, J.D., 1989. Silvicultural Systems. Oxford Science Publications, Oxford.

Mátyás, C., 1991. Seed Orchards, en: Giertych, M., C., M. (Eds.), Genetics of Scots pine. Elsevier, Amsterdam, pp. 125-147.

McCutchan, M., Fox, D., 1986. Effect of elevation and aspect on wind, temperature and humidity. J. Clim. Appl.

McDonald, T.P., Stokes, B.J., Aust, W.M., 1995. Soil physical property changes after skidder traffic with varying tire widths. J. For. Eng. 6, 41-50.

MCKENZIE, B.M., MULLINS, C.E., TISDALL, J.M., BENGOUGH, A.G., 2013. Root-soil friction: quantification provides evidence for measurable benefits for manipulation of root-tip traits. Plant. Cell Environ. 36, 1085-1092. doi:10.1111/pce.12037

Messier, C., Puttonen, P., 1995. Spatial and temporal variation in the light environment of developing Scots pine stands: the basis for a quick and efficient method of characterizing light. Can. J. For. Res. 25, 343-354.

Miller, R.E., Colbert, S.R., Morris, L.A., 2004. Effects of heavy equipment on physical properties of soils and on long-term productivity: a review of literature and current research. Nactional Council for Air and Stream Improvement.

Miller, R.E., Hazard, J., Howes, S., 2001. Precision, accuracy, and efficiency of four tools for measuring soil bulk density or strength. U.S.Department of Agriculture Forest Service, Portland, OR.

Miller, R.E., Scott, W., Hazard, J.W., 1996. Soil compaction and conifer growth after tractor yarding at three coastal Washington locations. Can. J. For. Res. 26, 225-236. doi:10.1139/x26-026

Ministerio de Agricultura, 1971. Instrucciones para la «Ordenación de Montes Arbolados». Dirección General de Montes, Caza y Pesca Fluvial., Madrid.

Mitchell, F.J.G., Kirby, K.J., 1990. The impact of large herbivores on the conservation of semi-natural woods in the British uplands. Forestry 63, 333-353. 
Modrý, M., Hubený, D., Rejsek, K., 2004. Differential response of naturally regenerated European shade tolerant tree species to soil type and light availability. For. Ecol. Manag. 188, 185-195.

Montero, G., 1987. 1ª Revisión del Proyecto de Ordenación del monte «Cabeza de Hierro» (Rascafría, Madrid).

Montero, G., 1994. Generalities on silviculture of Pinus sylvestris L. in Spain. Invest. Agrar. Sist. Recur. For. Fuera de serie 3, 251-259.

Montero, G., del Río, M., Roig, S., Rojo, A., 2008. Selvicultura de Pinus sylvestris L., en: Serrada, R., Montero, M., Reque, J. (Eds.), Compendio de selvicultura aplicada en España. INIA y FUCOVASA, Madrid, pp. 503 - 534.

Montero, G., Serrada, R., 2013. La situación de los bosques y el sector forestal en España - ISFE 2013. Sociedad Española de Ciencias Forestales, Lourizán (Pontevedra).

Montgomery, R.A., Chazdon, R.L., 2002. Light gradient partitioning by tropical tree seedlings in the absence of canopy gaps. Oecologia 131, 165-174.

Moon, J.W., 1938. Some field observations of the agronomic significance of compact subsoils. Soil Sci. Soc. Am. Proc. 3, 237-241.

Moorefield, J., Hopkins, H., 1951. Grazing habits of cattle in a mixed-prairie pasture. J. Range Manag. 4, 151157.

Mori, A., Mizumachi, E., Osono, T., Doi, Y., 2004. Substrate-associated seedling recruitment and establishment of major conifer species in an old-growth subalpine forest in central Japan. For. Ecol. Manag. 196, 287297.

Morillo, J.M., 1987. Estudio de las causas que limitan la regeneración natural de Pinus sylvestris L. en el cuartel «D» del monte Cabeza de Hierro. Trabajo fin de carrera.

Muukkonen, P., Mäkipää, R., Laiho, R., Minkkinen, K., Vasander, H., Finér, L., 2006. Relationship between biomass and percentage cover in understorey vegetation of boreal coniferous forests. Silva Fenn. 40, 231-245.

Navarro, R., Gálvez, C., 2001. Manual para la identificación y reproducción de semillas de especies vegetales autóctonas de Andalucía. Tomos I y II. Consejería de Medio Ambiente. Junta de Andalucía.

Nyland, R.D., 2003. Sylviculture. Concepts and applications. McGraw-Hill. Series in Forest Resources.

Olarieta, J.R., Rodríguez-Ochoa, R., Ascaso, E., 2007. Land management practices in the Chittagong Hill Tracts and sustainable alternatives. The CHARM Project, 2007.

Olderman, R.A.A., s. f. Forests: Elements of Silvology. Springer- Verlag, Berlin.

Oleskog, G., Sahlén, K., 2000a. Effects of Seedbed Substrate on Moisture Conditions and Germination of Pinus sylvestris Seeds in a Clearcut. Scand. J. For. Res. 15, 225-236. doi:10.1080/028275800750015046

Oleskog, G., Sahlén, K., 2000b. Effects of seedbed substrate on moisture conditions and germination of Scots pine (Pinus sylvestris) seeds in a mixed conifer stand. New For. 20, 119-133. doi:10.1023/A:1006783900412

Oliver, C.D., Larson, B.C., 1996. Forests stand dynamics. McGraw-Hill, New York.

Oosterbaan, A.., 1994. Results of trial with natural regeneration of Pinus sylvestris in the Netherlands. Invest. Agrar. Sist Recur. For. Fuera de s, 149- 153.

Örlander, G., 1986. Effect of planting and scarification on the water relations in planted seedlings of Scots pine. Stud. For. Suec. 173, 17.

Pardos, M., 2012. La regeneración natural de los pinares en los arenales de la Meseta Castellana. Instituto Universitario de Investigación en Gestión Forestal Sostenible (Universidad de Valladolid-INIA), Valladolid. 
Pardos, M., Montero, G., Cañellas, I., Ruiz del Castillo, J., 2005. Ecophysiology of natural regeneration of forest stands in Spain. For. Syst. 14, 434-445.

Pardos, M., Montes, F., Aranda, I., Cañellas, I., 2007. Influence of environmental conditions on germinant survival and diversity of Scots pine (Pinus sylvestris L.) in central Spain. Eur. J. For. Res. 126, 37-47. doi:10.1007/s10342-005-0090-6

Parish, R., Antos, J.A., 2005. Advanced regeneration and seedling establishment in small cutblocks in highelevation spruce-fir forest at Sicamous Creek, southern British Columbia. Can. J. For. Res. 35, 18771888.

Powers, R.F., 1999. On the sustainable productivity of planted forests. New For. 17, 263-306.

Powers, R.F., Andrew Scott, D., Sanchez, F.G., Voldseth, R. a., Page-Dumroese, D., Elioff, J.D., Stone, D.M., 2005. The North American long-term soil productivity experiment: Findings from the first decade of research. For. Ecol. Manage. 220, 31-50. doi:10.1016/j.foreco.2005.08.003

Puhe, J., 2003. Growth and development of the root system of Norway spruce (Picea abies) in forest stands a review. For. Ecol. Manage. 175, 253-273.

Pukkala, T., 1987. Simulation model for natural regeneration of Pinus sylvestris, Picea abies, Betula pendula and Betula pubescens. Silva Fenn. 21, 37-53.

Putman, R.J., 1996. Ungulates in temperate forest ecosystems: perspectives and recommendations for future research. For. Ecol. Manag. 88, 205-214.

R., S., 2000. Apuntes de Repoblaciones Forestales. Fundación Conde del Valle de Salazar. ETSI Montes. UPM., Madrid.

Ribbens, E., Silander, J.A., Pacala, S.W., 1994. Seedling recruitment in forests. Ecology 75, 1794-1806.

Rich, P.M., 1989. A manual for analysis of hemispherical canopy photography. Los Alamos.

Rich, P.M., 1990. Characterizing plant canopies with hemispherical photographs. Remote Sens. Rev. 5, 13-29. doi:10.1080/02757259009532119

Rich, P.M., Wood, J., Vieglais, D.A., Burek, K., Webb, N., 1999. Guide to HemiView: software for analysis of hemispherical photography. Cambridge, England.

Ripley, B.D., 1981. Spatial statistics. John Wiley \& Sons, New York.

Rivas Martínez, S., 1987. Memoria del mapa de series de vegetación de España 1: 400.000. ICONA. Ministerio de Agricultura, Pesca y Alimentación, Madrid.

Rodríguez Soalleiro, R., Sánchez Rodríguez, F. Gorgoso, J., Castedo, F., López Sánchez, C.A., Gadow, K.V., 2002. Evaluating standard treatment options for Pinus radiata plantations in Galicia (north-western Spain). Forestry $75,273-284$

Rodríguez-García, E., Ordóñez, C., Bravo, F., 2011. Effects of shrub and canopy cover on the relative growth rate (RGR) of Pinus pinaster seedlings of different sizes. Ann. For. Sci. 68, 337-346.

Roig Gómez, S., 1999. Caracterización edáfica de los principales pastizales naturales del valle del Paular (Madrid). Tesis doctoral. Universidad Polictecnica de Madrid.

Rojo, A., Montero, G., 1996. El pino silvestre en la Sierra de Guadarrama. Ministerio de Agricultura Pesca y Alimentación, Madrid.

Rojo Sainz, F., 1977. Fotología forestal y ordenación. Montes 187, 31-34.

Rooney, T.P., Waller, D.M., 2003. Direct and indirect effects of white-tailed deer in forest ecosystems. For. Ecol. Manag. 181, 165-173.

Rozas, V., 2002. Estructura y patrones de regeneración del roble y el haya en un bosque maduro del litoral occidental de Cantabria. Invest. Agr. Sist. Rec. For. 11, 107-136.

Ruano, I., Pando, V., Bravo, F., 2009. How do light and water influence Pinus pinaster Ait. Germination and early seedling development? For. Ecol. Manage. 258, 2647-2653. 
Rubio, L.V., 1987. Estudio de las causas que limitan la regeneración natural de Pinus sylvestris L. en el cuartel «B» del monte Cabeza de Hierro. Trabajo fin de carrera.

Sack, L., Grubb, P.J., 2002. The combined impacts of deep shade and drought on the growth and biomass allocation of shade-tolerant woody seedlings. Oecologia 131, 175-185.

Sainz Margareto, M., 1953. Tratamiento de aclareos sucesivos uniforme en el monte «Pinar de Navafría». Montes 49, 60-67.

Sainz Margareto, M., 1963. Método de ordenar transformando en el monte «Pinar de Navafría», en: II Asamblea Técnica Forestal. Madrid 11-16 de junio, 1962. Ministerio de Agricultura. Dirección General de Montes, Caza y Pesca Fluvial, Madrid.

Santos, M., 1987. Estudio de las causas que limitan la regeneración natural de Pinus sylvestris L. en el cuartel «E» del monte Cabeza de Hierro. Trabajo fin de carrera.

Sarvas, R., 1962. Investigations on the flowering and seed crop of Pinus sylvestris. Commun. Inst. For. Fenn. 53, 1-198.

Schmalz, H.J., Taylor, R. V, Johnson, T.N., Kennedy, P.L., Sandra, J., Newingham, B.A., Mcdaniel, P.A., 2013. Soil morphologic properties and cattle stocking rate affect dynamic soil properties. Rangel. Ecol. Manag. 66, 445-453. doi:10.2111/REM-D-12-00040.1

Schülz, J.P., 1990. Sylviculture 1. Principes d'education del forêts. Presses Polytechniques et Universitaires Romandes. Collection Gérer l'environnement.

Schülz, J.P., 1997. Sylviculture 2. La gestin des forêts irrégulières el melangées. Presses Polytechniques et Universitaires Romandes, Lausanne. Suiza.

Schupp, E.W., Fuentes, M., 1995. Spatial patterns of seed dispersal and the unification of plan population ecology. Ecoscience 2, 267-275.

Serrada, R., 2002. Apuntes de Selvicultura. E.U.I.T.Forestal, Madrid.

Serrada, R., 2011. Apuntes de Selvicultura. Fucovasa, Madrid.

Serrada, R., Montero, G., Reque, J.A., 2008. Compendio de Selvicultura Aplicada en España. Instituto Nacional de Investigación y Tecnología Agraria y Alimentaria. Fundación Conde del Valle de Salazar, Madrid.

Sigua, G.C., Coleman, S.W., 2009. Long-term effect of cow congregation zone on soil penetrometer resistance: implications for soils and forage quality. Agron. Sustain. Dev. 29, 517-523. doi:10.1051/agro/2009021

Smith, C.W., 1997. The effect of soil compaction and soil physical properties on the mechanical resistance of South African forestry soils. Geoderma 78, 93-111.

Soane, B.D., 1990. The role of organic matter in soil compactibility: a review of some practical aspects. Soil Tillage Res. 16, 179-201.

Steber, A., Brooks, K., Perry, C.H., Kolka, R., 2007. Surface compaction estimates and soil sensitivity in Aspen stands of the Great Lakes States. North. J. Appl. For. 24, 276-281.

Susmel, L., 1980. Normalizzazione delle foreste alpine. Basi ecosistemiche, equilibrio, modelli colturali, produttività. Liviana editrice, Padova.

Tarpey, R.A., Jurgensen, M.F., Palik, B.J., Kolka, R.K., 2008. The long-term effects of silvicultural thinning and partial cutting on soil compaction in red pine (Pinus resinosa Ait.) and northern hardwood stands in the northern Great Lakes Region of the United States. Can. J. Soil Sci. 88, 849-857.

Tegelmark, D.O., 1988. Site factors as multivariate predictors of the success of natural regeneration in Scots pine forests. For. Ecol. Manage. 109, 231-239.

Thornthwaite, C.M., 1948. An approach toward a rational classification of climate. Geogr. Rev. 38, 55-94.

Tibshirani, R., 1996. Regression Shrinkage and Selection via the Lasso. J. R. Stat. Soc. Ser. B 58, 267-278. 
Troup, R.S., 1952. Silvicultural systems. Oxford Univ. Press.

Valladares, F., Pearcy, R.W., 2002. Drought can be more critical in the shade than in the sun. Plant, Cell Environ. 25, 749-759.

Vasiliauskas, R., 2001. Damage to trees due to forestry operations and its pathological significance in temperate forests: A literature review. Forestry 74, 319-336. doi:10.1093/forestry/74.4.319

Veihmeyer, F.J., Hendrickson, A.H., 1945. Soil density and root penetration. Soil Sci. 65, 487-495.

Vera, F.W.M., 2000. Grazing Ecology and Forest History. CABI Publishing, Wallingford, Oxon, UK.

Vera Mella, N., 2005. Atlas climático de irradiación solar a partir de imágenes del satélite NOAA. Aplicación a la Península Ibérica. Universidad Politécnica de Cataluña. doi:84-689-4998-1

Walter, H.., Lieth, H.., 1967. Klimadiagramm-Weltatlas, Jena, VEB . ed.

Whiteley, G.M., Utomo, W.H., Dexter, a. R., 1981. A comparison of penetrometer pressures and the pressures exerted by roots. Plant Soil 61, 351-364. doi:10.1007/BF02182016

Worrell, R., Hampson, A., 1997. The influence of some forest operations on the sustainable management of forest soils - a review. Forestry 70, 61-85.

Ximénez de Embún, J., 1951. Los montes. Introducción a la selvicultura. Publicaciones del Ministerio de Agricultura. Servicio de Capacitación y Propaganda. Serie E, Manuales técnicos no 14. Madrid.

Zamora, R., Gómez, J.M., Hódar, J.A., Castro, J., García, D., 2001. Effect of browsing by ungulates on sapling growth of Scots pine in a Mediterranean environment: consequences for forest regeneration. For. Ecol. Manag. 144, 33-42.

Zamora, R., Gómez-Sal, A., Soriguer, R., Fernández-Haeger, J. Jordano, D., Jordano, P., 1996. Herbivoría en espacios protegidos. Ecosistemas 18, 70-71.

Zamora, R., Hódar, J.A., Gómez, J.M., 1999. Plant-herbivore interaction: beyond binary vision, en: Puignaire, F., Valladares, F. (Eds.), Handbook of functional ecology. Marcel Dekker, New York, pp. 677-718.

Zou, C., Penfold, C., Sands, R., Misra, R., Hudson, I., 2001. Effects of soil air-filled porosity, soil matric potential and soil strength on primary root growth of radiata pine seedlings. Plant Soil 105-115. 

